\title{
Beyond punishment: Achieving sustainable compliance with the law. The case of coca-reducing policies in Colombia
}

\author{
Dissertation in order to acquire the doctoral degree \\ from the Faculty of Economic Sciences, at the Georg-August-Universität Göttingen \\ Submitted by \\ Juanita Vasquez-Escallon \\ Born in Bogota, Colombia
}

Göttingen, 2015

First Supervisor: Prof. Marcela Ibanez

Second Supervisor: Prof. Axel Dreher

Third Supervisor: Prof. Stephan Klasen 


\section{Acknowledgements}

I thank the DAAD for funding my PhD studies and for outstanding support during the process, as well as the RTG Globalization and Development and the Chair of Development Economics for further funding and opportunities that helped improve my research process. I thank my supervisor, Prof. Marcela Ibanez, for her valuable feedback, support and guidance, and Prof. Axel Dreher for his timely suggestions, exhaustive feedback and advice. I thank Stephan Klasen for his timely and right on the spot comments. I am also greatly thankful to Econometria Consultores for their continuous support, suggestions and help with data collection, and to Oscar Rodriguez for his insightful comments, ideas and help with achieving the research agreement that allowed me to work with valuable data. I thankfully acknowledge UNODC Colombia for a wonderful cooperation. Without the friendliness of the farmers this work would not have been possible. I am deeply indebted to all RTG PhD Students who made the $\mathrm{PhD}$ experience a very positive one, and a transition to a new country a much exiting adventure. I also thank Esteban for his invaluable support and patience that pulled me through until the end, to my family for their encouragement and love, to my mom for being not only a source of strength but for helping me with style revisions, even late at night or on weekends. I dedicate this work to my dad, whose memory inspires all I do. All remaining mistakes can only be attributed to myself. 


\section{Contents}

1. Introduction and overview 1

2. When too much punishment decreases legality. The case of coca-reducing $\begin{array}{ll}\text { policies in Colombia } & 7\end{array}$

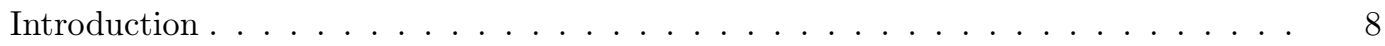

Crime and punishment theoretical background . . . . . . . . . . . . . . 9

The Colombian coca context and the spraying policy . . . . . . . . . . . . . . 10

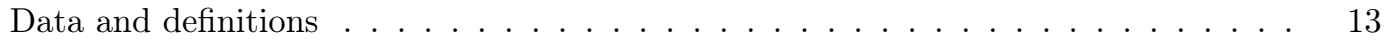

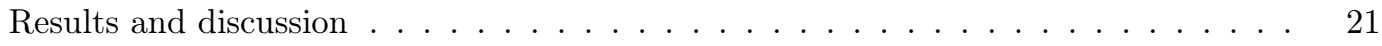

Possible channels . . . . . . . . . . . . . . . . . . . . . . . . . . . 39

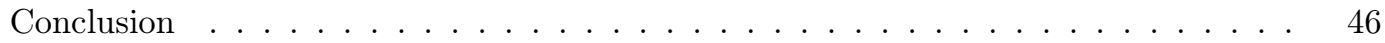

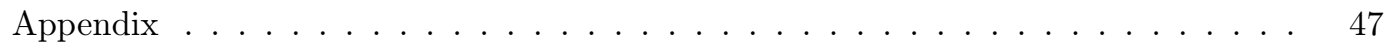

3. How alternative development spills over into more honest communities: An experimental approach in Colombia $\quad 55$

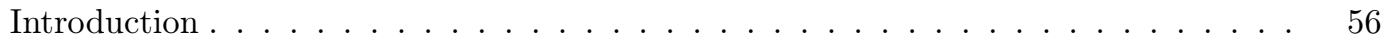

Local background . . . . . . . . . . . . . . . . . . . . . . . . . . . . 60

Identification strategy . . . . . . . . . . . . . . . . . . . . . . 62

Experimental design and procedures $\ldots \ldots \ldots \ldots \ldots$. . . . . . . . . . 67

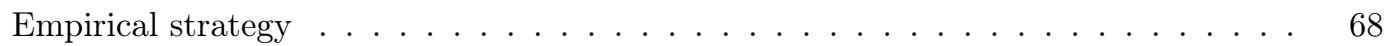

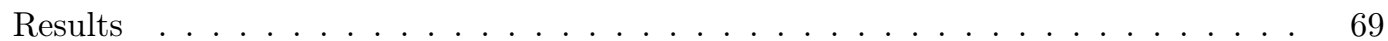

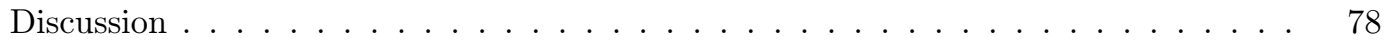

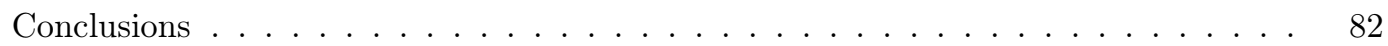

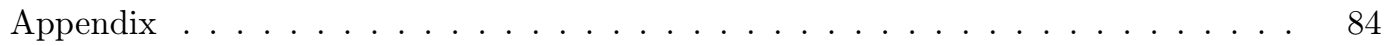

4. Can we fight drugs using communication campaigns? A framed field experi$\begin{array}{lr}\text { ment in Colombia } & 87\end{array}$

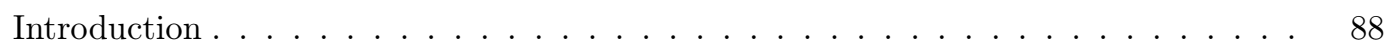

Background . . . . . . . . . . . . . . . . . . . . . 92

Experimental design . . . . . . . . . . . . . . . . . . . . . 95

Experimental procedures . . . . . . . . . . . . . . . . . . . . . . . . 101 


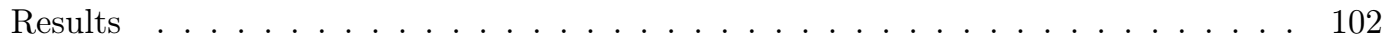

External validity . . . . . . . . . . . . . . . . . . . . . . 116

Discussion and conclusions _. . . . . . . . . . . . . . . . 117

Appendix . . . . . . . . . . . . . . . . . . . . . . . . . . . . 119

5. Changing minds and winning hearts: A natural experiment in Colombia $\mathbf{1 2 5}$

Introduction . . . . . . . . . . . . . . . . . . . . . 126

Local background . . . . . . . . . . . . . . . . . . . . . . . . . . . . . 129

Identification strategy $\ldots \ldots \ldots \ldots \ldots$

Experimental design . . . . . . . . . . . . . . . . . . . . . . . . 132

Hypothesis and predictions $\ldots \ldots \ldots \ldots \ldots \ldots \ldots$

Experimental procedures . . . . . . . . . . . . . . . . . . . . 138

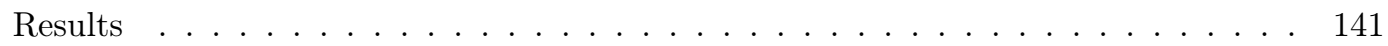

Final discussion and concluding remarks . . . . . . . . . . . . . 150

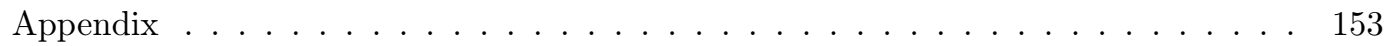

$\begin{array}{lr}\text { 6. Bibliography } & 160\end{array}$ 


\section{List of Figures}

1.1 Coca crops and eradication efforts . . . . . . . . . . . . . . . . 11

1.2 Spraying, spraying shocks, spraying disproportionality and coca grown per year 24

1.3 Coca and spraying disproportionality . . . . . . . . . . . . . . . . . 24

1.4 Legal crops and spraying shocks _. . . . . . . . . . . . . . . 25

1.5 Coca, spraying and spraying disproportionality for each different micro sample 26

1.6 Predictive margins of spraying disproportionality on legal crops . . . . . . . . . 31

1.7 Turning points for micro samples . . . . . . . . . . . . . . . . . . . . . 39

1.8 Spraying disproportionality and state legitimacy f . . . . . . . . . . . . 44

2.1 Probability of being treated based on retrospective baseline variables (2009) . . 67

2.2 Amount of rolls per possible number . . . . . . . . . . . . . . . . . 70

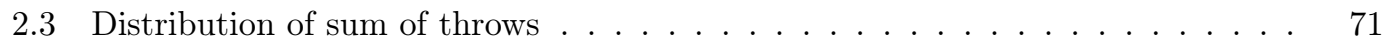

2.4 Reported throws and coca in municipality . . . . . . . . . . . . . . . . 73

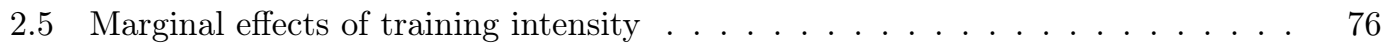

2.6 Marginal effects of poverty $($ only FGB $) \ldots \ldots \ldots \ldots$

4.1 Coca investment by participant type . . . . . . . . . . . . . . . . . . 143

4.2 Coca investments by group type . . . . . . . . . . . . . . . . . . . 143

4.3 Use of sad faces by group type . . . . . . . . . . . . . . . . . . 150 


\section{List of Tables}

1.1 Description of data sources $\ldots \ldots \ldots \ldots \ldots$

1.2 Summary statistics of coca growing municipalities f . . . . . . . . . . . 22

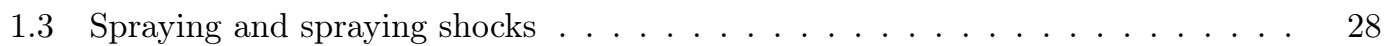

1.4 Legal crops, disproportionality of spraying and spraying shocks . . . . . . . . 30

1.5 Effect of spraying disproportionality on legal crops in UNODC sample . . . . 33

1.6 Effect of spraying disproportionality on legal crops in the Forest Warden Families

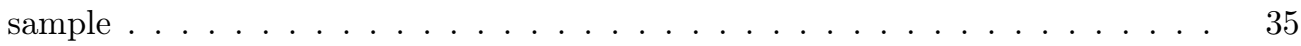

1.7 Effect of spraying intensity on coffee growers in coca affected coffee growing

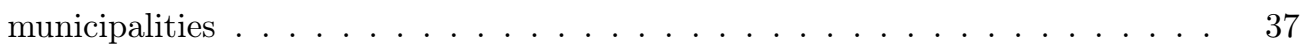

1.8 Effect of spraying disproportionality and displacement f . . . . . . . . . . . 40

1.9 Effect of spraying on legal crops . . . . . . . . . . . . . . . . . . . . 42

1.10 Relationship to state in UNODC sample . . . . . . . . . . . . . . 43

1.11 Legal crops and state legitimacy $\ldots \ldots \ldots \ldots \ldots$. . . . . . . . . . 45

A1.2 Marginal effects of interaction terms in spraying and spraying shock models . . 47

A1.1 Definition of variables in aggregate dataset . . . . . . . . . . . . . . . . 48

A1.3 Effect of spraying disproportionality on legal crops controlling for selection into coca cultivation . . . . . . . . . . . . . . . . . . . . 49

A1.4 Effect of spraying disproportionality on legal crops controlling for conflict vari-

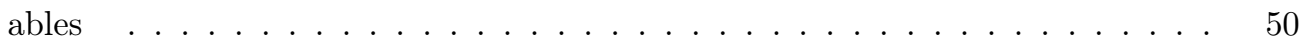

A1.5 Effect of spraying disproportionality on planted and cultivated legal crops . . . 51

A1.6 Beneficiaries, near controls and beneficiaries controlling for the inverse mills ratio 52

A1.7 Effect of spraying on legal crops controlling for displacement . . . . . . . . . . 53

A1.8 Spraying disproportionality and coca crops . . . . . . . . . . . . . 54

2.1 Descriptive statistics of municipalities in study, other coca growing municipalities not in the study and the rest of the country (excluding main cities) . . . . . . 61

2.2 Average characteristics of Forest Warden Families municipalities, distant control municipalities and coca-growing municipalities not in the study . . . . . . . . . 64

2.3 Phase-in of the Program in its initial seven waves . . . . . . . . . . . . . 65

2.4 Differences in key variables for each group and treatment priority as defined by

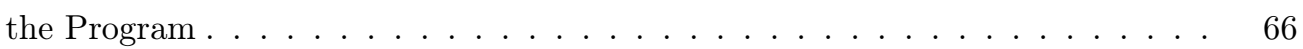

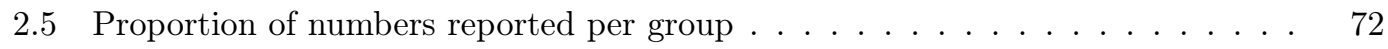


2.6 Impact of the Forest Warden Families Program on dishonesty . . . . . . . . . . 74

2.7 Possible determinants of die reports (dishonesty) . . . . . . . . . . . . . . 75

A2.1 Explanation of program presence based on targeting index variables . . . . . . 84

A2.2 Propensity score estimation using individual and municipal level variables for PSM results . . . . . . . . . . . . . . . . . . . . . 85

A2.3 Impact results from PSM analysis . . . . . . . . . . . . . . . . . . . 85

A2.4 Legal production and dishonesty . . . . . . . . . . . . . . . . . . 86

3.1 Arguments used to explain why coca is bad for the community . . . . . . . 95

3.2 Between subject design: Persuasion treatments . . . . . . . . . . . . . . 98

3.3 Within subject design: Marginal incentive to cultivate coca . . . . . . . . 100

3.4 Randomization checks at a community level . . . . . . . . . . . . . . . 104

3.5 Coca investments by treatment . . . . . . . . . . . . . . . 105

3.6 Attitudes towards coca: Descriptive statistics . . . . . . . . . . . . . . 107

3.7 Treatment effects on coca investments . . . . . . . . . . . . . . . . . 109

3.8 Heterogeneous treatment effects by density of coca in the neighborhood. . . . 112

3.9 Treatment effects on beliefs of what others invest in coca . . . . . . . . . . . 113

3.10 Treatment effects on attitudes towards coca . . . . . . . . . . . . . . 115

3.11 Treatment effects on probability to cultivate next year . . . . . . . . . . . . 116

A3.1 Variable definitions at a community and household level . . . . . . . . . . . . . 124

4.1 Phase-in of the Program in its initial seven waves . . . . . . . . . . . . . . 131

4.2 Priority to participate in the Program . . . . . . . . . . . . . . . . 132

4.3 Experimental treatments . . . . . . . . . . . . . . . . . . . 134

4.4 Descriptive characteristics of study municipalities and other coca-growing areas 139

4.5 Descriptive statistics for beneficiary and control groups and experimental treatments ............................ . . . . 142

4.6 Experimental coca investments by treatment and program type . . . . . . 146

4.7 Use of social control mechanisms (sad faces) . . . . . . . . . . . . . . . . 149

A4.1 Coca investments with coca invested by others in group . . . . . . . . . . 153

A4.2 Coca investments after being punished . . . . . . . . . . . . . . . . . 154 


\section{Acronyms}

\begin{tabular}{|c|c|}
\hline $\mathrm{AD}$ & Alternative Development \\
\hline BACRIM & Bandas Criminales (Criminal Bands) \\
\hline $\mathrm{COP}$ & Colombian Peso \\
\hline DC & Distant Controls \\
\hline \multirow{2}{*}{ DNP } & Departamento Nacional de Planeación \\
\hline & (National Planning Department of Colombia) \\
\hline DNE & Dirección Nacional de Estupefacientes (National Direction on drug related issues) \\
\hline ELN & Ejercito de Liberacion Nacional (National Liberation Army) \\
\hline EVA & Evaluación Anual Agropecuaria (Yearly Agricultural Evaluation) \\
\hline \multirow{2}{*}{ FARC } & Fuerzas Armadas Revolucionarias de Colombia \\
\hline & (Colombian Armed Revolutionary Forces) \\
\hline FWF/FGB & Forest Warden Families (Familias Guardabosques) \\
\hline GCDP & Global Commission on Drug Policy \\
\hline GDP & Gross Domestic Product \\
\hline ICRC & International Committee of the Red Cross \\
\hline ICV & Indice de Condiciones de Vida (Life Conditions Index) \\
\hline IDP & Internally Displaced People \\
\hline $\mathrm{FNC} / \mathrm{NCF}$ & Federación Nacional de Cafeteros (National Coffee Federation) \\
\hline HHI & Herfindhal and Hirschman Index \\
\hline NGO & Non-Governmental Organization \\
\hline PFGB & Programa Familias Guardabosques (Forest Warden Families Program) \\
\hline PSM & Propensity Score Matching \\
\hline \multirow{2}{*}{ SICA } & Sistema de Información Cafetero (Coffee Information System) \\
\hline & Sistema Integrado de Monitoreo de Cultivos Ilícitos \\
\hline \multirow{2}{*}{ SIMCI } & (Integrated System for Monitoring Illegal Crops) \\
\hline & Sistema de Identificación de Potenciales Beneficiarios de Programas Sociales \\
\hline SISBEN & (Identification System of Potential Social Program Beneficiaries) \\
\hline $\mathrm{TT}$ & Treatments \\
\hline UNGASS & United Nations General Assembly Special Session \\
\hline UNODC & United Nations Office on Drugs and Crime \\
\hline USA & United States of America \\
\hline USD & United States Dollars \\
\hline
\end{tabular}




\section{Introduction and Overview}

The problem of illegal drugs is not contained in producing countries, but represents a global threat that poses serious challenges to producer, transit and consumer countries. In Colombia, the struggle for the control of arable land for cultivation of illegal crops and of trafficking routes has devastating consequences such as homicides, forced displacement and massacres. The consumption of drugs by millions of users poses challenges to health and educational systems around the globe. The increasing use of cocaine in the United States 40 years ago spurred the so-called "war on drugs", which assumed that hard punishment and law enforcement would be enough to deter producers, traffickers and consumers from getting involved in the drug market. A natural place to wage this war was in the producing countries, which in the case of cocaine are only three: Colombia, Peru and Bolivia. This dissertation focuses on Colombia, where Plan Colombia, the largest anti-drug program in a producing country (Mejia et al., 2013) was implemented between 2000 and 2008 with large support from the United States. The program's primary focus was to tackle drug production, mainly through aerial spraying and forced eradication of coca crops, but it also included interdiction actions aimed at seizing drugs and precursor chemicals, destroying processing laboratories and weakening illegal armed groups, who control trafficking routes. Mejia et al. (2013) estimate the military component of Plan Colombia to have represented 1.1\% of the annual GDP between 2000 and 2008, close to US $\$ 1.1$ billion per year.

There has been a reduction in total coca bush cultivation, although its sustainability remains to be seen. Despite drops in coca cultivation in Colombia from roughly 100.000 hectares in 2007 to 48.000 hectares in 2012, this decrease stopped in 2013, when it showed a $1 \%$ increase with respect to 2012. The question remains whether the efforts are enough in order to prevent future increases or to sustain the downward trend. In fact, a downward trend had also followed the highest production peak of 161.000 hectares in 2000 down to 78.000 in 2006, when it again increased to 99.000 the following year. Out of the 32 coca producing departments in Colombia, 13 have shown a dipping trend, while seven show sharp increases. Moreover, farmers and traffickers have responded to the policies in different ways, such as using cheaper chemical inputs, cultivating smaller plots, growing coca in areas that the state cannot spray (natural parks and indigenous reserves) or that are hard to detect and changing their trafficking routes. The compensation between geographical areas and the adaptive behaviors of farmers and traffickers are signs that the existing drug-supply-reducing policies need to be revised. This was also the conclusion of the Global Commission on Drug Policy, which declared the global war on drugs as a failure. Thus, designing policies that do not displace illegality from one geographical point to

its neighbor, or from one illegal activity to another (e.g., illegal mining) will be more successful in attaining global and sustainable reductions in illegal activities.

This thesis dwells on how to achieve illegal crop reduction and compliance with the law in a sustainable fashion without exclusively relying on costly punishment, but by focusing on four 
different perspectives: ensuring State legitimacy, fostering a culture of legality, changing attitudes towards illegality, and strengthening mechanisms of community control. The dissertation is composed of four essays, each one studying one of these perspectives and providing policy relevant results.

The dissertation that follows uses various analytical techniques (experimental, survey analysis, secondary data analysis) at different levels of analysis (individual, community, municipality), which strengthens the general conclusion that when policies not only rely on risk and punishment in order to achieve compliance with the law, but also go beyond and include normative factors, the sustainability and success of the policies will be more likely. The results discussed below are of substantial value, at a time when drug policies are being discussed and when the United Nations General Assembly will be dedicating a special session on how to deal with the drug problem in 2016. This would set the agenda for answering even more questions. For instance, testing communication messages outside of the lab in the short and medium term could help strengthen our understanding on how attitudinal change leads to less illegal crops. Moreover, evaluating the effect of alternative development after monetary incentives have disappeared and exposure to culture of legality workshops is gone would give a better view of how sustainable are such interventions in the long term. A more ambitious agenda would look beyond illegal crops and include other illegal activities that are present in coca-growing areas to see up to what extent traditional punishment is simply changing the illegal activity that people engage in, and if the proposed strategies of strengthening culture of legality and state legitimacy, as well as changing attitudes and empowering communities prevent people from participating in illegal activities altogether.

\section{Essay 1. When too much punishment decreases legality. The case of coca-reducing policies in Colombia}

The first manuscript studies how an excessive and disproportionate use of enforcement, in this case aerial spraying of coca crops, can back-fire and undermine engagement in legal activities that could have been alternatives to illegal crops. Altogether the paper empirically studies what happens when the principle of proportionality of punishment (i.e., the severity of the punishment is adequate given the magnitude of the crime) is perceived to be broken. With the use of one macro aggregate dataset on all coca-growing municipalities in Colombia, and of three micro datasets with very different groups of farmers that have had very different exposures to coca crops and state presence, I test whether extreme disproportional use of aerial spraying reduces the hectares cultivated with legal crops, while proportional spraying induces legal crop production. This means that I test for the presence of a non-linear relationship between the punishment (dis)proportionality and the legal crops, whereby proportional punishment levels induce legal crop cultivation, but disproportional levels crowd it out. I further study the channels that may have led to such reduction, such as displacement of labor force, environmental/soil damage and loss of state legitimacy. I argue that the most important channel at play is the loss of legitimacy, as citizens judge the policy as unfair. 
The aggregated macro dataset and the dataset with the census of all coffee growers had a panel structure that allowed me to estimate fixed effect panel models. The two remaining datasets come from one-time surveys, one implemented by UNODC in a historically important coca growing region and the other with beneficiaries of Colombia's biggest alternative development program. The three farmer-level datasets collect individual information on legal crop production and are then combined with aggregate levels of aerial spraying at a municipal level. The UNODC's sample on coca crop cultivation is an exception and has (credible) individual level information on coca cultivation. In all these cases it can be assumed that individual productive decisions on either illegal or legal crops will not determine the magnitude of the spraying policy in their municipalities. My results from the four available datasets point to a non-linear effect of punishment on legality: spraying shocks or extreme spraying in relation to the amount of illegal crops reduce engagement in legal crops, while proportional levels of spraying induce them. I find that disproportionate spraying also generates displacement, but that it does not explain the full effect. Moreover, I find that as spraying disproportionality increases, the confidence that people have in the state's capacity to solve problems decreases. These results have strong policy implications for the existing drug policies in place, as extreme use of aerial spraying will not only not achieve its expected effects in coca reduction, but will alienate the population from the state and ultimately reduce their investments in legal crops.

\section{Essay 2. How alternative development spills over into more honest communities: An experimental approach in Colombia}

The second essay is joint work with Marcela Ibanez and studies the impact of an alternative development program on the culture of legality. This program provides farmers that are already growing coca - or at risk of doing so - with legal productive alternatives, and offers them workshops aimed at introducing social capital skills and culture of legality. Success in the program would be fully achieved if farmers not only stop working with illegal crops during the duration of the Program, but if their behavior regarding illegality in general is also changed. We test this by introducing a dishonesty experiment in the middle of a survey that was being implemented in order to evaluate the overall impact of the Forest Warden Families Program (FGB) in Colombia. This experiment allowed us to observe general cheating patterns for program beneficiaries and non-beneficiaries. Although the Program was not randomized, it did have a targeting index built with observable variables (that were shared with us) that determined who should be treated. Given resource and logistical restrictions not all municipalities were treated at the same time and the Program was rolled out over time, allowing us looking for the most similar controls by using the propensity of being treated in the future based on this index.

We find that people that live in areas that have been treated by the FGB alternative development program cheated less than those that had not been exposed to it, and find as well that as exposure to the program increases, dishonesty decreases, supporting our hypothesis that the culture of legality workshops start changing people's illegal behavior, but that this process may take time. We also find two relationships, that even though are not necessarily causal, 
are still interesting. The first is that people that have been exposed to higher magnitudes of coca crops also cheat more in the experiment, which goes in the direction that when people live in environments where illegality is the norm, other aspects of life are also affected by this illegality. The second is that there is a non-linear relationship between poverty and dishonesty, by which people that are close to the poverty threshold cheat the most, compared to those that are way below and farther up from the threshold. This suggests that the Program's focus on coca reduction and compliance with legality spills over into other realms of ethical behavior and leads to not only more legal, but also more honest communities. The main policy implication of this paper is that exposing people to workshops that explain to them the importance of complying with the law and of playing by the rules changes behavior in a way that suggests that people will be more ready to stay away from illegal activities in the future. When people believe in legality and do not act legally solely because of fear, sustainability of drug-reducing policies is more likely.

\section{Essay 3. Can we fight drugs using communication campaigns? A framed field experiment in Colombia}

The third essay is joint work with Marcela Ibanez and studies how communication messages can be used in order to change attitudes towards legality and to reduce investments in coca crops. The main assumption behind this paper is that economic behavior is shaped not only by economic incentives but also by normative factors that could be potentially altered by being exposed to persuasive communication messages. This paper uses a framed field experiment in a historical coca-growing area in the south of Colombia with farmers that live in communities that grow or have grown coca crops in order to test the effect of persuasive messages as a strategy to reduce attitudes towards coca, captured by experimental investments in these illegal crops. Our design varies the salience and the degree of informativeness of the messages that participants receive, highlighting the particular negative effects that growing coca brings to their communities. We test four different messages that are true in real life and that were also mentioned by the farmers in preliminary qualitative workshops in the field; namely that i) coca brings violence to their communities by increasing homicides, forced displacement and other violations to human rights, ii) that coca erodes the values of the youth, reduces their interest in going to school and makes them want to get easy money, iii) that coca has negative impacts on the environment because of the pesticides and chemicals that are used its production and iv) that coca increases violence, but now we assign specific values to the increase in homicides, land mines, displacement, etc. Our experiment replicates real world situations such as the need for farmers to decide between a legal activity or an illegal crop, the existence of risk of being caught with coca, the higher profit from coca than from the legal activity and the reality of negative externalities to the communities in the form of the treatments that we introduced. Participants decide whether to invest on coca or cattle in ten consecutive rounds without talking or communicating with other participants, and get paid according to their decisions at the end of the game. 
We find that the messages that make salient the relation of coca with violence are the ones that are most effective at reducing investments in coca. Our results suggest that the main mechanism at play is an attitudinal change towards coca rather than a change in beliefs. Interestingly, we find that exposure to the experimental treatments translate into lower intentions to cultivate coca in the future. We conclude that interventions that aim at increasing "awareness" of the negative effects that coca brings to the communities are a promising policy instrument in the fight against drugs. Moreover, we believe that by changing attitudes towards working with illegal crops and by at least changing what people intend to do in the future, the sustainability of illegal crop reductions is strengthened, as what generates the reduction is not the fear of punishment, which goes away as soon as the risk goes down, but an overall change in attitudes that could potentially change the decision-making process that people go through when deciding to invest in a legal or in an illegal activity.

\section{Essay 4. Changing minds and winning hearts: An experimental approach in Colom- bia}

The last study, joint work with Marcela Ibanez, focuses on how alternative development programs that pay people to refrain from growing coca alter the underlying social norm regarding coca and lead to a reduction of the willingness to invest in illegal crops. Additionally, we study how to trigger the use of internal control mechanisms by the communities themselves, and how these mechanisms can be either supported or minimized depending on the external enforcement policies that communities may be bound by. We use a framed field experiment to study the effectiveness of two types of public policies in achieving legality and also look at their combined effect when interacted. We focus on policies that activate social norms within communities and on those that use standard deterrence mechanisms. Our experiment takes place in a coca growing area in the north of Colombia where we can study the impact of an alternative development program on farmers' willingness to invest in coca and to establish mechanisms of social control. The Program required communities to organize their own verification committee that would make sure that the whole community was coca free, which makes this an interesting characteristic of the Program to investigate further. Our experimental design leaves the risk of being caught and the size of the punishment constant, but varies the policies that rule each session's environment. As with the experiment from the third paper, this experiment replicates real world decisions and situations, in order to maximize the external validity of our results. We expose people to five experimental treatments (plus a control group, where there is no risk of being caught with coca and no punishment): i) external enforcement that punishes only those that invested in coca, ii) external enforcement that punishes not only those that invested in coca but other group members, iii) mechanisms of internal control that can be used by participants to punish other group member's actions, and two additional treatments that interact internal mechanisms of control with either individual liability or group liability external enforcement. Participants decide whether to invest in coca or in cattle in five different rounds, and we introduce a feedback mechanism to ensure that people can find out what other group members did 
in the previous rounds. As in the previous experiment, participants get paid according to their decisions at the end of the game.

We find that the program enhances coca reduction and increases internal social control. In turn, internal control mechanisms decrease coca investments among program beneficiaries and social control is triggered when people observe other group members deviate from legality. By having exogenous punishment interact with internal compliance mechanisms, we find that external punishment that makes whole groups liable crowds-out internal control mechanisms; whereas punishment that makes individuals liable for their actions enhances internal social control. We conclude that by giving farmers incentives to act legally, there are positive effects that lead to enhancing compliance and reducing the need to rely explicitly on costly external punishment. The policy implications from this paper are straightforward: communities can keep coca investments down and will do so as long as the state only punishes those who break the law (with manual eradication, for instance) and abstains from punishing the whole group when only a few are guilty (through aerial spraying of coca crops, for example). This goes back to the legitimacy discussion mentioned in the first paper, where punishment that seems unjust discourages compliance with legality. 


\title{
2. When too much punishment decreases legality. The case of coca reducing policies in Colombia
}

\begin{abstract}
States want their people to follow the law. They can either persuade them, sanction law-breakers, or both. But sanctions do not only alter people's perception of risks and costs; they also affect how people view their state and its legitimacy, unleashing a series of non-economic factors that determine compliance with the law. In fact, when a sanction is perceived as unjust it may be inefficient in reducing law violations and could crowdout legality in other aspects of life. Law scholars warn against violating the principle of proportionality by exerting extreme punishment in comparison with the magnitude of the crime, as it may result in the loss of citizen cooperation with the law. I take one of Colombia's drug-reducing policies, aerial spraying of coca crops and study the effect of its disproportionate use on legal crops. My results point to a non-linear effect of punishment on legality: spraying shocks or extreme spraying in relation to the amount of illegal crops found reduce engagement in legal crops, while proportional levels of spraying induce legality. I use four different sources of data to test this relationship: macro data on all coca growing municipalities in Colombia, and micro data of three very different sets of farmers, namely coca growers surveyed by the UNODC, farmers that are beneficiaries of Colombia's biggest alternative development Program (Forest Warden Families) and coffee growers in municipalities that have had coca. I find the same results in all four samples and conclude that when the state overdoes its coercive actions, these can backfire and crowd out legality.
\end{abstract}

Keywords: Public Policy, Colombia, illegal behavior, agriculture

JEL Classifications: D78, O13, K42, Q12, O54 


\section{Introduction}

Achieving citizen compliance with the law is a primary goal for any state. However, a simple recipe of increasing costs (risk of being caught and size of punishment) can even back fire in ways that hinder legality-based development. A balance must be struck between, on the one hand, signaling that certain behaviors are detrimental to society and should therefore be punished - the expressive function of the law (Kahan 1997; Bohnet and Cooter, 2003; Cooter, 1988) - and on the other, keeping punishment within reasonable limits as a basic consideration of fairness: the principle of proportionality (Balmer, 2008; von Hirsch, 1992). I empirically test this balance using a coca crop-reducing policy (aerial spraying) implemented in Colombia for

over a decade and test whether disproportional doses of punishment crowd out one of the main legal alternative to coca crops, legal crops.

My main hypothesis is that severe punishment (disproportional punishment) may be perceived as a violation of the principle of proportionality, changing the way people perceive the state's fairness, which could in turn lead to lower levels of general law compliance, captured by a reduction in investments in legal crops. I study the channels that may lead to such a reduction: First, legal crops could simply be destroyed when the herbicide is off-target; second, a high spraying disproportionality could mean that many hectares that are not planted with coca are sprayed discouraging farmers from planting legal crops in the future; third, the environment could deteriorate and become unsuitable for agricultural activities; fourth, people are displaced because of the spraying, reducing the rural labor needed for working with legal crops; and fifth, legitimacy of the state is diminished and so are any efforts to cooperate and adhere to a culture of legality by communities that experienced disproportionate spraying. I find that many channels can be simultaneously at play and find support for the crop damage/ environmental channel, as well as for the displacement and legitimacy channels.

I test these hypotheses with the use of four different data sources. The first one is a panel macro dataset covering all coca growing regions of Colombia between 2007 and 2012 and three micro data sources, the first one being a United Nations Office for Drugs and Crime (UNODC) survey carried out in 2012 with coca growers in the Putumayo-Caqueta region, one of Colombia's traditional coca growing regions. The second dataset comes from a sample of beneficiaries surveyed in 2012 for the evaluation of the Forest Warden Families (FWF) Program, Colombia's current biggest alternative development program, and the third is a coffee growers' panel census between 2007 and 2013 collected by the National Coffee Federation. These three samples represent very different types of farmers; the first group has been heavily involved in coca growing and highly exposed to spraying and manual eradication while the second group has also been involved in coca growing or has been at high risk of getting involved with coca but has received support from the state to voluntarily change coca for a legal crop. The third group has focused on coffee and has been exposed to coca and coca crop spraying to a much lesser degree than the first two. I find that high levels of spraying disproportionality reduce legal crops but proportional spraying induces legal crops, and these results persist in the micro-datasets despite huge differences between the three groups. Additional evidence points to the fact that 
this reduction is not due to legal crops being damaged by spraying, but to a conscious decision of not planting legal crops after a spraying shock has occurred.

This is a novel study in two ways. It is to the best of my knowledge the first study to empirically test how a policy aimed at reducing an illegal behavior (illegal crops) generates positive and negative externalities on a closely related legal behavior (legal crops) depending on the proportionality of the punishment. ${ }^{1}$ Additionally, even though there are studies that capture the efficiency (or inefficiency) of coca spraying in reducing coca crops (see studies mentioned in Section 3), no study looks at the externalities that this policy has on legal crops, which are the closest legal alternative available to coca for farmers. Thus, this paper contributes to better understanding how the law and economic decisions are connected, and how public policies might have both positive and negative externalities depending on their implementation.

This paper is divided into 7 sections. The next one mentions the general theoretical background around the balance between crime and punishment followed by a short description of the Colombian context regarding coca and the aerial spraying policy. Section 4 describes the data sets used and defines disproportionate spraying and spraying shocks, while section 5 sets out the methodology for the analysis. Section 6 presents descriptive statistics and empirical results, and explores possible channels involved in the reduction of legal crops as a result of intensified spraying. Finally, section 7 concludes.

\section{Crime and punishment theoretical background}

The question of how severely a crime should be punished has been largely debated by legal scholars and political scientists. The law has a deterring function by increasing the costs of committing a crime, and an expressive function (Kahan 1997; Bohnet and Cooter, 2003; Cooter, 1998), that serves to educate the public by showing what is morally undesirable (Feldman, 2011). But, for the law to be effective in reducing criminal activity it needs to be perceived as fair and appropriate for their institutions (Kuperan and Sutinen, 1998) and just (Jackson et al., 2012; Tyler, 2006; Tyler and Fagan, 2008; Thoumi, 2009; Dahrendorf, 1980).

Severe punishment erodes law abiders' disposition to obey and changes their moral assessment of cooperation, as extreme punishment is sometimes seen as a tool to punish certain social classes or minorities disproportionally (Kahan, 1997). This is in line with Jackson et al. (2012) who mention that "the experience of procedural unfairness - including disrespectful treatment and unfair decision making - erodes feelings of shared group membership and with the authority concerned" (p.1053). Sheffrin and Triest (1991) also find that perceived inequities in the system lead to lower compliance. Frey and Jegen (2001) mention that when people feel that the authorities representing the law treat them respectfully and fairly, they comply more (see Tyler 1989, 1997 and 2006 for an extensive empirical evidence on fairness and compliance).

\footnotetext{
${ }^{1}$ Thoumi (2009) mentions that authoritarian regimes that exclude certain groups can end up incentivizing crime, but he does not look at how legal counterparts are crowded out and does not develop any empirical analysis.
} 
A basic consideration of fairness is the principle of proportionality (Balmer, 2008; von Hirsch, 1992). Balmer (2008) points out that this principle dates back to the Code of Hammurabi and the old testament, where "an eye for an eye" sets the argument that the magnitude of the punishment should be similar to that of the crime. Von Hirsch (1992) gives proportionality a crucial role in the sanctioning theory, as it gives people a notion of justice and fairness. According to this author, fairness would be accomplished by avoiding both extremes of severity and leniency. The link between fairness and trust in the state has also been researched; postcommunist states have shown evidence that the single most important determinant of trust in institutions was in fact how fair they were perceived by the citizens (Kluegel and Mason, 2004), and in the US people are concerned about justice as much or even more than about outcomes (Tyler et al., 1989). Regarding the reduction of coca supply in Colombia, Thoumi (2009) mentions the need for a very intense spraying campaign in order to effectively get rid of coca crops, but notes that it would be so disproportional and intense that it would violate democratic principles. Hence, if disproportionate punishment is used, trust in the governing authorities is negatively affected, endangering economic outcomes such as investments in productive activities (Knack and Keefer, 1997). Disproportionate punishment could even be inefficient, as Kahan (1997) argues that when punishment is applied with high-certainty but low severity it is more likely to generate a low-crime equilibrium, in contrast with a low-certainty but high-severity scenario. This high-severity vs. low-severity punishment underlies the coming analysis.

This theoretical background sets the stage for empirically testing the balance between, on the one hand, raising legality by teaching people what is right and wrong (expressive function of the law) as well as deterring others by increasing the costs of committing crimes (Becker, 1968), and on the other, reducing compliance when citizens perceive the principle of proportionality to be broken when punishment is extreme with respect to the crime.

\section{The Colombian coca context and the spraying policy}

Colombia has been a key player in illegal drug markets as one of the world's largest producers and exporters of cocaine (UNODC, 2014). A period of rapid coca growth in the 1990's spurred an ambitious plan to restrain illegal supply of drugs in Colombia, Plan Colombia. According to Mejia et al. (2013), of all coca and cocaine-reducing policies implemented (aerial spraying, manual eradication, control of chemical precursors, detection and destruction of laboratories and seizures) aerial spraying was by far the most important. In fact, Mejia and Restrepo (2013) use data from the U.S. General Accountability Office and mention that out of the yearly U.S. disbursements of around US $\$ 593$ million per year between 2000 and 2008, $69 \%$ went to eradication programs, without taking into account the initial US\$800 million that was disbursed in 2008 that also went to anti-narcotic programs.

As described by Mejia et al. (2013) aerial spraying is carried out mainly by US contractor planes who spray mainly Round $\mathrm{Up} \AA$ herbicide on coca fields. The main component of this herbicide is glyphosate and it includes other ingredients that help it penetrate the plant and destroy it. Since it is a herbicide, it equally affects coca crops and all other non-genetically modified crops. 
The herbicide is absorbed by the plant's foliage and thus is only effective in growing plants. Conversations with authorities and other experts underline the difficulty of spraying only above coca crops; strong winds and the necessity to spray from higher than recommended heights to reduce the risk of being shot down increase the probability of the herbicide hitting other crops.

Figure 1.1 shows the evolution of coca crops and the two main stick policies that have been used in the last eleven years up to 2012, mainly aerial spraying and manual eradication. However, the figure shows that even though there is a downward trend in crops, it still does not show a decisive trend towards a zero coca scenario and it is not correlated with eradication efforts. In fact, the UNODC 2014 Colombia drug census finds many areas where coca has fallen in the absence of spraying. ${ }^{2}$ It is also important to note that hectares sprayed are always higher than the end of the year reported coca hectares. This is due first to technical reasons, whereby a plant is completely killed after being sprayed four times (there are on average four coca harvests in a year, and each spraying makes sure none of these harvests succeed) and also because some farmers react to the policy by replanting and protecting coca plants from chemical spraying damage. ${ }^{3}$ The fight between protecting the coca bush or replanting it vs. the efforts deployed by the state to destroy it, is at the heart of this discussion.

Figure 1.1: Coca crops and eradication efforts

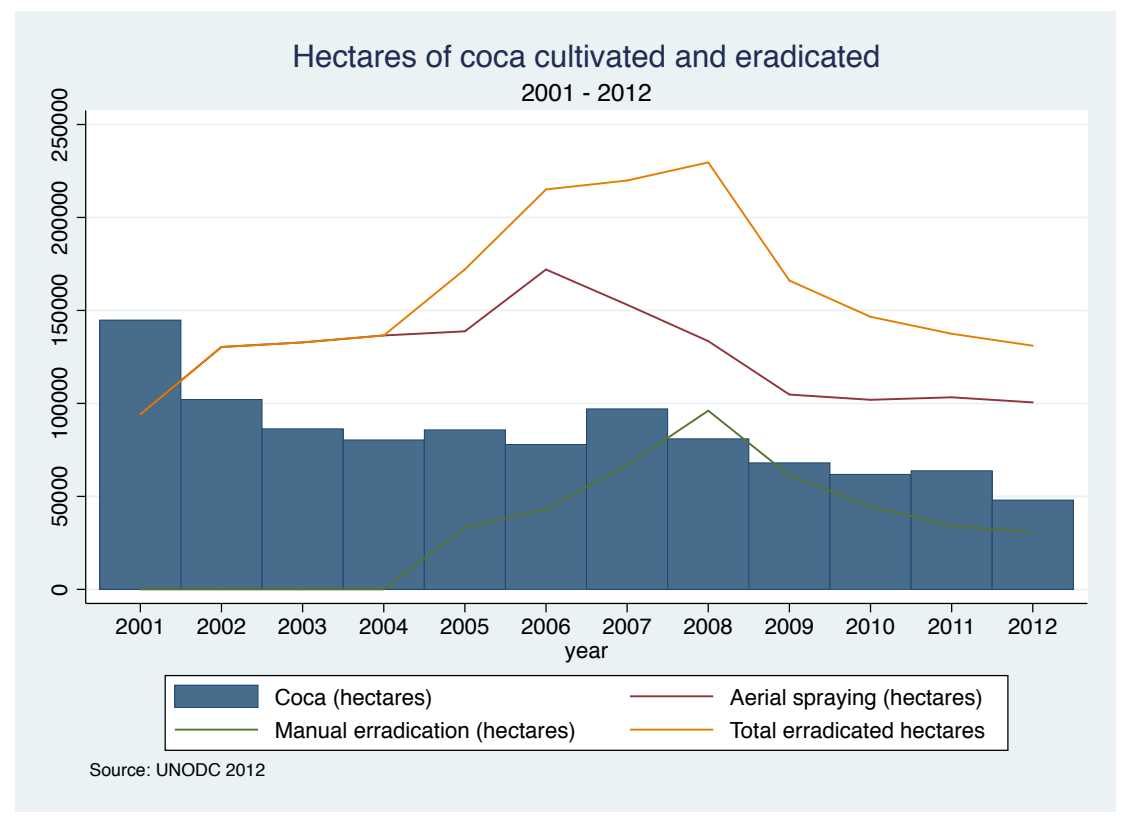

Despite such great efforts, many consider the war on drugs to have failed and to have caused "devastating consequences for individuals and societies around the world" (Global Commission

\footnotetext{
${ }^{2} \mathrm{An}$ additional point is that even though coca is decreasing, other forms of illegality are increasing, such as illegal gold mining (Idrobo et al., 2014). Thus, achieving reductions in one form of illegality while another one emerges leaves a big question mark on the effectiveness of coercive policies seeking to reduce overall illegality.

${ }^{3}$ Such as washing coca bushes with water after spraying, covering them with a molasses coating or "pruning" them, an operation where, as described by Mejia and Posada (2008), farmers cut the top of the coca bush and, since the only part of the plant that is attacked is the leaves, they are able to harvest it one month later.
} 
on Drug Policy GCDP, 2011, p. 4). This conclusion also stems from the increasing amount of academic research around the effectiveness of coca-reducing policies. Mejia et al. (2013) use diplomatic friction with Ecuador as an exogenous variation for spraying in the Southern border of the country, and find small but significant effects of spraying on coca crop reduction. However, they can not control for the so called "balloon effect" of migration of crops to other areas and thus state their result as an upper bound. Reyes (2011) uses an instrumental variables approach to estimate the effect of spraying on coca crops, finding spraying not only to be ineffective but also generating an increase in coca crops. Moreno-Sánchez et al. (2003) find that spraying is ineffective as it leads farmers to crop coca in a more extensive way. Ibanez (2013) uses a unique micro dataset and finds that even though eradication reduces coca, the elasticity of supply of these policies is low. Out of all the municipalities in Colombia, $28 \%$ have grown coca at least one year with a persistent character and $52 \%$ of coca growing municipalities have done it for 10 years or more, despite state control.

Other studies tackle the negative side effects of this policy on the population. Rozo (2013) finds that even though spraying decreases illegal coca crops, the socioeconomic conditions of the population deteriorate and that effects on poverty and health persist even after two years. Camacho and Mejia (2013) study the externalities of spraying on human health and find negative effects reflected in dermatological problems and increased abortions. Additional side effects have been found on other spheres: coca spraying undermines trust in the state and in political institutions (Garcia, 2011), erodes community strategies to control coca farming by other community members (Chapter 4) and relates to higher levels of generalized dishonesty (Chapter $2)$.

So far, none of the models developed to analyze coca growing decisions and effectiveness of cocareducing policies take into account the possibility of a non-linear relationship between severity of punishment and the decision to switch to legal crops. Reyes (2011) assumes that farmers diversify their crop portfolio and increase other crops when the risks associated with coca are too high and Clemens (2008) uses legal crops as the alternative counterpart for opium in his theoretical model of crop farming. Chumacero (2008) develops a general equilibrium model for production, trafficking and consumption of illegal goods which introduces government actions to counteract illegal drugs both through increasing risks or increasing punishment, but here legal crops are modeled to always increase when coca is reduced by any governmental policy. Bogliciano and Naranjo (2012) also develop a general equilibrium model and even touch on legal production, but in both cases the authors assume that the reasoning behind choosing coca over a legal crop depends merely on risk and relative profits.

Some studies go beyond the analysis of risk and relative profit and find evidence that noneconomic and moral aspects shape illegal behavior (Ibanez and Carlsson, 2010; Ibanez and Martinsson, 2013; Chapter 3; Chapter 4), but they all assume the choice of the legal crop to be affected by drug-reducing policies only indirectly through their effect on coca, and assume coca and legal crops to be pure substitutes. Dube and Vargas (2013) study the effect of price shocks on civil conflict and rule out that coca cultivation increases after a fall in coffee prices, 
strengthening the idea that legal and illegal crops do not necessarily substitute each other. Until now there is no evidence that farmers do in fact turn to legal crops when risk of punishment is high, nor that the decision to plant legal crops also depends on the disproportionality of the "stick" policies directed at illegal crops. This study also contributes to the literature by expanding our knowledge on additional side effects caused by coca spraying and by giving an empirical example of how disproportional punishment back-fires.

This study takes place amid a regional debate on the effectiveness of drug policies. Never before had the Inter-American Commission on Human Rights (IACHR) granted a hearing regarding the impact of drug policy on human rights, and it happened in March 2014. Bolivia decided to change its constitution to allow traditional coca use within its territory and Uruguay became the first country to adopt a legal and regulated cannabis market. The need for debate is such, that there will be a UN General Assembly Special Session (UNGASS) on drugs in 2016, with drug policy at center stage and the world's leaders as discussants. Objective evidence of the direct and indirect effects of drug policy are needed in order to design effective and less harmful strategies.

\section{Data and definitions}

\section{Data}

This study draws on two different strands of data; one that focuses on legal crops and another that covers coca crops, spraying efforts and other conflict-related data in Colombia. I use aggregate and micro data to tackle both.

Data on annual coca hectares come from the UNODC-SIMCI office in Colombia. They take satellite pictures on a yearly basis and divide the country in grids of $1 \mathrm{~km} \mathrm{x} 1 \mathrm{~km}$, which they then aggregate at a municipal level. The amount of coca hectares reported for a given year is what is captured in the picture as of December 31, making it a "net" measurement of coca hectares at the end of the year, after coca growing, coca harvesting, manual eradication, aerial spraying and replanting took place.

Aerial spraying is the responsibility of the drug enforcement police. The decision on where and how much to spray is made based on the SIMCI coca figures, but field observation (such as flights over regions with a coca history or where coca was spotted by satellite pictures) is also used to capture coca dynamics. I use the spraying data that the anti narcotics police reports to UNODC-SIMCI for the 2001-2011 period. It was impossible to have access to spraying information from the $1 \mathrm{~km}$ by $1 \mathrm{~km}$ grid, and for this reason I use the municipal levels for both coca and spraying.

Information on legal crops at a municipal level comes from the Ministry of Agriculture's annual agricultural evaluations (EVA) dating all the way back to 1970, but I will focus on the 2007-2012 period, since these are the years in which revised data exists. These agricultural evaluations cover 1.122 municipalities (nationwide) and most agricultural products, and collect information 
on the hectares planted and harvested, as well as on production. I will focus on harvested areas as they are the most comparable among products and will only work with crops and not with forestry or livestock. This information comes annually from a consensus among local experts, authorities and producer associations, whom, based on their on-field knowledge assess the amounts planted, harvested and produced of each type of product. They collect information on transitory products on a half-year basis, and permanent products on an annual basis. ${ }^{4}$ Even though each municipality has its own experts (since they have to be local and know the area very well), there are standardized data collection forms and rules on the way information should be collected and processed in order to ensure comparability. This allows me to work with a 5 -year highly balanced panel dataset that enables the use of fixed effects at a municipality level.

I focus my analysis only on areas that have had coca at least once since 2001 since it is also here where the spraying policy is applied. Coca growing areas (and consequently areas where spraying takes place) are not comparable with regions where coca has never been grown, ${ }^{5}$ since people can choose to move to areas where coca is grown, possibly due to lower levels of state presence, easier access to land, or a higher degree of tolerance to the presence of illegal actors, among other reasons. With this in mind I end up with 112 municipalities that have had coca at least once, have been sprayed and have information on legal crops. This means that results here are not representative of the whole country, but only to coca growing regions. Since it is in these regions where the policy is applied, it is the relevant area of interest. Moreover, these results are interesting even if they do not speak about the whole country, as understanding how law enforcement is perceived in illegality-prone areas is key to curbing crime where it abounds.

I use additional secondary information to characterize municipalities in terms of their exposure to armed conflict, and to other variables that can be relevant for agricultural production. Conflict-related variables such as displacement, homicides, combats and attacks come from Colombia's President Office's Observatory of Human Rights. I include a security threat index built by the Ministry of Defense, that classifies municipalities in low-middle-high threat, based on presence of armed groups, combats, homicides, land-mines, and other conflict-related variables, and also use their information on presence of illegal armed groups (number of combatants). This threat-index then classifies municipalities in three groups, red, yellow and green, from highest to lowest threat. The information regarding population size, population density and other population variables, as well as the distance of each municipality to a productive agglomeration and land prices comes from the Ministry of Agriculture and the Registrar General's

\footnotetext{
${ }^{4}$ It could be argued that this way of capturing the data is not the best, as each municipality has its own set of experts that in the end decide the amount of agricultural activity in each municipality. However, this is the most disaggregated source of information that there is and the most comprehensive of the country. More information on how the EVAs are collected by the Ministry of Agriculture can be found here: http://www.agronet.gov.co/agronetweb1/Estad\%C3\%ADsticas.aspx

${ }^{5}$ For instance, according to official figures, coca growing areas have $23 \%$ less electricity coverage than their counterparts, have $185 \%$ more forest cover, are $50 \%$ less densely populated in rural areas, are $67 \%$ farther away from urban clusters, have a $10 \%$ lower fiscal performance, were $13 \%$ poorer in 2005 as measured by a multidimensional poverty index than their rural non-coca counterparts, depend $10 \%$ more on income transfers from the capital, have a forced displacement intensity $302 \%$ higher than non-coca areas, have $52 \%$ less roads per squared kilometer, have 3 times more the amount of landmine victims, 3.35 more armed actions and 5 times more combats than non-coca areas, have $444 \%$ more FARC presence, 3 times more massacres and a $46 \%$ higher homicide rate than their counterparts.
} 
Office. I control for institutional quality by including a fiscal performance index calculated by the government of Colombia that indicates better use of public resources as the index takes on higher values.

In order to have a micro look on how individuals change their productive decisions when faced with a macro coca-reducing policy I employ three very different datasets of farmers that are exposed to various levels of coca growing and spraying, as shown in the results section. The three samples are described below.

The first group comes from a survey carried out by UNODC-SIMCI with 239 coca growers in the Putumayo-Caqueta region in Colombia in 2012, in order to estimate the economic structure of the farms in terms of income, costs and profitability, in areas under the influence of coca crops. This region has been highly exposed to coca growing but has limited state support to replace it with legal crops, and is also an area where coca has traditionally been grown and remains as one of the largest coca producing regions. The survey selection process is as follows: UNODC has satellite pictures of $1 \mathrm{~km} \times 1 \mathrm{~km}$ grids, and based on them performs a randomized selection of grids in two steps. First, a $1 \mathrm{~km} \times 1 \mathrm{~km}$ grid is selected and then, within the grid, conglomerates of two coca farms and two non-coca farms are randomly chosen. Enumerators then go to the field and look for the farms that appeared in the satellite pictures. This survey is particularly useful because it offers accurate data on both coca crops and legal crops by individual farmers, which allows me to use coca involvement information on an individual basis. It also asks farmers whether their coca crops were damaged by aerial spraying in the past. Thanks to an academic agreement with UNODC, I was able to introduce a set of questions in this survey, addressing the issue of state legitimacy by asking people to rank the quality of public utilities and express their trust in the government's capacity to solve some problems that are the responsibility of the state. This allows me to capture if coca spraying shocks reduce state legitimacy, one of the proposed channels.

The second group comes from a survey conducted in 2012 by Econometria Consultores for the evaluation of the Forest Warden Families, the current biggest alternative development program in Colombia. The survey includes 1236 program beneficiaries (who were beneficiaries at the time of the survey), randomly selected from the seventh wave of the Program, ${ }^{6}$ and stratified by municipality. This group is interesting as it allows me to study to what extent punitive measures - once state support is received - continue to influence the decision to grow legal crops. This group is different in the sense that they have also been exposed to high levels of coca growing, but have received the Forest Warden Families Program, which has provided them with money, workshops and technical assistance in order to replace coca with legal products. The survey is very comprehensive and includes household information for all household members, as well as

\footnotetext{
${ }^{6}$ This was the baseline for an impact evaluation, where also 1210 neighboring controls and 1264 distant controls were surveyed. The FWF Program built a targeting index for all municipalities in the country based on observables that define the priority of treating communities within that municipality. Because of resource constraints the program has been rolled-out since 2006 and in fact, since the evaluation and early 2014, 18\% of the distant control municipalities have been treated. Distant controls were chosen based on this index and matched with the treatments to find the most similar municipalities. However, I focus only on the beneficiary group, as I am interested in the behavior of famers that are receiving support to stop growing coca, and although I also look at the behavior of distant controls, I do not emphasize the differences between both groups.
} 
productive information for all land plots in terms of products grown, amount of land used for their production, etc. Even though the survey asks about individual involvement with coca, not many people answered and responses might also be underestimated, rendering the use of aggregate coca growing measures as advisable.

The third group is a subsample of coffee growers from the Coffee Information System (SICA for its acronym in Spanish) from 2007 to 2013. This dataset is a census and has information on every coffee plot in this period and each plot can be attributed to an individual farmer. It collects information on total plot area, area planted with coffee, the coffee variety used, and the age of the coffee crops, among other variables. This dataset is then merged with information on the type of assistance coffee growers have received from the National Coffee Federation (NCF). From 2009 onwards I am also able to go beyond the area dedicated to coffee and use coffee production per plot; this variable comes from a NCF algorithm based on the coffee variety, crop age, and plot density which determines production on the basis of these characteristics. As I mentioned before, I only focus on regions that have grown coca in at least one point in time, so I take a subsample that covers coffee growers living in areas that have grown coca crops at least once. This leaves me with a panel dataset of 6 periods for 155.278 coffee farmers in 111 municipalities. However, as will be seen in the results section, the levels of coca in coffee growing regions are particularly low when compared to the rest of the coca growing areas in the country, making this group interesting to study, since it allows testing my hypothesis that disproportionate punishment can crowd out investments in legal crops also in places that have better access to markets and where legal crops are more likely to prosper.

Table 1.1: Description of data sources

\begin{tabular}{llll}
\hline Data & Unit of analysis & Type & Size \\
\hline \multirow{2}{*}{ Aggregate data } & Municipality & Panel: 2002-2012 (coca/spray) & 112 municipalities \\
UNODC & Panel: 2007-2012 (legal crops) & 239 coca farmers \\
Forest Warden Families & Household & Cross-section 2012 & 1,236 beneficiaries \\
Coffee growers & Farm/Household & Panel: 2007-2012 & 155,278 farmers \\
\hline
\end{tabular}

Note: In all cases I only use municipalities that have had coca at least once in the available time series

One last point regarding data is that the micro data mentioned has information regarding productive choices (area allocated to legal products in the case of UNODC and FWF, and production in the case of coffee growers), but no information on spraying or spraying disproportionality. Only in the case of the UNODC sample I am able to use self-reported involvement in coca as a control variable, but for the other two I need to use aggregate coca growing levels on a municipality basis. This means that I will analyze how a macro policy affects individual decisions. Even though I do not have spraying information available at an individual level, the way in which the policy is implemented implies that aggregate spraying levels are appropriate to explain individual investment decisions: first, people can see the planes. Even if they are not flying right above them, they can easily sense that neighboring plots are being sprayed and see how many times the plane flies over the same areas. Second, even if they miss the plane, 
the spraying is discussed with neighbors and other farmers on market days or other gatherings. Third, given the threats facing spraying aircraft, the spraying passes are released above the recommended height, which reduces the pilot's capacity to spray only designated areas, and increases the chances that winds will carry glyphosate to non-intended sites. Ibanez (2013) uses a similar strategy to circumvent the endogeneity of aggregate eradication on coca-growing decisions and argues that policies can be treated as exogenous when individual household data are available, as the decision of one farmer is marginal and does not increase the probability of being targeted by eradication. Thus, having individual data respond to aggregate levels of spraying seems to be a plausible solution for tackling endogeneity.

\section{Definitions}

This paper studies the effect of spraying disproportionality rather than spraying per se on legal crops. I define disproportionate spraying as the ratio between spraying in year $t$ and coca reported by SIMCI in year $t-1$, namely SprayingDisproport $=\frac{\text { Sprayingt }}{\text { Cocat }_{t-1}} .{ }^{7}$ Since spraying decisions are made based on the previous year's reported coca hectares, it makes sense to use it as a denominator. When looking at the descriptive statistics it is also clear that spraying follows coca hectares with a lag of one year, especially in the years with high coca growing levels.

I also use a dichotomous definition of disproportionality and call it a spraying shock, which I define as 1 for all those that are above the mean of the spraying disproportionality and 0 for those that are at the mean or below. The main reasons behind choosing the mean are: first, when looking at the macro data the median of spraying disproportionality is 1.4 , whereas the mean is almost three times higher. Those above the mean comprise $22 \%$ of the sample, so choosing an ever higher threshold would leave a very small amount of observations in this group. Additionally, the mean falls around 4, which coincides with the amount of times the authorities say they need to spray one field in order to really kill the plant. Therefore, those above the mean are also above the "necessary" amount of spraying for effective coca eradication.

SprayShock $= \begin{cases}1 & \text { SprayInt }_{i}>\overline{\text { SprayInt }} \\ 0 & \text { SprayInt }_{i}<=\overline{\text { SprayInt }}\end{cases}$

The purpose of this study is to test the effect of spraying disproportionality and spraying shocks on legal crops. I do this with the four groups described in the data section, of which two have a panel structure and two a cross-sectional structure. In the standard and most common models of crime more punishment leads to less crime, and the criminal activity is replaced with the legal activity using a linear relationship. However, my hypothesis is that punishment has an upper limit that backfires when it is exceeded, or in legal terms, when the punishment ceases

\footnotetext{
${ }^{7}$ Low levels of this ratio, in particular those between one and four could be interpreted as proportional. The point of the name is to show that I am not focusing on spraying per se but on how spraying relates to coca. Even though higher disproportionality levels would also imply higher probability of being eradicated (risk), disproportionality cannot be interpreted as such, since the probability of eradication cannot be higher than one.
} 
to be proportional to the crime. I test this by including a squared-term for the ratio between the punishment and the crime (disproportionality).

The rationale behind using spraying disproportionality rather than spraying levels is twofold: first, it captures the disproportion between a punishment and a crime, which is what I argue leads to a loss of legitimacy, and ultimately to a disregard for legality, as Tyler's arguments would predict. Second, spraying follows coca and it is very hard to disentangle the effect of coca (and subsequently spraying) on legal crops. There is evidence that coca is highly related with violence and armed conflict (Thoumi, 2009; Diaz and Sanchez, 2004; García, 2011) and that the armed conflict has a negative impact on agriculture (Arias et al., 2014; Ibanez et al., 2013; Vasquez, 2010), which makes the identification of the impact of spraying on agriculture hard to pin down. However, disproportionate spraying captures another dimension that is not driven by the presence of coca nor is it related to conflict per se, as shown in the results section, opening the possibility to pin down the effect of a spraying policy's disproportionate use on legal crops.

I argue that the effects of spraying disproportionality on legal crops can be interpreted as causal. First, spraying decisions follow the presence of coca crops and do not take legal crops into account. In fact, the pairwise correlation between the lag of legal crops and spraying disproportionality is negligible (0.03) and statistically insignificant at standard significance levels, making reverse causality unlikely. However, since legal crops could be substituted by coca (and vice versa) depending on the relative profits and risk of being caught, some endogeneity could be introduced. In order to correct for this I use spraying disproportionality, which, as will be seen in the results section, does not follow coca presence. Second, in the two panel datasets I am able to use a fixed effects model that takes away time-invariant unobservables that might affect the decision to plant legal crops. Worrisome unobservables such as a region's soil quality, altitude, geographic location, overall institutional presence (which changes very slowly over time) and unobservable characteristics that attract people to coca growing areas are accounted for. Third, I restrict my analysis to areas that have seen a coca field at least once in the available years, as mentioned above. Areas where coca has never been grown are structurally different and at first sight incomparable with areas with coca. Therefore, if I only focus on coca regions, these unobserved differences that make coca growing possible in some areas are equal for all municipalities in the analysis, and are differenced out. ${ }^{8}$ Fourth, I exploit lags in the panel models and, as a result, can test whether any spraying disproportionality experienced in the past affects current legal crops. Fifth, in addition to macro crop data I use micro sources of data with individual production decisions, which do not determine policy but on the contrary, potentially adapt to it. The use of three very different groups of people to test the effect is in itself a robustness test, and further reduces any potential bias in the sense

\footnotetext{
${ }^{8}$ As a robustness check I estimated a Heckman selection model and used the inverted mills ratio as an independent variable in macro data models to control for self-selection and the results remain the same. I estimated one Heckman model per year to ensure that the mills ratio did not disappear with the fixed effects. The inverted mills ratio is not significant in any of the specifications. I do not use this specification as the main result as the inverted mills ratio is highly correlated with some explanatory variables creating potential multicollinearity problems.
} 
that individual responses to policy exposure are exogenous. Sixth, I have a rich set of control variables that control for the driving factors behind the decisions to work with legal crops.

I run all specifications in two versions, one with the continuous disproportionate spraying as the explanatory variable, and one with the spraying shock as the independent variable of interest. The first captures how small changes in proportionality affect legal crops and the introduction of the squared term allows me to estimate possible turning points. The shock captures the effect of simply having been exposed to higher spraying as necessary. The aggregate data and coffee grower census employ a fixed effects approach and exploit lags in spraying disproportionality and shocks, whereas the UNODC and FWF samples are cross-sections. I present the models used for each group below.

\section{Panel Data Specification}

I will describe the general specification for the aggregate macro information and then will explain how this same set up is used for each micro sample. As mentioned, I have five year panel data with aggregated data on both spraying disproportionality and legal crops and I use the following fixed effects model to capture the effect of the former on the latter:

$$
Y_{i t}=\alpha+\beta_{1} I_{i t}+\beta_{2} I_{i t}^{2}+\beta_{3} I_{i t-1}+\beta_{4} I_{i t-1}^{2}+\beta_{5} I_{i t-2}+\beta_{6} I_{i t-2}^{2}+\beta_{7} X_{i t}+\eta_{t}+\mu_{i}+\varepsilon_{i t}
$$

where $Y_{i t}$ represents the harvested legal crop hectares, ${ }^{9}$ expressed as natural logarithm for ease of interpretation in municipality $i$ in year $t \cdot{ }^{10} I_{i t}$ and $I^{2}{ }_{i t}$ are the linear and squared terms of spraying disproportionality as defined above. I include two lags of disproportionate spraying to capture the persistence of the effect or the moment when the effect emerges. It could be possible that people planted their crops at the beginning of the year and experienced spraying later on and thus did not react immediately. $X_{i t}$ captures time-varying municipal control variables that should be present in an agriculture output model such as rural and urban population densities, percentage of rural population in municipality, land prices and institutional quality. In this vector I also include lagged coca crops and the lagged change in coca crops, also in natural logarithms. ${ }^{11}$ Variables such as distance to markets, size of the municipality, area devoted to national parks, altitude and soil quality are time invariant and thus fall out with the municipality fixed effects. $\eta_{t}$ and $\mu_{i}$ are time and municipality fixed effects respectively, and $\varepsilon_{i t}$ is the error term, clustered at the municipality level.

When the spraying shock is used instead of spraying disproportionality the empirical specification looks like Equation 2, where $S_{i t}$ is a dummy variable that takes a value of one when there

\footnotetext{
${ }^{9}$ As a robustness check I also run the same model with the amount of hectares planted as the dependent variable.

${ }^{10}$ All the municipalities in the dataset report a value of harvested crops greater than zero, so no observations are lost when using the natural logarithm.

${ }^{11}$ The control variables are chosen following agricultural economics production functions, where urban population represents the demand for agricultural products, the rural population density and percentage of rural population capture the labor supply for agricultural goods and land prices represent the value of the land, a key production factor in the rural sector. I also include institutional quality as it has been extensively shown to matter in growth and production models. This variable comes from the National Planning Department, which has created an institutional quality indicator that takes into account how they manage their finances, savings and other aspects related to fiscal performance. A small constant is added to coca crops so that the zeroes are not lost when using the natural logarithm.
} 
is a spraying shock. As in Equation 1 it is also lagged two periods. These dummy variables capture spraying disproportionality, after controlling for $A_{i t}$, the natural logarithm of spraying. ${ }^{12}$ $Y i t$ remains the same, as well as $X_{i t}$, the fixed effects and the error term.

$$
Y_{i t}=\alpha+\beta_{1} S_{i t}+\beta_{2} S_{i t-1}+\beta_{3} S_{i t-2}+\beta_{4} A_{i t}+\beta_{5} A_{i t-1}+\beta_{6} A_{i t-2}+\beta_{7} X_{i t}+\eta_{t}+\mu_{i}+\varepsilon_{i t}
$$

The coffee growers' subgroup uses the panel specification as Equations 1 and 2. The main change is that the dependent variable is not areas with coffee but coffee production and productivity measured as the number of $60 \mathrm{~kg}$ bags of coffee produced and bags per hectare. This is a much better indicator of agricultural output which can only be captured with a homogeneous product like coffee. Control variables include individual plot characteristics such as the area dedicated to coffee, the coffee variety, the number of farms used for production, the age of the crop, whether the coffee has been replanted or newly planted, the coffee crop density, and the coffee growers-rural population ratio in the municipality. I also add individual and time fixed effects and additionally cluster standard errors at the municipal level.

\section{Cross-Section Specification}

The cross section specifications are similar to Equations 1 and 2, but drop the individual fixed effects and do not use additional lags. The FWF sample is a cross-section collected in 2012. I use disproportionate spraying in 2011 and the total spraying shocks between 2001 and 2011 as treatment variables for the disproportionality and shock specifications respectively. I use survey weights for expansion, which are stratified at the municipal level and thus take care of the intra-municipal correlation. I make sure that the rest of the control variables are at an individual level so that the only variables at the municipal level are the treatment variables. I also control for municipal coca levels in 2006, before the Program started. The control variables included are per capita expenditure per month, perceived land quality, percentage of land with a title, gender and age of the household head, time spent in the same community, participation in productive associations, a morality index built to capture culture of legality and moral perception of coca. ${ }^{13}$

The UNODC sample is also a cross-section collected in 2012. For the spraying disproportionality I use the average of the whole period (2001-2011). Unlike FWF which has a national coverage, this sample is geographically concentrated and using the average spraying disproportionality captures a better picture than using its value in 2011, which dropped vis-à-vis 2010 and previous years in this region. The shocks are also captured by the sum of shocks between 2001 and 2011. Since this survey focused on coca production, I have detailed information on self-reported coca crops, which gives me the possibility to control for coca at an individual level (I control for the amount of years each farmer has cultivated coca and for their involvement with processing

\footnotetext{
${ }^{12}$ Spraying is included with the caveats above mentioned in mind. The main variable of interest is the shock, but spraying levels must be controlled for. Once the shock is included, spraying levels play a similar role as the linear term of the (dis)proportionality variable in the continuos case, and thus can be seen as a robustness check for the results obtained from the latter. A small constant is added to spaying so that the zeroes are not lost when using the natural logarithm.

${ }^{13}$ The questionnaire included a set of questions that asked about people's justifications for doing immoral activities such as stealing electricity, not paying for public transportation, among others, and also about their justifications for working with coca. These questions are combined to form a morality index.
} 
coca leaves into coca paste or coca base), which is an advantage compared to the other two micro datasets. I can also control for whether their own crops have been affected by spraying. Additional controls are age and sex of household heads, holding a title over their land, the self reported quality of public utilities, trust in authorities, total disposable land and years living in the farm. Errors are clustered at the municipal level.

\section{Hypotheses}

My hypotheses can be formulated in terms of expected coefficients. First, I expect the coefficient associated with the linear term of spraying disproportionality to be positive (as should be the coefficient accompanying spraying in Eq. 2). This should capture the commonly assumed relationship between spraying and coca, whereby increased punishment should induce farmers to opt out of coca and invest in legal crops. However, I expect this positive relationship to have an upper limit, and presume the squared term (or the shock variable in Eq. 2) to have a negative coefficient and reduce the area planted with legal crops, as it captures severe and disproportionate punishment. Second, the coefficient related to coca could go in two directions. It could be negative if there is a substitution effect between coca crops and legal crops, especially if production factors such as labor and land are scarce and fixed; in this case, more coca would imply less legal crops (negative coefficient). It could be positive if there is resource abundance or if coca is being closely camouflaged with legal crops in order to avoid detection (planting coca under banana trees so that the foliage covers the coca plants in the aerial satellite pictures). The coefficient on spraying in the shock specification should be positive; once the shock is controlled for, spraying should induce a switch from illegal to legal crops.

\section{Results and discussion}

My empirical strategy is set out as follows. First I present a general description of the municipalities and the farmers surveyed, followed by descriptive results on spraying, spraying disproportionality and coca levels and show that at a first sight spraying disproportionality does not follow coca. I then strengthen these results with a fixed effects model that stresses the lack of positive correlation between coca and spraying disproportionality. With this evidence I continue with testing the relationship between spraying disproportionality and legal crops in the four samples, starting with the aggregate macro data followed by the micro data samples, ordered from highest spraying disproportionality (UNODC) to lowest (coffee growers).

\section{Characteristics of municipalities and surveyed farmers}

Coca-growing municipalities are also legal crop producers. The top ten crops are corn, plantain, cassava, beans, rice, cocoa, sugar cane, coffee, tomatoes and avocado; these are the same in non-coca growing municipalities, except that in the latter cold-weather crops such as potatoes enter the list. In the majority of coca-growing municipalities legal crops account for most of 
the agricultural production; only in 6 municipalities ${ }^{14}$ the area dedicated to coca is larger than the area dedicated to legal crops, in the rest, the average area dedicated to coca amounts to $3 \%$ of the area used for legal crops. Around $31 \%$ of the rural population lives in coca-growing municipalities, and according to UNODC (2013) 61,700 households are directly involved with coca. In 2013 coca production amounted to $3 \%$ of the agricultural GDP (UNODC, 2014). Table 1.2 presents descriptive statistics of the main independent variables used in the models for coca growing municipalities.

Table 1.2: Summary statistics of coca growing municipalities

\begin{tabular}{lcccc}
\hline \hline & & & & \\
& mean & sd & $\min$ & $\max$ \\
\hline Coca hectares & 425.05 & 1000.80 & 0 & 14606 \\
Sprayed hectares & 1510.66 & 2704.42 & 0 & 29416 \\
Cultivated area (ha) & 32457.84 & 55398.99 & 1 & 696975 \\
Spraying disproportionality & 3.73 & 14.23 & 0 & 306 \\
Threat Yellow Zone & 0.33 & 0.47 & 0 & 1 \\
Threat Red Zone & 0.46 & 0.50 & 0 & 1 \\
Distance to Urban Center (km) & 69.72 & 65.64 & 0 & 397 \\
Fiscal Performance Index & 58.85 & 9.31 & 0 & 87 \\
Urban Population & 14185.78 & 50945.82 & 0 & 615795 \\
Rural Population & 11667.85 & 9540.34 & 0 & 85386 \\
Population density in rural area & 19.84 & 30.53 & 0 & 357 \\
Num. Armed Actions & 1.19 & 3.18 & 0 & 46 \\
Num. FARC & 21.08 & 59.76 & 0 & 948 \\
Num. ELN & 4.47 & 11.42 & 0 & 115 \\
Num. BACRIM & 5.32 & 15.08 & 0 & 144 \\
Num. Combats & 3.85 & 9.61 & 0 & 119 \\
Num. Landmines & 3.05 & 8.21 & 0 & 111 \\
\hline \hline A description of these variables and their sources can be found in the Appendix
\end{tabular}

The farmers in the UNODC sample are the most exposed to coca as can be seen in Figure 1.5 , and for $58 \%$ of the sample, growing coca is their main economic activity. The majority are male $(85 \%)$ and most $(75 \%)$ only have primary education or no education at all. As is the case in many coca growing areas, half of the sample was born in a different place and migrated to the region on average 22 years before, which coincides with the initial growth of coca in these areas around the 80 's. Only $30 \%$ have titles over their land. Before migrating, $50 \%$ were farmers, and $60 \%$ said they had migrated due to poverty or unemployment, but only $5.5 \%$ were already working with illegal crops. These farmers are still exposed to poor living conditions: only $3 \%$ have access to drinking water and $13.5 \%$ to electricity, and even though there are health facilities, schools and roads in the majority of places, farmers perceive them as very low quality. The average size of their farm is 13 hectares, but only 1.6 hectares are cultivated with either permanent or transitory crops.

\footnotetext{
${ }^{14}$ These municipalities are situated in the departments of Amazonas, Cauca and Vichada. Amazonas and Vichada are in or close to the amazon rainforest, which is for environmental reasons not under large-scale agricultural exploitation. Cauca has become an important coca cultivation hotspot recently.
} 
The Forest Warden Families have been on average exposed to smaller coca quantities in their regions, but are also a marginalized population. Most of them (82\%) live in dispersed rural areas, $56 \%$ reach their farm through a gravel path, 32\% through a gravel road, $10 \%$ through a river, and only $2 \%$ access it through a paved road. Only $43 \%$ live above poverty ${ }^{15}$ and $82 \%$ have primary schooling or less. They have also been exposed to high levels of violence, with $26 \%$ of the sample reporting having experienced a violent calamity. The FWF farmers follow the same productive pattern observed for the aggregate data: $33 \%$ grow transitory crops, $18 \%$ grow plantain, $12 \%$ grow coffee and $8.6 \%$ grow cocoa, and $76 \%$ of the households use part of these crops to feed their family. As is the case for the UNODC sample, only $30 \%$ hold a title over their land. The median FWF farm has two hectares, with one hectare dedicated to productive activities.

Even though the coffee growers' census does not collect socioeconomic data on the farmers, it can be merged with the SISBEN dataset, which collects the socioeconomic information in order to target beneficiaries for social programs, allowing me to characterize these farmers. Although this is the population with the least exposure to coca crops and spraying, coffee farmers in municipalities where coca has been grown are also marginalized, as $91.8 \%$ are poor, according to the ICV. Earnings amount to approximately USD 49 per month and they have studied 3.1 years on average. Farms measure 6.5 hectares, but only 1.2 hectares are actually used to grow coffee. As in the other two samples, only $29 \%$ have a title over their land.

\section{Descriptive evidence}

Figure 1.2 shows coca, spraying and spraying disproportionality levels between 2001 and 2011. Some things are interesting to note from this Figure: spraying follows coca in the expected way but spraying disproportionality and spraying shocks seem to follow a completely different logic; they increase until 2007 even though both coca and spraying were decreasing, and they do not seem to follow coca patterns. Spraying disproportionality and spraying shocks increase until 2007 when they reach a maximum, and decrease thereon, with the exception of 2010. Figure 1.3 shows the geographical distribution of coca, spraying and spraying disproportionality in 2007 , where it is seen that the areas with highest coca hectares coincide with the areas of spraying but less so with areas with high disproportionality.

\footnotetext{
${ }^{15}$ Measured by the ICV, the livelihoods index, a multi-poverty index constructed by the National Planning Department whose components where asked in the survey.
} 
Figure 1.2: Spraying, spraying shocks, spraying disproportionality and coca grown per year
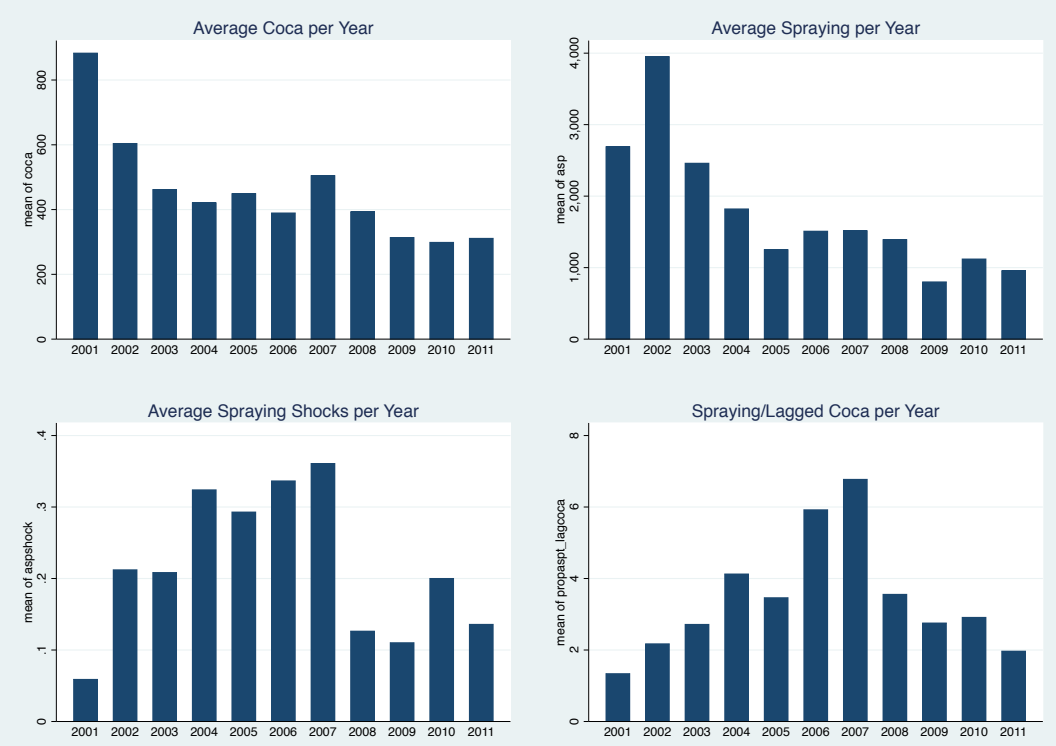

Figure 1.3: Coca and spraying disproportionality

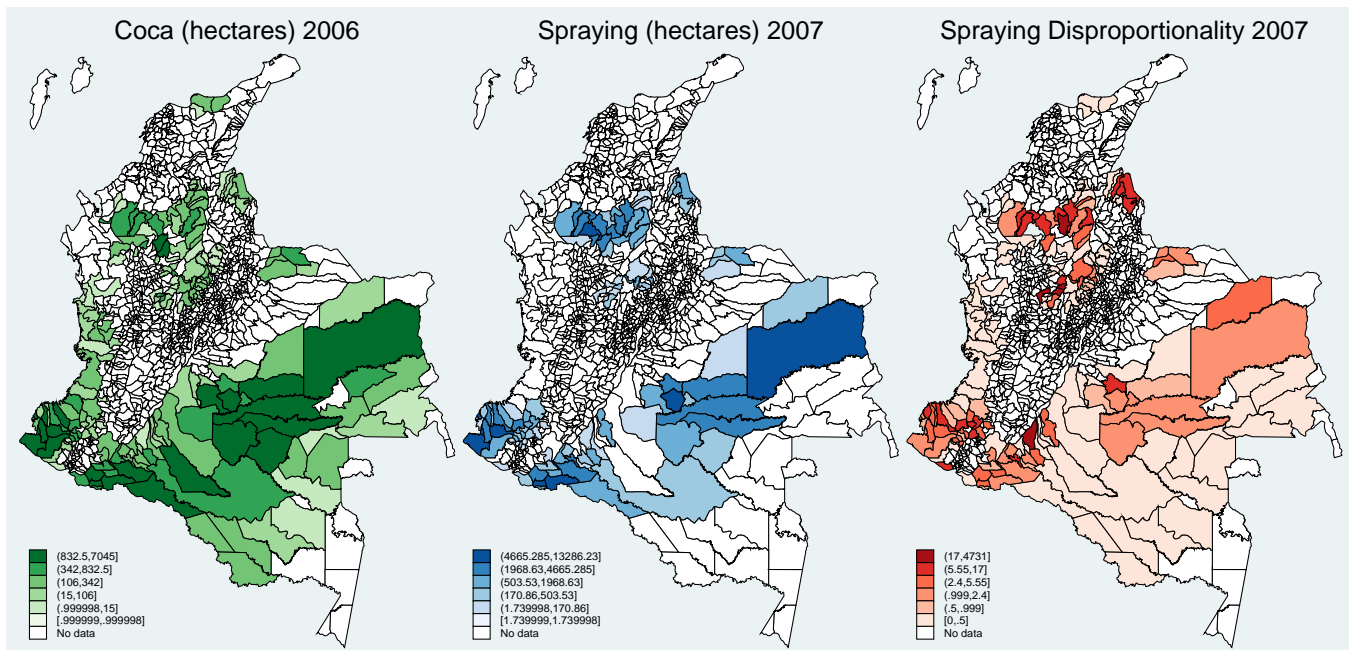

Now I turn to legal crops and look at their patterns for all municipalities that have grown coca at least once, and divide them between those who experience a shock and those who do not. Figure 1.4 shows that those that experience a shock have on average less legal crops than those that do not. It is interesting to note that the big fall in legal crop harvested areas in 2009 for those who experienced a shock followed the year of highest spraying disproportionality. Even though both groups were decreasing their legal crop areas, those who were exposed to a shock showed a much steeper decrease than those that were not. It is also quite interesting to note that 
as spraying disproportionality decreases, crops recover for both groups, but it is especially those exposed to shocks that bounce back remarkably fast. Without claiming causality, this suggests that increases (decreases) in spraying disproportionality have quite an important lagged effect on legal crops, especially for those municipalities that have been exposed to spraying shocks.

Figure 1.4: Legal crops and spraying shocks

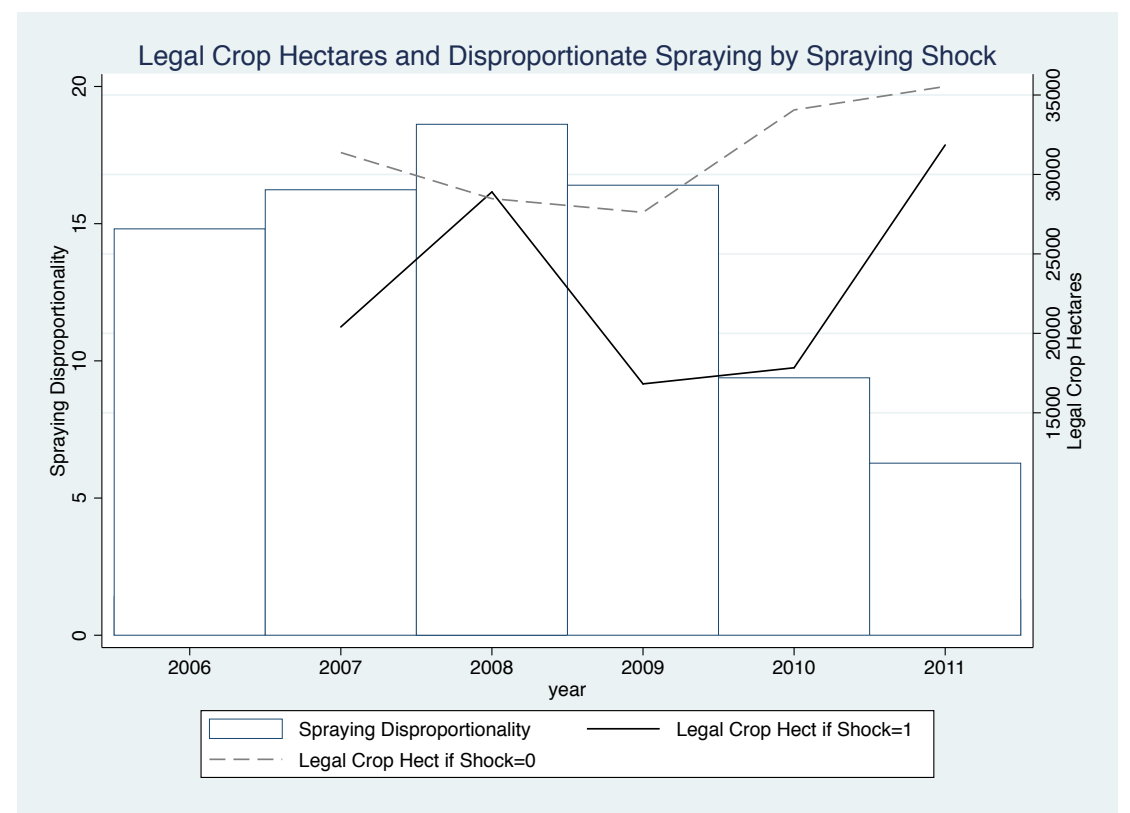

As mentioned in the data section, the three micro samples are quite different and this also shows in the levels of coca, spraying and spraying disproportionality they have been exposed to. As expected, the UNODC sample has the highest exposure to coca and spraying, because it surveys farmers that live in the Putumayo-Caqueta region, a historical coca growing area. The Forest Warden Families sample follows a similar pattern to that of UNODC, but of a smaller magnitude. The FWF includes coca growing regions and regions at high risk of having coca, while also focusing on areas that have been recovered by the state in recent years, which explains the divergence in coca trends with regards to the UNODC sample in the last year. Spraying disproportionality has also been highest among UNODC and FWF samples. As expected, coffee growers in municipalities where coca has been grown show lower exposure to coca, spraying and disproportionality than farmers in the UNODC and FWF samples. These three samples offer great richness in the analysis, as I can check how farmers' productive decisions react to disproportionate spraying in three different environment-related scenarios: very high exposure, medium-high exposure and low exposure. 
Figure 1.5: Coca, spraying and spraying disproportionality for each different micro sample

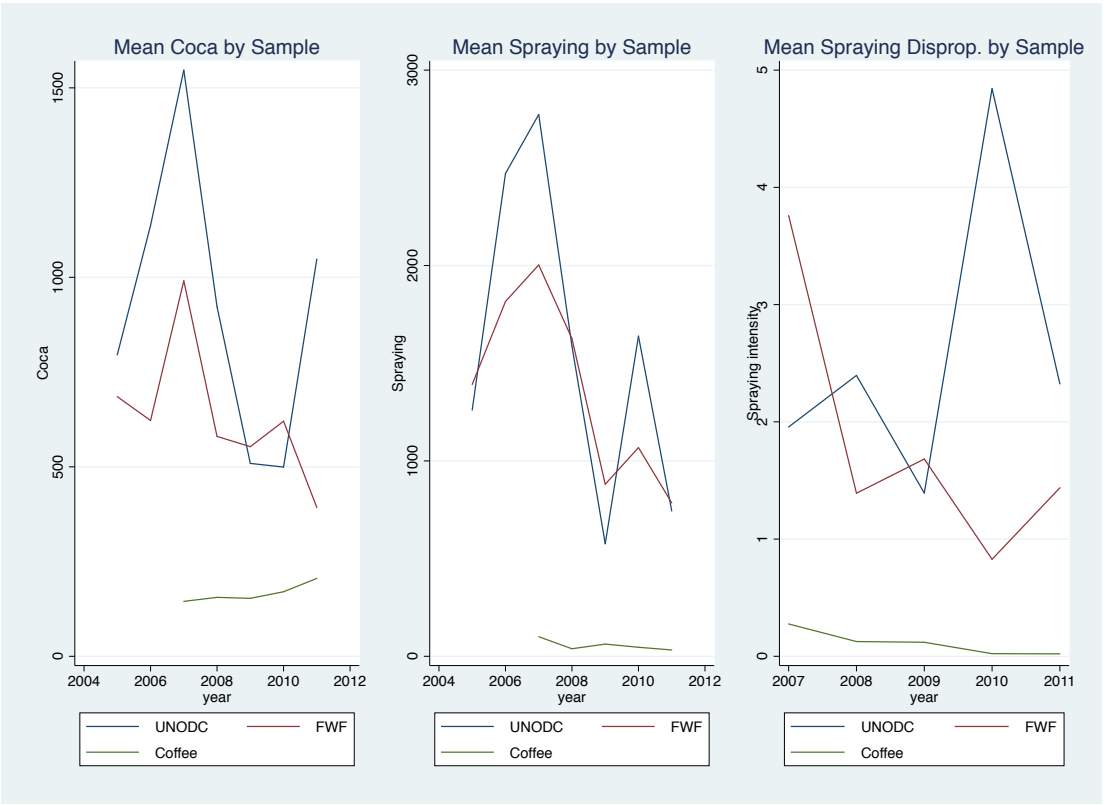

\section{Empirical results: macro data}

\section{Determinants of spraying, spraying disproportionality and spraying shocks}

I first start with exploring the determinants of spraying and spraying shocks. Table 1.3 presents three regressions: the first column explains spraying, the second spraying disproportionality and the third spraying shocks, all of them using a fixed effects panel data model for all municipalities with coca production at some point between 2002 and 2011. ${ }^{16}$ I follow Reyes' (2011) logic that spraying happens within distances where spraying planes can be protected from being shot down. ${ }^{17}$ This means that spraying should be highest around urban centers where the state has more control and low where there is significant presence of illegal armed groups or where the threat to security is highest (all of these are also correlated with distance up to a certain extent). I use other variables following Bogliciano and Naranjo (2012) such as coca production, crime rate and displacement (See Appendix for definitions).

I find that spraying is higher in places where the threat to the state ${ }^{18}$ is medium and high (yellow and red zones). In order to be able to include the distance to urban cities in a fixed effects model, I interact it with the threat to the state index and find that spraying increases with the distance to an urban center for both yellow and red zones, but decreases when this distance becomes too large (squared term). Although spraying decisions are made based on previous year's coca, I include the lagged change in coca crops and the area cultivated with

\footnotetext{
${ }^{16} \mathrm{~A}$ table with the marginal effects of all the variables included in the regressions can be found in the appendix.

${ }^{17}$ Reyes uses distance to military bases instead of distance to cities. However, I find that distance to the closest urban cluster (not necessarily the closest city, but the closest agglomeration as defined by the City System Mission) has a similar effect to that found in Reyes' (2011) first stage.

${ }^{18}$ See Appendix for definition of threat to the state index and its categories.
} 
coca with a two years lag, in order to avoid problems when estimating the regressions with spraying disproportionality and spraying shock, where coca in $t-1$ is the denominator. As was also seen in the descriptive statistics, an increase in coca crops in the previous year increases spraying, as expected. ${ }^{19}$ Increased presence of illegal armed groups FARC, ELN and criminal groups (BACRIM) also reduces spraying levels. Where combats are not so high spraying is high, meaning perhaps that where combats are taking place the state is present, trying to recover its territory from the illegal armed groups. As a result spraying aircraft may be protected by state forces, but only in those situations in which the intensity of the fight is not extreme.

Spraying disproportionality and a spraying shock do not seem to respond to the same variables, in fact, some have the opposite effect and the explanatory power of the overall models is quite low. In the first place, neither disproportionate spraying nor spraying shocks are determined positively by lagged coca levels; an increase in coca levels is correlated with a smaller probability of experiencing a shock, suggesting that a shock is not meant to counteract high levels of illegal crops. Moreover, a spraying shock is not likely to happen in situations where the threat to the state is high, and if it does, it will take place near the urban center. In contrast to spraying, presence of the FARC, BACRIM or ELN is not related to a spraying shock. Only combats and armed actions relate positively to a shock.

I went further into possible differences between those that had experienced a shock and those that had not, took key variables for agricultural production at their earliest levels (2004 and before) and looked at whether there were any significant differences between them. I found no differences between the groups for rural land prices, forced displacement intensity, homicide rates, rural and urban population sizes, rural population density, roads (in kilometers), primary roads, number of years growing coca, forest density, distance to urban centers, fiscal performance, rural poverty index in 2005, armed actions and presence of ELN and FARC guerrilla groups.

There a few variables with differences: municipalities that experienced a shock rely four percentage points less in transfers from the central government, are 400 meters above sea level higher, had higher rural poverty in 1993 and are qualified 0.7 points higher in the threat to the state index that ranges from one to ten. In the models I control for the variables that are different either as control variables or as fixed effects.

These results show that spraying disproportionality or a spraying shock does not follow the same logic as spraying, but is rather a phenomenon that is not easy to explain, at least with the socioeconomic and conflict variables at hand, and seems to include an element of randomness which could have come from the pilot himself or the flight conditions during the overpass. This randomness could also be a military intelligence move that I cannot quantify. For the purpose of this study, this is evidence that supports that a spraying shock is exogenous to the farmers' legal crop growing decisions.

\footnotetext{
${ }^{19} \mathrm{I}$ also run a regression including coca in $\mathrm{t}-1$ and find a very strong and positive correlation with spraying in year t. Running the model with coca ( $\mathrm{t}-1)$ instead of the changes in levels and the second lag also increases the overall R2 of the spraying regression to 0.17 . This would be the optimal model for explaining spraying but cannot be used with spraying disproportionality and spraying shocks, since they both have coca in t-1 in the denominator.
} 
Table 1.3: Spraying and spraying shocks

\begin{tabular}{|c|c|c|c|}
\hline & $\begin{array}{c}(1) \\
\text { lnSpraying }\end{array}$ & $\begin{array}{c}(2) \\
\text { Spraying Disp }\end{array}$ & $\begin{array}{c}(3) \\
\text { Spraying Shock }\end{array}$ \\
\hline Threat Yellow Zone & $\begin{array}{c}15.8922^{\text {*** }} \\
(4.3121)\end{array}$ & $\begin{array}{l}-29.1304 \\
(35.5777)\end{array}$ & $\begin{array}{c}0.3522 \\
(1.2748)\end{array}$ \\
\hline Threat Red Zone & $\begin{array}{c}13.3593^{* * *} \\
(4.4176)\end{array}$ & $\begin{array}{l}-50.9193 \\
(35.1075)\end{array}$ & $\begin{array}{l}-0.0400 \\
(1.3459)\end{array}$ \\
\hline Threat Yellow Zone $\times$ Distance to urban $(\ln )$ & $\begin{array}{c}6.6377^{* * *} \\
(1.4626)\end{array}$ & $\begin{array}{l}-10.0316 \\
(12.4300)\end{array}$ & $\begin{array}{c}0.0926 \\
(0.4351)\end{array}$ \\
\hline Threat Red Zone $\times$ Distance to urban $(\ln )$ & $\begin{array}{c}6.5020^{* * *} \\
(1.5434)\end{array}$ & $\begin{array}{c}-6.2049 \\
(12.2493)\end{array}$ & $\begin{array}{c}0.1243 \\
(0.4748)\end{array}$ \\
\hline Threat Yellow Zone x Distance to urban $(\ln ) 2$ & $\begin{array}{c}-0.7268^{* * *} \\
(0.1625)\end{array}$ & $\begin{array}{c}1.1127 \\
(1.3629)\end{array}$ & $\begin{array}{l}-0.0081 \\
(0.0483)\end{array}$ \\
\hline Threat Red Zone x Distance to urban (ln) 2 & $\begin{array}{c}-0.6934^{* * *} \\
(0.1705)\end{array}$ & $\begin{array}{c}0.9737 \\
(1.3674)\end{array}$ & $\begin{array}{l}-0.0076 \\
(0.0524)\end{array}$ \\
\hline $\ln \operatorname{Coca}(\mathrm{t}-1)-\ln \operatorname{Coca}(\mathrm{t}-2)$ & $\begin{array}{l}0.4212^{* *} \\
(0.1814)\end{array}$ & $\begin{array}{l}-2.7714 \\
(1.7583)\end{array}$ & $\begin{array}{c}-0.1462^{* *} \\
(0.0576)\end{array}$ \\
\hline $\ln$ Coca $(t-2)$ & $\begin{array}{c}0.4081 \\
(0.3062)\end{array}$ & $\begin{array}{l}-1.3725^{*} \\
(0.7147)\end{array}$ & $\begin{array}{c}-0.2711^{* * *} \\
(0.0955)\end{array}$ \\
\hline Rural density & $\begin{array}{l}-0.1301 \\
(0.2157)\end{array}$ & $\begin{array}{c}0.1590 \\
(0.2867)\end{array}$ & $\begin{array}{c}0.0257 \\
(0.0587)\end{array}$ \\
\hline Num. armed actions & $\begin{array}{l}-0.0045 \\
(0.0395)\end{array}$ & $\begin{array}{l}-0.1472^{*} \\
(0.0840)\end{array}$ & $\begin{array}{c}-0.0179^{* *} \\
(0.0078)\end{array}$ \\
\hline Num. FARC & $\begin{array}{c}0.0027 \\
(0.0031)\end{array}$ & $\begin{array}{c}0.0052 \\
(0.0084)\end{array}$ & $\begin{array}{c}0.0014 \\
(0.0011)\end{array}$ \\
\hline Num. FARC $\times$ Num. FARC & $\begin{array}{l}-0.0000^{*} \\
(0.0000)\end{array}$ & $\begin{array}{l}-0.0000 \\
(0.0000)\end{array}$ & $\begin{array}{l}-0.0000 \\
(0.0000)\end{array}$ \\
\hline Num. ELN & $\begin{array}{l}-0.0357^{*} \\
(0.0205)\end{array}$ & $\begin{array}{l}-0.0409 \\
(0.0372)\end{array}$ & $\begin{array}{c}0.0003 \\
(0.0035)\end{array}$ \\
\hline Num. BACRIM & $\begin{array}{l}0.0320^{* *} \\
(0.0157)\end{array}$ & $\begin{array}{c}0.0221 \\
(0.0372)\end{array}$ & $\begin{array}{c}0.0066 \\
(0.0040)\end{array}$ \\
\hline Num. BACRIM $\times$ Num. BACRIM & $\begin{array}{c}-0.0003^{* *} \\
(0.0001)\end{array}$ & $\begin{array}{l}-0.0002 \\
(0.0003)\end{array}$ & $\begin{array}{c}-0.0001^{* *} \\
(0.0000)\end{array}$ \\
\hline Num. Combats & $\begin{array}{l}0.0596^{*} \\
(0.0339)\end{array}$ & $\begin{array}{c}0.0753 \\
(0.0602)\end{array}$ & $\begin{array}{c}0.0033 \\
(0.0104)\end{array}$ \\
\hline Num. Combats $\times$ Num. Combats & $\begin{array}{l}-0.0001 \\
(0.0003)\end{array}$ & $\begin{array}{l}-0.0004 \\
(0.0005)\end{array}$ & $\begin{array}{c}0.0000 \\
(0.0001)\end{array}$ \\
\hline Num. Mines & $\begin{array}{c}0.0468 \\
(0.0368)\end{array}$ & $\begin{array}{c}0.0779 \\
(0.0833)\end{array}$ & $\begin{array}{c}0.0148 \\
(0.0118)\end{array}$ \\
\hline Num. Mines $\times$ Num. Mines & $\begin{array}{l}-0.0012^{*} \\
(0.0006)\end{array}$ & $\begin{array}{l}-0.0010 \\
(0.0014)\end{array}$ & $\begin{array}{l}-0.0002 \\
(0.0002)\end{array}$ \\
\hline Constant & $\begin{array}{c}4.4470 \\
(3.0014)\end{array}$ & $\begin{array}{c}10.6098^{* *} \\
(5.2601)\end{array}$ & $\begin{array}{c}0.9978 \\
(0.8420)\end{array}$ \\
\hline Observations & 251 & 251 & 251 \\
\hline Num.Municipalities & 107 & 107 & 107 \\
\hline R2 Overall & 0.02 & 0.00 & 0.05 \\
\hline R2 Within & 0.26 & 0.22 & 0.21 \\
\hline R2 Between & 0.03 & 0.00 & 0.04 \\
\hline
\end{tabular}




\section{Spraying disproportionality and legal crops at the macro level}

Table 1.4 presents the first piece of evidence regarding the effect of disproportionate spraying on the area harvested with legal crops. The first three columns follow the specification in Equation 1 that uses the continuous spraying (dis)proportionality variable as the main explanatory variable, but they differ in the dependent variable used. Since the effects of spraying could vary depending on the type of crop being used, I test the effects first on all legal crops, on transitory and on permanent crops. All regressions hint at the same relationship: very high levels of spraying disproportionality or spraying shocks reduce legal crops, whereas low levels (or proportional levels) increase legal crops. I find that the relationship has an inverted U shape ${ }^{20}$ where mild levels up spraying induce legal crops, but disproportionate levels reduce them. Figure 1.6 shows that when spraying disproportionality is above seven, legal crops are reduced. ${ }^{21}$ This effect is statistically significant in the second lag for all crops and permanent crops, and in the first and second lag for transitory crops.

The last three columns use spraying shocks as the main independent variable, as specified in Equation 2. The signs remain the same and the shock reduces legal crops in year $t$ and in $\mathrm{t}-1$. The effect of this shock is quite large, as it reduces legal crops in $19.4 \%$ in year $\mathrm{t}$ and up to $23.4 \%$ one year later. Spraying induces legal crops, as seen with the linear term of the continuous disproportionality.

There also seems to be a substitution effect between lagged coca increases and legal crops. This is an expected result as people have a fixed amount of land and they choose between coca and other crops or activities, or through coca's close relationship with conflict.

The negative coefficient of the squared disproportionate spraying could mean two things: that spraying intensity increases legal crops at a decreasing rate or that legal crops decrease after a turning point. I find evidence for the latter as shown in Figure 1.6 that presents the predicted margins of the relationship between spraying disproportionality and harvested legal crops.

\footnotetext{
${ }^{20}$ I tested a linear and cubic specification as a robustness check. In the linear specification only the first lag had a negative sign, but none of the spraying disproportionality variables $(\mathrm{t}, \mathrm{t}-1, \mathrm{t}-2)$ were significant. In the cubic specification I obtained a positive linear term, negative quadratic term (significant in the first lag) and positive cubic term, but never statistically significant. I remain confident that the quadratic specification is what best suits the theory of disproportionality.

21 As a robustness check I estimate a Heckman selection model for each year in the period of analysis to get an inverted mills ratio for the whole period. I then include the inverted mills ratio as a control variable to control for possible selection effects that may not have been controlled for with the fixed effects and find that spraying disproportionality reduces legal crops contemporaneously as well as in the second lag for all products (see Table A1.3 in the Appendix).
} 
Table 1.4: Legal crops, disproportionality of spraying and spraying shocks

\begin{tabular}{|c|c|c|c|c|c|c|}
\hline & $\begin{array}{l}\text { (1) } \\
\text { All }\end{array}$ & $\begin{array}{c}(2) \\
\text { Transitory }\end{array}$ & $\begin{array}{c}(3) \\
\text { Permanent }\end{array}$ & $\begin{array}{l}(4) \\
\text { All (Shock) }\end{array}$ & $\begin{array}{c}(5) \\
\text { Trans (Shock) }\end{array}$ & $\begin{array}{c}(6) \\
\text { Perm (Shock) }\end{array}$ \\
\hline Spraying Disp & $\begin{array}{c}0.040 \\
(0.026)\end{array}$ & $\begin{array}{c}0.002 \\
(0.052)\end{array}$ & $\begin{array}{c}0.033 \\
(0.030)\end{array}$ & & & \\
\hline Spraying Disp 2 & $\begin{array}{l}-0.002 \\
(0.002)\end{array}$ & $\begin{array}{c}0.000 \\
(0.003)\end{array}$ & $\begin{array}{l}-0.002 \\
(0.002)\end{array}$ & & & \\
\hline Spraying Disp (t-1) & $\begin{array}{c}0.030 \\
(0.037)\end{array}$ & $\begin{array}{l}0.071^{*} \\
(0.043)\end{array}$ & $\begin{array}{c}0.042 \\
(0.032)\end{array}$ & & & \\
\hline Spraying Disp 2 (t-1) & $\begin{array}{l}-0.003 \\
(0.002)\end{array}$ & $\begin{array}{l}-0.005^{*} \\
(0.003)\end{array}$ & $\begin{array}{l}-0.003 \\
(0.002)\end{array}$ & & & \\
\hline Spraying Disp (t-2) & $\begin{array}{c}0.073^{* * *} \\
(0.025)\end{array}$ & $\begin{array}{c}0.099^{* *} \\
(0.038)\end{array}$ & $\begin{array}{l}0.040^{*} \\
(0.024)\end{array}$ & & & \\
\hline Spraying Disp 2 (t-2) & $\begin{array}{c}-0.003^{* * *} \\
(0.001)\end{array}$ & $\begin{array}{c}-0.006^{* * *} \\
(0.002)\end{array}$ & $\begin{array}{l}-0.002^{*} \\
(0.001)\end{array}$ & & & \\
\hline Spraying Shock & & & & $\begin{array}{c}-0.215^{* *} \\
(0.091)\end{array}$ & $\begin{array}{l}-0.221 \\
(0.154)\end{array}$ & $\begin{array}{l}-0.141 \\
(0.091)\end{array}$ \\
\hline Spraying Shock (t-1) & & & & $\begin{array}{c}-0.267^{* *} \\
(0.126)\end{array}$ & $\begin{array}{c}-0.266^{*} \\
(0.155)\end{array}$ & $\begin{array}{l}-0.019 \\
(0.146)\end{array}$ \\
\hline Spraying Shock (t-2) & & & & $\begin{array}{c}0.053 \\
(0.100)\end{array}$ & $\begin{array}{l}-0.104 \\
(0.148)\end{array}$ & $\begin{array}{c}0.175 \\
(0.128)\end{array}$ \\
\hline ln Spraying (t) & & & & $\begin{array}{c}0.085^{* * *} \\
(0.023)\end{array}$ & $\begin{array}{c}0.033 \\
(0.036)\end{array}$ & $\begin{array}{l}0.075^{*} \\
(0.039)\end{array}$ \\
\hline ln Spraying (t-1) & & & & $\begin{array}{l}0.057^{*} \\
(0.033)\end{array}$ & $\begin{array}{l}0.092^{*} \\
(0.049)\end{array}$ & $\begin{array}{c}0.001 \\
(0.042)\end{array}$ \\
\hline ln Spraying (t-2) & & & & $\begin{array}{c}0.027 \\
(0.032)\end{array}$ & $\begin{array}{c}0.053 \\
(0.044)\end{array}$ & $\begin{array}{l}-0.042 \\
(0.062)\end{array}$ \\
\hline Lagged Change in ln Coca & $\begin{array}{l}-0.108^{*} \\
(0.059)\end{array}$ & $\begin{array}{l}-0.116 \\
(0.071)\end{array}$ & $\begin{array}{l}-0.007 \\
(0.041)\end{array}$ & $\begin{array}{c}-0.145^{* * *} \\
(0.050)\end{array}$ & $\begin{array}{l}-0.129 \\
(0.079)\end{array}$ & $\begin{array}{c}-0.097^{* *} \\
(0.042)\end{array}$ \\
\hline $\ln$ Coca $(t-2)$ & $\begin{array}{l}-0.068 \\
(0.064)\end{array}$ & $\begin{array}{l}-0.074 \\
(0.095)\end{array}$ & $\begin{array}{l}-0.054 \\
(0.066)\end{array}$ & $\begin{array}{c}-0.268^{* * *} \\
(0.084)\end{array}$ & $\begin{array}{c}-0.289^{* *} \\
(0.121)\end{array}$ & $\begin{array}{l}-0.136^{*} \\
(0.075)\end{array}$ \\
\hline Product cluster (HHI) & $\begin{array}{c}1.836^{* * *} \\
(0.616)\end{array}$ & $\begin{array}{c}-2.214^{* *} \\
(0.994)\end{array}$ & $\begin{array}{l}1.785^{*} \\
(1.031)\end{array}$ & $\begin{array}{l}1.416^{* * *} \\
(0.612)\end{array}$ & $\begin{array}{c}-2.625^{* *} \\
(1.012)\end{array}$ & $\begin{array}{c}1.529 \\
(0.954)\end{array}$ \\
\hline ln Rural Land Price (t-1) & $\begin{array}{l}-0.055 \\
(0.050)\end{array}$ & $\begin{array}{l}-0.050 \\
(0.077)\end{array}$ & $\begin{array}{l}-0.034 \\
(0.041)\end{array}$ & $\begin{array}{l}-0.048 \\
(0.055)\end{array}$ & $\begin{array}{l}-0.050 \\
(0.080)\end{array}$ & $\begin{array}{l}-0.019 \\
(0.043)\end{array}$ \\
\hline Change in Fiscal Performance & $\begin{array}{l}-0.005 \\
(0.005)\end{array}$ & $\begin{array}{c}-0.012^{* *} \\
(0.005)\end{array}$ & $\begin{array}{l}-0.005 \\
(0.005)\end{array}$ & $\begin{array}{l}-0.005 \\
(0.004)\end{array}$ & $\begin{array}{c}-0.013^{* *} \\
(0.006)\end{array}$ & $\begin{array}{l}-0.005 \\
(0.005)\end{array}$ \\
\hline Fiscal Performance (t-1) & $\begin{array}{l}-0.004 \\
(0.009)\end{array}$ & $\begin{array}{l}-0.015 \\
(0.009)\end{array}$ & $\begin{array}{l}-0.010 \\
(0.009)\end{array}$ & $\begin{array}{l}-0.005 \\
(0.008)\end{array}$ & $\begin{array}{l}-0.016^{*} \\
(0.010)\end{array}$ & $\begin{array}{l}-0.009 \\
(0.008)\end{array}$ \\
\hline Change in ln Rural Pop & $\begin{array}{l}-0.248 \\
(6.574)\end{array}$ & $\begin{array}{c}3.688 \\
(6.306)\end{array}$ & $\begin{array}{l}-1.353 \\
(5.868)\end{array}$ & $\begin{array}{c}0.626 \\
(6.267)\end{array}$ & $\begin{array}{c}3.984 \\
(5.870)\end{array}$ & $\begin{array}{l}-0.100 \\
(5.903)\end{array}$ \\
\hline ln Rural Pop (t-1) & $\begin{array}{c}0.395 \\
(6.683)\end{array}$ & $\begin{array}{c}3.161 \\
(6.430)\end{array}$ & $\begin{array}{l}-1.681 \\
(5.839)\end{array}$ & $\begin{array}{c}1.356 \\
(6.312)\end{array}$ & $\begin{array}{c}3.737 \\
(5.887)\end{array}$ & $\begin{array}{l}-0.205 \\
(5.894)\end{array}$ \\
\hline Rural density & $\begin{array}{l}-0.063 \\
(0.158)\end{array}$ & $\begin{array}{c}-0.449^{* * *} \\
(0.157)\end{array}$ & $\begin{array}{c}0.107 \\
(0.175)\end{array}$ & $\begin{array}{l}-0.093 \\
(0.192)\end{array}$ & $\begin{array}{l}-0.391 \\
(0.245)\end{array}$ & $\begin{array}{c}0.041 \\
(0.174)\end{array}$ \\
\hline Change in ln Urban Pop & $\begin{array}{c}15.339 \\
(20.133)\end{array}$ & $\begin{array}{c}33.986 \\
(24.122)\end{array}$ & $\begin{array}{c}17.150 \\
(22.522)\end{array}$ & $\begin{array}{c}13.542 \\
(19.422)\end{array}$ & $\begin{array}{c}37.097 \\
(24.912)\end{array}$ & $\begin{array}{c}15.534 \\
(21.205)\end{array}$ \\
\hline ln Urban Pop (t-1) & $\begin{array}{c}2.828 \\
(5.924)\end{array}$ & $\begin{array}{c}6.079 \\
(6.106)\end{array}$ & $\begin{array}{c}3.196 \\
(4.952)\end{array}$ & $\begin{array}{c}2.359 \\
(5.482)\end{array}$ & $\begin{array}{c}5.209 \\
(5.164)\end{array}$ & $\begin{array}{c}2.503 \\
(4.805)\end{array}$ \\
\hline Proportion rural & $\begin{array}{l}-2.157 \\
(24.972)\end{array}$ & $\begin{array}{c}13.276 \\
(24.265)\end{array}$ & $\begin{array}{c}-1.837 \\
(21.046)\end{array}$ & $\begin{array}{c}-4.204 \\
(23.562)\end{array}$ & $\begin{array}{c}8.449 \\
(21.381)\end{array}$ & $\begin{array}{l}-5.066 \\
(20.929)\end{array}$ \\
\hline Perc. income from transfers & $\begin{array}{c}0.003 \\
(0.002)\end{array}$ & $\begin{array}{c}0.000 \\
(0.003)\end{array}$ & $\begin{array}{c}0.003 \\
(0.003)\end{array}$ & $\begin{array}{c}0.003 \\
(0.002)\end{array}$ & $\begin{array}{l}-0.000 \\
(0.003)\end{array}$ & $\begin{array}{c}0.003 \\
(0.003)\end{array}$ \\
\hline Constant & $\begin{array}{l}-17.217 \\
(19.222)\end{array}$ & $\begin{array}{c}-80.344^{* * *} \\
(24.479)\end{array}$ & $\begin{array}{c}-4.849 \\
(17.460)\end{array}$ & $\begin{array}{l}-20.041 \\
(22.849)\end{array}$ & $\begin{array}{c}-75.077^{* * *} \\
(23.749)\end{array}$ & $\begin{array}{c}-9.643 \\
(18.506)\end{array}$ \\
\hline Observations & 283 & 279 & 283 & 282 & 278 & 282 \\
\hline Num.Clusters & 83 & 82 & 83 & 82 & 81 & 82 \\
\hline R2 Overall & 0.33 & 0.11 & 0.08 & 0.36 & 0.11 & 0.11 \\
\hline R2 Within & 0.24 & 0.21 & 0.17 & 0.26 & 0.19 & 0.20 \\
\hline R2 Between & 0.27 & 0.12 & 0.07 & 0.31 & 0.15 & 0.11 \\
\hline
\end{tabular}


Figure 1.6: Predictive margins of spraying disproportionality on legal crops

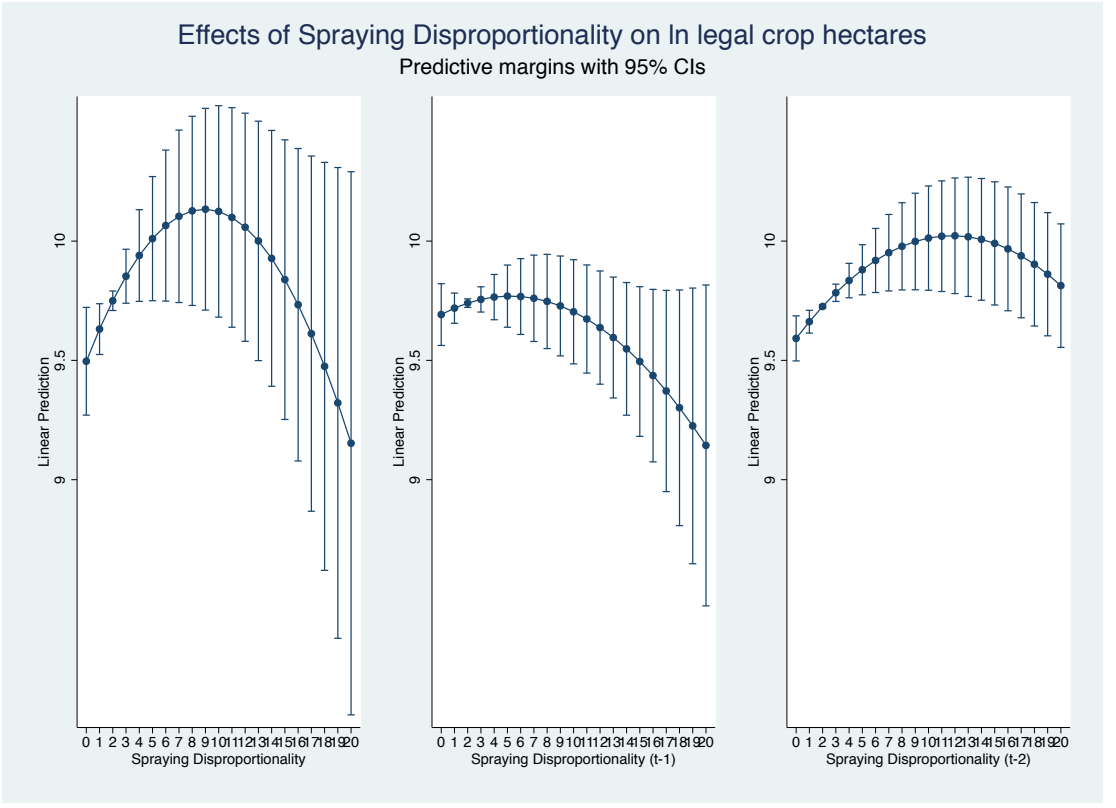

The predicted margins are shown for the majority of the municipalities ${ }^{22}$ and it is clear that the turning point is relevant for the analyzed sample. When spraying is between six and ten times the amount of coca found, the policy starts reducing legal crops. This turning point is shorter in the first lag of spraying disproportionality: when for each hectare cultivated with coca six to seven hectares are spayed, the number of hectares cultivated with legal crops in the next year drops. This figure also shows that the contemporary spraying and the first lag also behave as expected by the disproportionality concept, but the confidence intervals are too large for the effect to be statistically significant.

As a robustness test I control for various conflict related variables. ${ }^{23}$ Results become even stronger, as disproportionate spraying reduces crops significantly in the first and second lags (see Table A1.4 in the Appendix). Regarding prices, it is also important to note that there is no evidence that the reduction of legal crops follows a drop in legal crop prices, as prices for both coffee and cocoa, the flagship products in alternative development regions, were increasing in the years of this analysis. ${ }^{24}$ In terms of coca prices, the relevant price is the fresh coca leaf price, which has been monitored by UNODC since 2005. This price has remained stable between 2007 and 2011, ranging from $1.2 \mathrm{USD} / \mathrm{kg}$ in 2007, to $1.3 \mathrm{USD} / \mathrm{kg}$ in 2011. Prices are set by the illegal armed groups or narcotrafficants in a monopsony-type arrangement, where coca farmers have no say in setting the price. The stability of this period means that behavioral changes in

\footnotetext{
${ }^{22} 98 \%$ of the municipalities analyzed report a spraying disproportionality smaller than 25. I run robustness checks leaving out municipalities with extreme disproportionality values and the results hold.

${ }^{23}$ I do not use this as my main specification, since there is a high multicollinearity between coca and conflict variables, so I leave coca as an explanatory variable in the main specification.

${ }^{24} \mathrm{I}$ have not been able to find information on prices at the municipal level. Prices are aggregated by major markets, and not enough geographical variation is present in order to include them in the analysis.
} 
terms of legal crop cultivation do not stem from a change in coca leaf prices. As an additional robustness check I run the same regression with planted legal crop hectares instead of harvested area and the effects are the same (see Table A1.5 in the Appendix).

\section{Empirical results: Micro Data}

Micro data allow a much stronger test of the spraying disproportionality effect on legal crops, as the analysis turns to the effect of a global or macro policy on the individual decision to grow legal crops. In this section I start by presenting the spraying disproportionality effects on the UNODC surveyed coca growing farmers in the Putumayo-Caqueta region of Colombia in 2012, followed by the effects on Forest Warden Families, finishing with a look at the effect on coffee growers.

One thing to keep in mind when analyzing the following results is that legal crop decisions are made at an individual level, but spraying and spraying disproportionality are captured at a municipality level, as this is the smallest unit of spraying that I was able to access. This means that the effect I capture is the lower bound of disproportionality on legal crops, as it is likely that many of the surveyed respondents were not personally affected by aerial spraying. Still, as already mentioned, farmers can change their legal crop planting behavior following a regional spraying campaign. Conversations with farmers in coca growing areas make me confident that people know what areas are being sprayed, how often and how severely.

\section{UNODC survey with coca growers}

Table 1.5 presents the effects of spraying intensity on legal crops for the UNODC sample using the cross section version of Equation 1, where I find similar effects as those observed in the macro data. Since this is not a panel for the individual responses that come from the survey, I can only observe the effect of spraying disproportionality on legal crops in 2012. Looking at the secondary data structure, there is high correlation between disproportionate spraying, spraying and coca in different years. For this reason I decide to test the effect of the sum of spraying shocks on legal crops, as mentioned in the methodology section. ${ }^{25}$

I find that one additional spraying shock between 2002 and 2011 reduces the area planted to legal crops by $13 \%$. Once spraying shocks are taken into account, a $1 \%$ increase in spraying increases legal crops by $0.35 \%$. In this case too, spraying can crowd-in legality as long as it is not disproportionate or extreme, as captured by a spraying shock. This effect is mainly driven by permanent crops, which could suggest that in these areas proportional spraying induces an idea of longer term eradication, which is necessary for permanent crops that require larger investments in time and resources. When people are exposed to too many shocks, people opt out of such investments, but do not change their transitory crops, as these are also destined for self-consumption. The effect of the continuos disproportionality variable is not as strong as the

${ }^{25}$ I also test the effect of spraying shocks in 2011, the year before the survey, and the results hold. 
sum of the spraying shocks for this sample; despite having the expected signs, only the squared term is marginally statistically significant (at a $10 \%$ level) when looking at transitory crops.

Table 1.5: Effect of spraying disproportionality on legal crops in UNODC sample

\begin{tabular}{|c|c|c|c|c|c|c|}
\hline & \multicolumn{2}{|c|}{ All Crops } & \multicolumn{2}{|c|}{ Transitory } & \multicolumn{2}{|c|}{ Permanent } \\
\hline & $\begin{array}{c}(1) \\
\text { Disprop }\end{array}$ & $\begin{array}{c}(2) \\
\text { Shock }\end{array}$ & $\begin{array}{c}(3) \\
\text { Disprop }\end{array}$ & $\begin{array}{c}(4) \\
\text { Shock }\end{array}$ & $\begin{array}{c}(5) \\
\text { Disprop }\end{array}$ & $\begin{array}{c}(6) \\
\text { Shock }\end{array}$ \\
\hline Total spray shocks & & $\begin{array}{c}-0.176^{* *} \\
(0.058)\end{array}$ & & $\begin{array}{l}-0.033 \\
(0.039)\end{array}$ & & $\begin{array}{c}-0.143^{* *} \\
(0.047)\end{array}$ \\
\hline ln Spray 2011 & & $\begin{array}{c}0.353^{* * *} \\
(0.094)\end{array}$ & & $\begin{array}{l}0.162^{*} \\
(0.082)\end{array}$ & & $\begin{array}{l}0.191^{* *} \\
(0.076)\end{array}$ \\
\hline Spraying Disproportional & $\begin{array}{c}0.540 \\
(0.393)\end{array}$ & & $\begin{array}{c}0.286 \\
(0.163)\end{array}$ & & $\begin{array}{c}0.254 \\
(0.389)\end{array}$ & \\
\hline Spraying Disproportional 2 & $\begin{array}{l}-0.125 \\
(0.070)\end{array}$ & & $\begin{array}{c}-0.060^{*} \\
(0.031)\end{array}$ & & $\begin{array}{l}-0.065 \\
(0.067)\end{array}$ & \\
\hline Coca affected by spraying (1) & $\begin{array}{c}1.210^{* * *} \\
(0.146)\end{array}$ & $\begin{array}{c}1.196^{* * *} \\
(0.135)\end{array}$ & $\begin{array}{c}0.704^{* * *} \\
(0.128)\end{array}$ & $\begin{array}{c}0.711^{* * *} \\
(0.130)\end{array}$ & $\begin{array}{c}0.505^{* * *} \\
(0.078)\end{array}$ & $\begin{array}{c}0.486^{* * *} \\
(0.084)\end{array}$ \\
\hline Processes coca leaf (2) & $\begin{array}{c}-0.456^{*} \\
(0.229)\end{array}$ & $\begin{array}{c}-0.357^{*} \\
(0.167)\end{array}$ & $\begin{array}{l}-0.172 \\
(0.109)\end{array}$ & $\begin{array}{l}-0.155 \\
(0.107)\end{array}$ & $\begin{array}{l}-0.284 \\
(0.178)\end{array}$ & $\begin{array}{c}-0.202 \\
(0.119)\end{array}$ \\
\hline Years growing coca & $\begin{array}{c}-0.019^{* *} \\
(0.008)\end{array}$ & $\begin{array}{c}-0.023^{* *} \\
(0.007)\end{array}$ & $\begin{array}{c}-0.017^{* * *} \\
(0.004)\end{array}$ & $\begin{array}{c}-0.017^{* * *} \\
(0.003)\end{array}$ & $\begin{array}{l}-0.003 \\
(0.005)\end{array}$ & $\begin{array}{l}-0.006 \\
(0.005)\end{array}$ \\
\hline Female & $\begin{array}{l}-0.317 \\
(0.256)\end{array}$ & $\begin{array}{l}-0.361 \\
(0.256)\end{array}$ & $\begin{array}{l}-0.268^{*} \\
(0.118)\end{array}$ & $\begin{array}{c}-0.288^{* *} \\
(0.116)\end{array}$ & $\begin{array}{l}-0.049 \\
(0.219)\end{array}$ & $\begin{array}{l}-0.073 \\
(0.215)\end{array}$ \\
\hline Age & $\begin{array}{c}0.019^{* * *} \\
(0.003)\end{array}$ & $\begin{array}{c}0.017^{* * *} \\
(0.004)\end{array}$ & $\begin{array}{c}0.001 \\
(0.002)\end{array}$ & $\begin{array}{c}0.000 \\
(0.003)\end{array}$ & $\begin{array}{c}0.018^{* * *} \\
(0.003)\end{array}$ & $\begin{array}{c}0.016^{* * *} \\
(0.003)\end{array}$ \\
\hline Years in Community & $\begin{array}{l}-0.009 \\
(0.006)\end{array}$ & $\begin{array}{l}-0.009 \\
(0.006)\end{array}$ & $\begin{array}{c}-0.008^{* * *} \\
(0.001)\end{array}$ & $\begin{array}{c}-0.008^{* * *} \\
(0.001)\end{array}$ & $\begin{array}{l}-0.001 \\
(0.005)\end{array}$ & $\begin{array}{l}-0.000 \\
(0.006)\end{array}$ \\
\hline Farm area (ha) & $\begin{array}{l}0.018^{* *} \\
(0.006)\end{array}$ & $\begin{array}{l}0.021^{* *} \\
(0.006)\end{array}$ & $\begin{array}{c}0.010 \\
(0.005)\end{array}$ & $\begin{array}{l}0.011^{*} \\
(0.005)\end{array}$ & $\begin{array}{c}0.009^{* * *} \\
(0.002)\end{array}$ & $\begin{array}{c}0.010^{* * *} \\
(0.002)\end{array}$ \\
\hline Has Title over land & $\begin{array}{l}0.742^{* *} \\
(0.307)\end{array}$ & $\begin{array}{c}0.748^{* *} \\
(0.303)\end{array}$ & $\begin{array}{c}0.439^{* *} \\
(0.164)\end{array}$ & $\begin{array}{c}0.444^{* *} \\
(0.163)\end{array}$ & $\begin{array}{l}0.303^{*} \\
(0.149)\end{array}$ & $\begin{array}{l}0.303^{*} \\
(0.149)\end{array}$ \\
\hline Constant & $\begin{array}{l}-0.080 \\
(0.445)\end{array}$ & $\begin{array}{c}-1.563^{* *} \\
(0.465)\end{array}$ & $\begin{array}{c}0.079 \\
(0.194)\end{array}$ & $\begin{array}{l}-0.622 \\
(0.615)\end{array}$ & $\begin{array}{l}-0.159 \\
(0.479)\end{array}$ & $\begin{array}{l}-0.941 \\
(0.498)\end{array}$ \\
\hline $\mathrm{R} 2$ & 0.33 & 0.34 & 0.34 & 0.35 & 0.16 & 0.18 \\
\hline Observations & 238 & 238 & 238 & 238 & 238 & 238 \\
\hline Num.Municipalities & 8 & 8 & 8 & 8 & 8 & 8 \\
\hline
\end{tabular}

Clustered standard errors in parentheses. Significance levels ${ }^{*} \mathrm{p}<0.10,{ }^{* *} \mathrm{p}<0.05,{ }^{* * *} \mathrm{p}<0.01$

Variable definitions: (1) Dummy that takes the value of 1 if respondent reported their coca crops affected. (2) Takes value of 1 when person processes coca leaf into coca paste. State capaticty and perceived public service quality explained in data section. 
This sample has very detailed information on coca cultivation and production on an individual basis so it makes more sense to use individual coca information than aggregate data. I find that those who report having their coca fields affected by spraying in the past year increase the area planted with legal crops, which goes in line with the finding that proportionate spraying increases legal crops. I also find that people who not only grow but also process coca leaves, allocate less land to legal crops. This suggests that even though spraying might lead to more legal crops, this might not be because people are becoming more "legal", but because they are just avoiding risk. Those who not only grow but also process coca may still have some opportunities in the coca business despite the spraying, and are not yet opting for legality. I also control for key variables for explaining investments in legal crops such as land titles and land size and find all of them to be positive and significant.

\section{Forest Warden Families}

The Forest Warden Families is the biggest alternative development program currently underway in Colombia. It targets coca growing areas and regions that are at high risk of growing coca (because of the balloon effect) and gives its beneficiaries money on the condition to keep their lands coca-free. Additionally, they attend culture of legality workshops and receive technical assistance in the hope that substituting legal products for coca will be sustainable. Even though the government targets municipalities, only some communities in each municipality receive the program, which means that there could still be coca-growing areas in the targeted municipalities, which, as a result, would continue being exposed to spraying. As mentioned, FWF communities may be exposed to spraying because they i) see the planes flying to neighboring regions, ii) hear stories from neighboring communities or iii) get sprayed themselves by mistake (pilot miscalculation, or strong winds that carry the glyphosate to their fields). In fact, even though FWF areas should not have experienced any spraying since joining the program, $10 \%$ say that spraying has been one of the main problems preventing their new productive activities from flourishing. A big difference between the UNODC and the FWF sample is that even though the latter are also exposed to low quality of public services and more than half of them are considered to be poor (53\%), at least they have received support in finding an alternative livelihood and therefore have seen another face of the state. This could make a big difference when it comes to be willing to follow the law and live under legality, as suggested by the second chapter of this dissertation.

The effect of spraying disproportionality on legal crops is presented in Table 1.6. Column one presents the effects of the disproportionate spraying one year prior to the survey (2011) and column two presents the effect of the total amount of shocks on legal crops. I find that spraying disproportionality in 2011 and the cumulative amount of spraying shocks decreases legal crops in 2012. However, in this case spraying does not have a positive effect as was the case in the macro data and the UNODC sample. 
Table 1.6: Effect of spraying disproportionality on legal crops in the Forest Warden Families sample

\begin{tabular}{|c|c|c|}
\hline & $\begin{array}{c}(1) \\
\text { Spraying Disproportionality }\end{array}$ & $\begin{array}{c}(2) \\
\text { Spraying Shock }\end{array}$ \\
\hline Total spraying shocks & & $\begin{array}{c}-0.1559^{* * *} \\
(0.0518)\end{array}$ \\
\hline Ln spraying 2011 & & $\begin{array}{l}-0.0883^{*} \\
(0.0522)\end{array}$ \\
\hline Spraying disprop 2011 & $\begin{array}{c}0.1228 \\
(0.1439)\end{array}$ & \\
\hline Spraying disprop 22011 & $\begin{array}{c}-0.0485^{* *} \\
(0.0222)\end{array}$ & \\
\hline Ln coca 2006 & $\begin{array}{c}0.3287^{* * *} \\
(0.0396)\end{array}$ & $\begin{array}{c}0.4929^{* * *} \\
(0.0744)\end{array}$ \\
\hline Ln monthly pc expenditure & $\begin{array}{c}0.2893^{* * *} \\
(0.0680)\end{array}$ & $\begin{array}{c}0.2196^{* * *} \\
(0.0686)\end{array}$ \\
\hline Immorality (1) & $\begin{array}{c}-0.0794^{* * *} \\
(0.0298)\end{array}$ & $\begin{array}{l}-0.0541^{*} \\
(0.0310)\end{array}$ \\
\hline Perceived good quality land (2) & $\begin{array}{l}0.2111^{* *} \\
(0.0833)\end{array}$ & $\begin{array}{c}0.2563^{* * *} \\
(0.0858)\end{array}$ \\
\hline Perc. land with title & $\begin{array}{c}0.0082^{* * *} \\
(0.0010)\end{array}$ & $\begin{array}{c}0.0086^{* * *} \\
(0.0010)\end{array}$ \\
\hline Male HH head & $\begin{array}{l}0.1610^{*} \\
(0.0825)\end{array}$ & $\begin{array}{l}0.1628^{*} \\
(0.0843)\end{array}$ \\
\hline Years at home & $\begin{array}{c}0.0016 \\
(0.0025)\end{array}$ & $\begin{array}{c}0.0030 \\
(0.0025)\end{array}$ \\
\hline Age head of $\mathrm{HH}$ & $\begin{array}{c}0.0135^{* * *} \\
(0.0032)\end{array}$ & $\begin{array}{c}0.0107^{* * *} \\
(0.0032)\end{array}$ \\
\hline Belongs to productive association & $\begin{array}{l}0.1694^{*} \\
(0.1013)\end{array}$ & $\begin{array}{l}0.1779^{*} \\
(0.1076)\end{array}$ \\
\hline No coca for moral reasons $(3)$ & $\begin{array}{c}0.0975 \\
(0.0877)\end{array}$ & $\begin{array}{c}0.1101 \\
(0.0897)\end{array}$ \\
\hline Constant & $\begin{array}{c}-5.7790^{* * *} \\
(0.8371)\end{array}$ & $\begin{array}{c}-5.2474^{* * *} \\
(0.8354)\end{array}$ \\
\hline $\mathrm{R} 2$ & 0.34 & 0.32 \\
\hline People & 678 & 678 \\
\hline Expanded pop & 3946 & 3946 \\
\hline Strata (municipalities) & 15 & 15 \\
\hline
\end{tabular}

A possible explanation for this is that FWF have a contractual agreement with the government by which they pledged to keep their land free of coca and voluntarily agreed to eradicate illegal crops in return for support with legal crops. Aerial spraying could thus be seen as a violation of the state's commitment, as spraying not only destroys illegal crops but legal ones as well. 
Once in the field, stories of FWF crops being sprayed are not uncommon, giving rise to feelings of deceit among community members. I control for coca in 2006, the year before the seventh phase of the program started, in order to capture coca without the effects of the Program. It seems that higher levels of coca before the inception of the Program led to higher legal crop growing levels in 2011, suggesting crop substitution. ${ }^{26}$

Since the government was interested in capturing the culture of legality aspect, the survey included a series of questions regarding the amount of unethical actions that people found morally wrong. It is interesting to note that in the case of FWF, the higher the number of unethical activities not judged as immoral, the lower the levels of legal crop cultivation. When the same regression is ran for the neighboring controls (people in the same municipalities but in communities that did not receive the program) this variable is insignificant, suggesting that the program's efforts to promote a culture of legality are playing a role in people's productive decisions.

\section{Coffee Growers in coca growing areas}

The last sample deals with coffee growers, a group of special interest in Colombia as it is one of the country's most important export products. For various reasons, the majority of the coffee growing areas have had very low presence of coca crops. However, some of them have been affected and I focus my analysis only on these ones. Table 1.7 shows the effect of spraying disproportionality and spraying shocks on two coffee production-related variables, following the specification in equations 1 and 2. The first variable is the amount of $60 \mathrm{~kg}$ bags of coffee produced by the farmer as a measure of production (controlling for plot size) and the second the amount of $60 \mathrm{~kg}$ bags per hectare, a measure of productivity. These are much more accurate measures of agricultural output than area, but it can only be used with this sample because the product is comparable among all producers. ${ }^{27}$ Table 1.7 shows the results.

\footnotetext{
${ }^{26}$ The evaluation also collected data on distant controls and near controls. In the Appendix I show results for both the treatment group and the neighboring control group, which was exposed to exactly the same levels of spraying disproportionality in the municipality level. However, this comparison should be handled with care, as the impact evaluation showed spill over effects on this group, and thus the program might affect the outcome variable as well. The neighboring controls reduce legal crops in the face of a spraying shock, but not with the disproportionality variable. The distant control group exhibits very high levels of spraying disproportionality before the survey was undertaken and thus are not comparable in this sense. Program participation could only be related to legal crops through the relationship of legal crops and violence, since the avoided operations in red zones. Still, control municipalities were also chosen with this in mind. I also did an additional check and calculated the inverse mills ratio for participating in the program, which I then added as an independent variable (see Table A1.6 in the Appendix). The reducing effect of severe spraying remains. I do not use this specification as the main specification because the inverted mills ratio is highly correlated with the observable variables that determine participation and which I also control for in the main specification. Since these variables are important for determining participation given program rules, and I account for them in the main model (gender of household head, as female heads of household were targeted, age of household head, land with title), selection effects are already accounted for. See more on the comparability of the treatment and control groups in Chapter 2 .

${ }^{27}$ Even though coffee bags are a better way to capture overall coffee production than coffee area, I run the same regressions using coffee area as dependent variable so as to obtain comparability with the other samples and find no effect of spraying intensity on the amount of areas cultivated with coffee.
} 
Table 1.7: Effect of spraying intensity on coffee growers in coca affected coffee growing municipalities

\begin{tabular}{|c|c|c|c|c|}
\hline & \multicolumn{2}{|c|}{$60 \mathrm{~kg}$ Bag of Coffee } & \multicolumn{2}{|c|}{ Bags per Hectare } \\
\hline & $\begin{array}{c}(1) \\
\text { Disprop }\end{array}$ & $\begin{array}{c}(2) \\
\text { Shock }\end{array}$ & $\begin{array}{c}(3) \\
\text { Disprop }\end{array}$ & $\begin{array}{c}(4) \\
\text { Shock }\end{array}$ \\
\hline Spraying Shock & & $\begin{array}{c}-1.133^{* * *} \\
(0.345)\end{array}$ & & $\begin{array}{c}-0.800^{* * *} \\
(0.195)\end{array}$ \\
\hline Spraying Shock (t-1) & & $\begin{array}{c}0.607 \\
(0.693)\end{array}$ & & $\begin{array}{c}0.316 \\
(0.475)\end{array}$ \\
\hline ln Spraying & & $\begin{array}{c}0.085 \\
(0.082)\end{array}$ & & $\begin{array}{c}0.020 \\
(0.061)\end{array}$ \\
\hline ln Spraying (t-1) & & $\begin{array}{c}0.051 \\
(0.080)\end{array}$ & & $\begin{array}{c}0.031 \\
(0.080)\end{array}$ \\
\hline Spraying Disprop & $\begin{array}{c}0.572 \\
(0.441)\end{array}$ & & $\begin{array}{c}0.109 \\
(0.254)\end{array}$ & \\
\hline Spraying Disprop2 (t) & $\begin{array}{l}-0.079^{*} \\
(0.046)\end{array}$ & & $\begin{array}{l}-0.025 \\
(0.027)\end{array}$ & \\
\hline Spraying Disprop (t-1) & $\begin{array}{c}0.105 \\
(0.154)\end{array}$ & & $\begin{array}{c}0.018 \\
(0.035)\end{array}$ & \\
\hline Spraying Disprop2 (t-1) & $\begin{array}{l}-0.003 \\
(0.003)\end{array}$ & & $\begin{array}{l}-0.000 \\
(0.000)\end{array}$ & \\
\hline Spraying Disprop (t-2) & $\begin{array}{l}-0.017 \\
(0.128)\end{array}$ & & & \\
\hline Spraying Disprop2 (t-2) & $\begin{array}{l}-0.002 \\
(0.002)\end{array}$ & & & \\
\hline Lagged Change in ln Coca & $\begin{array}{l}-0.044 \\
(0.158)\end{array}$ & $\begin{array}{l}-0.109 \\
(0.145)\end{array}$ & $\begin{array}{l}-0.101 \\
(0.101)\end{array}$ & $\begin{array}{l}-0.126 \\
(0.098)\end{array}$ \\
\hline ln Coca (t-2) & $\begin{array}{c}0.360 \\
(0.224)\end{array}$ & $\begin{array}{c}0.048 \\
(0.177)\end{array}$ & $\begin{array}{l}-0.104 \\
(0.155)\end{array}$ & $\begin{array}{l}-0.193 \\
(0.145)\end{array}$ \\
\hline ln Area with Coffee & $\begin{array}{l}1.803^{* *} \\
(0.851)\end{array}$ & $\begin{array}{l}1.853^{* *} \\
(0.815)\end{array}$ & & \\
\hline Num. Farms (1) & $\begin{array}{c}1.944^{* * *} \\
(0.367)\end{array}$ & $\begin{array}{c}1.772^{* * *} \\
(0.336)\end{array}$ & $\begin{array}{c}-0.427^{* *} \\
(0.174)\end{array}$ & $\begin{array}{c}-0.425^{* *} \\
(0.172)\end{array}$ \\
\hline Num. Coffee Growers in Region & $\begin{array}{l}-0.001 \\
(0.001)\end{array}$ & $\begin{array}{l}-0.001 \\
(0.001)\end{array}$ & $\begin{array}{l}-0.000 \\
(0.000)\end{array}$ & $\begin{array}{l}-0.000 \\
(0.001)\end{array}$ \\
\hline Perc. Rural Population & $\begin{array}{c}19.227 \\
(50.428)\end{array}$ & $\begin{array}{l}-16.387 \\
(44.190)\end{array}$ & $\begin{array}{l}-35.334 \\
(33.454)\end{array}$ & $\begin{array}{l}-46.280 \\
(31.882)\end{array}$ \\
\hline Plot Age (years) & $\begin{array}{c}0.176^{* * *} \\
(0.055)\end{array}$ & $\begin{array}{c}0.165^{* * *} \\
(0.054)\end{array}$ & $\begin{array}{c}0.108^{* * *} \\
(0.019)\end{array}$ & $\begin{array}{c}0.108^{* * *} \\
(0.019)\end{array}$ \\
\hline Owns Land & $\begin{array}{c}-1.084^{* * *} \\
(0.401)\end{array}$ & $\begin{array}{c}-1.095^{* * *} \\
(0.381)\end{array}$ & $\begin{array}{c}-0.117^{* *} \\
(0.047)\end{array}$ & $\begin{array}{c}-0.114^{* *} \\
(0.045)\end{array}$ \\
\hline New Crop (2) & $\begin{array}{c}3.143^{* * *} \\
(0.310)\end{array}$ & $\begin{array}{c}3.095^{* * *} \\
(0.302)\end{array}$ & $\begin{array}{c}-0.186^{* * *} \\
(0.059)\end{array}$ & $\begin{array}{c}-0.184^{* * *} \\
(0.059)\end{array}$ \\
\hline Renewed Crop (3) & $\begin{array}{c}3.652^{* * *} \\
(1.235)\end{array}$ & $\begin{array}{c}3.482^{* * *} \\
(1.280)\end{array}$ & $\begin{array}{c}-0.787^{*} \\
(0.451)\end{array}$ & $\begin{array}{c}-0.789^{*} \\
(0.451)\end{array}$ \\
\hline Perc. with Colombia-Type Coffee (4) & $\begin{array}{c}0.467 \\
(1.148)\end{array}$ & $\begin{array}{c}0.663 \\
(1.001)\end{array}$ & $\begin{array}{c}0.600 \\
(0.929)\end{array}$ & $\begin{array}{c}0.614 \\
(0.931)\end{array}$ \\
\hline Crop Density (5) & $\begin{array}{c}0.001 \\
(0.000)\end{array}$ & $\begin{array}{l}0.001^{*} \\
(0.000)\end{array}$ & $\begin{array}{c}0.000^{* * *} \\
(0.000)\end{array}$ & $\begin{array}{c}0.000^{* * *} \\
(0.000)\end{array}$ \\
\hline Constant & $\begin{array}{l}-14.676 \\
(37.951)\end{array}$ & $\begin{array}{c}13.323 \\
(33.092)\end{array}$ & $\begin{array}{c}31.495 \\
(26.304)\end{array}$ & $\begin{array}{c}40.380 \\
(25.490)\end{array}$ \\
\hline Num.People & 67082 & 71503 & 71503 & 71503 \\
\hline Num.Municipalities & 56 & 60 & 60 & 60 \\
\hline R2 Overall & 0.29 & 0.23 & 0.02 & 0.02 \\
\hline R2 Within & 0.14 & 0.13 & 0.06 & 0.06 \\
\hline R2 Between & 0.25 & 0.21 & 0.03 & 0.03 \\
\hline $\begin{array}{l}\text { Clustered standard errors in parenthe } \\
\text { (1) Number of farms worked by the fa } \\
\text { (3) Renewed existing coffee plantation } \\
\text { (4) Percentage of land that has Colom } \\
\text { (5) Area with coffee/Productive area. }\end{array}$ & $\begin{array}{l}\text { s. Significe } \\
\text { mer. (2) E }\end{array}$ & $\begin{array}{l}\text { ce levels } * \\
\text { ablished ne } \\
\text { e, a more r }\end{array}$ & $\begin{array}{l}0.10,{ }^{* *} \mathrm{p} \\
\text { coffee crol }\end{array}$ & $\begin{array}{l}5, * * * \mathrm{p}< \\
\text { field. } \\
\text { ciety. }\end{array}$ \\
\hline
\end{tabular}


First, the effect of spraying disproportionality, despite having the same signs as the other samples (positive in low disproportionality and negative in high) only generates a loss in production and productivity when it is captured via spraying shocks and not via the continuous disproportionality variable (only the squared term in t has a statistically significant reducing effect). It could be that overall proportionate spraying levels and low exposures to coca lead to only capturing negative effects when one identifies shocks. Spraying itself also does not seem to significantly encourage legal coffee production, despite its positive sign.

One possible reason for the weaker effects for coffee growers is that they are exposed to the lowest levels of coca cultivation and also of spraying. Moreover, the production data starts in 2009 , precisely when it seemed that spraying disproportionality was following coca and spraying trends, and consequently its effects could be quite low, if any.

\section{Overview of micro level results}

To wrap up the results from the micro data sets, Figure 1.7 shows the turning points for each of the samples. All turning points affect people in the sample and do not happen in an implausible value. It is also interesting to note that the turning points happen at different values of spraying disproportionality depending on the sample; FWF beneficiaries are the first to start decreasing their legal production, and they do so when spraying disproportionality is at around one, which is expected as they feel their voluntary decision to achieve a coca-free territory is not being corresponded by the state. The UNODC sample decreases production when spraying is about twice the amount of coca found and coffee growers decrease coffee production when spraying is four times as much coca. This means that even though the turning point with macro data shows a much higher turning point (spraying seven times as much coca), this could obscure regional variation, where sensitivity to the policy might be much higher. The spraying strategy itself assumes a necessary four overpasses to achieve efficient coca reduction, a number that will already backfire in some regions with legal crop reduction. 
Figure 1.7: Turning points for micro samples

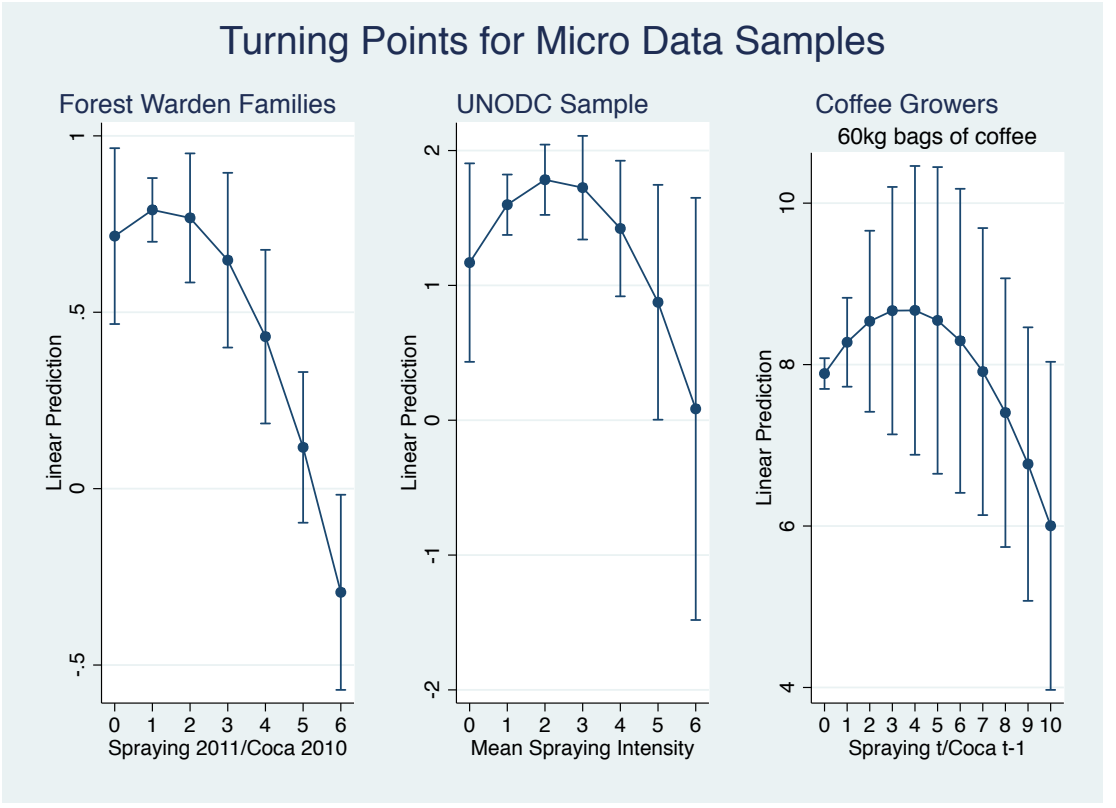

\section{Possible channels}

Which are the channels that may be causing this reduction in legal crops once high intensity levels of spraying are reached? Although I lack all the necessary information to pin down the channels with full certainty, I can grasp the surface of possible mechanisms at hand, even if no strong conclusions or causality claims can be drawn. I focus on three possible channels: displacement, environmental damage (and crop damage) and loss of legitimacy.

\section{Displacement}

One possibility is that such intense spraying events might have led people to move out of their territory; in fact, there is some evidence that among the displaced some people mention spraying as the reason for moving. Dion and Russler (2008) find that during the implementation of Plan Colombia aerial spraying reduced coca crops mainly through generating displacement. Palacios (2012) also provides evidence in this direction and mentions a report from an NGO for IDPs (CODHES) that denounces the displacement of 13.000 people due to aerial spraying. I used the official data collected by the government of Colombia on forced internal displacement in order to test its relationship with disproportional spraying. The variable used is the rate of expulsion from one municipality per 100.000 inhabitants. I cannot disaggregate this variable by the cause of displacement (sometimes captured in official documents) and use the variable that includes all people that were displaced by violence (and not for economic reasons). However, the aggregated variable is also useful since according to informal conversations with government officials, many displaced do not report spraying as the reason for displacement, as they fear being treated as coca-growers and criminals and therefore potentially losing State support. 
Table 1.8 presents the effect of spraying disproportionality on forced displacement using the aggregated panel dataset. Disproportionate spraying seems to have a short term effect on displacement, that is reversed after two years, which suggests that part of the loss in legal crops could be due to a loss in rural workforce. ${ }^{28}$

Table 1.8: Effect of spraying disproportionality and displacement

\begin{tabular}{|c|c|}
\hline & $\begin{array}{c}(1) \\
\ln \text { Displacement }\end{array}$ \\
\hline Spraying Disp & $\begin{array}{c}0.082^{* * *} \\
(0.025)\end{array}$ \\
\hline L.Spraying Disp & $\begin{array}{l}-0.003 \\
(0.031)\end{array}$ \\
\hline L2.Spraying Disp & $\begin{array}{c}-0.039^{* *} \\
(0.017)\end{array}$ \\
\hline Change in Coca & $\begin{array}{c}0.436^{* * *} \\
(0.109)\end{array}$ \\
\hline $\ln$ Coca (t-2) & $\begin{array}{c}0.298^{* * *} \\
(0.110)\end{array}$ \\
\hline Num. FARC & $\begin{array}{l}-0.001 \\
(0.001)\end{array}$ \\
\hline Num. ELN & $\begin{array}{c}0.006 \\
(0.004)\end{array}$ \\
\hline Num. BACRIM & $\begin{array}{l}0.003^{*} \\
(0.002)\end{array}$ \\
\hline Num. Combats & $\begin{array}{l}0.008^{* *} \\
(0.003)\end{array}$ \\
\hline L.ln Rural Land Price & $\begin{array}{l}-0.164 \\
(0.104)\end{array}$ \\
\hline Constant & $\begin{array}{c}6.432^{* * *} \\
(0.823)\end{array}$ \\
\hline Observations & 174 \\
\hline Num.Municipalities & 79 \\
\hline $\mathrm{R} 2$ Overall & 0.10 \\
\hline R2 Within & 0.46 \\
\hline R2 Between & 0.02 \\
\hline
\end{tabular}

Table 1.4 shows that the negative effect of disproportionality actually lasts at least two years, suggesting that there may be something else at play. Still, this effect of contemporaneous displacement could be the reason why the linear component of spraying at time $t$ is not positively significant in the macro data but becomes significant after the first lag, since it is after two years of the intense spraying that displacement starts to reverse.

When I include displacement in the original specification (see Table A1.7 in the Appendix), I find that it reduces legal crops only when they are transitory, a result that has already been found in the literature (Ibanez et al., 2013), but it does not take away the significance of

\footnotetext{
${ }^{28}$ There is no evidence of a quadratic relationship between spraying intensity and displacement. The linear term has a negative sign and the squared term a positive one, but none of the terms are significant in none of the lags. However, there is no theoretical reason to defend a quadratic relationship.
} 
spraying disproportionality, suggesting that there is more to the story than only displacement of the labor force.

\section{Environmental damage}

A second possibility is that since glyphosate falls indiscriminately on the land and is nonselective, it affects both illegal and legal plants. High levels of spraying may have damaged the soil and prevented both legal and illegal productive crops from developing. Studies on the effect of glyphosate on the environment are not conclusive. Relyea (2005) finds negative effects on amphibious populations, Navarrete-Frías et al. (2005) show effects on deforestation. During field visits I heard farmers complain about animals dying and crops' yields declining in the subsequent season. An ICRC report ${ }^{29}$ mentions that spraying passes over the fields are not accurately targeted, leading to the destruction of legal crops, including those that are part of alternative development projects. Still, other studies indicate that the effect is not long lasting (Busse et al., 2001) or that crops recover quickly after spraying (Franz et al., 1997). The inconsistency may be due to differences in the amount of glyphosate used. Monsanto, the

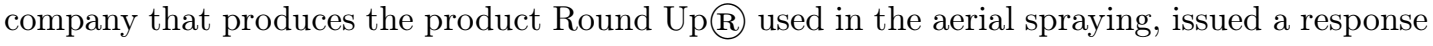
to Relyea's study indicating that the product was not to be used over water and that the study had been done with very high Round Up® concentrations. Since in this context the product is not being used for gardening or agricultural purposes, Monsanto's own concerns regarding the use of Round Up® may underlie the potential environmental damage caused by spraying.

My focus is on spraying disproportionality, not measured as high levels of spraying, but as the proportion of spraying to coca. In this sense, high disproportionality does not necessarily mean highest levels of spraying but rather a very high disproportion between spraying and coca. If the negative effects I find are due to environmental damage, a reduction of legal crops should arise when using spraying, rather than spraying disproportionality. In fact, it it hurts the land, one should not see positive signs of spraying inducing legal crops in neither the linear nor square term. When I test the relationship between spraying levels and legal crops using the Equation 1 specification in Table 1.4 (but changing disproportional spraying by spraying levels), I find that there are no significant effects of spraying and spraying squared on the same year nor on the first lag, precisely where environmental damage was most likely to happen (see Table 1.9). ${ }^{30}$ There some evidence of an inverted U relationship in the second lag with transitory crops that goes in the same direction as disproportionality, but does not indicate environmental harm, as the linear term is positive. In fact, two years after high levels of spraying there is an increase in legal crops, as the government expects. This results stresses the finding that disproportionality matters. This also rules out the possibility that people are not planting because they are afraid to get sprayed again, since large amounts of spraying would give people the same signal and, if it is not disproportional, it even seems to increase legal crops in the medium term. ${ }^{31}$

\footnotetext{
${ }^{29}$ ICRC. Colombia: cultivos lícitos de campesinos afectados por aspersiones aéreas contra la coca. http://www.icrc.org/spa/resources/documents/feature/2012/colombia-report-2011-displacement-feature3.htm

${ }^{30}$ The same comments for past panel data specifications apply to this model. In particular, I do not include variables that are time invariable such as municipal size, since they drop out with the fixed effects, and reduce collinearity between spraying and coca by keeping coca in changes instead as in absolute terms.

${ }^{31}$ I cannot rule out that subsistence crops are destroyed, given their small scale and the possibility of not
} 
Table 1.9: Effect of spraying on legal crops

\begin{tabular}{lccc}
\hline & $(1)$ & $(2)$ & $(3)$ \\
& All & Transitory & Permanent \\
\hline Spraying (t) & 0.070 & 0.138 & 0.022 \\
Spraying2 (t) & $(0.068)$ & $(0.107)$ & $(0.083)$ \\
& -0.004 & -0.014 & -0.001 \\
ln Spraying (t-1) & $(0.007)$ & $(0.011)$ & $(0.008)$ \\
& 0.024 & $0.291^{* *}$ & -0.172 \\
Spraying 2 (t-1) & $(0.088)$ & $(0.129)$ & $(0.167)$ \\
& -0.004 & $-0.026^{* *}$ & 0.013 \\
Spraying (t-2) & $(0.009)$ & $(0.011)$ & $(0.014)$ \\
& $-0.191^{* * *}$ & -0.075 & -0.264 \\
Spraying 2 (t-2) & $(0.060)$ & $(0.129)$ & $(0.203)$ \\
& $0.019^{* * *}$ & 0.011 & 0.022 \\
Change in ln Coca & $(0.006)$ & $(0.012)$ & $(0.016)$ \\
& -0.002 & 0.020 & -0.002 \\
Lagged Change in ln Coca & $(0.041)$ & $(0.052)$ & $(0.046)$ \\
& -0.029 & -0.015 & -0.001 \\
Constant & $(0.049)$ & $(0.069)$ & $(0.043)$ \\
& -13.604 & $-67.723^{* * *}$ & 1.375 \\
Observations & $(21.156)$ & $(22.660)$ & $(18.873)$ \\
Num.Municipalities & 283 & 279 & 283 \\
R2 Overall & 83 & 82 & 83 \\
R2 Within & 0.32 & 0.09 & 0.08 \\
R2 Between & 0.23 & 0.21 & 0.20 \\
\hline
\end{tabular}

Clustered standard errors in parentheses. Control variables included.

Significance levels ${ }^{*} \mathrm{p}<0.10,{ }^{* *} \mathrm{p}<0.05,{ }^{* * *} \mathrm{p}<0.01$

\section{Legitimacy Loss}

The third channel, loss of legitimacy, is highly likely in coca growing areas where, according to Garcia (2011), people are mainly exposed to the coercive face of the state and would tend to develop a contentious relationship with the authorities, as they see their basic livelihood (illegal crops) being destroyed by the state. The loss of legal crops due to spraying, especially in subsistence farming, increases discontent, as food security is also under attack by a state policy. I explore this channel with the UNODC sample, where legitimacy questions were asked. Even though the sample is not representative of all coca growing areas in Colombia, results are nonetheless suggestive of what happens when spraying is used intensively in areas that have commonly been marginalized by the state and where coca has been the norm for a large part of their history.

It is interesting to note the type of relationship that people in the surveyed area have with the state (Table 1.10). In terms of public utilities, most people recognize the existence of

appearing in aggregate data sets or not even being mentioned by farmers when asked about their agricultural activities. In fact, in the UNODC sample while $58 \%$ of the legal production goes to self-consumption for the farmers that have experienced a spraying shock, farmers who have not experienced a shock only consume $33 \%$ of their legal crop production. Moreover, farmers could get involved with legal crops through working for others during harvest season in non-coca areas, but capturing this effect would need a more general framework that is beyond the scope of this study. 
transportation and education services, and to a lesser degree, of drinking water and electricity, and the very low access to both. However, once they are asked to rank the quality of these services, where 1 is very bad and 5 is very good, not one single service was ranked as high as having a medium quality of 3 , and all except for education are rated below 2 . This indicates that, to begin with, people's perception of what the state provides to them is not particularly good. The survey also asks about the capacity of the state to solve problems related to public services (water, electricity, education, health, productive alternatives and unemployment, nutrition and security). In all cases except for education, half or less than half of the surveyed perceive the state as capable of solving the problem. In fact, out of the 6 possible problems, on average people think that the state can solve 2.87 .

Table 1.10: Relationship to state in UNODC sample

\begin{tabular}{lc}
\hline \multicolumn{2}{c}{ Public goods, State Capacity and Alternatives to Coca } \\
\hline \multicolumn{2}{c}{ Existence of public services } \\
\hline Drinking water & $2.9 \%$ \\
Health & $84.0 \%$ \\
Electricity & $13.4 \%$ \\
Education & $92.9 \%$ \\
Transportation & $95.8 \%$ \\
\hline \multicolumn{2}{c}{ Quality of Public Services (1 very bad, 5 very good) } \\
\hline Drinking water & 0.07 \\
Health & 1.87 \\
Electricity & 0.45 \\
Education & 2.84 \\
Transportation & 1.90 \\
\hline Perceived capacity of the state to solve problems related to: \\
\hline Quality of Public Services & $50.8 \%$ \\
Access and quality of education & $61.3 \%$ \\
Health & $50.0 \%$ \\
Productive alternatives/Unemployment & $39.2 \%$ \\
Nutrition problems & $45.4 \%$ \\
Security Problems & $43.9 \%$ \\
Total Problems it can solve (max.6) & 2.87 \\
\hline \multicolumn{2}{c}{ Alternatives to Coca given by the state } \\
\hline Has received support to substitute coca & $0.4 \%$ \\
Voluntary eradication program exists & $4.2 \%$ \\
Productive project exists & $8.8 \%$ \\
Someone in HH in PP & $6.3 \%$ \\
Wants to stop growing coca & $78.7 \%$ \\
\hline
\end{tabular}

Source: UNODC, SIMCI

The problems where state capacity is perceived as the lowest relate to productive alternatives, which is highly related to legal options outside coca. When asked directly about the alternatives 
offered to them by the state in order to stop coca cultivation, even though $78.7 \%$ claim wanting to stop growing coca only $0.4 \%$ have received support, and $4.2 \%$ point out that a voluntary eradication program exists in their region. This is worrisome because people in these regions perceive only the coercive side of the state, which may lead them to have a wrong view of the state's motivations, a key element for wanting to follow the law. I heard a coca farmer once say that he understood that what he was doing was wrong, and knew that he could be punished for it, but that he only saw the state when he saw the planes. Then he added, "why don't they send a plane full of seeds and fertilizers after the spraying plane? Then we could at least get some support from the government" (Coca farmer in Putumayo region, December 2011).

Results suggest that disproportionate spraying further alienates people from the state. Figure 1.8 Panel A shows how many problems people think the state can solve (out of a given list). It turns out that if one focuses on the inner values, higher exposure to spraying shocks in the year prior to the survey reduces the people's belief that the state can deliver. ${ }^{32}$ Additionally, a negative binomial regression of spraying disproportionality (and other controls) on how many problems the state can solve give rise to Panel B of Figure 1.8, which clearly shows a negative relationship between spraying intensity and trust in the state's capacity. The descriptive statistics presented above depict an already troubled relationship between the state and the people in this area because of the former's lack of presence and efficacy. Those results together with this Figure point to a possible story of resentment, or, as Veldab-Brown (2006) noted, a loss of "hearts and minds" from farmers that see their livelihoods threatened but find no support for alternative options ahead.

Figure 1.8: Spraying disproportionality and state legitimacy
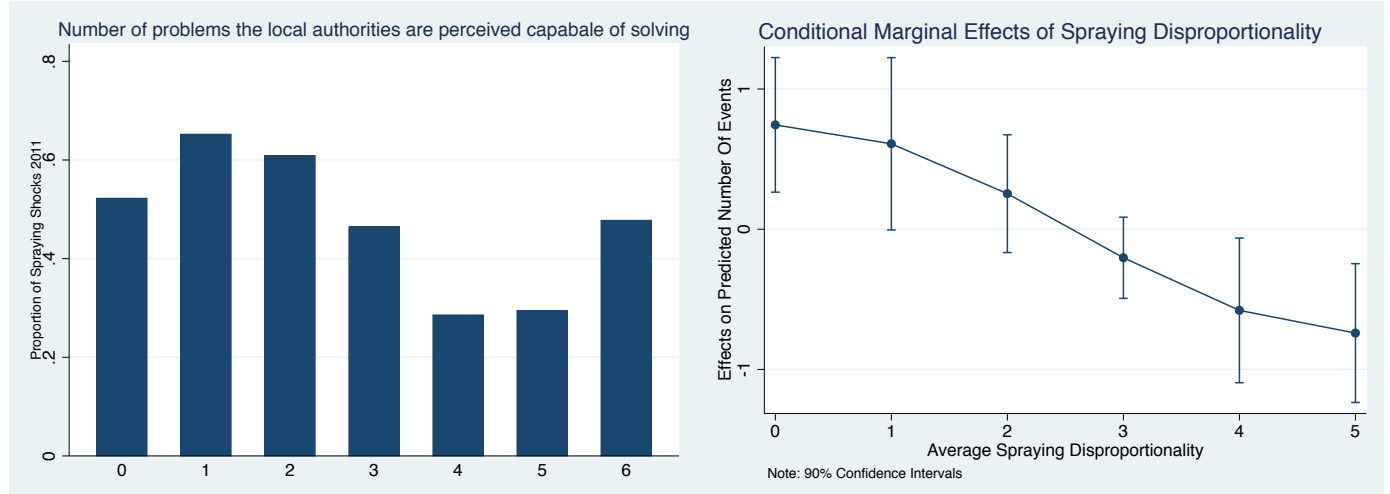

Table 1.11 presents a stronger way to see if legitimacy is playing a role in the amount of legal crops planted. The first column explains legal crops in terms of state capacity and trust in the state variables, and of other control variables included in Table 1.5, and excludes any measure of spraying disproportionality, while the second and third columns replicate include spraying disproportionality. It can be seen that when spraying disproportionality is not included in the

\footnotetext{
${ }^{32}$ The extreme values are hard to interpret, as there are people who may have very absolute positions vis-à-vis the state or that do not want to support/oppose the government and therefore express a complete/null state capacity.
} 
regression, perceived state capacity has a positive and statistically significant relationship with legal crops, which turns insignificant when spraying disproportionality is included, suggesting that this variable captures the effect of state legitimacy. If this is the case, if this is in fact the channel that is driving legality out of the fields, the state needs to carefully balance cocareducing efforts with legitimacy-enhancing actions.

Table 1.11: Legal crops and state legitimacy

\begin{tabular}{|c|c|c|c|}
\hline & $\begin{array}{c}(1) \\
\text { Without Disprop }\end{array}$ & $\begin{array}{c}(2) \\
\text { Including Disprop }\end{array}$ & $\begin{array}{c}(3) \\
\text { Including Shock }\end{array}$ \\
\hline Perceived State Capacity & $\begin{array}{l}0.563^{*} \\
(0.290)\end{array}$ & $\begin{array}{c}0.499 \\
(0.283)\end{array}$ & $\begin{array}{c}0.493 \\
(0.278)\end{array}$ \\
\hline Spraying Disproportional & & $\begin{array}{c}0.551 \\
(0.301)\end{array}$ & \\
\hline Spraying Disproportional 2 & & $\begin{array}{l}-0.122^{*} \\
(0.055)\end{array}$ & \\
\hline Total spray shocks & & & $\begin{array}{c}-0.127^{* *} \\
(0.047)\end{array}$ \\
\hline ln Spray 2011 & & & $\begin{array}{c}0.358^{* * *} \\
(0.081)\end{array}$ \\
\hline Constant & $\begin{array}{c}-0.692^{*} \\
(0.328)\end{array}$ & $\begin{array}{l}-1.129 \\
(0.604)\end{array}$ & $\begin{array}{c}-2.653^{* * *} \\
(0.510)\end{array}$ \\
\hline $\mathrm{R} 2$ & 0.35 & 0.37 & 0.38 \\
\hline Observations & 237 & 236 & 236 \\
\hline Num.Clusters & 9 & 8 & 8 \\
\hline
\end{tabular}

\section{Coca crops}

One last question is what is happening with coca and whether the only thing that is going on is a substitution between legal crops and coca. Although this is not the focus of my study, as this question has already been answered with very rigorous instruments and identification strategies, as mentioned in Section 3, it is still interesting to look at the relationships that appear once using spraying disproportionality rather than spraying levels. ${ }^{33}$ Using the macro data, the relationship between spraying disproportionality and coca crops is $\mathrm{U}$ shaped but neither the linear nor the squared term are significant in any of the lags. This relationship can only be tested with the UNODC sample, where individual involvement with coca is asked and is reliable. I find that spraying disproportionality reduces the proportion of people cultivating coca by $18 \%$, and there is no evidence of a non-linear effect (See Table A1.8 in Annex). This indicates that it is possible that legal crops are substituting coca crops when spraying is proportionate, but when spraying turns disproportionate, investments in any agricultural product, either legal or illegal go down.

\footnotetext{
${ }^{33}$ Ibanez (2010) and Ibanez (2013) use the ratio between coca hectares and coca sprayed as their variable of interest to capture its effect on coca crops. The difference with this study is that it does not include the squared term, and used both spraying and coca hectares contemporaneously in the ratio.
} 


\section{Conclusion}

This paper analyzes the effect of severe punishment on legal behavior using the case of drug policy in Colombia, namely aerial spraying of coca crops. Until now it was thought for the most part that if risks, costs and other moral factors were high enough, people would opt out of illegality in favor of legality; in this case, that if the costs and risks of cultivating coca are too high, farmers would go back to a legal crop. This study endogenizes the legal outside option and makes it dependent on the disproportionality of punishment. Severe punishment that is disproportionate to the crime committed violates the proportionality principle, necessary for the law and the state to be perceived as fair and legitimate. Legitimacy is in turn a main determinant in people's willingness to obey the law and live according to a culture of legality and the rule of law. Thus, once people are exposed to extreme punishment, even though illegality might decrease, legality could also be crowded out. This study tests this balance and finds exactly what legal scholars would predict: extremely severe punishment crowds out legality, while mild punishment crowds it in.

I test this relationship using aggregate data on all agricultural crops in Colombia, and three micro data sets with very different types of farmers: coca growers, beneficiaries of an alternative development program to substitute legal crops for coca and coffee growers. The findings point to similar results across all groups. I also test some channels that drive this relationship and find that disproportionate spraying displaces farmers but only for a short period of time, generating a loss in legal crops as a result of a loss of rural labor force. I do not find evidence that the reduction of legal crops after severe punishment may be due to environmental damage, although more research should be done in this direction for more precise estimations. Finally, results support the loss of legitimacy channel, whereby disproportionate spraying undermines trust in the state.

These results have direct policy implications. It has long been said that achieving order and compliance with the law relying only on force and without state legitimacy is extremely costly and inefficient. Such levels of punishment are unsustainable, undemocratic and unfair, and could therefore trigger negative spill over effects that reduce overall legality. I find that disproportionate spraying and spraying shocks, instead of inducing farmers to opt in for legal crops, actually make them opt out. In fact, an aspersion shock reduces legal crop harvests by $19 \%$, a large effect especially when one considers that Colombia's agricultural sector rarely grows above $4 \%$ in one year. If spraying is kept within "fairness" limits, it has the opposite effect and crowds in legality. Drug policy should be shaped accordingly and extreme spraying shocks should be avoided at all cost if a sustainable reduction in coca and in other types of illegality is to be achieved. 


\section{Appendix}

Table A1.2: Marginal effects of interaction terms in spraying and spraying shock models

\begin{tabular}{|c|c|c|c|}
\hline & $\begin{array}{c}(1) \\
\text { Spraying }\end{array}$ & $\begin{array}{c}(2) \\
\text { Spraying Disproportionality }\end{array}$ & $\begin{array}{c}(3) \\
\text { Spraying Shock }\end{array}$ \\
\hline Threat Yellow Zone & $\begin{array}{c}0.297 \\
(0.622)\end{array}$ & $\begin{array}{l}-3.929 \\
(6.175)\end{array}$ & $\begin{array}{l}0.373^{* *} \\
(0.183)\end{array}$ \\
\hline Threat Red Zone & $\begin{array}{c}0.206 \\
(0.680)\end{array}$ & $\begin{array}{l}-2.687 \\
(3.451)\end{array}$ & $\begin{array}{l}0.356^{*} \\
(0.205)\end{array}$ \\
\hline Distance to urban $(\ln )$ & $\begin{array}{c}-7.416^{* * *} \\
(1.831)\end{array}$ & $\begin{array}{c}12.850 \\
(14.903)\end{array}$ & $\begin{array}{l}-0.037 \\
(0.559)\end{array}$ \\
\hline $\operatorname{lnCoca}(\mathrm{t}-1)-\ln \mathrm{Coca}(\mathrm{t}-2)$ & $\begin{array}{l}0.421^{* *} \\
(0.181)\end{array}$ & $\begin{array}{l}-2.771 \\
(1.758)\end{array}$ & $\begin{array}{c}-0.146^{* *} \\
(0.058)\end{array}$ \\
\hline $\ln$ Coca $(\mathrm{t}-2)$ & $\begin{array}{l}0.408 \\
(0.306)\end{array}$ & $\begin{array}{l}-1.372^{*} \\
(0.715)\end{array}$ & $\begin{array}{c}-0.271^{* * *} \\
(0.095)\end{array}$ \\
\hline Rural density & $\begin{array}{l}-0.130 \\
(0.216)\end{array}$ & $\begin{array}{c}0.159 \\
(0.287)\end{array}$ & $\begin{array}{c}0.026 \\
(0.059)\end{array}$ \\
\hline Num. armed actions & $\begin{array}{l}-0.004 \\
(0.039)\end{array}$ & $\begin{array}{c}-0.147^{*} \\
(0.084)\end{array}$ & $\begin{array}{c}-0.018^{* *} \\
(0.008)\end{array}$ \\
\hline Num. FARC & $\begin{array}{c}0.002 \\
(0.003)\end{array}$ & $\begin{array}{c}0.005 \\
(0.008)\end{array}$ & $\begin{array}{l}0.001 \\
(0.001)\end{array}$ \\
\hline Num. ELN & $\begin{array}{c}-0.036^{*} \\
(0.020)\end{array}$ & $\begin{array}{l}-0.041 \\
(0.037)\end{array}$ & $\begin{array}{c}0.000 \\
(0.003)\end{array}$ \\
\hline Num. BACRIM & $\begin{array}{l}0.028^{* *} \\
(0.014)\end{array}$ & $\begin{array}{c}0.018 \\
(0.033)\end{array}$ & $\begin{array}{c}0.006 \\
(0.004)\end{array}$ \\
\hline Num. Combats & $\begin{array}{l}0.058^{* *} \\
(0.030)\end{array}$ & $\begin{array}{c}0.070 \\
(0.053)\end{array}$ & $\begin{array}{c}0.004 \\
(0.009)\end{array}$ \\
\hline Num. Mines & $\begin{array}{c}0.034 \\
(0.031)\end{array}$ & $\begin{array}{c}0.066 \\
(0.070)\end{array}$ & $\begin{array}{c}0.013 \\
(0.010)\end{array}$ \\
\hline Observations & 251 & 251 & 251 \\
\hline
\end{tabular}

Municipality fixed effect linear models. Clustered standard errors at municipality level in parentheses.

Significance levels ${ }^{*} \mathrm{p}<0.10,{ }^{* *} \mathrm{p}<0.05,{ }^{* * *} \mathrm{p}<0.01$

Variable definitions in Appendix 


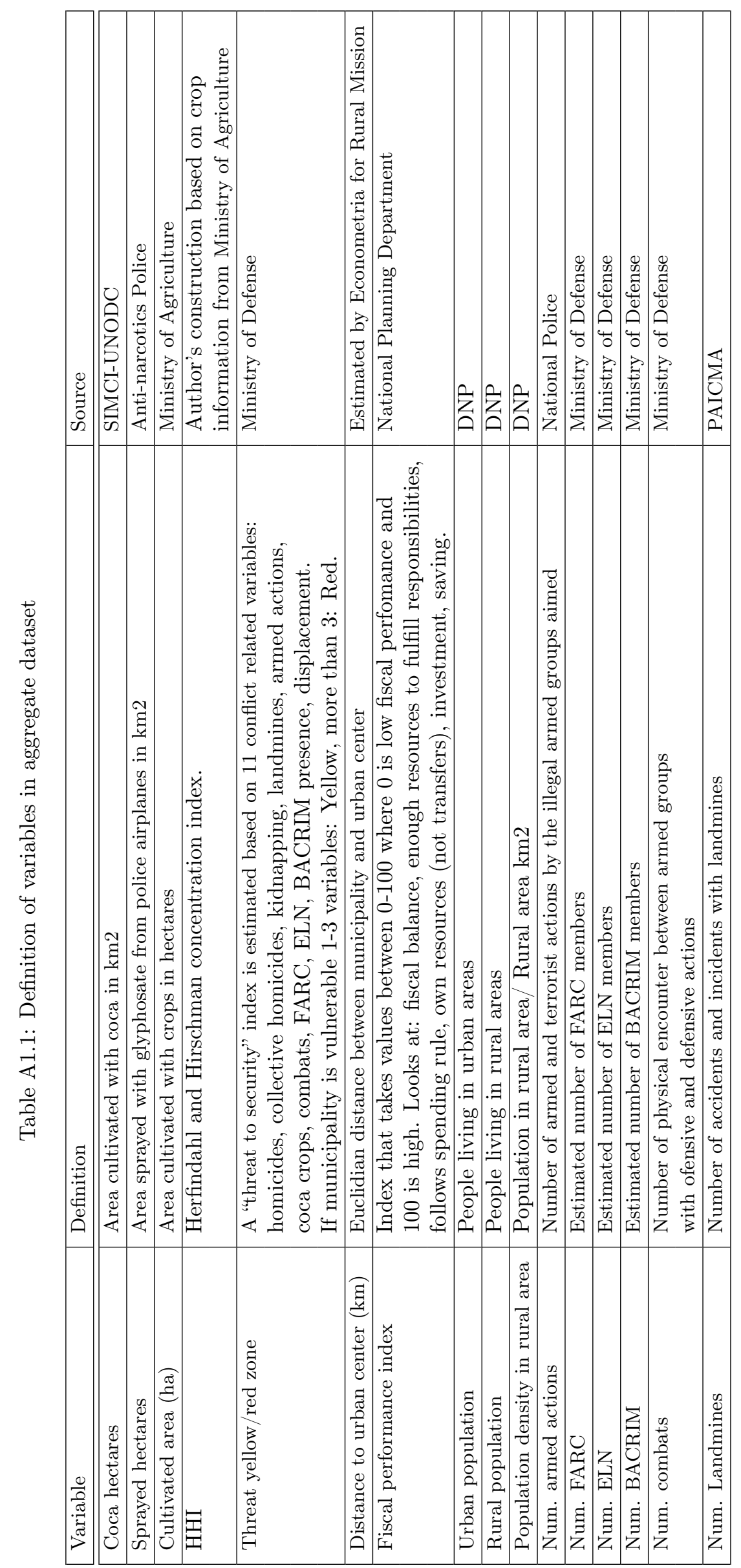


Table A1.3: Effect of spraying disproportionality on legal crops controlling for selection into coca cultivation

\begin{tabular}{|c|c|c|c|c|}
\hline & $\begin{array}{l}\text { (1) } \\
\text { All }\end{array}$ & $\begin{array}{c}(2) \\
\text { Transitory }\end{array}$ & $\begin{array}{c}(3) \\
\text { Permanent }\end{array}$ & $\begin{array}{l}(4) \\
\text { All (shock) }\end{array}$ \\
\hline Spraying Disp & $\begin{array}{l}0.057^{*} \\
(0.029)\end{array}$ & $\begin{array}{c}0.036 \\
(0.053)\end{array}$ & $\begin{array}{c}0.041 \\
(0.034)\end{array}$ & \\
\hline Spraying Disp 2 & $\begin{array}{l}-0.003 \\
(0.002)\end{array}$ & $\begin{array}{l}-0.001 \\
(0.003)\end{array}$ & $\begin{array}{l}-0.002 \\
(0.002)\end{array}$ & \\
\hline Spraying Disp (t-1) & $\begin{array}{c}0.044 \\
(0.039)\end{array}$ & $\begin{array}{l}0.080^{*} \\
(0.044)\end{array}$ & $\begin{array}{c}0.041 \\
(0.034)\end{array}$ & \\
\hline Spraying Disp $2(\mathrm{t}-1)$ & $\begin{array}{l}-0.004 \\
(0.002)\end{array}$ & $\begin{array}{c}-0.006^{* *} \\
(0.003)\end{array}$ & $\begin{array}{l}-0.003 \\
(0.002)\end{array}$ & \\
\hline Spraying Disp (t-2) & $\begin{array}{c}0.080^{* * *} \\
(0.026)\end{array}$ & $\begin{array}{c}0.109^{* *} \\
(0.041)\end{array}$ & $\begin{array}{l}0.041^{*} \\
(0.024)\end{array}$ & \\
\hline Spraying Disp 2 (t-2) & $\begin{array}{c}-0.003^{* * *} \\
(0.001)\end{array}$ & $\begin{array}{c}-0.006^{* * *} \\
(0.002)\end{array}$ & $\begin{array}{l}-0.002^{*} \\
(0.001)\end{array}$ & \\
\hline Spraying Shock & & & & $\begin{array}{c}-0.182^{*} \\
(0.099)\end{array}$ \\
\hline Spraying Shock (t-1) & & & & $\begin{array}{c}-0.271^{* *} \\
(0.133)\end{array}$ \\
\hline Spraying Shock (t-2) & & & & $\begin{array}{c}0.115 \\
(0.109)\end{array}$ \\
\hline ln Spraying (t) & & & & $\begin{array}{c}0.096^{* * *} \\
(0.024)\end{array}$ \\
\hline ln Spraying (t-1) & & & & $\begin{array}{l}0.061^{*} \\
(0.036)\end{array}$ \\
\hline ln Spraying (t-2) & & & & $\begin{array}{c}0.028 \\
(0.033)\end{array}$ \\
\hline Inverted mills ratio & $\begin{array}{c}0.220 \\
(0.277)\end{array}$ & $\begin{array}{c}0.296 \\
(0.468)\end{array}$ & $\begin{array}{c}0.181 \\
(0.264)\end{array}$ & $\begin{array}{c}0.346 \\
(0.229)\end{array}$ \\
\hline lagged Change in ln Coca & $\begin{array}{c}-0.125^{* *} \\
(0.057)\end{array}$ & $\begin{array}{r}-0.169^{* *} \\
(0.066)\end{array}$ & $\begin{array}{l}-0.014 \\
(0.042)\end{array}$ & $\begin{array}{c}-0.159^{* * *} \\
(0.048)\end{array}$ \\
\hline $\ln$ Coca $(t-2)$ & $\begin{array}{l}-0.100 \\
(0.060)\end{array}$ & $\begin{array}{l}-0.103 \\
(0.089)\end{array}$ & $\begin{array}{l}-0.063 \\
(0.068)\end{array}$ & $\begin{array}{c}-0.297^{* * *} \\
(0.087)\end{array}$ \\
\hline Constant & $\begin{array}{l}-10.055 \\
(19.015)\end{array}$ & $\begin{array}{c}-90.993^{* * *} \\
(26.941)\end{array}$ & $\begin{array}{c}-3.478 \\
(19.727)\end{array}$ & $\begin{array}{l}-13.099 \\
(22.737)\end{array}$ \\
\hline Observations & 266 & 262 & 266 & 264 \\
\hline Num.Municipalities & 79 & 78 & 79 & 78 \\
\hline R2 Overall & 0.24 & 0.09 & 0.04 & 0.28 \\
\hline R2 Within & 0.24 & 0.23 & 0.17 & 0.26 \\
\hline R2 Between & 0.18 & 0.11 & 0.04 & 0.25 \\
\hline
\end{tabular}


Table A1.4: Effect of spraying disproportionality on legal crops controlling for conflict variables

\begin{tabular}{|c|c|c|}
\hline & $\begin{array}{l}(1) \\
\text { All }\end{array}$ & $\begin{array}{c}(2) \\
\text { Transitory }\end{array}$ \\
\hline Spraying Disp & $\begin{array}{l}0.020 \\
(0.072)\end{array}$ & \\
\hline Spraying Disp 2 & $\begin{array}{l}-0.004 \\
(0.007)\end{array}$ & \\
\hline Spraying Disp (t-1) & $\begin{array}{l}0.067 \\
(0.057)\end{array}$ & \\
\hline Spraying Disp 2 (t-1) & $\begin{array}{l}-0.005 \\
(0.003)\end{array}$ & \\
\hline Spraying Disp (t-2) & $\begin{array}{l}0.091^{* *} \\
(0.042)\end{array}$ & \\
\hline Spraying Disp 2 (t-2) & $\begin{array}{c}-0.004^{* *} \\
(0.002)\end{array}$ & \\
\hline Spraying Shock & & $\begin{array}{c}-0.334^{* *} \\
(0.128)\end{array}$ \\
\hline Spraying Shock (t-1) & & $\begin{array}{l}-0.144 \\
(0.201)\end{array}$ \\
\hline Spraying Shock (t-2) & & $\begin{array}{c}0.101 \\
(0.165)\end{array}$ \\
\hline ln Spraying (t) & & $\begin{array}{c}0.046 \\
(0.043)\end{array}$ \\
\hline ln Spraying (t-1) & & $\begin{array}{l}0.109^{* *} \\
(0.051)\end{array}$ \\
\hline ln Spraying (t-2) & & $\begin{array}{l}0.016 \\
(0.046)\end{array}$ \\
\hline Lagged Change in ln Coca & $\begin{array}{l}-0.115 \\
(0.083)\end{array}$ & $\begin{array}{c}-0.222^{* *} \\
(0.087)\end{array}$ \\
\hline $\ln$ Coca $(t-2)$ & $\begin{array}{l}-0.045 \\
(0.099)\end{array}$ & $\begin{array}{c}-0.340^{* *} \\
(0.129)\end{array}$ \\
\hline Threat Yellow Zone & $\begin{array}{l}-0.256 \\
(0.399)\end{array}$ & $\begin{array}{l}-0.519 \\
(0.521)\end{array}$ \\
\hline Threat Red Zone & $\begin{array}{l}-0.373 \\
(0.448)\end{array}$ & $\begin{array}{l}-0.566 \\
(0.508)\end{array}$ \\
\hline Num. armed actions & $\begin{array}{l}0.005 \\
(0.008)\end{array}$ & $\begin{array}{l}-0.003 \\
(0.010)\end{array}$ \\
\hline Num. FARC & $\begin{array}{l}-0.000 \\
(0.001)\end{array}$ & $\begin{array}{l}0.000 \\
(0.001)\end{array}$ \\
\hline Num. ELN & $\begin{array}{l}-0.009 \\
(0.008)\end{array}$ & $\begin{array}{l}-0.006 \\
(0.009)\end{array}$ \\
\hline Num. BACRIM & $\begin{array}{l}0.000 \\
(0.002)\end{array}$ & $\begin{array}{l}-0.001 \\
(0.002)\end{array}$ \\
\hline Num. Landmines & $\begin{array}{l}-0.007 \\
(0.009)\end{array}$ & $\begin{array}{l}-0.002 \\
(0.009)\end{array}$ \\
\hline Constant & $\begin{array}{l}-31.763 \\
(32.672)\end{array}$ & $\begin{array}{l}-38.513 \\
(34.096)\end{array}$ \\
\hline Observations & 172 & 171 \\
\hline Num.Municipalities & 79 & 79 \\
\hline R2 Overall & 0.33 & 0.32 \\
\hline R2 Within & 0.35 & 0.37 \\
\hline R2 Between & 0.27 & 50 \\
\hline
\end{tabular}


Table A1.5: Effect of spraying disproportionality on planted and cultivated legal crops

\begin{tabular}{|c|c|c|c|c|}
\hline & $\begin{array}{c}(1) \\
\text { Cultivated }\end{array}$ & $\begin{array}{c}(2) \\
\text { Planted }\end{array}$ & $\begin{array}{c}(3) \\
\text { Cultivated }\end{array}$ & $\begin{array}{c}(4) \\
\text { Planted }\end{array}$ \\
\hline Spraying Disp & $\begin{array}{c}0.040 \\
(0.026)\end{array}$ & $\begin{array}{l}0.036^{*} \\
(0.021)\end{array}$ & & \\
\hline Spraying Disp 2 & $\begin{array}{l}-0.002 \\
(0.002)\end{array}$ & $\begin{array}{l}-0.002 \\
(0.002)\end{array}$ & & \\
\hline Spraying Disp (t-1) & $\begin{array}{c}0.030 \\
(0.037)\end{array}$ & $\begin{array}{c}0.019 \\
(0.032)\end{array}$ & & \\
\hline Spraying Disp $2(\mathrm{t}-1)$ & $\begin{array}{l}-0.003 \\
(0.002)\end{array}$ & $\begin{array}{l}-0.002 \\
(0.002)\end{array}$ & & \\
\hline Spraying Disp (t-2) & $\begin{array}{c}0.073^{* * *} \\
(0.025)\end{array}$ & $\begin{array}{c}0.064^{* * *} \\
(0.021)\end{array}$ & & \\
\hline Spraying Disp 2 (t-2) & $\begin{array}{c}-0.003^{* * *} \\
(0.001)\end{array}$ & $\begin{array}{c}-0.003^{* * *} \\
(0.001)\end{array}$ & & \\
\hline Spraying Shock & & & $\begin{array}{c}-0.215^{* *} \\
(0.091)\end{array}$ & $\begin{array}{c}-0.160^{*} \\
(0.083)\end{array}$ \\
\hline Spraying Shock (t-1) & & & $\begin{array}{c}-0.267^{* *} \\
(0.126)\end{array}$ & $\begin{array}{l}-0.204^{*} \\
(0.110)\end{array}$ \\
\hline Spraying Shock (t-2) & & & $\begin{array}{c}0.053 \\
(0.100)\end{array}$ & $\begin{array}{c}0.054 \\
(0.080)\end{array}$ \\
\hline ln Spraying (t) & & & $\begin{array}{c}0.085^{* * *} \\
(0.023)\end{array}$ & $\begin{array}{l}0.056^{* *} \\
(0.022)\end{array}$ \\
\hline ln Spraying (t-1) & & & $\begin{array}{c}0.057^{*} \\
(0.033)\end{array}$ & $\begin{array}{c}0.033 \\
(0.033)\end{array}$ \\
\hline ln Spraying (t-2) & & & $\begin{array}{c}0.027 \\
(0.032)\end{array}$ & $\begin{array}{c}0.014 \\
(0.033)\end{array}$ \\
\hline Lagged Change in ln Coca & $\begin{array}{l}-0.108^{*} \\
(0.059)\end{array}$ & $\begin{array}{c}-0.118^{* *} \\
(0.055)\end{array}$ & $\begin{array}{c}-0.145^{* * *} \\
(0.050)\end{array}$ & $\begin{array}{c}-0.126^{* * *} \\
(0.046)\end{array}$ \\
\hline $\ln$ Coca $(\mathrm{t}-2)$ & $\begin{array}{l}-0.068 \\
(0.064)\end{array}$ & $\begin{array}{l}-0.075 \\
(0.063)\end{array}$ & $\begin{array}{c}-0.268^{* * *} \\
(0.084)\end{array}$ & $\begin{array}{c}-0.192^{* *} \\
(0.079)\end{array}$ \\
\hline Constant & $\begin{array}{c}-17.217 \\
(19.222)\end{array}$ & $\begin{array}{l}-29.557 \\
(20.478)\end{array}$ & $\begin{array}{l}-20.041 \\
(22.849)\end{array}$ & $\begin{array}{l}-32.768 \\
(23.953)\end{array}$ \\
\hline Observations & 283 & 283 & 282 & 282 \\
\hline Num.Municipalities & 83 & 83 & 82 & 82 \\
\hline R2 Overall & 0.33 & 0.38 & 0.36 & 0.40 \\
\hline R2 Within & 0.24 & 0.34 & 0.26 & 0.33 \\
\hline R2 Between & 0.27 & 0.35 & 0.31 & 0.36 \\
\hline
\end{tabular}


Table A1.6: Beneficiaries, near controls and beneficiaries controlling for the inverse mills ratio

\begin{tabular}{|c|c|c|c|c|c|c|c|}
\hline & \multicolumn{4}{|c|}{ Disproportion } & \multicolumn{3}{|c|}{ Shock } \\
\hline & $\begin{array}{c}(1) \\
\text { FGB }\end{array}$ & $\begin{array}{c}(2) \\
\text { FGB }\end{array}$ & $\begin{array}{c}(3) \\
\text { N.Control }\end{array}$ & $\begin{array}{c}(4) \\
\text { N.Control }\end{array}$ & $\begin{array}{c}(5) \\
\text { FGB }\end{array}$ & $\begin{array}{c}(6) \\
\text { FGB }\end{array}$ & $\begin{array}{c}(7) \\
\text { N.Control }\end{array}$ \\
\hline Total spray shocks & & & & & $\begin{array}{c}-0.156^{* * *} \\
(0.052)\end{array}$ & $\begin{array}{l}-0.088 \\
(0.056)\end{array}$ & $\begin{array}{c}-0.203^{* * *} \\
(0.078)\end{array}$ \\
\hline lnSpray 2011 & & & & & $\begin{array}{c}-0.088^{*} \\
(0.052)\end{array}$ & $\begin{array}{c}-0.246^{* * *} \\
(0.056)\end{array}$ & $\begin{array}{c}0.101 \\
(0.081)\end{array}$ \\
\hline SprayInt 2011 & $\begin{array}{c}0.123 \\
(0.144)\end{array}$ & $\begin{array}{c}0.138 \\
(0.156)\end{array}$ & $\begin{array}{l}-0.242 \\
(0.247)\end{array}$ & $\begin{array}{l}-0.034 \\
(0.046)\end{array}$ & & & \\
\hline SprayInt2 2011 & $\begin{array}{c}-0.049^{* *} \\
(0.022)\end{array}$ & $\begin{array}{c}-0.051^{* *} \\
(0.024)\end{array}$ & $\begin{array}{c}0.034 \\
(0.037)\end{array}$ & & & & \\
\hline $\operatorname{lnCoca} 2006$ & $\begin{array}{c}0.329^{* * *} \\
(0.040)\end{array}$ & $\begin{array}{c}0.334^{* * *} \\
(0.043)\end{array}$ & $\begin{array}{c}0.228^{* * *} \\
(0.059)\end{array}$ & $\begin{array}{c}0.250^{* * *} \\
(0.057)\end{array}$ & $\begin{array}{c}0.493^{* * *} \\
(0.074)\end{array}$ & $\begin{array}{c}0.649^{* * *} \\
(0.075)\end{array}$ & $\begin{array}{c}0.160 \\
(0.098)\end{array}$ \\
\hline lnExpenditure pc & $\begin{array}{c}0.289^{* * *} \\
(0.068)\end{array}$ & $\begin{array}{c}0.304^{* * *} \\
(0.073)\end{array}$ & $\begin{array}{c}0.444^{* * *} \\
(0.086)\end{array}$ & $\begin{array}{c}0.449^{* * *} \\
(0.086)\end{array}$ & $\begin{array}{c}0.220^{* * *} \\
(0.069)\end{array}$ & $\begin{array}{c}0.248^{* * *} \\
(0.072)\end{array}$ & $\begin{array}{c}0.433^{* * *} \\
(0.085)\end{array}$ \\
\hline Immorality & $\begin{array}{c}-0.079^{* * *} \\
(0.030)\end{array}$ & $\begin{array}{c}-0.065^{*} \\
(0.035)\end{array}$ & $\begin{array}{c}0.027 \\
(0.059)\end{array}$ & $\begin{array}{c}0.027 \\
(0.059)\end{array}$ & $\begin{array}{c}-0.054^{*} \\
(0.031)\end{array}$ & $\begin{array}{c}-0.051 \\
(0.034)\end{array}$ & $\begin{array}{c}0.031 \\
(0.060)\end{array}$ \\
\hline Good land & $\begin{array}{c}0.211^{* *} \\
(0.083)\end{array}$ & $\begin{array}{c}0.311^{* * *} \\
(0.091)\end{array}$ & $\begin{array}{c}0.194 \\
(0.150)\end{array}$ & $\begin{array}{c}0.193 \\
(0.150)\end{array}$ & $\begin{array}{c}0.256^{* * *} \\
(0.086)\end{array}$ & $\begin{array}{c}0.374^{* * *} \\
(0.091)\end{array}$ & $\begin{array}{c}0.187 \\
(0.147)\end{array}$ \\
\hline Perc.land with title & $\begin{array}{c}0.008^{* * *} \\
(0.001)\end{array}$ & & $\begin{array}{c}0.006^{* * *} \\
(0.002)\end{array}$ & $\begin{array}{c}0.006^{* * *} \\
(0.002)\end{array}$ & $\begin{array}{c}0.009^{* * *} \\
(0.001)\end{array}$ & & $\begin{array}{c}0.006^{* * *} \\
(0.002)\end{array}$ \\
\hline Male & $\begin{array}{l}0.161^{*} \\
(0.083)\end{array}$ & & $\begin{array}{c}0.193 \\
(0.249)\end{array}$ & $\begin{array}{c}0.167 \\
(0.251)\end{array}$ & $\begin{array}{l}0.163^{*} \\
(0.084)\end{array}$ & & $\begin{array}{c}0.158 \\
(0.248)\end{array}$ \\
\hline Years home & $\begin{array}{c}0.002 \\
(0.002)\end{array}$ & $\begin{array}{c}0.005^{* *} \\
(0.002)\end{array}$ & $\begin{array}{c}-0.009^{* *} \\
(0.004)\end{array}$ & $\begin{array}{c}-0.009^{* *} \\
(0.004)\end{array}$ & $\begin{array}{c}0.003 \\
(0.002)\end{array}$ & $\begin{array}{c}0.005^{* *} \\
(0.002)\end{array}$ & $\begin{array}{c}-0.009^{* *} \\
(0.004)\end{array}$ \\
\hline Age & $\begin{array}{c}0.013^{* * *} \\
(0.003)\end{array}$ & & $\begin{array}{l}0.009^{*} \\
(0.005)\end{array}$ & $\begin{array}{l}0.009^{*} \\
(0.005)\end{array}$ & $\begin{array}{c}0.011^{* * *} \\
(0.003)\end{array}$ & & $\begin{array}{l}0.010^{*} \\
(0.005)\end{array}$ \\
\hline Productive association & $\begin{array}{l}0.169^{*} \\
(0.101)\end{array}$ & $\begin{array}{c}0.055 \\
(0.101)\end{array}$ & $\begin{array}{c}-0.040 \\
(0.365)\end{array}$ & $\begin{array}{c}-0.029 \\
(0.347)\end{array}$ & $\begin{array}{c}0.178^{*} \\
(0.108)\end{array}$ & $\begin{array}{c}0.106 \\
(0.106)\end{array}$ & $\begin{array}{l}-0.022 \\
(0.381)\end{array}$ \\
\hline Coca immoral & $\begin{array}{c}0.098 \\
(0.088)\end{array}$ & $\begin{array}{c}0.064 \\
(0.094)\end{array}$ & $\begin{array}{c}-0.174 \\
(0.165)\end{array}$ & $\begin{array}{l}-0.160 \\
(0.159)\end{array}$ & $\begin{array}{c}0.110 \\
(0.090)\end{array}$ & $\begin{array}{c}0.108 \\
(0.095)\end{array}$ & $\begin{array}{l}-0.146 \\
(0.158)\end{array}$ \\
\hline Inverted mills ratio & & $\begin{array}{c}0.875^{* * *} \\
(0.181)\end{array}$ & & & & $\begin{array}{c}0.980^{* * * *} \\
(0.184)\end{array}$ & \\
\hline Constant & $\begin{array}{c}-5.779^{* * *} \\
(0.837)\end{array}$ & $\begin{array}{c}-6.138^{* * *} \\
(0.911)\end{array}$ & $\begin{array}{c}-5.717^{* * *} \\
(1.135)\end{array}$ & $\begin{array}{c}-6.049^{* * *} \\
(1.087)\end{array}$ & $\begin{array}{c}-5.247^{* * *} \\
(0.835)\end{array}$ & $\begin{array}{c}-6.029^{* * * *} \\
(0.897)\end{array}$ & $\begin{array}{c}-5.742^{* * *} \\
(1.079)\end{array}$ \\
\hline $\mathrm{R} 2$ & 0.34 & 0.27 & 0.24 & 0.23 & 0.32 & 0.26 & 0.25 \\
\hline Num.Observations & 678 & 677 & 647 & 647 & 678 & 677 & 647 \\
\hline Expanded pop & 3946 & 3941 & 2433 & 2433 & 3946 & 3941 & 2433 \\
\hline Num.Strata & 15 & 15 & 15 & 15 & 15 & 15 & 15 \\
\hline
\end{tabular}


Table A1.7: Effect of spraying on legal crops controlling for displacement

\begin{tabular}{|c|c|c|c|}
\hline & $\begin{array}{l}(1) \\
\text { All }\end{array}$ & $\begin{array}{c}(2) \\
\text { Transitory }\end{array}$ & $\begin{array}{c}(3) \\
\text { Permanent }\end{array}$ \\
\hline Displacement Intensity Rate & $\begin{array}{l}-0.00000 \\
(0.00001)\end{array}$ & $\begin{array}{c}-0.00002^{* *} \\
(0.00001)\end{array}$ & $\begin{array}{l}-0.00000 \\
(0.00001)\end{array}$ \\
\hline Spraying Disp & $\begin{array}{c}0.03053 \\
(0.02422)\end{array}$ & $\begin{array}{l}-0.01643 \\
(0.04821)\end{array}$ & $\begin{array}{c}0.01720 \\
(0.02700)\end{array}$ \\
\hline Spraying Disp 2 & $\begin{array}{l}-0.00150 \\
(0.00157)\end{array}$ & $\begin{array}{c}0.00123 \\
(0.00285)\end{array}$ & $\begin{array}{l}-0.00133 \\
(0.00186)\end{array}$ \\
\hline Spraying Disp (t-1) & $\begin{array}{c}0.02794 \\
(0.03783)\end{array}$ & $\begin{array}{c}0.05464 \\
(0.03965)\end{array}$ & $\begin{array}{c}0.02909 \\
(0.03270)\end{array}$ \\
\hline Spraying Disp 2 (t-1) & $\begin{array}{l}-0.00277 \\
(0.00227)\end{array}$ & $\begin{array}{l}-0.00451 \\
(0.00275)\end{array}$ & $\begin{array}{l}-0.00205 \\
(0.00200)\end{array}$ \\
\hline Spraying Disp (t-2) & $\begin{array}{c}0.06894^{* * *} \\
(0.02427)\end{array}$ & $\begin{array}{c}0.09183^{* *} \\
(0.03863)\end{array}$ & $\begin{array}{c}0.03566 \\
(0.02515)\end{array}$ \\
\hline Spraying Disp 2 (t-2) & $\begin{array}{c}-0.00295^{* * *} \\
(0.00093)\end{array}$ & $\begin{array}{r}-0.00510^{* *} \\
(0.00194)\end{array}$ & $\begin{array}{l}-0.00170 \\
(0.00107)\end{array}$ \\
\hline Lagged Change in ln Coca & $\begin{array}{c}-0.10475^{*} \\
(0.05860)\end{array}$ & $\begin{array}{l}-0.11288 \\
(0.07040)\end{array}$ & $\begin{array}{l}-0.01134 \\
(0.04197)\end{array}$ \\
\hline $\ln$ Coca $(t-2)$ & $\begin{array}{l}-0.06441 \\
(0.06065)\end{array}$ & $\begin{array}{l}-0.04494 \\
(0.08353)\end{array}$ & $\begin{array}{l}-0.03354 \\
(0.06484)\end{array}$ \\
\hline Product cluster (HHI) & $\begin{array}{c}1.84903^{* * *} \\
(0.61063)\end{array}$ & $\begin{array}{c}-2.32764^{* *} \\
(1.02468)\end{array}$ & $\begin{array}{l}1.76845^{*} \\
(1.02929)\end{array}$ \\
\hline ln Rural Land Price & $\begin{array}{l}-0.06827 \\
(0.06616)\end{array}$ & $\begin{array}{l}-0.04160 \\
(0.06724)\end{array}$ & $\begin{array}{l}-0.06606 \\
(0.05651)\end{array}$ \\
\hline L.ln Rural Land Price & $\begin{array}{l}-0.01801 \\
(0.04808)\end{array}$ & $\begin{array}{l}-0.02797 \\
(0.07461)\end{array}$ & $\begin{array}{l}-0.00381 \\
(0.05153)\end{array}$ \\
\hline D.Fiscal Performance & $\begin{array}{l}-0.00340^{*} \\
(0.00185)\end{array}$ & $\begin{array}{c}-0.00566^{*} \\
(0.00295)\end{array}$ & $\begin{array}{l}-0.00082 \\
(0.00259)\end{array}$ \\
\hline D.ln Rural population & $\begin{array}{c}2.47042 \\
(2.24154)\end{array}$ & $\begin{array}{c}8.74403^{* * *} \\
(2.13135)\end{array}$ & $\begin{array}{l}1.55780 \\
(2.37421)\end{array}$ \\
\hline L.ln Rural population & $\begin{array}{l}3.06626 \\
(2.36823)\end{array}$ & $\begin{array}{c}8.19968^{* * *} \\
(2.28947)\end{array}$ & $\begin{array}{l}1.28845 \\
(2.35266)\end{array}$ \\
\hline Rural density & $\begin{array}{l}-0.05294 \\
(0.15664)\end{array}$ & $\begin{array}{c}-0.46008^{* * *} \\
(0.16198)\end{array}$ & $\begin{array}{c}0.10607 \\
(0.17846)\end{array}$ \\
\hline D.ln Urban population & $\begin{array}{l}-27.41241 \\
(34.26608)\end{array}$ & $\begin{array}{c}-2.28661 \\
(59.32844)\end{array}$ & $\begin{array}{c}-8.93088 \\
(22.67661)\end{array}$ \\
\hline LD.ln Urban population & $\begin{array}{c}42.63963 \\
(27.94733)\end{array}$ & $\begin{array}{c}32.47889 \\
(50.23108)\end{array}$ & $\begin{array}{c}24.19664 \\
(17.20111)\end{array}$ \\
\hline Proportion rural & $\begin{array}{c}-15.27223^{* * *} \\
(5.56093)\end{array}$ & $\begin{array}{c}-10.23585^{*} \\
(5.59326)\end{array}$ & $\begin{array}{c}-15.61294^{* *} \\
(6.20378)\end{array}$ \\
\hline Perc. income from transfers & $\begin{array}{c}0.00349 \\
(0.00218)\end{array}$ & $\begin{array}{c}0.00054 \\
(0.00294)\end{array}$ & $\begin{array}{c}0.00273 \\
(0.00268)\end{array}$ \\
\hline Constant & $\begin{array}{c}-9.57635 \\
(19.66146)\end{array}$ & $\begin{array}{c}-60.38994^{* * *} \\
(19.10639)\end{array}$ & $\begin{array}{c}3.36716 \\
(19.39288)\end{array}$ \\
\hline Observations & 283 & 279 & 283 \\
\hline Num.Municipalities & 83 & 82 & 83 \\
\hline R2 Overall & 0.31 & 0.09 & 0.06 \\
\hline R2 Within & 0.25 & 0.21 & 0.16 \\
\hline R2 Between & 0.25 & 0.11 & 0.06 \\
\hline
\end{tabular}

Clustered standard errors in parentheses. Significance levels ${ }^{*} \mathrm{p}<0.10,{ }^{* *} \mathrm{p}<0.05,{ }^{* * *} \mathrm{p}<0.01$ 
Table A1.8: Spraying disproportionality and coca crops

\begin{tabular}{|c|c|c|c|c|}
\hline & $\begin{array}{c}(1) \\
\text { Spraying disp squared }\end{array}$ & $\begin{array}{c}(2) \\
\mathrm{dy} / \mathrm{dx}\end{array}$ & $\begin{array}{c}(3) \\
\text { Spraying disp linear }\end{array}$ & $\begin{array}{c}(4) \\
\mathrm{dy} / \mathrm{dx}\end{array}$ \\
\hline Spraying Disproportional & $\begin{array}{l}-0.164 \\
(0.734)\end{array}$ & $\begin{array}{c}-0.177^{* * *} \\
(0.031)\end{array}$ & $\begin{array}{c}-0.651^{* * *} \\
(0.147)\end{array}$ & $\begin{array}{c}-0.184^{* * *} \\
(0.029)\end{array}$ \\
\hline Spraying Disproportional 2 & $\begin{array}{l}-0.087 \\
(0.121)\end{array}$ & & & \\
\hline Coca affected by spraying (1) & $\begin{array}{l}-0.111 \\
(0.267)\end{array}$ & $\begin{array}{l}-0.031 \\
(0.075)\end{array}$ & $\begin{array}{l}-0.086 \\
(0.228)\end{array}$ & $\begin{array}{l}-0.024 \\
(0.065)\end{array}$ \\
\hline Years growing coca & $\begin{array}{c}-0.041^{* *} \\
(0.018)\end{array}$ & $\begin{array}{c}-0.012^{* *} \\
(0.005)\end{array}$ & $\begin{array}{c}-0.040^{* *} \\
(0.020)\end{array}$ & $\begin{array}{c}-0.011^{* *} \\
(0.006)\end{array}$ \\
\hline Female & $\begin{array}{c}0.184 \\
(0.198)\end{array}$ & $\begin{array}{c}0.052 \\
(0.058)\end{array}$ & $\begin{array}{c}0.193 \\
(0.204)\end{array}$ & $\begin{array}{c}0.055 \\
(0.061)\end{array}$ \\
\hline Age & $\begin{array}{l}-0.004 \\
(0.009)\end{array}$ & $\begin{array}{l}-0.001 \\
(0.003)\end{array}$ & $\begin{array}{l}-0.004 \\
(0.009)\end{array}$ & $\begin{array}{l}-0.001 \\
(0.003)\end{array}$ \\
\hline Years in Community & $\begin{array}{l}-0.004 \\
(0.010)\end{array}$ & $\begin{array}{l}-0.001 \\
(0.003)\end{array}$ & $\begin{array}{l}-0.003 \\
(0.009)\end{array}$ & $\begin{array}{l}-0.001 \\
(0.003)\end{array}$ \\
\hline Farm area (ha) & $\begin{array}{c}-0.024^{* * *} \\
(0.009)\end{array}$ & $\begin{array}{c}-0.007^{* *} \\
(0.003)\end{array}$ & $\begin{array}{c}-0.024^{* * *} \\
(0.009)\end{array}$ & $\begin{array}{c}-0.007^{* *} \\
(0.003)\end{array}$ \\
\hline Perceived State Capacity & $\begin{array}{l}-0.467 \\
(0.316)\end{array}$ & $\begin{array}{l}-0.131 \\
(0.090)\end{array}$ & $\begin{array}{l}-0.446 \\
(0.334)\end{array}$ & $\begin{array}{l}-0.126 \\
(0.096)\end{array}$ \\
\hline Perceived Quality Public SS & $\begin{array}{l}-0.044 \\
(0.253)\end{array}$ & $\begin{array}{l}-0.012 \\
(0.071)\end{array}$ & $\begin{array}{l}-0.044 \\
(0.258)\end{array}$ & $\begin{array}{l}-0.012 \\
(0.073)\end{array}$ \\
\hline Has Title over land & $\begin{array}{c}0.132 \\
(0.175)\end{array}$ & $\begin{array}{c}0.037 \\
(0.050)\end{array}$ & $\begin{array}{c}0.115 \\
(0.173)\end{array}$ & $\begin{array}{c}0.033 \\
(0.049)\end{array}$ \\
\hline Constant & $\begin{array}{l}2.303^{*} \\
(1.350)\end{array}$ & & $\begin{array}{c}2.845^{* * *} \\
(0.826)\end{array}$ & \\
\hline \multicolumn{5}{|l|}{$\mathrm{R} 2$} \\
\hline Observations & 236 & 236 & 236 & 236 \\
\hline Num.Municipalities & 8 & & 8 & \\
\hline
\end{tabular}

Clustered standard errors in parentheses. Significance levels ${ }^{*} \mathrm{p}<0.10,{ }^{* *} \mathrm{p}<0.05,{ }^{* * *} \mathrm{p}<0.01$

Variable definitions: (1) Dummy that takes the value of 1 if responden reported their coca crops affected. (2) Takes value of 1 when person processes coca leaf into coca paste. State capaticty and perceived public service quality explained in data section. 


\title{
3. How alternative development achieves more honest com- munities: An experimental approach in Colombia ${ }^{\dagger}$
}

\begin{abstract}
Dishonesty is widespread: evidence shows than when people have the chance, they will cheat. This behavior costs societies billions of dollars every year, and has motivated research on how it can be reduced. We focus on a legality-building policy applied to a novel group: farmers that live in coca growing regions in Colombia, who are exposed to high levels of violence, poverty and widespread illegality. We build on the impact evaluation of Colombia's biggest alternative development program that offers culture of legality workshops to their beneficiaries, and gives them monetary incentives to keep their territories free of coca. This allows us to see if the program is able to bring dishonesty down, and to explore the novel relationship between poverty and dishonesty, and between moral reminders and dishonesty. We introduced a die-type honesty experiment similar to that of Fischbacher and Heusi (2008) to the impact evaluation, which was played by 3710 individuals. We find evidence that beneficiaries are more honest than their distant counterparts and generate spillovers to their neighbors. We also find a non-linear relationship between dishonesty and poverty, where dishonesty decreases when the poverty line has been crossed, but increases right before crossing it. Moreover, as exposure to the program's workshops increases, dishonesty decreases. This suggests that the program's focus on coca reduction and compliance with legality spills over into other realms of ethical behavior and achieves not only more legal, but also more honest communities.
\end{abstract}

Keywords: Cheating, morality, alternative development, public policy

JEL codes: K4, O21, D03

\footnotetext{
$\dagger$ Joint work with Marcela Ibanez. We would like to thank Econometria Consultores and Oscar Rodriguez for their important suggestions and for incorporating the dishonesty experiment in the survey. We also thank DNP in Colombia for the research agreement that allowed us to use the data. We also thank Axel Dreher for his comments and suggestions.
} 


\section{Introduction}

Acts of dishonesty appear to be common and widespread, not only from "bad apples" but from the average person (Ariely, 2013; Vetter et al., 2010; Bazerman and Banaji, 2004; Azar et al., 2013; Fosgaard, 2013). Although "bad apples" cause sensation in the media, it is the daily "minor" dishonesty that hurts societies the most (Mazar and Ariely, 2006; Loewen et al. 2013). For example, insurance fraud costs the United States 24 billion every year and "wardrobing" (buying something, using it for one day and returning it) amounted to $\$ 16$ billion in 2002 in the US economy (Mazar and Ariely, 2006). Dishonesty does not escape the academic field. For instance, Butler (2010) found that in the journal Nature, between $6 \%$ to $23 \%$ of its papers had plagiarism while an anonymous survey from top medical journals found that $17.6 \%$ of their papers had been published in the name of guest authors and $7.6 \%$ had been written by ghost authors (Wislar et al., 2011). ${ }^{1}$

The quest for effective measures to curb dishonesty is currently active and much attention has been given to identifying factors that either trigger or limit people's natural tendency to cheat (Fosgaard, 2013; Ariely 2013; Gneezy, 2005; Schweitzer and Hsee, 2002; Shu et al., 2011; Ploner and Regner, 2013; Gravert, 2013; Gino et al., 2013; Mazar et al., 2008; Mazar and Ariely, 2006; Shu, Gino and Bazerman, 2011; Gneezy et al., 2013). While most of the research has focused on student populations in developed countries, ${ }^{2}$ there is relatively little research of this topic in developing countries affected by high exposure to illegality (i.e., corruption, black economy, money laundry and tax evasion) and violence and civil conflict, as is the case in Colombia.

We contribute to this research focusing on a population that has never been considered in this topic before: people who live in rural and marginalized coca growing areas that suffer from state absence, high levels of poverty, few (legal) economic activities and high levels of violence and armed conflict. Our unique sample allows us to analyze unexplored questions such as whether exposure to an illegal environment, violence and conflict are positively associated with dishonesty and whether there is a positive association between poverty and an individual's propensity to lie.

The second contribution of our analysis is to consider the feedback effect of anti-drug policies. We focus on the impact of the the Forest Warden Families program (FGB from its Spanish name), the most important alternative development program in Colombia, on individual propensity to lie. ${ }^{3}$ The FGB Program offers farmers living in coca growing areas a regular cash transfer for a three-year period conditional on their promise to keep their land coca-free. The assumption behind this program is that by offering farmers a regular income, they will learn the advantages of working in the legal sector and voluntarily decide to remain working

\footnotetext{
${ }^{1}$ Guest authors are usually senior authors that have had no or very little contact with the manuscript, but that have been invited to put their name as authors in order to increase the chances of the manuscript being recognized and published. We refer to ghost authorship in the form known mainly in the medical field, where a company (pharmaceutical) hires an author to write a manuscript (ghost author) but then asks a well known author to be the "real" author.

${ }^{2}$ Exceptions to lab experiments with students are Bucciol et al. (2013); Azar et al. (2013).

${ }^{3}$ Econometria-SEI (2012). Evaluación del Programa Familias Guardabosques y Grupo Móvil de Erradicación.
} 
within legality even when the incentive is taken away. To foster the permanent transformation of farmers from coca to the legal economy, or the so called "culture of legality," one important component of the Program is mandatory attendance to workshops, where farmers learn the meaning and importance of following the law and living by the rules set in a democratic process. ${ }^{4}$ Our analysis aims at shedding light on the effectiveness of this intervention to reduce other immoral behaviors, such as cheating.

We are interested in investigating whether such an intervention can move people's moral compass beyond coca related activities and increase honesty. Mazar and Ariely (2006) state that "if the reason for dishonest actions lies in a lack of internalized social norms, our primary recommendation would be to invest in educational efforts and socialization to increase the strength of the internal reward mechanism" (pp. 13). This is what the FGB is trying to do with its interventions, and our study wants to see whether it has worked out or not.

To identify the impact of the FGB Program on dishonesty, we compare program beneficiaries with a group of producers that live in similar areas. First, they live in municipalities that are equally likely to be targeted by the Program, based on the Program's own targeting index. Moreover, the Program has been rolled-out in time allowing for comparisons between those who have already received the Program and those that will most likely benefit in the future. Second, they have similar experience cultivating coca and have been similarly affected by antidrug policies other than the FGB Program, such as manual eradication or aerial spraying. Lastly, they have been similarly affected by conflict and violence. Furthermore, in the analysis we explore variation in the intensity of exposure to the educational workshop. Given capacity constraints of the governmental agency responsible for the FGB program (Accion Social at the beginning of the Program and the Unidad Admistrativa de Consolidacion Territorial - UACT in its latest stage) and the growing expectation to involve local partners, this agency contracts third party agencies like universities and NGOs to be responsible for the implementation of the educational workshops. While the topic and aim of the workshops is predefined as well as the number of workshops that need to be offered, implementing agencies have some degree of freedom to decide when and how to deliver them. We find that depending on the region and implementing agency, there is variation in the intensity of exposure to these workshops. Agencies are chosen after a competitive process in their own regions and are chosen based on the same criteria, assuring similarities in capacity and quality. We explore this variation in exposure to educational workshops to identify if impacts are channeled through moral reminders sent by the Program.

We use data from the 2012 evaluation of the FGB Program provided by the National Planning Office - DNP. ${ }^{5}$ The data contains information of a representative sample at the national level of over 3710 thousand households living in seven departments and in 34 municipalities in the country. ${ }^{6}$ We worked together with the consulting firm so that within the surveys conducted

\footnotetext{
${ }^{4}$ The description of the "social component" is found in internal Program documents such as the: Guia de Procedimientos (procedures guide) and the ABC del Programa (ABC of the Program)

${ }^{5}$ Econometria-SEI (2012). Evaluación del Programa Familias Guardabosques y Grupo Móvil de Erradicación.

${ }^{6}$ There are 33 departments and 1021 municipalities in the country. 23 of these departments had coca in the
} 
to evaluate the impacts of the Program, we were allowed to conduct a short experiment. To measure the impacts of the Program in honesty we used an experiment similar to the one used by Fischbacher and Heusi (2008). Participants were offered the possibility to gain a small incentive as a retribution for participating in the survey. We explained that the amount to be paid would be determined by luck. ${ }^{7}$ Participants were asked to sit in private where no one, including the enumerator, could see them, and throw a regular six-sided fair dice ten times writing the result in a paper after each throw. The sum of the numbers obtained in the ten independent throws were multiplied by one hundred and paid as credit for mobile phones. ${ }^{8}$

In this experiment honesty is not directly observable; instead, it is possible to use the distribution over throws and compare it with the expected mean, the expected distribution of each trow or the expected distribution over the sum of trows in order to analyze the average level of honesty in the group. Moreover, in the analysis we correlate the value of the claimed payment with socioeconomic characteristics of the participants to uncover interesting relations. We find a non-linear correlation between dishonesty and poverty where the poorest and the richest are more honest than those close to the poverty threshold. We also find that the environment in which people live plays a key role in people's moral actions: people living in areas with high levels of coca also exhibit the highest dishonesty levels. People seem to reflect in the game their real-life "illegality-type" behavior, since those cultivating coca the year before the survey tend to be more dishonest than non-coca farmers.

Regarding the impacts of FGB, we find that FGB beneficiaries are less dishonest than nonbeneficiaries living in distant regions. Our results indicate that this result is channeled through the education effect of the Program's workshops, as dishonesty decreases with participation in the workshops.

This paper makes various contributions to the research on dishonesty. One behavioral pattern that commonly emerges is that people cheat when given the chance to do so. Yet, people do not cheat to a maximum degree, or at least as much as they could (Mazar and Ariely, 2006; Gneezy, 2005; Ariely, 2013; Fischbacher and Heusi, 2008; Gneezy et al., 2013). This form of incomplete cheating seems from people's need to balance the incentives to profit from cheating with keeping a positive image of themselves (Fischbacher and Heusi 2008; Fosgaard, 2013, Aquino and Reed, 2002; Ploner and Regner, 2013; Gravert, 2013, Gino et al., 2010; Shalvi and Leiser, 2013; Gneezy, 2005; Pascual-Ezama et al., 2013). Mazar and Ariely (2006) and Ariely (2013) rationalize this behavior in the theory of self-concept maintenance according to which there is an internal threshold that allows "some" dishonesty after which it becomes unacceptable. In our analysis, we test how generalizable this theory is in case of populations that live in conditions of high illegality and violence.

Empirical evidence suggests that one particular immoral act in one domain, spills-over into other domains (for a review see Ariely, 2013). For instance, experimental evidence finds that

time of the survey.

${ }^{7}$ All participants in the survey agreed to participate in the game, reducing problems of self-selection.

${ }^{8}$ Coverage of mobile telephones in Colombia is relatively good and it is estimated that 80 percent of rural households have a mobile telephone. Most of the people prefer prepaid contracts and even for those with fixed contracts it is possible to buy additional credit. 
when people are given counterfeit glasses to wear, they cheat more in honesty experiments that had nothing to do with glasses or fake products (Gino et al., 2010). It also seems that dishonesty not only has negative externalities within a person, but from an environment to the person. Mazar et al. (2008; p.2) find that placing people in a "morally permissive environment is sufficient to increase cheating." We explore the opposite direction and study if morality in one aspect (being exposed to the possibility to leave coca crops) also generates positive externalities in other aspects of moral traits, like honesty.

This paper is also related with the literature on "moral reminders" (Mazar et al., 2008; Shu et al., 2011, 2012). Moral reminders have the potential to bring a person's attention to her own moral standards, making her more conscious of unacceptable behaviors by such standards. Experimental tests have shown that moral reminders affect dishonesty. For example, Mazar et al. (2008) design a game where people can cheat and compare students that were asked to sign to comply with an honor code before playing with a control group. They found that their intervention eliminated cheating, even in universities that do not have an honor code. Shu et al. $(2011,2012)$ ask people to sign their names on the tax-refund or insurance claim form before they fill it out. Compared to the control group, where people signed their names at the end of the form (after dishonesty already happened), those who signed at the beginning claimed less tax returns and smaller insurance claims. Mazar et al. (2008) implement an experiment where people are asked to recall either the 10 commandments or the last 10 books they have read, and find that those who had to think of the commandments (regardless of their ability to name them correctly or their religious beliefs) cheated much less than those who recalled the books. We contribute to this research investigating how exposure to educational workshops that focus on the substitution of coca by legal crops, generates spill over effects in other norms like honesty. This research is complementary to our work on the impacts of participation in the FGB Program on norms regarding coca cultivation (Chapter 3).

There are several studies looking at how poverty and crime are related but come up with different results, with some studies finding no relationship at all. Sariaslan et al. (2013) find a strong positive relationship between poverty and crime in Sweden, that disappears as soon as unobserved family confounders are accounted for. Bjerk (2007) re-examines the relationship and shows that ignoring non-linearities and having problematic measures of poverty has led to the weak or non-existent effects. He finds that once non-linearities are accounted for, and income is not the main indicator used for capturing for poverty, the relationship between crime and poverty is empirically stronger. Hipp and Yates (2011) add evidence to the relationship and find a diminishing positive relationship between neighborhood poverty and crime. Muroi and Baumann (2009) find that a quadratic relationship best fits the data using property and violent crime and median income and poverty rate as crime and poverty variables respectively. Even though the relationship between poverty and crime has been studied both theoretically and empirically in the literature (although in developed countries), the relationship between poverty and dishonesty or immorality has been overlooked and our study sheds some light in this direction. We build on the poverty-crime literature and explore non-linear effects between poverty and crime, and use multidimensional poverty measures instead of income. 
The rest of the paper is organized as follows: Section 2 discusses the local background while Section 3 discusses the identification strategy used. Section 4 presents the experimental design and procedures, followed by Section 5 where we present the empirical strategy used to analyze our information. Section 6 presents descriptive results and the impact of the Program on dishonesty, and disentangles the channels that relate to it. We discuss these results in more detail in Section 7 and conclude in Section 8.

\section{Local background}

Colombia is regarded among the most unsafe places in the world. It appears in the list of 40 countries for which the US Department of State provides regular travel warnings. 2014 Travel Warning Report advices:

"The Department of State strongly encourages U.S. citizens to exercise caution and remain vigilant as terrorist and criminal activities remain a threat throughout the country. Explosions occur throughout Colombia on a regular basis, including in Bogota. Small towns and rural areas of Colombia can be extremely dangerous due to the presence of terrorists and criminal elements, including armed gangs (referred to as BACRIM in Spanish), that are active throughout much of the country. Violence associated with the BACRIM has spilled over into many of Colombia's major cities. These groups are heavily involved in the drug trade, extortion, kidnapping, and robbery.

U.S. government officials and their families in Colombia normally are permitted to travel to major cities only by air. They may not use inter- or intra-city bus transportation, or travel by road outside urban areas at night."

One of the factors that has fueled crime and violence is the drug trade. Colombia is the largest producer of cocaine and it is estimated that $70 \%$ of all cocaine that enters the USA is produced there. The cultivation of coca, the main active component in cocaine, affects large parts of the territory: 23 out of 33 departments were affected by the production of coca in 2012, 250 municipalities (25\%) were threatened by coca ${ }^{9}$ and 62.400 households were engaged in its cultivation (UNODC, 2012). Some studies have already found evidence that supports the association between coca and crime. Castillo et al. (2013) find that an increase in the value of coca of $10 \%$ increases homicides and forced displacement by $1.25 \%$ and $3 \%$ respectively. Angrist and Kugler (2008) find that areas with accelerated coca production became more violent and reported more deaths specially among young males. We focus on areas in Colombia with high levels of coca, and explore whether alternative development programs translate into more honest communities.

Table 2.1 presents the descriptive statistics of the municipal level characteristics in the municipalities that were included in our analysis compared to other municipalities in the country

\footnotetext{
${ }^{9}$ UNODC developed an index that includes affected area, persistence, expansion, concentration, abandonment and regrowing of coca crops to calculate a threat index.
} 
with coca, and with the national average excluding main cities. ${ }^{10}$ The municipalities in our study are similar to other municipalities that have coca in most variables, although they have grown coca one-and-a-half years more than other coca regions, pose a slightly higher threat to the state and have a lower proportion of rural population. Yet, compared with municipalities without coca, they are very different: they have a higher forced displacement rate, have twice as high homicide rate, pose a higher threat to the state and are poorer, as captured by an unsatisfied basic needs index.

Table 2.1: Descriptive statistics of municipalities in study, other coca growing municipalities not in the study and the rest of the country (excluding main cities)

\begin{tabular}{llll}
\hline & In study & $\begin{array}{l}\text { Out of study } \\
\text { with coca }\end{array}$ & $\begin{array}{l}\text { Out of study } \\
\text { no coca }\end{array}$ \\
\hline Prop. land with coca 2009 & 0.002 & 0.002 & 0.000 \\
& $(0.0004)$ & $(0.0002)$ & - \\
Years with coca until 2012 & 10.3 & $8.9^{* * *}$ & $0.71^{* * *}$ \\
& $(0.42)$ & $(0.24)$ & $(0.09)$ \\
Forced displacement rate 2009 & 538.9 & 397.8 & $67.0^{* * *}$ \\
& $(92.10)$ & $(65.23)$ & $(6.72)$ \\
Num. military actions 2009 & 1.06 & 1.56 & $0.29^{* *}$ \\
& $(0.30)$ & $(0.31)$ & $(0.04)$ \\
Homicide rate 2009 & 57.1 & 44.9 & $24.5^{* * *}$ \\
& $(8.48)$ & $(3.28)$ & $(0.94)$ \\
Threat to state index 2009 & 2.59 & $2.38^{*}$ & $1.49^{* * *}$ \\
& $(0.11)$ & $(0.05)$ & $(0.02)$ \\
Prop. rural population 2009 & 0.54 & $0.67^{* * *}$ & 0.58 \\
& $(0.03)$ & $(0.02)$ & $(0.01)$ \\
Unsatisfied basic needs (2005) & 55.7 & 58.1 & $45.7^{* *}$ \\
& $(3.88)$ & $(1.58)$ & $(1.14)$ \\
Num. Municipalities & 34 & 190 & 883 \\
\hline Note: Significance relative to municipalities in the study at & \\
index calculated by the Program. Threat to state index comes from the Ministry of Defense and takes into \\
account combats, displacement, coca, armed actions, presence of illegal armed groups among other variables. \\
Unsatisfied basic needs is a multipoverty index calculated from the 2005 census, that goes from 1 to 100, where \\
1 is no needs unsatisfied and 100 all needs unsatisfied. \\
Sources: Colombian Ministry of Defense, Ministry of Agriculture, PFGB
\end{tabular}

In response of the problem of drugs, Colombia has launched a two side strategy that combines eradication and alternative development. The first strategy aims at decreasing coca by destroying the crops either manually or by aerial spraying. The second strategy aims at decreasing coca by providing legal economic alternatives to the farmers. The Forest Warden Families Program (FWF or FGB for the spanish name) is Colombia's flagship alternative development program since 2003. This Program offers beneficiaries a monetary subsidy for up to three years ${ }^{11}$ conditional on them keeping their land free of coca. One of the main objectives of the Program has been to generate a culture of lawfulness, hoping that it will ensure that beneficiaries will not go back to coca crops once the program has ended. Hence, the Program emphasizes the importance

\footnotetext{
${ }^{10}$ Many variables were calculated for 2009 because it is the year before the seventh phase of the FGB program started, which defined where our study took place.

${ }^{11}$ The value of the subsidy offered has varied over the different implementation phases.
} 
of complying with the law in their workshops. Our objective is to identify if this intervention has had the expected result, by capturing legality with a general dishonesty measure.

\section{Identification strategy}

Our analysis is based on the data for the impact evaluation of the Forest Warden Families Program. ${ }^{12}$ This study was commissioned by the national government (National Planning Office - DNP) and carried out by the consultancy firm Econometria Consultores from November 2011 to September 2012. The evaluation was based on a survey that collected extensive information on household and individual socioeconomic characteristics, economic activities and relations to coca (precisely what the program wants to tackle). As no baseline existed, the survey collected retrospective and current data. The farmers that participated in the evaluation were selected according to the following criteria. First, a nationwide representative sample of 1236 Program beneficiaries from a universe of 8664 families from the seventh wave of the Program that started in 2010 was selected. At the time of the evaluation, they were active Program beneficiaries. All municipalities that had FGB presence in this wave were selected; each municipality was stratified by size and within each stratum treated veredas ${ }^{13}$ were chosen. Within the veredas, beneficiary households were chosen at random from the Program's own beneficiary lists. Second, replicating the conditions the program uses to select beneficiaries, they selected 1264 distant controls that lived in areas never touched by the Program, to serve as the pure control group. Another 1210 controls were chosen to serve as near-controls (farmers who live in the same municipality but were not selected to participate in the program), who were chosen simply based on their geographical proximity to the beneficiaries, in order to capture possible spillover effects. Most of our results will focus on the differences between beneficiaries and distant controls. ${ }^{14}$

The choice of the distant controls exploited the program's clear guidelines on who should be targeted and used the index the program created to prioritize municipalities based on these rules. The program was not able to reach all areas of interest at the same time, and has been rolled out since 2003, giving us the possibility to exploit this time variation to select the controls. The index is based on municipal data (and thus targets municipalities) and includes variables such as presence and amount of coca and poppy crops, being a national border, willingness to participate in the program, population size and density, presence and size of woodland, presence of USAID alternative development programs, among others. Using a probit model we checked whether in fact these variables determined participation in the program and we

\footnotetext{
${ }^{12}$ Econometria-SEI (2012). Evaluación del Programa Familias Guardabosques y Grupo Móvil de Erradicación.

${ }^{13} \mathrm{~A}$ vereda is the smallest administrative unit. It can usually be thought of as a community in rural areas.

${ }^{14}$ The evaluation also focused on capturing spillover effects that were expected especially in variables that had to do with agricultural production and productive activities that could have stemmed from the creation of clusters around new legal activities. Since they were chosen only based on their geographical proximity they don't assure comparability between the groups when estimating impacts. The evaluation used the distant controls for estimating impacts and the near control for capturing spill-over effects.
} 
find convincing results that they do. ${ }^{15}$ Based on this model the consultancy firm estimated the probability of being chosen and selected the distant controls that had the closest estimated probabilities to the FGB municipalities, and balanced both high and low probabilities, so that the whole range was included. The neighboring controls were chosen based on their distance and links to the treatment communities. All neighboring control communities were inside treated municipalities. Once a control municipality was chosen, local authorities in charge of the rural sector and the technical assistance of the region produced a list of all households that according to the programs' rules would be eligible. ${ }^{16}$ From this list the consultancy firm randomly selected the control group.

Table 2.2 presents average characteristics for the FGB municipalities in our study, the distant control municipalities, and other municipalities that have coca in the country in 2009, a year before the program started in these regions. Overall, treatment and control municipalities are very similar in almost all the variables tested. Importantly, both treatment and distant control municipalities have a very similar targeting index, which is the key variable for receiving the program. Treatment and distant control municipalities only differ in the homicide rate, which is higher in the latter. However, when looking at coca and conflict related variables, both groups are statistically identical. This table also shows that the selection of control municipalities was well done, as the differences that were observed between FGB municipalities and other municipalities with coca are not replicated in the sample. This procedure allows to select municipalities and households that are as comparable as possible.

\footnotetext{
${ }^{15}$ See Table A2.1 in the Appendix with a probit model that estimates the probability of being in the program based on these variables.

${ }^{16}$ In order to be eligible the household needs to derive its income from an agricultural activity, must have a piece of land to work with, can't be a public servant, should be living in the community before the program arrived, be older than 14 and be a household head and not having received the program in the past. Additionally, families with children and female heads of household were given priority.
} 
Table 2.2: Average characteristics of Forest Warden Families municipalities, distant control municipalities and coca-growing municipalities not in the study

\begin{tabular}{|c|c|c|c|}
\hline & FGB in study & Distant Controls & $\begin{array}{c}\text { Not in study } \\
\text { with coca }\end{array}$ \\
\hline \multirow[t]{2}{*}{ Targeting index } & 27.3 & 27.9 & 23.6 \\
\hline & $(2.44)$ & $(1.81)$ & $(0.72)$ \\
\hline \multirow[t]{2}{*}{ Prop. land with coca } & 0.002 & 0.001 & 0.002 \\
\hline & $(0.0006)$ & $(0.0005)$ & $(0.0002)$ \\
\hline \multirow[t]{2}{*}{ Years with coca } & 10.7 & 9.4 & $8.9 * * *$ \\
\hline & $(0.49)$ & $(0.71)$ & $(0.24)$ \\
\hline \multirow[t]{2}{*}{ Forced displacement rate } & 604.7 & 401.4 & 397.8 \\
\hline & $(111.45)$ & $(156.42)$ & $(65.23)$ \\
\hline \multirow[t]{2}{*}{ Num. military actions } & 1.17 & 0.82 & 1.56 \\
\hline & $(0.38)$ & $(0.46)$ & $(0.31)$ \\
\hline \multirow[t]{2}{*}{ Homicide rate } & 45.4 & $81.5^{* *}$ & 44.9 \\
\hline & $(7.82)$ & $(18.46)$ & $(3.28)$ \\
\hline \multirow[t]{2}{*}{ Threat to the state index } & 2.61 & 2.55 & 2.38 \\
\hline & $(0.13)$ & $(0.20)$ & $(0.05)$ \\
\hline \multirow[t]{2}{*}{ Prop. rural population } & 0.56 & 0.51 & $0.67^{* *}$ \\
\hline & $(0.04)$ & $(0.04)$ & $(0.02)$ \\
\hline \multirow[t]{2}{*}{ Unsatisfied basic needs (2005) } & 56.7 & 53.1 & 58.1 \\
\hline & $(3.80)$ & $(9.88)$ & $(1.58)$ \\
\hline Num. municipalities & 23 & 11 & 181 \\
\hline
\end{tabular}

Note: Significance relative to municipalities in the study at ${ }^{* * *} 0.01,{ }^{* *} 0.05$ and ${ }^{*} 0.1$ significance levels Targeting index calculated by the Program. Threat to state index comes from the Ministry of Defense and takes into account combats, displacement, coca, armed actions, presence of illegal armed groups among other variables. Unsatisfied basic needs is a multipoverty index calculated from the 2005 census, that goes from 1 to 100 , where 1 is no needs unsatisfied and 100 all needs unsatisfied.

As we mentioned, the FGB Program has been rolled out since 2003 in seven waves, and Table 4.1 shows how it has been rolled out since the beginning. ${ }^{17}$ Our identification strategy greatly benefits from the fact that the priority level of the incoming municipalities has been very similar in every wave. Only the sixth phase that was aimed at preventing coca to enter regions that had been greatly affected by heavy rains is not comparable. The differences between the phases were mainly the duration and amount of the conditional payments and the way the savings component ${ }^{18}$ was designed.

\footnotetext{
${ }^{17}$ In 2012 the institutional structure of most of the offices that were responsible for conflict-related activities (and were not military) changed. This caused very large changes in the Program, which was placed under new direction and new institutional structure. Between end of 2011 and February 2014, 15,689 families entered the Program. From the 11 distant control municipalities that we included, two have been treated in this period of time. Most of the remaining families belong to municipalities that had already been treated in the past by the Program.

${ }^{18}$ The FGB Program wants its beneficiaries to save and has established different mechanisms to do so. First it was voluntary, then every beneficiary had to save in a group-account and in the last version the Program keeps part of their payments and gives them back when they agree on the productive investments that they want to make.
} 
Table 2.3: Phase-in of the Program in its initial seven waves

\begin{tabular}{cccccccc}
\hline $\begin{array}{c}\text { Program } \\
\text { wave }\end{array}$ & $\begin{array}{c}\text { Starting } \\
\text { year }\end{array}$ & $\begin{array}{c}\text { Depart- } \\
\text { ments }\end{array}$ & $\begin{array}{c}\text { Munici- } \\
\text { palities }\end{array}$ & Veredas & $\begin{array}{c}\text { New } \\
\text { municip }\end{array}$ & Families & $\begin{array}{c}\text { Mean } \\
\text { target index }\end{array}$ \\
\hline I & $2003-2004$ & 7 & 13 & 352 & 13 & 18,392 & 18.0 \\
II & $2005-2006$ & 13 & 34 & 709 & 26 & 17,832 & 20.0 \\
III & $2006-2007$ & 11 & 24 & 434 & 21 & 17,406 & 24.0 \\
IV & $2007-2008$ & 15 & 44 & 828 & 42 & 33,546 & 23.6 \\
V & 2008 & 10 & 25 & 763 & 19 & 19,743 & 24.6 \\
VI* & 2009 & 3 & 7 & 136 & 7 & 7,408 & 16 \\
VII & 2010 & 10 & 25 & 344 & 11 & 8,664 & 23.9 \\
\hline
\end{tabular}

Source: Forest Warden Families Program

*Wave VI was intended at those municipalities that had suffered greatly from heavy rains, and it operated in a different fashion. It intended to prevent the introduction of illegal crops when people were economically vulnerable.

The next question is whether the beneficiaries of the program, or the treated (TT) are comparable with the distant controls (DC). Table 2.4 presents the differences in key observables at an individual level between these groups before the program started, to avoid capturing program effects. We classified beneficiaries and distant controls by the priority the program had assigned each of their municipalities of receiving treatment (very high, high and low) based on the targeting index. Using this criteria, 57 percent of our sample is classified as very high priority, 35 percent into the high priority and 8.5 percent in the low priority category. We find that beneficiaries and distant controls that live in municipalities with a very high priority of being treated are very similar in those observable characteristics that could potentially affect norms of honesty, such as how much coca was present in their area before the Program started. Given differences in some socioeconomic variables, we make sure to control for them in the analysis. Even though the control group seems less poor than the treatment group, both groups are statistically the same when looking at who is above and below the poverty threshold (67 points in the livelihoods index), in which case both groups are considered mostly poor. Despite both groups having a majority of male-headed households, the treatment group has a lower proportion as the Program targets female-headed households.

With these results we estimate the impact of the Program for those that have the highest priority of being treated, as here the control group is the most comparable. Those in municipalities with a high priority are also comparable, although the distant controls seem to score one point above the treatments and are poor to a lesser extent. Those in low priority regions do not seem to be comparable. Given these results we base our analysis in the beneficiaries and non-beneficiaries that live in high priority municipalities to increase comparability. Since we are basing out comparisons on observable information, we added additional data that could also affect our results such as the municipality's fiscal performance as a way to measure the capacity of local authorities, and included distance to big cities. ${ }^{19}$ The inclusion of additional control variables

\footnotetext{
${ }^{19}$ We checked whether a household's poverty level might have played a role when determining program participation and confirm that PFGB is not targeting based on poverty, as appears in the program's guidelines. Therefore we don't match on this variable.
} 
also helps reduce intra-cluster correlation between people living in the same municipality. We use these variables as control variables in order to estimate the Program's impact.

Table 2.4: Differences in key variables for each group and treatment priority as defined by the Program

\begin{tabular}{lcccccc}
\hline & Very High & Very High & High & High & Low & Low \\
& TT & DC & TT & DC & TT & DC \\
\hline Targeting index & 32.33 & 32.24 & 19.38 & $20.60^{* * *}$ & 1.26 & 4 \\
& $(0.13)$ & $(0.11)$ & $(0.31)$ & $(0.08)$ & $(0.16)$ & \\
Not poor (ICV) 2009 & 0.14 & 0.17 & 0.20 & $0.12^{* *}$ & 0.10 & 0.15 \\
& $(0.01)$ & $(0.02)$ & $(0.03)$ & $(0.02)$ & $(0.03)$ & $(0.04)$ \\
Livelihoods index 2009 & 51.29 & $54.33^{* * *}$ & 54.57 & $51.91^{* *}$ & 49.75 & $54.80^{* *}$ \\
& $(0.47)$ & $(0.76)$ & $(0.98)$ & $(0.60)$ & $(1.24)$ & $(1.34)$ \\
Threat to the state* & 5.35 & 5.31 & 2.45 & 2.22 & 3.46 & $0.40^{* * *}$ \\
& $(0.03)$ & $(0.03)$ & $(0.14)$ & $(0.03)$ & $(0.21)$ & $(0.00)$ \\
Age of HH head & 44.65 & $49.12^{* * *}$ & 49.68 & 50.64 & 44.35 & $52.89^{* * *}$ \\
& $(0.55)$ & $(0.75)$ & $(1.03)$ & $(0.55)$ & $(1.63)$ & $(1.46)$ \\
Sex of HH head (male) & 0.73 & $0.83^{* * *}$ & 0.79 & $0.89 * * *$ & 0.59 & $0.94^{* * *}$ \\
& $(0.02)$ & $(0.02)$ & $(0.03)$ & $(0.01)$ & $(0.05)$ & $(0.03)$ \\
Coca before FGB* & 9180.49 & 8592.28 & 258.53 & 498.96 & $12993.71+$ & $(1513.19)$ \\
Observations & $(278.16)$ & $(180.17)$ & $(16.36)$ & $(6.61)$ & 113 & 83 \\
\hline
\end{tabular}

Note: Significance levels $* * * 0.01,{ }^{* *} 0.05$ and $* 0.1$.

*These variables are at the municipal level, for the municipalities where these people live.

+ There are only two municipalities in this category. One of them, San Jose del Guaviare, has historically had very high levels of coca, and this single point pushes the average to outstanding levels.

When we take the retrospective variables that described the households in 2009, one can estimate a probability of being treated based on individual characteristics in order to see how similar they are. Figure 2.1 shows the propensity scores for the whole sample (left) and for those that live in very high priority municipalities. If we take the whole sample there is enough common support in order to carry out comparisons, even though the distant controls are skewed towards the left. When we only take those that live in high priority municipalities, the distant controls are no longer skewed and the distribution among them is very similar. Given all the reasons mentioned, we feel confident that both municipalities and households coming from treated and non-treated areas are suitable for estimating the impact of the FGB Program on dishonesty, especially when we focus on those who live in high priority areas. 
Figure 2.1: Probability of being treated based on retrospective baseline variables (2009)

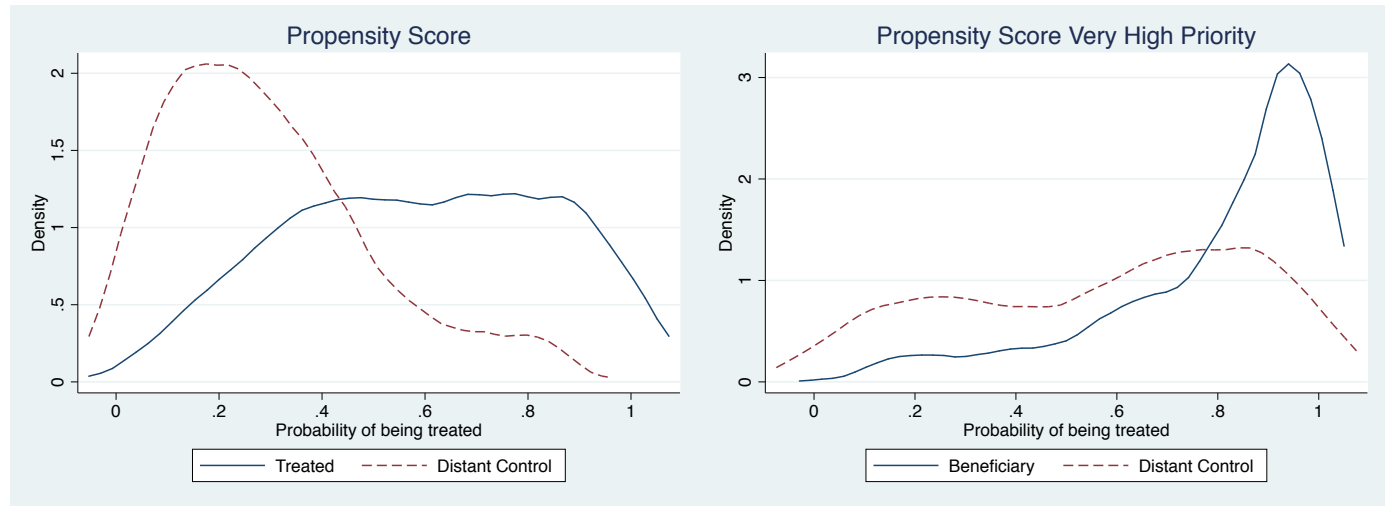

Experimental design and procedures

Our experimental design follows Fischbacher and Heusi (2008). Participants are asked to roll a six-sided fair die 10 times in private, and report what they got in each throw. The payment is estimated by summing the value reported over the ten throws and multiplying it by 100 . The maximum payments is 6000 (3 USD) or the equivalent of one third of a daily salary.

Decisions were made in private and did not depend on the decisions of other participants, since each survey took place in the person's house. ${ }^{20}$ Many of the places where the surveys were collected are dangerous and giving cash to the enumerators could have placed them in high risk. For this reason people were paid in cellphone minutes. Cellphone coverage in rural areas is high and has become very popular, even among farmers in distant regions. However, people buy the phone without a calling plan, and buy "calling minutes" whenever they have some extra cash. People could choose the company where they wanted to buy minutes from and gave their cellphone information to the enumerator who passed this information to Econometria, where some team members made sure that the minutes were delivered to the phone numbers given. They also implemented random monitoring of this delivery and made sure that people had received the amount promised. This payment in minutes was seen very positively by the people, as everyone wants to have minutes but can usually not afford them. If someone did not have a cellphone, they could send the minutes to the cellphone they usually used, owned typically by a spouse, parent, child, friend, etc.

This experimental structure does not allow us to identify individual lying, but lets us compare what people did with what is expected from throwing a fair six-sided die 10 times. In particular, we can compare whether people's answers differed from the expected mean of 3.5, whether each possible number was reported with its expected probability of $1 / 6(0.167)$ and if the obtained distribution follows the expected uniform distribution.

\footnotetext{
${ }^{20} \mathrm{We}$ asked the enumerator to turn around and move away from the respondent. Given the low schooling rates among our population, some people said they could not write. In this case, the enumerator clearly showed and explained each side of the die, and gave him the possibility to shout each roll to the enumerator to write down. In this case the enumerator would be far and facing an opposite direction, but would listen and write down each throw. This happened in very few cases, but allowed everyone to play.
} 
We embedded the experiment in the middle of the impact evaluation survey, right when the household section was finished and before the business/economic activity section started. They were told that since the survey was long, they deserved some time to relax, play a game and also have the chance to get some economic gain from their time, which depended only on their luck. This way they could not relate the experiment with a question on values or honesty. It was never mentioned that their answers would be checked, nor were they told that they should not cheat; they were simply allowed to play, no questions asked.

\section{Empirical strategy}

Main specification for impact estimation

To assess the impact of the Program we run an OLS regression for the following model: ${ }^{21}$

$$
\text { SumThrows }=\beta_{0}+\beta_{1} F G B_{i}+\beta_{2} \text { TargetIndex } i+\beta_{3} X_{i}+\varepsilon_{i}
$$

where, $F G B$ is the variable of interest and takes a value equal to one for beneficiaries of the program, TargetIndex is the index built by the Program and used to target program municipalities and $X$ includes additional variables such as sex of household head, distance to the closest urban cluster and fiscal performance of the municipality. We use the sampling weights defined by the impact evaluation where the strata are municipalities. Evidence of spillover effects from the treatments to their neighboring controls, and the comparability results shown in the identification section advised the use of the distant controls as the comparison group.

\section{Possible channels and interesting correlations}

We have two main channels that we want to test: moral reminders and justifications. Moral reminders appeared during the workshops, were people were reminded about the importance of adhering to the law and following the rules of the state. Justifications for growing coca are many, but the one that is most commonly heard is that without coca people will not make a living (poverty). In fact, participants were asked if they thought that people would work or start working again with coca and if so, why. More than half $(55 \%$, no difference between treatment and control) stated that people would work with coca, and out of those, the most cited reason for both groups was "because people need to get income for their families."

Since only the treatment group received moral reminders, we run the regression described in Eq. 4 with only FGB respondents, where we look at the effect of treatment intensity on dishonesty.

\footnotetext{
${ }^{21}$ As a robustness check we estimate the impact using propensity score matching with Abadie and Imbens' $(2006,2011,2012)$ methods for correct standard errors. This check is useful as it not only controls for the observable variables as OLS does including them in the propensity score, but additionally matches each beneficiary with a control that has the same probability of being treated. The common support assumption was presented in the identification strategy section. We double checked that the variables included in the Propensity Score Matching were actually the right ones to determine participation by estimating a boosted regression (Shonlau, 2005) that non-parametrically calculates the influence of each variable in determining participation. This analysis concludes that the secondary data variables have the highest influence in determining FGB treatment. We also set a caliper of 0.15 (half of the standard deviation of the propensity score) as the maximum distance between two observations to be matched, and prevents that observations that have very different propensity scores are matched. Results of this exercise can be seen in the Appendix.
} 
Attendance to the workshops is mandatory and not showing up can cause beneficiaries to stop receiving the monetary transfers. The Program hires local actors to carry out the workshops such as universities, NGOs and other types of organizations, who must follow a curriculum and teach specific topics, but who have freedom to decide how they teach and how to allocate the hours that they need to teach in total. In the end, everyone will have received the same intensity of treatment, but there could be differences in the intensity received at the point of the evaluation, as people where still being treated, or because some people entered the program at different moments. This exogenous variation of intensity of treatment allows us to interpret the relationship between program intensity and reported rolls as causal.

To test the poverty-dishonesty relationship we include the ICV index as a poverty measure in the regression. The livelihoods index (ICV in Spanish) is an index constructed by the Colombian government to capture multidimensional poverty which includes quality of housing, access to public utilities, education variables and household composition. The index ranges between 0 and 100, where 0 is absolute poverty and 100 is no poverty. The Constitutional Court has established a threshold of 67 to define who is poor and non-poor according to this measure.

We also want to test additional relationships, such as whether living in a place that has higher historical levels of coca relates to higher dishonesty, or if higher social capital prevents dishonesty. Even though we can't establish a causal link between honesty and poverty or illegality, a correlation is also of great interest. For comparison purposes we run the same regression for the control group (without treatment intensity) to see whether the relationships operate in a similar way. We estimate the following linear equation:

$$
\text { SumThrows }=\beta_{0}+\beta_{1} I_{i}+\beta_{2} I_{i}^{2}+\beta_{3} P_{i}+\beta_{4} P^{2}+\beta_{5} C_{i}+\beta_{6} S_{i}+\beta_{7} O_{i}+\varepsilon_{i}
$$

Where $I$ is the intensity of treatment measured in hours of workshops received, and captures the effect of one additional hour of exposure to workshops on dishonesty, with its squared term to to see if there are diminishing returns to the intervention or turning points; $P$ is the livelihoods index with its square term to capture non-linearities of poverty with dishonesty as suggested by Bjerk (2007), Muroi and Baumann (2009) and Hipp and Yates (2011). C contains variables related to violence, coca, and coca spraying strategies used by the government, $S$ contains variables regarding social capital, $O$ has additional control variables and $\varepsilon$ is an error term. These sets of variables aim to test the different possible hypotheses behind dishonesty that we discussed.

\section{Results}

This section presents the results of the study starting with an overview of who are the people sampled, followed by descriptive statistics of dishonesty patterns. We then show the results of the Program on dishonesty and finish with a model that explores the mechanisms that could have led to the impacts found. All results are discussed in section 7. 


\section{Descriptive results}

\section{Farmer's characteristics}

Survey and secondary data confirm that we are dealing with a population that has not been considered before in dishonesty studies; mainly poor, marginalized and mostly rural. Only $43 \%$ of our sample lives above poverty, $82 \%$ have at most primary schooling (22\% have no education whatsoever and $42 \%$ did not finish elementary school) and $82 \%$ live in dispersed rural areas. The average monthly per capita expenditure is approximately 66 USD. All municipalities where people live have had coca at some point since 2001; security wise $70.7 \%$ have been on average "red" zones and $25.5 \%$ yellow zones, as defined by the Ministry of Defense; in fact, $26.5 \%$ reported a violent calamity in the past 5 years. ${ }^{22}$

\section{Are people cheating?}

To answer this question we consider the proportion of times that each number was reported. Figure 2.2 presents the results and suggests that people are not truthfully reporting their throws. Higher numbers are more often reported than low numbers. Compared with the predicted probability of appearance (16.7 percent), the number one was less likely to be reported (14.5 percent of the throws) while the number six was more likely to be reported (19.2 percent of the throws).

Figure 2.2: Amount of rolls per possible number

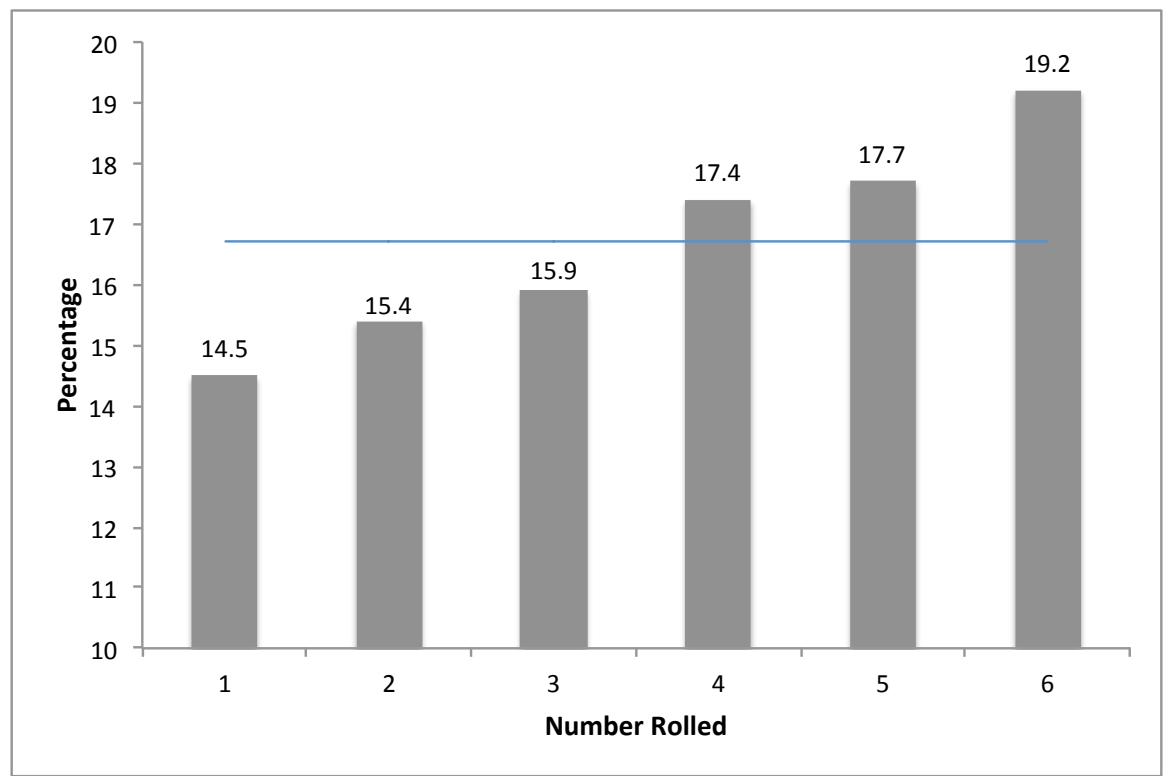

\footnotetext{
${ }^{22}$ Red zones have a serious insecurity problem that needs special resources and actions. Insecurity is measured by threats concerning: homicides, massacres, kidnappings, land mines, coca fields, presence of illegal armed groups, combats with armed groups and internal forced displacement. Yellow areas have some insecurity issues regarding some aspects and need to be monitored.
} 
An alternative approach to consider the degree of honesty in the game is to compare the predicted distribution (a normal distribution with mean=35) with the distribution of the total sum reported. Figure 2.3 presents this comparison. We find that the average value reported is significantly higher than the predicted mean value ( $\mathrm{t}$-test, $\mathrm{p}<0.1$ ). Moreover, we find that the Kolmogorov-Smirnof test rejects the equality of the reported distribution to what is expected from throwing a balanced die 10 times. However, even though the majority obtained a larger than expected sum, only a few seemed to cheat completely. These findings point to incomplete lying and conform with the theory of self-concept maintenance (Mazar et al., 2008).

Figure 2.3: Distribution of sum of throws

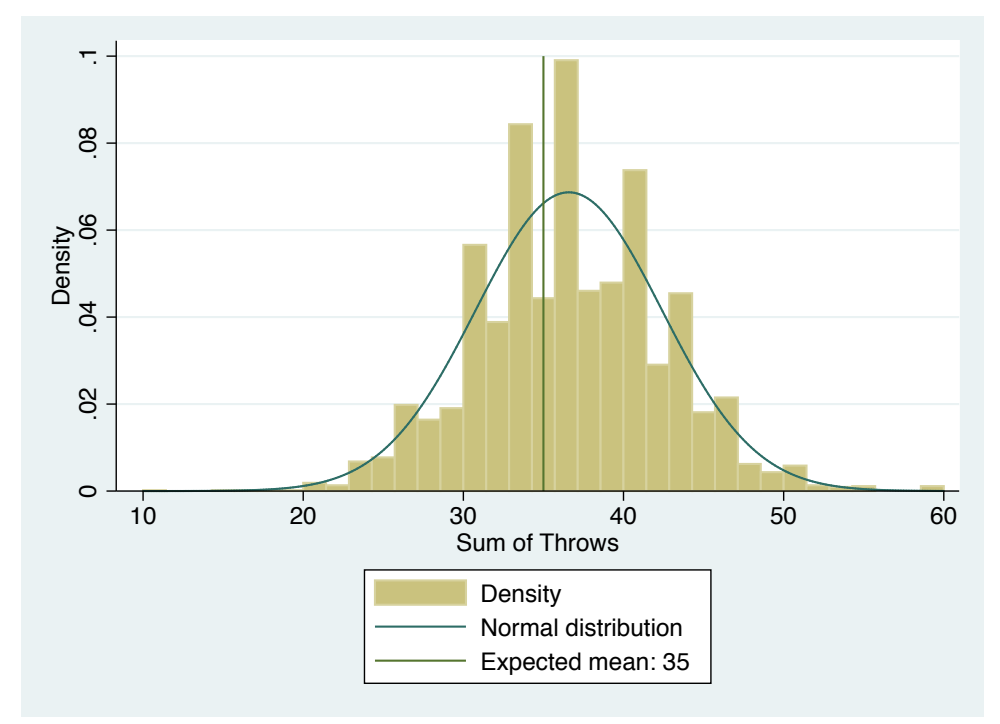

Are beneficiaries of FGB more honest?

We now focus our attention on differences between program beneficiaries and non-beneficiaries. Table 2.5 shows the proportion of times each number was reported for beneficiaries and distant controls. We find that dishonesty occurs for all groups and that a low number is less likely to be reported than a large number. However, the degree of dishonesty is relatively higher in the distant control group than in the beneficiary group. When considering the mean of the throws, FGB beneficiaries report on average 3.63 and distant controls 3.72 - all statistically different from the expected average of 3.5 (p-value of t-test 0.003 ). 
Table 2.5: Proportion of numbers reported per group

\begin{tabular}{lll}
\hline Rolled & FWF & Distant Control \\
\hline \hline 1 & $0.147^{* * *}$ & $0.141^{* * *}$ \\
2 & $0.157^{* * *}$ & $0.147^{* * *}$ \\
3 & 0.163 & $0.157^{* * *}$ \\
4 & 0.16 & $0.177^{* * *}$ \\
5 & $0.179^{* * *}$ & $0.181^{* * *}$ \\
6 & $0.187^{* * *}$ & $0.198^{* * *}$ \\
\hline
\end{tabular}

Note: Significantly different than the expected probability of each throw of $1 / 6(0.167)$ at $* * *$ $0.01,{ }^{* *} 0.05$ and ${ }^{*} 0.1$ levels

We tried to get closer to an individual measurement of dishonesty by comparing the distribution of throws for each individual to the expected uniform distribution and computing a KolmogorovSmirnof test with the exact p-value of their difference. ${ }^{23}$ This is a very demanding test as the whole distribution is taken into account and it must differ from the expected mean, thus we establish these results as a lower-boundary for cheating, since those that are cheating by a little, or only with some particular numbers would not come out as cheaters under this definition. Under this lower-bound approach we find that $8.3 \%$ of the beneficiaries and $11.9 \%$ of the distant controls most likely cheated, as there is a significant difference between the observed distribution of throws and the predicted distribution at a $95 \%$ level.

Dishonesty and the environment

We now explore the relationship between dishonesty and the environment people are exposed to; namely the amount of coca hectares in their municipality. Figure 2.4 presents the relation between number of coca hectares and the average reported die-rolls. We find that municipalities with higher exposure to illegality (more coca) also exhibit a higher reported die-roll average, suggesting a positive association between dishonesty and other forms of illegality. ${ }^{24}$

\footnotetext{
${ }^{23}$ We estimate the exact p-value to account for very few observations (10 per person).

${ }^{24}$ We only look at FGB beneficiaries to avoid possible uncontrolled endogeneity in descriptive results that don't yet include the observed rules that determine program participation.
} 
Figure 2.4: Reported throws and coca in municipality

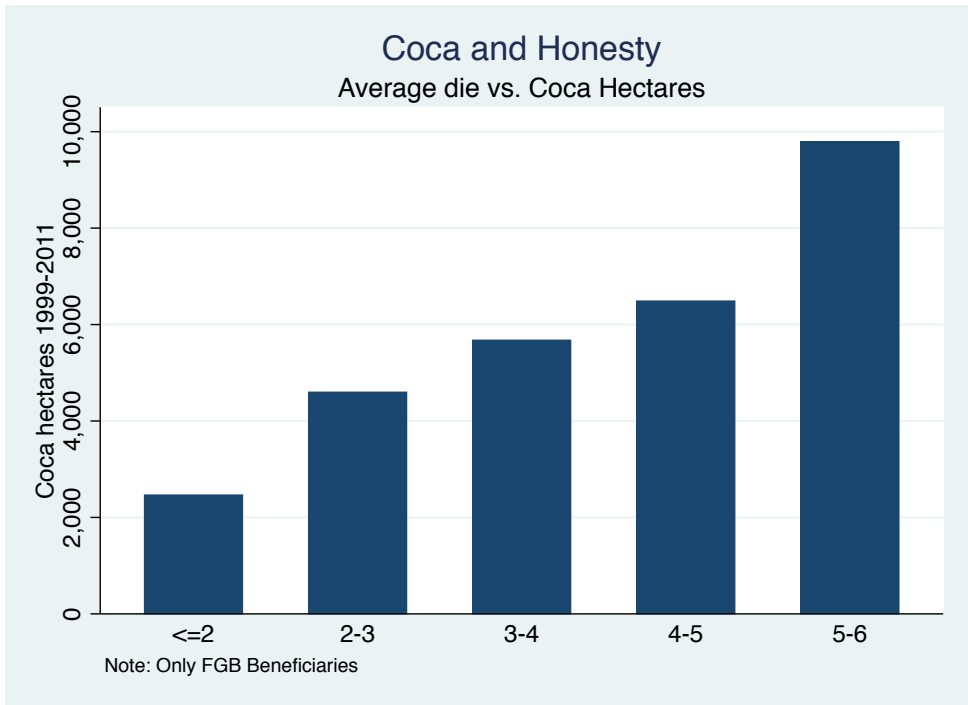

\section{Impact of the program on dishonesty}

Up to here we have only shown possible relationships and differences between groups, but we have not established any type of causality. The next results address possible endogeneity problems by controlling for variables that determine participation as well as for variables that were different at the beginning of the Program, and answer how large the impact of the FGB Program was, and what factors could be behind it.

Table 2.6 shows the impact of the Program on the reported sum of throws, our approximation of dishonesty. The first column presents the effect of the intervention, controlling for variables that determined selection into treatment. Since we are interested in the poverty channel and the Program gives money to its beneficiaries (giving rise to the question of welfare effects), we want to make sure that the effect of the program holds, once we control for the livelihoods index. We find that the Program lowered dishonesty by one unit of the sum of reported rolls, and by 1.2 units when poverty is included. ${ }^{25}$ Poverty itself also plays a significant non-linear role that we will discuss below. It is interesting to note that the program decreases dishonesty, while having a high chance of being prioritized by the targeting index has a positive relationship with dishonesty. In the next regressions we disaggregate the index by some of its components and try to see which of its elements might relate to higher dishonest behavior. What is important to note is that the program counteracts these factors and reduces dishonesty. We will discuss this finding in the next section.

\footnotetext{
${ }^{25}$ When we implement PSM as a robustness check, we find higher reducing effects of the Program of 1.8 units on the average (ATE) and 2.1 on the treated (ATT), for those who live in very high priority areas. We also find positive, but smaller impacts when we consider the whole sample of 1.4 (ATE) and 1.6 (ATT). See Tables A2.2 and A2.3 in the Appendix for results.
} 
Table 2.6: Impact of the Forest Warden Families Program on dishonesty

\begin{tabular}{|c|c|c|}
\hline Sum of Die Throws & (1) & $(2)$ \\
\hline FGB & $\begin{array}{c}-1.001^{* *} \\
(0.447)\end{array}$ & $\begin{array}{c}-1.150^{* * *} \\
(0.440)\end{array}$ \\
\hline Targeting Index & $\begin{array}{l}0.065 \\
(0.039)\end{array}$ & $\begin{array}{c}0.074^{*} \\
(0.039)\end{array}$ \\
\hline Gender: Male & $\begin{array}{c}-1.013^{* *} \\
(0.425)\end{array}$ & $\begin{array}{c}-1.072^{* *} \\
(0.425)\end{array}$ \\
\hline Distance to closest city $(\mathrm{x} 100 \mathrm{~km})$ & $\begin{array}{c}0.001 \\
(0.001)\end{array}$ & $\begin{array}{c}0.001 \\
(0.001)\end{array}$ \\
\hline Municipal fiscal performance & $\begin{array}{l}-0.044^{*} \\
(0.023)\end{array}$ & $\begin{array}{l}-0.041^{*} \\
(0.023)\end{array}$ \\
\hline Livelihoods Index baseline & & $\begin{array}{c}0.167^{* *} \\
(0.075)\end{array}$ \\
\hline Livelihoods Index squared & & $\begin{array}{c}-0.002^{* *} \\
(0.001)\end{array}$ \\
\hline Constant & $\begin{array}{c}37.867^{* * *} \\
(1.681)\end{array}$ & $\begin{array}{c}33.909^{* * * *} \\
(2.408)\end{array}$ \\
\hline Observations & 1284 & 1282 \\
\hline Num. Strata (municipalities) & 18 & 18 \\
\hline
\end{tabular}

\section{Interesting relationships and possible channels}

Table 2.7 shows regression results that relate to the total sum of die reports for beneficiaries and distant controls in terms of five different potential drivers: intensity of exposure to culture of legality workshops (only for the treated); livelihoods index (poverty); conflict, coca and violence (illegal environment); social capital, and other variables. The rich survey collected for the impact evaluation permits exploring each of these relations. We start with treatment intensity, as we want to know whether exposure to workshops that highlight topics such as social capital, associability and most importantly for us, culture of legality were behind changes in dishonesty. The program relies on local implementing actors who carry out the workshops and technical assistance and they decide how it should be executed, how many hours, which types of activities, etc. Since attending workshops is mandatory, variation in treatment intensity depends on the implementer and not on the beneficiaries' motivation to participate. ${ }^{26}$

\footnotetext{
${ }^{26}$ We looked at the correlation between treatment intensity and control variables and found no relation between treatment intensity and poverty, threat to the state (security), trust, land quality, age and sex of head of household. We found a statistically marginal correlation with being part of an association and with having received other programs from the State. These variables all enter as control variables in the regression for this reason.
} 
Table 2.7: Possible determinants of die reports (dishonesty)

\begin{tabular}{|c|c|c|c|}
\hline \multirow[b]{3}{*}{ Sum of Die Throws } & \multicolumn{2}{|c|}{ Treatment } & \multirow{3}{*}{$\frac{\text { Distant Control }}{(3)}$} \\
\hline & (1) & $(2)$ & \\
\hline & & & \\
\hline Livelihoods Index & $\begin{array}{c}0.19069^{* * *} \\
(0.0679)\end{array}$ & $\begin{array}{c}0.19304^{* * *} \\
(0.0677)\end{array}$ & $\begin{array}{c}0.04883 \\
(0.1408)\end{array}$ \\
\hline Livelihoods Index squared & $\begin{array}{c}-0.00160^{* * *} \\
(0.0006)\end{array}$ & $\begin{array}{c}-0.00163^{* * *} \\
(0.0006)\end{array}$ & $\begin{array}{c}-0.00087 \\
(0.0012)\end{array}$ \\
\hline Participation in social programs & $\begin{array}{r}-0.30350 \\
(0.4048)\end{array}$ & $\begin{array}{r}-0.34046 \\
(0.4050)\end{array}$ & $\begin{array}{l}1.09656 \\
(0.6743)\end{array}$ \\
\hline Coca in municipality (x100 hectares) & $\begin{array}{c}0.00568^{*} \\
(0.0029)\end{array}$ & $\begin{array}{c}0.00608^{* *} \\
(0.0030)\end{array}$ & $\begin{array}{c}0.02885^{* *} \\
(0.0134)\end{array}$ \\
\hline Spraying intensity & $\begin{array}{c}0.28664^{* * *} \\
(0.1052)\end{array}$ & $\begin{array}{c}0.29318^{* * *} \\
(0.1055)\end{array}$ & $\begin{array}{c}0.28161^{* *} \\
(0.1404)\end{array}$ \\
\hline Manual erradication intensity & $\begin{array}{r}-0.00212 \\
(0.0240)\end{array}$ & $\begin{array}{r}-0.00016 \\
(0.0238)\end{array}$ & $\begin{array}{c}1.83401^{* * * *} \\
(0.6000)\end{array}$ \\
\hline Productive association & $\begin{array}{c}0.31929 \\
(0.4018)\end{array}$ & $\begin{array}{l}0.25425 \\
(0.4030)\end{array}$ & $\begin{array}{c}-2.50458^{*} \\
(1.4180)\end{array}$ \\
\hline Threat to security & $\begin{array}{c}0.49503^{* * *} \\
(0.1589)\end{array}$ & $\begin{array}{c}0.50043^{* * *} \\
(0.1590)\end{array}$ & $\begin{array}{c}0.00000 \\
(.)\end{array}$ \\
\hline Trust in others & $\begin{array}{l}0.89297 \\
(0.6470)\end{array}$ & $\begin{array}{l}0.89958 \\
(0.6469)\end{array}$ & $\begin{array}{r}-0.55912 \\
(1.0627)\end{array}$ \\
\hline Christian household head & $\begin{array}{l}0.20672 \\
(0.4123)\end{array}$ & $\begin{array}{l}0.13426 \\
(0.4123)\end{array}$ & $\begin{array}{r}-0.64297 \\
(0.8239)\end{array}$ \\
\hline Age household head & $\begin{array}{c}-0.01125 \\
(0.0123)\end{array}$ & $\begin{array}{r}-0.01011 \\
(0.0124)\end{array}$ & $\begin{array}{r}-0.00360 \\
(0.0242)\end{array}$ \\
\hline Gender: Male & $\begin{array}{c}-0.95377^{* *} \\
(0.4325)\end{array}$ & $\begin{array}{c}-0.90023^{* *} \\
(0.4330)\end{array}$ & $\begin{array}{r}-1.41401 \\
(0.9552)\end{array}$ \\
\hline Intensity of training & & $\begin{array}{c}0.00851^{*} \\
(0.0043)\end{array}$ & \\
\hline Intensity of training squared & & $\begin{array}{c}-0.00001^{* * *} \\
(0.0000)\end{array}$ & \\
\hline Constant & $\begin{array}{c}27.79855^{* * *} \\
\quad(2.3528)\end{array}$ & $\begin{array}{c}27.40636^{* * *} \\
(2.3690)\end{array}$ & $\begin{array}{c}33.70429^{* * *} \\
\quad(4.8041)\end{array}$ \\
\hline Subpopulation Observations & 1077 & 1077 & 440 \\
\hline Num.Municipalities & 19 & 19 & 4 \\
\hline
\end{tabular}

We find an interesting non-linear significant effect of treatment intensity on dishonesty that can be better appreciated in Figure 2.5. The first hours of workshops do not make a difference; in fact, they could even increase dishonesty (a potential reason for this is discussed in the next section). However, as exposure increases, dishonesty decreases: at 350 hours of training (around 8 weeks) dishonesty starts decreasing and when people have received around 730 hours of workshops dishonesty is no longer observable, as people's total report equals the expected report of 35. From this point forward even smaller amounts are reported. We control for 
participation in other state programs, to make sure that the effect is coming from FGB's intervention and not from participation in other programs simultaneously or in the past.

Figure 2.5: Marginal effects of training intensity

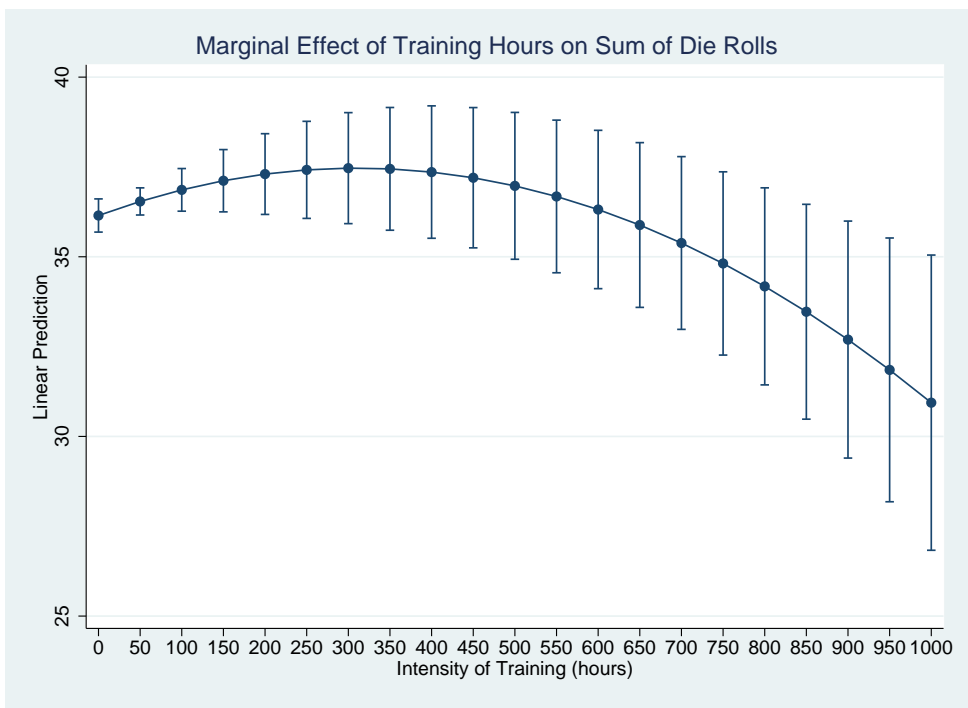

As we mentioned, the program is also generating a welfare effect, as its main treatment is giving people bimonthly payments conditional on farmers keeping their land (and the whole community) coca free. If cheating is mainly fueled by necessity, controlling for poverty might take away the significance of legality workshops. We find that poverty relates to dishonesty in a non-linear way. ${ }^{27}$ In fact, the sum of reported throws is at its peak when the farmers are at the threshold between being poor and non-poor with respect to their livelihoods index. When people cross this threshold, dishonesty starts decreasing. However, the poorest of the distribution are also the ones that cheat the least.

This relationship can be better observed in Figure 2.6, where it is clear that dishonesty starts to decrease as poverty reaches the poor/non-poor cutoff of 67 points. It is interesting to note that this relationship is only visible in the treatment group. In the distant controls, even though the signs are in the same direction, the relationship is insignificant. A very important result is that controlling for poverty does not affect the impact that treatment intensity has on dishonesty.

\footnotetext{
${ }^{27}$ We test a linear and cubic relationship between poverty and dishonesty and none are significant. This goes in line with the literature that has found a non-linear, positive-diminishing relationship between poverty and crime (Bjerk, 2007; Muroi and Baumann, 2009; Hipp and Yates, 2011).
} 
Figure 2.6: Marginal effects of poverty (only FGB)

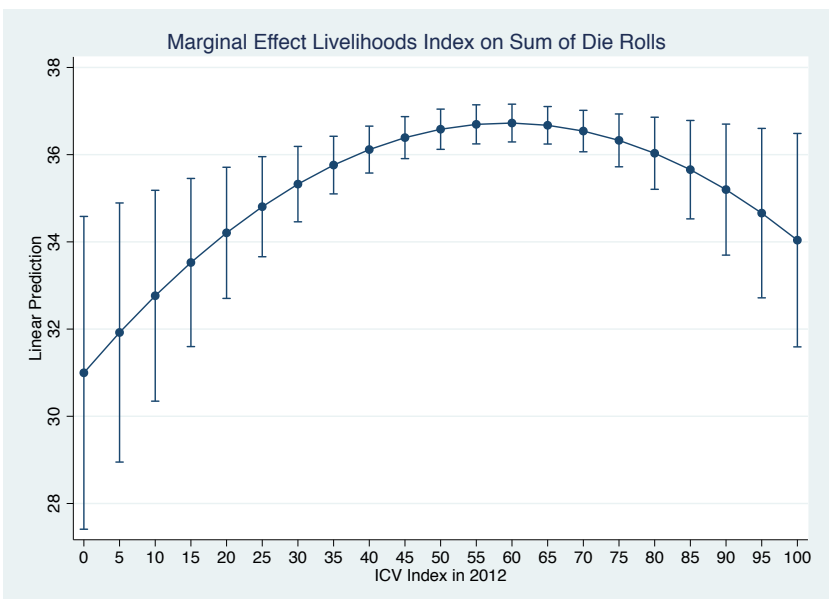

Next we explore how the type of environment people are exposed to relates to dishonesty. We have access to both secondary municipal data and self-reported survey data to tackle the conflict, violence and coca dimensions. ${ }^{28}$ We also look into the intensity of forced coca eradication, by calculating the amount of coca hectares sprayed over the amount of coca hectares in the municipality at the end of the previous year. ${ }^{29}$ We can not draw causality conclusions from this analysis, as we can not be sure people did not self-select into high coca and high violence areas. We have some evidence that the causality goes in the direction of the regression (coca generates dishonesty) as the average person has lived in their community for 29 years and the median for 27 years, which means that they arrived before the coca booming years of the 1990's and the early 2000's. Nonetheless we are cautious and don't claim causality in this relationship.

Interestingly, we find a positive and very strong relationship at $1 \%$ of significance between hectares of coca fields in the municipality and total die reports: higher amounts of coca in a municipality are related to higher reports (indicative of higher dishonesty), in both treatment and control groups. Living in the average coca exposure of 5449 hectares in coca regions relates to higher dishonesty in 0.33 units compared to those that live in a coca-free region, and living at the maximum exposure would increase cheating by 2.6 points, a big difference considering that the impact of the program reduces dishonesty by around 1.2 units. Since coca is an important component of the targeting index, this might be one of the reasons why, even after controlling for program participation, the targeting index positively relates with dishonesty. High aerial spraying intensity has a strong and positive correlation with dishonesty (controlling for coca hectares), and this effect is quite large: those living at the average spraying intensity already increase their dishonesty by 1.45 points, while those exposed to the maximum intensity would

\footnotetext{
${ }^{28}$ Coca is included in this topic given the close relationship between coca and armed conflict in Colombia.

${ }^{29}$ It is possible that in one municipality the same hectare was sprayed various times during the year due to replanting or the fact that people were able to protect their coca from the spray. In this sense, some municipalities experience much higher eradication intensity than others.
} 
report 13 more points. It is interesting to note that for FGB beneficiaries this relationship is only observed with aerial spraying and not with manual eradication, while for the control group manual eradication also increases dishonesty. In terms of violence we take the security index that captures military confrontations, attacks and other conflict-related variables and find that the higher the threat to security that a municipality poses, the higher is the reported sum of throws. If we use a sub-category of this index, threat to personal security, its effect goes up to 1.5 points. We stay with the overall index, which captures more aspects of security. ${ }^{30}$

None of the social capital and collective action variables seem to affect people's behavior in the die experiment. Whether people trust other community members does not have any effect and if they work as part of a producers' association also does not make a difference, except for the control group, where being part of an association is related to lower reported sum of throws.

We introduce personal variables such as age, gender and belonging to an evangelic church and find that only gender makes a difference: Respondents that come from households with male heads report lower total throws.

\section{Discussion}

We now discuss each of our hypotheses in light of the results. We first point out that our population behaves similarly to what other studies have found: people are cheating but not maximally. Even though it was perfectly possible to report a 6 in every single throw, only 6 people did this $(0.16 \%)$, and only $1.02 \%$ reported values that where always above 3 . However, these numbers are much lower than what others have found; for instance, in Fischbacher and Heusi's (2008) experiment, one fifth of their study subjects lie fully. However, differences in experimental design can lead to differences in the results. ${ }^{31}$ It seems that people tried to keep their self-concept of being an honest person by making sure that they also reported low numbers once in a while, but still tried to get a higher payoff by reporting higher paying numbers: a one was reported $14.5 \%$ of the times, while a 6 came up $19.2 \%$ of the throws. This conforms to all the studies mentioned in the literature review that find some sort of self-concept maintenance. Ariely (2013) calls this balancing act the process of rationalization which states that "as long as we cheat by only a little bit, we can benefit from cheating and still view ourselves as marvelous human beings."

Moreover, some evidence points to the fact that even though people cheated, this did not change their level of acceptance of unethical actions mentioned in the survey: most of them still find unethical behaviors unjustifiable and having cheated in the game does not make a difference. We did find acceptance of two unethical behaviors positively related to higher reported rolls, namely, taking energy without paying for it and not paying taxes. This could mean that

\footnotetext{
${ }^{30}$ In the highest priority distant control group this variable is dropped as it is highly collinear with manual and aerial eradication. Until alternative development is not in place in a municipality, eradication strategies differ.

${ }^{31}$ In their experiment people had to report only the first roll of the die. Also, in their case the highest paying number was 5 , because 6 was taken as a 0 .
} 
some people have a higher threshold before they feel that a behavior is wrong. Self-deception (Mazar and Ariely, 2006; Bazerman and Banaji, 2004) could play a role here, as people reframe an unethical act in a way that is not perceived to be wrong and in this way have a higher threshold before their internal mechanism that limits dishonesty is activated.

This tendency to cheat incompletely was common for both treatment and control groups, with one difference: treatments cheated more toward the extremes but reported middle values such as three and four in the expected way, while controls cheated always, and didn't report any value in the expected way. They switched from under-reporting all values equal or less than three, to over-reporting everything equal to or greater than four.

This brings us to whether the Program had any effect on cheating; we found that being part of FGB reduces dishonest behavior, especially for those who have had greater exposure to the workshops. The program does two things that might be behind these results: first, it offers workshops and technical assistance where culture of legality is emphasized, and second, it requires every community member and program beneficiary to sign a contract where they promise to keep their land free of coca (similar to signing the tax return form before filling it out). This can be looked at through the lens of the "moral reminder" studies already mentioned, since the program could trigger such reminders through both of these channels. Even when people receive technical assistance they are reminded that its aim is supporting the switch from illegal activities to legal products. Together with their pre-program promise to keep their land legal, ethical concerns are raised and continually made salient to program beneficiaries.

The legality workshops are also relevant for social norms, as they define what is acceptable or unacceptable (Kallgren et al. 2000). In fact, the literature points out that when social norms are perceived to be weak, social norms are less likely to be followed (Vetter et al., 2010). Frequent "morality cues" in the form of culture of legality workshops could develop into an internal social norm that embraces legality and leads community members to reward those who comply with the law and punishing those that go against it (Mazar and Ariely, 2006). The Program requires communities to form "surveillance groups" so that the community itself controls coca production in its territory; their success in achieving compliance with a coca-free land might rest in how well a social norm of legality is internalized (Campbell, 1964).

It is interesting to note that in the workshops legality is mentioned in terms of illegal activities and not in terms of cheating. Our results suggest that once morality is activated in one aspect, other aspects where it may play a role are also activated. As mentioned earlier, dishonesty spreads from one aspect to another. Our results suggest that the opposite is also true: once morality is improved in one domain (working in the legal sector), it can influence morality in other domains (not cheating).

Another point we want to discuss is the non-linearity of the intensity of treatment on dishonesty and the fact that only when people are exposed to high doses of intervention does their dishonesty decrease, while if they only receive small doses the intervention might even backfire and generate negative effects. One possible explanation is the relationship between team work and cheating, which has been found to increase dishonesty (Gino et al., 2013; Ariely 2013; Ploner 
and Regner, 2013). These experimental studies found that when people were put in groups where their acts of cheating also helped other group members, they cheated even more than when the benefit of cheating was individual. Dishonesty was higher even when supervision was present, but the group and supervisors knew each other and developed a relationship. It seems that working in groups and cheating on behalf of others helps people rationalize dishonest behavior and makes unethical actions seem less immoral. FGB operates in regions where social capital and trust have been hurt by armed conflict. The workshops also aim at strengthening social capital, associative work and community ties, thus bringing the community together. As social ties are restored, the possibility of collectively being dishonest also arises (for example, going back to coca and helping each other not getting caught). However, if the community is at the same time highly exposed to culture of legality workshops, and the moral standards of the community and its members are made salient, the possible negative effects of group collaboration might be counteracted, as we found.

The non-linear relationship between poverty and dishonesty is, as far as we know, new in the literature. We find that maximum die reports are found right before the poverty threshold is crossed, which points to the possibility that what motivates cheating is not poverty, but the distance to overcoming poverty. If one is too far from the threshold, cheating might not even appear to make any difference, but when crossing the threshold seems plausible, then an idea such as "the means justify the ends" might kick in. Despite not being able to claim causality of this result, the relationship could be indicative of possible indirect effects of the Program in reducing dishonesty, which could be further studied. In particular, if the cash transfers farmers receive and the alternative crops work in favor of overcoming poverty, then dishonesty is also further reduced. This result goes in the same direction as that of crime and poverty, where poverty has a positive but diminishing relationship with crime.

Living in an area where coca is highly present also relates to honesty in a negative way. The fact that coca cultivation is acceptable in these regions could easily lead to a social norm of tolerance to working with illegal crops. ${ }^{32}$ Ariely (2013) states that when the social norms that define which behaviors are appropriate or not are not very clear, what others do becomes a clear signal of what is right or wrong. Gino et al. (2009) find that cheating can increase by observing the bad behavior of others, especially when people feel that they belong to the same group. Thus, if someone in a distant rural area sees others start working with coca and profit from it, he could quickly think that this behavior is not wrong because others are doing it, and can rationalize engaging in coca growing much easier. If we add to this what we discussed earlier of immorality spreading from one aspect of life to another, illegality in economic activities could spread into general cheating or dishonesty. Following the logic of the Broken Windows theory (Wilson and Kelling, 1982) and of the neighborhood effects literature, when people see others not conforming to a norm of legality, they are less likely to follow it, and create a vicious circle of illegality.

\footnotetext{
${ }^{32}$ As we cannot argue causality, it is possible that areas where tolerance to illegality is high attracts people that are less willing to follow the law. This relationship is also problematic. Once people self-select into high illegality areas, social norms of legality are even harder to arise.
} 
The very strong and positive relationship between dishonesty and the state's primary antinarcotics strategy, aerial spraying, calls for attention. Even though FGB is a voluntary eradication Program, beneficiaries have been exposed to forced eradication (aerial spraying and/or manual eradication) in many ways. Before entering the program they could have been targeted by a spraying campaign and been themselves sprayed; after entering the program they could have been exposed by miscalculation of a pilot spraying neighboring areas, by hearing stories about their non-beneficiary neighbors being sprayed, or by seeing spraying planes fly above them. Presence of spraying airplanes and how often they are seen are a sign to the locals of how strong the state's spraying policy is in the area, even if they are not themselves sprayed on. Since we have aerial spraying information at the municipal level and not the community level, ${ }^{33}$ we can only test the relationship between dishonesty and living in a municipality that has endured a given amount of eradication intensity. High aerial spraying disproportionality could signal a battle between the state and the population, as the latter actively seeks to undermine the government's eradication efforts by re-cultivating coca and defending their coca fields, and the former insists on spraying whenever the coca reappears. Why people so strongly defend coca in these areas is not clear; it is possible that some communities have even higher tolerance for illegal activities, which correlates with an overall higher threshold for unethical behavior and leads to the relationship found. It could also be that farmers view any other agricultural activity as unfeasible because of a lack of roads and infrastructure and see their livelihoods attacked, in which case the poverty channel could play a role. Moreover, many of these communities have had high presence of illegal actors for longer periods of time, where they, and not the State have been the ones in charge of day-to-day order and where the rule of force, rather than the rule of law has been followed. In fact, the positive relationship between security threat and dishonesty could mean that people's overall moral compass might be damaged from exposure to events that constantly violate the rule of law along with human rights, and to environments where violent and illegal acts are normal.

This result calls for caution when using forced eradication, especially aerial spraying, as the main mechanism for eradication: the reduction of coca per se that results from high eradication disproportionality might not lead to sustainable results in the long term, as people might feel alienated from the state, and thus could tend to oppose the rule of law in the future. This creates a situation that can very likely hamper people's moral compass and is very well described in Vanda Felbab-Brown's studies on counterinsurgency and the war on drugs: very strong forced eradication programs directly attack the livelihoods of marginalized farmers who, alienated from the state, seek protection by illegal armed groups and even favor them. She states that without "winning the hearts and minds" of farmers, eradication efforts and even counterinsurgency efforts will be in vain. It is interesting to see that this increase in dishonesty is not statistically significant with manual eradication in the treatment group, but it is in the control group. Aerial spraying might be perceived as unjust by the population, as it affects not only coca plantations but also legal crops, and it often also falls on people who do not have coca but are close to

\footnotetext{
${ }^{33}$ We talked directly to the anti-narcotics police who have this data and tried very hard to get it but it was not possible.
} 
coca plantations. ${ }^{34}$ For the control group, without being given alternatives to coca, manual eradication would be seen in a similar light to aerial spraying. This reassures the argument that the rise in dishonesty comes from a loss of legitimacy of the state that could trigger anti-rule of law behaviors.

The only personal characteristic negatively correlated with dishonesty is having a male head of household. Other studies have found results in three directions: some find that women cheat more than men (Fosgaaard, 2013), others quite the opposite (Azar et al., 2013; Vetter et al. 2010; Bucciol et al., 2013) and others find no effect at all (Childs, 2012). As Childs (2012) states, gender differences could be country or culture-specific and until now it is not clear why one gender would cheat more than the other.

Finally we would like to point out some limitations and drawbacks of our study. One possible drawback is the inability to measure individual cheating; however, the workshop interventions are aimed at the whole community and powerful conclusions can be drawn at this level, making this drawback less crucial.

An additional limitation is the inability to establish a causal link between the dishonesty found in the experiment and present or future engagement with coca crops. We found that only $7.3 \%$ of the beneficiaries believe that people from the community would grow coca in the next six months compared to $16.7 \%$ of the distant controls and $13.7 \%$ of the neighboring controls. We would need individual follow-up measures that capture coca fields at the community level to confirm the link between honesty and coca-free communities. Despite this limitation, we take a look at the other side of the coin, the relationship between dishonesty and legal crops (see Table A2.4 in the Appendix), and find that those who reported higher throws in the experiment use lower percentages of their land for legal agricultural purposes, even after controlling for land size and other variables. Even though this is no proof of causality nor of long-term sustainability, it does show that general honesty is linked with legal productive decisions in the short run.

This study also leaves an interesting door open for future research concerning the open question of why dishonesty levels in our experiment, both for the treatment and control groups, are so much lower than those reported in other experiments in developed countries in urban settings. One first step would be to run this same experiment within Colombia in urban and rural settings and a much wider variation of poverty and exposure to violence, after tackling the challenge of the endogeneity caused by self-selection into coca growing areas, urban areas, etc. This would shed some light on whether systematically cheating is lower in rural areas, where family ties and social capital tend to be stronger.

\section{Conclusions}

We study the impact on dishonesty of an alternative development program targeted to coca growing regions in Colombia where the rule of law is low and a culture of illegality is the

\footnotetext{
${ }^{34}$ Chapter 1 studies the relationship between spraying disproportionality and legal crops and finds that very disproportionate spraying campaigns crowd out legal activities.
} 
norm. Through a dishonesty experiment we found that the Forest Guarding Families Program's intervention that emphasizes culture of legality significantly reduces cheating. This suggests a spillover from voluntary eradication efforts to more general realms of people's morality, reflected in more honest communities.

We find that high intensity aerial eradication efforts could backfire into even more dishonest communities with higher thresholds for illegal behavior if not accompanied by support to the communities, preventing their alienation from the state. This has very strong implications on the effectiveness of policies that want to change norms of compliance with the law, especially in areas where illegality is the norm. Once moral reminders are systematically introduced in people's lives, moral standards change and with them the internal personal threshold that decides what an unacceptable behavior is. The reduction in dishonesty we observe could be an indicator of changing social norms towards unethical behavior as a whole and can potentially derive in more honest communities that are willing to try harder on the side of legality before they cross over to illegality once again. The support of the state to ensure that communities remain strong in this path is crucial, making post-eradication efforts key at this point.

The program recognizes that economic incentives also play an important role in people's decision to work with coca and for this reason gives conditional cash transfers to its beneficiaries for a limited amount of time. It also understands that if people's moral compass is not altered, as soon as the cash disappears, coca will return. The intervention is able to alter this moral compass in two complementary ways: first, by giving cash it removes the possibility people have to rationalize illegality with a survival argument (if I don't grow coca I can't feed my family); second, by exposing beneficiaries to culture of legality workshops, moral reminders trigger people's awareness of their own morality and help create a social norm of what is acceptable or not. The big question is whether, after the first part of the intervention disappears, the second will be strong enough to keep people away from illegality. A more pressing question is whether the social norms that evolve from exposure to the program will be strong enough to achieve sustainable coca reductions in the future. 


\section{Appendix}

Table A2.1: Explanation of program presence based on targeting index variables

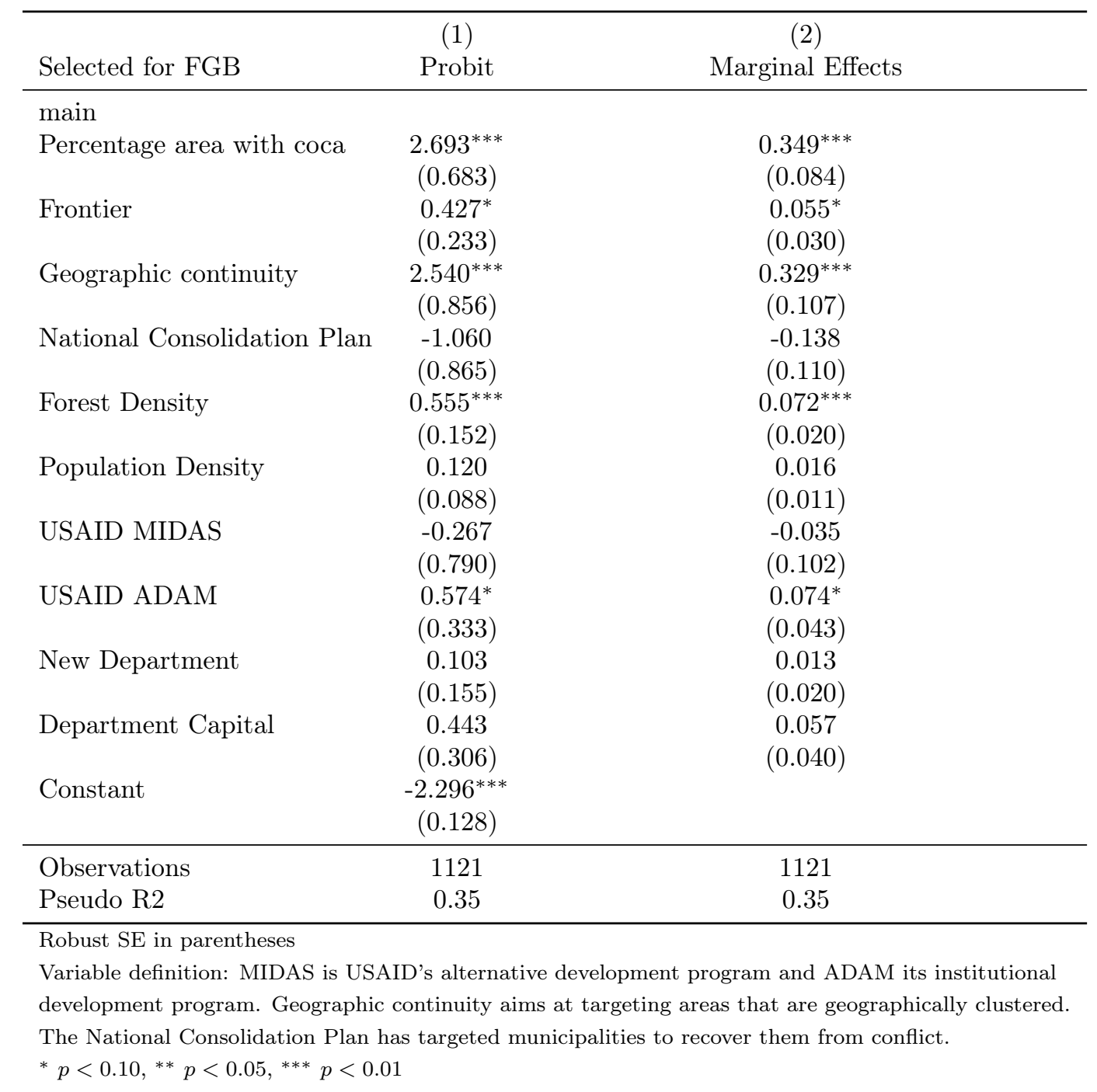


Table A2.2: Propensity score estimation using individual and municipal level variables for PSM results

\begin{tabular}{|c|c|c|}
\hline Probability of being treated & $\begin{array}{c}(1) \\
\text { All sample }\end{array}$ & $\begin{array}{c}(2) \\
\text { High Priority }\end{array}$ \\
\hline \multicolumn{3}{|l|}{ tratpuro } \\
\hline \multicolumn{3}{|l|}{ HH Level } \\
\hline Livelihoods index 2009 & $\begin{array}{l}-0.00096 \\
(0.00547)\end{array}$ & $\begin{array}{l}-0.00860 \\
(0.00581)\end{array}$ \\
\hline Gender: Male & $\begin{array}{c}-0.40749^{* * *} \\
(0.09859)\end{array}$ & $\begin{array}{c}-0.31948^{* *} \\
(0.14619)\end{array}$ \\
\hline Age of HH head & $\begin{array}{c}-0.00961^{* * *} \\
(0.00216)\end{array}$ & $\begin{array}{c}-0.01037^{* * *} \\
(0.00226)\end{array}$ \\
\hline Food security & $\begin{array}{l}-0.10765 \\
(0.10495)\end{array}$ & $\begin{array}{l}-0.15411 \\
(0.14629)\end{array}$ \\
\hline Num. people in HH 2009 & $\begin{array}{c}0.18036^{* * *} \\
(0.02862)\end{array}$ & $\begin{array}{c}0.13897^{* * *} \\
(0.02338)\end{array}$ \\
\hline Targeting index & $\begin{array}{l}-0.46454 \\
(0.38102)\end{array}$ & $\begin{array}{l}-0.67935 \\
(1.15181)\end{array}$ \\
\hline Targeting index squared & $\begin{array}{c}0.00774 \\
(0.00618)\end{array}$ & $\begin{array}{c}0.00988 \\
(0.01655)\end{array}$ \\
\hline Municipality Level & & \\
\hline Threat to the state & $\begin{array}{c}0.15498 \\
(0.17215)\end{array}$ & $\begin{array}{c}0.13353 \\
(0.28921)\end{array}$ \\
\hline Coca in municipality & $\begin{array}{c}0.00008 \\
(0.00009)\end{array}$ & $\begin{array}{c}0.00006 \\
(0.00007)\end{array}$ \\
\hline Distance to closest city & $\begin{array}{c}0.00000 \\
(0.00001)\end{array}$ & $\begin{array}{l}0.00003^{* *} \\
(0.00001)\end{array}$ \\
\hline Municipal fiscal performance & $\begin{array}{c}0.01743 \\
(0.05077)\end{array}$ & $\begin{array}{c}0.06677 \\
(0.05634)\end{array}$ \\
\hline Constant & $\begin{array}{c}5.46140 \\
(6.57493)\end{array}$ & $\begin{array}{c}6.55457 \\
(18.53563)\end{array}$ \\
\hline Observations & 2117 & 1281 \\
\hline Num. Strata (municipalities) & 29 & 18 \\
\hline Pseudo R2 & 0.17 & 0.32 \\
\hline
\end{tabular}

Table A2.3: Impact results from PSM analysis

\begin{tabular}{lcc}
\hline & All & Very high priority \\
\hline \multirow{2}{*}{ Average Treatment Effect (ATE) } & $-1.36^{* *}$ & $-1.82^{* *}$ \\
& $(0.58)$ & $(0.78)$ \\
Average Treatment on the Treated (ATT) & $-1.61^{*}$ & $-2.09^{*}$ \\
& $(0.89)$ & $(1.11)$ \\
\hline
\end{tabular}

Significance level: $\mathrm{p}<0.01^{* * *}, \mathrm{p}<0.05^{* *}, \mathrm{p}<0.1^{*}$. Abadie and Imbens robust standard errors in parentheses. 
Table A2.4: Legal production and dishonesty

\begin{tabular}{|c|c|}
\hline Percentage of land under legal production & $\begin{array}{c}(1) \\
\text { OLS }\end{array}$ \\
\hline Sum of Throws & $\begin{array}{c}-0.303^{* *} \\
(0.154)\end{array}$ \\
\hline Beneficiaries & $\begin{array}{l}4.606^{* *} \\
(1.938)\end{array}$ \\
\hline High priority & $\begin{array}{l}-1.668 \\
(2.206)\end{array}$ \\
\hline Low priority & $\begin{array}{c}9.937^{* * *} \\
(3.631)\end{array}$ \\
\hline Farm area & $\begin{array}{c}-0.029^{* *} \\
(0.014)\end{array}$ \\
\hline Perc. land with title & $\begin{array}{l}-0.013 \\
(0.021)\end{array}$ \\
\hline Land perceived of good quality & $\begin{array}{l}3.704^{* *} \\
(1.796)\end{array}$ \\
\hline Access to farm by paved road & $\begin{array}{c}2.789 \\
(1.897)\end{array}$ \\
\hline Belongs to productive association & $\begin{array}{l}2.829 \\
(2.408)\end{array}$ \\
\hline Time living in community & $\begin{array}{c}0.019 \\
(0.047)\end{array}$ \\
\hline Age of HH head & $\begin{array}{c}-0.115^{*} \\
(0.069)\end{array}$ \\
\hline Livelihoods index & $\begin{array}{c}0.267^{* * *} \\
(0.072)\end{array}$ \\
\hline Num. people working in $\mathrm{HH}$ & $\begin{array}{l}-0.970 \\
(1.058)\end{array}$ \\
\hline Gender: Male & $\begin{array}{c}-5.298^{* *} \\
(2.121)\end{array}$ \\
\hline Coca in municipality & $\begin{array}{c}-0.001^{* * *} \\
(0.000)\end{array}$ \\
\hline Participates in social program & $\begin{array}{c}0.565 \\
(1.868)\end{array}$ \\
\hline Threat to the state & $\begin{array}{l}-0.322 \\
(0.488)\end{array}$ \\
\hline Num. people in HH 2009 & $\begin{array}{c}0.770 \\
(1.161)\end{array}$ \\
\hline Distance to closest city & $\begin{array}{c}-0.000^{* *} \\
(0.000)\end{array}$ \\
\hline Municipal fiscal performance & $\begin{array}{l}-0.155 \\
(0.141)\end{array}$ \\
\hline Constant & $\begin{array}{c}85.653^{* * * *} \\
(12.083)\end{array}$ \\
\hline Observations & 1801 \\
\hline Num. Strata (municipalities) & 29 \\
\hline $\mathrm{R} 2$ & 0.10 \\
\hline
\end{tabular}




\title{
4. Can we fight drugs using communication campaigns? A framed field experiment in Colombia ${ }^{\dagger}$
}

\begin{abstract}
Economic behavior is shaped not only by economic incentives but also by normative factors. Hence, a promising alternative to reduce crime is the use of persuasive communication. This paper uses a field experiment to test the effect of persuasive messages as a strategy in the fight against drugs in Colombia. Our design varies the salience and the degree of informativeness of the messages that participants receive, while highlighting particular negative effects of growing coca in the community. We find that messages that make the relation of coca cultivation with violence salient are the most effective at reducing coca investments. Our results suggest that the main mechanism at play is attitudinal change rather than a change in beliefs. Interestingly, we find that exposure during the experiment to persuasive messages translates into lower intentions to cultivate coca in the future. We conclude that interventions that aim at increasing "awareness" of the negative effects that coca has in the community are a promising policy instrument in the fight against drugs.
\end{abstract}

JEL codes: A13, G11, D03, D83, K42, Z13

Keywords: Field experiment, attitudinal change, communication campaigns, illegal behavior.

\footnotetext{
${ }^{\dagger}$ Joint work with Marcela Ibanez. This study was financed by the Courant Research Center for Poverty, Equity and Growth, University of Göttingen and the German Science Foundation under the Grant RTG1723.
} 


\section{Introduction}

Extensive empirical evidence supports monetary incentives as an instrument to deter crime (Andreoni et al., 1998; Cameron, 1988). However, there is relatively little evidence on how normative factors can be "triggered" to affect behavior. In this paper we investigate the efficiency of persuasive messages as a strategy to reduce crime.

The context of our analysis is the war on drugs in Colombia, the largest supplier of cocaine to the US and European markets. In response to the drug problem, Colombia has engaged in an aggressive campaign to eradicate illegal crops. Although 1.1\% of the annual GDP was invested annually in the military component of the fight against drugs between 2000 and 2008 (Mejia et al., 2013), the results of this policy are rather disappointing (Ibanez, 2013; Rozo, 2013; Mejía et al., 2013). In this context, it seems necessary to identify alternative policy instruments to decrease the supply of illicit drugs.

Empirical evidence suggests that in areas with coca crops, the number of violent deaths among the young male population is higher than in comparable areas (Angrist and Kugler, 2008). Mejia and Restrepo (2013) find that a 10\% increase in the price of coca is associated with a $1.25 \%$ increase in homicides, a $3 \%$ increase in displacement, a $2 \%$ increase in attacks by insurgent groups and a $1 \%$ increase in incidents involving land mine explosions. ${ }^{1}$ Besides, the production and processing of coca is associated with negative effects on the environment (UNODC, 2006; Davalos et al., 2011). It is estimated that between 2001 and 2013, 275,588 hectares of forest were cut down in Colombia exclusively to grow coca (UNODC, 2014), and Rincón-Ruiz and Kallis (2013) estimate that between 2001 and 2008 about 110 thousand hectares of primary forests were cleared to establish coca fields. Additionally, large amounts of agrochemicals are used in the cultivation and processing of coca base. Bernal (2007) reports 28 different types of pesticides used to protect the leaves, and estimates that about 2.7 liters of herbicides are used annually. The transformation of the leaf to coca paste also generates pollution. The gasoline, sulfuric acid, ammoniac and other chemicals used to producer one kilo of coca paste are freely disposed in the environment, contaminating water sources.

Normative and moral factors seem to be important in explaining coca growing decisions in Colombia. Ibanez (2010) finds that producers belonging to protestant groups, producers with higher degrees of moral development and those that have higher trust in state institutions are less likely to grow coca. This finding suggests that an alternative policy instrument in the fight against drugs could be persuasive communication.

Highlighting the negative consequences of illicit drug production seems to be a sensitive approach to persuade illicit crop producers to voluntarily abandon them, but would this policy work? Which type of messages would be more effective in persuading producers? Who would be persuaded by these messages? What would be the mechanisms to explain such behavioral change?

\footnotetext{
${ }^{1}$ Similar estimations are provided by Botero Degiovanni (2013).
} 
To test the effect of persuasive communication messages on illegal crop cultivation we conducted a framed field experiment with farmers living in Putumayo, a region with one of the longest coca cultivation traditions in the world. Mimicking coca cultivation decisions, participants have to decide how to allocate an endowment between more profitable but risky coca cultivation and a secure but low-return legal product. Spelling out the negative effects of coca as deforestation, pollution, increased violence and school dropout, we allow investments in coca to generate negative externalities. Our experimental design uses four different frames to highlight various negative consequences of coca cultivation. One of our frames considers the environmental consequences that coca cultivation generates as deforestation, pollution and health problems. Two frames consider the effects on violence such as increased presence of illicit armed groups, more insecurity and domestic violence. Yet one of the frames is only descriptive while the other provides quantitative information. The last frame considers the negative effects on values (easy money, no respect for others). The different degrees of informativeness and salience of the frames allow us to explore the potential channels driving investment decisions. Moreover, using a post-experimental survey we test whether making the negative consequences of coca salient influences the opinions and attitudes of farmers toward coca cultivation and the intention to cultivate coca in the future.

We find that communication messages are effective in changing investment decisions, generating changes in people's attitudes and altering the intentions to cultivate coca in the future. Particularly, we find that messages that communicate the violence that coca generates are the most effective in reducing farmers' willingness to invest in coca.

This paper contributes to different areas of research. The first strand is the economic analysis of persuasion. Economic models of persuasion consider that a sender provides a message with the potential interest of changing the receiver's behavior. According to these models, persuasive communication can explain behavioral change due to belief formation or preference changes. Persuasive messages can convey new information that is used by rational Bayesian receivers to update beliefs (Stigler, 1961 and Tesler, 1964). ${ }^{2}$ Persuasion messages can also help as a signal (Nelson, 1970) or alternatively, can help to affect behavior of non-perfect rational agents who have attention deficits and over-react to more salient messages (Karlan et al., 2010). Persuasion messages can trigger categorical thinkers to change behavior even when the messages are uninformative (Mullainathan et al., 2008). A second channel by which persuasion can affect beliefs is by affecting preferences. We build on these theoretical models and empirically investigate different mechanisms that lead to behavioral change.

There is extensive empirical research on the effectiveness of persuasive communication to increase desirable behaviors such as inter-group prejudice and conflict, racial prejudice, use of contraceptives, HIV prevention, saving for the old age, loan take-up, obesity and recycling, among others (Paluck, 2009; Paluck and Green, 2009; DellaVigna et al., 2012; Kellstedt, 2000; Mesina, 2005; Palmgreen et al., 2008; Karlan et al., 2010; Choi et al., 2012; Bertrand, 2009;

\footnotetext{
${ }^{2}$ Sophisticated receivers can take into account strategic motives of the persuader leading to persuasion games (Milgron and Roberts, 1986) in which the sender tries to develop an optimal persuasion strategy (Kamerica and Gentzkow, 2011). Alternatively, the receiver could neglect the incentives of the sender (Eyster and Rabin, 2009).
} 
Carlson, 2001; Burn and Oskamp, 1986; Chong et al., 2013). Also recent papers have considered the use of persuasive communication to increase political participation and shape political attitudes and attitudes towards candidates (Gerber et al., 2008; Gerber et al., 2009; Oberholzer-Gee and Waldfogel, 2009; DellaVigna and Kaplan, 2007; DellaVigna and Gentzkow, 2009; Gentzkow and Shapiro, 2010; Gamson, 1992; Nelson et al., 1997; Wood, 2000). While most of these studies find that communication leads to behavioral change, they do not investigate the effect of communication campaigns on law compliance as we do in this paper.

The second strand to which we contribute is the economic models of law compliance. There is a relatively long tradition in economics trying to understand why individuals comply with the law. Empirical literature largely supports the predictions of Becker's (1968) economic model of crime (Cameron, 1988; Freeman, 1999; Witte and Witt, 2000; Levitt, 2004). However, the standard model of crime fails to explain why compliance rates are so high: people report taxes correctly and pay TV licenses even if the benefits from breaking the law are positive (Andreoni, 1998; Fellner et al., 2013). To account for this anomaly, behavioral economic models of crime recognize that economic behavior is not only driven by economic incentives but also depends on normative factors. First, individuals have an internal sense of what is right and wrong and deviating from this standard generates a feeling of internal disappointment or guilt (Etzioni, 1986; Sen, 1986; Vanberg, 1988). Second, individuals have a sense of respect towards authorities and the law, which generates a moral obligation to comply (Tyler, 1990). Lastly, individuals respond to the pressure of the social environment and follow the social code on what is accepted out of fear of being stigmatized (Elster, 1989; Axelrod, 1986; Akerlof and Yellen, 1986). We contribute to this research by investigating whether it is possible to persuade individuals to comply with the law by using non-monetary interventions that aim at triggering normative factors.

The third strand of literature to which we contribute is on moral suasion. Moral suasion is defined as a persuasive tactic used by an authority to influence agents to adhere to a policy. Moral suasion has been used as a strategy to increase tax compliance, with mixed results. In early field experiments, Schwartz and Orleans (1967), McGraw and Scholz (1991) and more recently Hasseldine et al. (2007) find that using moral appeals increased reported tax. Yet, other field experiments have not found significant effects (Blumenthal et al., 2001; Fellner et al., 2013). Moral suasion has however been effective in decreasing late book returns in the public library of Barcelona (Apesteguia et al., 2013) and increasing honesty in payments for newspapers sold in unguarded newspaper boxes (Pruckner and Sausgruber, 2013). We contribute to this research by investigating in the field-lab the effectiveness of persuasive communication on coca investments, and by investigating the mechanisms that lead to behavioral change. Similarly as DalBo and DalBo (2013), we use a lab experiment in the field to investigate how information frames affect beliefs and attitudes, yet we focus on law compliance, whereas they focus of voluntary contributions to a public good.

Our intervention differs from previous work in many dimensions. First, unlike previous interventions we do not use explicit normative appeals. Instead of telling participants what the 
"correct" behavior is, we provide participants with an example on the social consequences of investing in coca (an illegal activity). Second, while previous papers point at the positive effects of law compliance, we look at the negative effects of breaking the law. Consistent with prospect theory (Kahneman and Tversky, 1979) aversion to losses is expected to play a larger role and hence, persuasive messages that emphasize losses are expected to have larger behavioral effects. Third, our intervention does not consider social interaction effects and we do not refer to the behavior of others. Instead, we are interested in testing whether the intervention affects belief formation by changing what people expect that others will do. Lastly, unlike previous papers we are not only interested in measuring the behavioral response to the intervention, but we are also interested in understanding the mechanisms that lead to such change. To achieve this task we conduct our intervention in the field-lab, or following List and Levitt's classification, we use a framed field experiment and not a natural experiment.

The use of an experiment to measure the effect of communication campaigns has many advantages over observational data. The comparison of participants' decisions in a controlled environment allows us to identify the channels that lead to behavioral changes. Our experiment allows us to test the effect of persuasive messages on the beliefs about others' behavior, while keeping constant the beliefs about the social cost of investing in coca and about the risk of being sanctioned. Moreover, using survey data we are able to investigate the short term effects of messages on attitudes. The lab in the field also offers the possibility to observe illegal behavior, something that is harder to achieve with observational data. Since the experiment is conducted with participants who face the experimental decisions also in their daily life, we can capture reactions to communication messages in the population that would be targeted by this policy.

The last strand of literature we contribute to is the empirical analysis of the effectiveness of anti-drug policies. The few papers that evaluate the impact of anti-drug policies in Colombia find that coca production falls as the risk of eradication increases, the marginal return of the alternative is higher or the investment in alternative development grows (Moreno-Sanchez et al., 2003; Ibanez and Carlsson, 2010; Reyes, 2011; Ibanez and Martinsson, 2013; Ibanez, 2013; Rozo, 2013; Mejia et al., 2013). We build on this literature by exploring in the field-lab whether alternative policies can be used in the fight against drugs, in particular if communication campaigns can be used to persuade coca farmers to abandon the illicit activity. While the effect of communication campaigns on drug use has been investigated before (Derzon and Lipsey, 2002; Palmgreen, 2006), this is the first paper that considers the effect of communication campaigns on drug production.

The paper is organized in seven sections. After this introductory section, section 2 presents the background of the war on drugs in Colombia and provides a motivation for the intervention used. Section 3 presents the experimental design and discusses the main hypothesis of the study. Section 4 presents the experimental procedures. Section 5 presents the results. Section 6 discusses the external validity of the experiment and the last section concludes. 


\section{Background}

\section{The war on drugs}

The fight against drugs has been critical for Colombia in the last two decades when the country became a major cocaine producer and started suffering the consequences of this problem.

Two main strategies are used to control drug supply: eradication and alternative development. Eradication focuses on the detection and destruction of the crops. The second strategy aims at raising the opportunity cost of coca growing by establishing alternative legal opportunities, although has been used to a lesser degree compared with the first. Between 2008 and 2010, the Colombian government spent about US $\$ 1,1$ billion per year on military component of the war against drug production and trafficking, with additional US subsidies of US\$406 million per year (Mejia et al., 2013). ${ }^{3}$

The efficiency of anti-drug policies is however highly contested. Rydell, Caulkings and Everingham (1996) conclude that it is more cost-effective to implement demand control (treatment) than enforcement. Grossman and Mejia (2008) and Mejia and Restrepo (2013) use micro simulation models to estimate the cost-effectiveness of different anti-drug strategies in Colombia, and conclude that it is more effective to control trafficking than production. Using micro data, Ibanez (2013) shows that coca cultivation is very inelastic to eradication efforts and that a one percent increase in eradication decreases coca cultivation in only 0.22 percentage points. Mejia et al. (2013) consider exogenous variation in restrictions to aerial spraying along the Ecuadorian border imposed in 2006 to identify the local effects of this policy. They find that spraying an additional hectare reduces coca cultivation between 0.02 and 0.065 hectares in a given year. Rozo (2013) gets similar results exploring restrictions to spraying inside national parks. Aerial spraying has also been criticized on the grounds of the side effects that it generates on human health. Camacho and Mejia (2013) show that spraying is associated with increased dermatological problems and miscarriages.

Concerns about the sustainability of supply control efforts in the war on drugs calls for an alternative approach. Authorities proposed that in order to eradicate coca it was necessary to create a culture of lawfulness that succeeds in "eradicating coca from peoples' minds and hearts." In 2008, the DNE (Colombia's agency against illegal drugs), the Ministry of Justice and the United Nations Office on Drugs and Crime (UNODC) implemented a mass communication campaign by radio and television, seeking to persuade producers not to cultivate coca. ${ }^{4}$ Using a simple message, a girl said "don't grow coca, the plant that kills." ${ }^{5}$ The message further explains that coca cultivation is illicit and generates losses at the personal, family and community level. Although the campaign was criticized on the grounds of disregarding diversity of cultural values of indigenous populations that use coca for religious and traditional purposes, this was the first

\footnotetext{
${ }^{3}$ This represented $1.1 \%$ of the annual GDP. In the subsequent period the economy grew so the expenditure of the war on drugs had a lower share of GDP.

${ }^{4}$ Previous campaigns have addressed consumption problems or trafficking without making reference to problems of production.

${ }^{5}$ The original messages in spanish was "No cultives coca, la mata que mata."
} 
time a large-scale intervention was carried out in the country, with the objective of increasing awareness of the problems that drug production brings to the community. Inspired by the above campaign, we investigate the effectiveness of persuasive communication to change attitudes towards coca and coca cultivation. As communication campaigns are part of the strategy that the government is setting up to recover territories that have been hardly hit by conflict and illegality, a relevant question is how effective they are in changing people's attitudes and which type of messages are more effective in persuading producers to stop working with illegal crops.

Understanding the effects that communication campaigns can have on legality opens up a whole new avenue of interventions that are able to reach more people at lower costs, and complement the efforts of other government interventions. Additionally, if communications do in fact change attitudes towards illegality, the sustainability of other strategies in the fight against drugs is likely to increase.

\section{Attitudes towards coca}

To persuade producers to abandon coca, the first step is to understand why they cultivate it and what they think about this activity. In November 2011, in cooperation with UNODC Colombia, we organized two focus group sessions with around 25 cocoa producers that lived in coca areas and who were beneficiaries of alternative development programs. The objective of this workshop was to collect information on people's views on the drug problem. We specifically asked participants: "In the region many people cultivate coca. Why do you think they do it?" Participants could vote on the following options: i) Coca is more profitable than other products, ii) There are no other productive options, iii) People are forced to cultivate it, iv) It (coca) has better market, v) Coca is a common activity and almost everybody cultivates it, vi) Other. Not surprisingly, the most voted reason was coca's higher profitability with respect to other crops. However, in the subsequent discussion many participants disagreed with this statement and argued that in the past coca was a better option but that "now" producers were just receiving enough to cover production costs. The high risk of eradication, lower prices of coca base and high production costs make this activity no longer attractive. In the discussion, easier transportation of coca versus other products ${ }^{6}$ and market security emerged as key factors explaining why farmers prefer to grow coca. One participant said: "people entered the coca business even though they knew it was illegal to obtain 'easy' money." Another participant added: "those who started cultivating coca did it not because there were no options, but due to ambition." Workshop participants pointed out that the "coca boom" had not brought progress to the region. Throughout the workshop the relation of illicit armed groups, coca cultivation and violence was often mentioned. One respondent said: "After the coca boom no money was left. The only legacy was death and poverty."

When we asked participants for the reasons why many people were not cultivating coca in the region, the most voted reason was that they had other productive options, for example cocoa,

\footnotetext{
${ }^{6}$ Coca leaves are usually collected at the producer's farm. In case farmers need to carry the harvested leaves out of their farm, its weight is much lower than other products such as cacao, plantain, etc., making transportation easier and cheaper.
} 
oil palm, avocado, and that these options could be as profitable as coca. Moral aspects were also cited as a reason for not cultivating coca. One participants said: "My parents did not cultivate due to scrupulousness." Other said: "People realize that it harms others in the USA and Europe." Another participant added: "Experience with coca in the family allowed us to think about the problems with coca. The youth are being damaged, they went to work with coca (raspar) and left their studies. They got used to the easy money without much effort. The good habits were lost." Finally, a preference to live in legality and avoid problems with the authorities and other community members, was commonly cited. One participant said: "People like to live in legality." Another one added: "For many, living in peace is important and therefore they do not cultivate," "without coca people can live in peace. Leaving the illicit crops decreased violence."

Finally, we asked what was needed for people to stop cultivating coca. One respondent said "An infusion of scrupulousness." Participants considered that people need to understand the damage that they generate to their communities and become conscious of the damage that they cause the younger generations. Interestingly, participants considered that campaigns should focus on the impact on the consumer more than the impact on their own communities. Another group considered that people needed productive options to see the advantages of living in legality. A respondent said "Some people have the consciousness to stop cultivating, but do not have the resources to do it." Another participant considered that the problem was related with consumption. "Policies need to target consumption, but not production. If nobody buys, then it would not be profitable to cultivate." These answers suggest that persuasion campaigns, accompanied by alternative development projects could have the potential to decrease coca cultivation. We aim at testing this hypothesis in the paper.

Based on the focus group sessions, we selected three sets of arguments on the consequences of coca cultivation to build our treatments. These argument can be classified according to how often they were mentioned in the workshop and hence how informative they are. Table 3.1 presents the summary of arguments used by participants in the workshop when pointing at the negative consequences of coca and the reasons to stop cultivating it. We find that the argument that is most commonly used (less informative) is related with violence. This argument was used 16 times. Participants associate coca cultivation with the arrival of illegal armed groups, increased weapon possession, disputes over coca proceeds and with "death." People noticed that there was an increase in domestic violence and a lack of trust in others. The second most common argument (middle degree of informativeness) was related to what we denominate "change in values." People mention that the good traditions were lost, that children abandoned school to work with coca, that people wanted easy money. The third set of arguments (high information value) is related with the environment. These arguments are less frequently mentioned, with few participants recognizing the impacts on deforestation of natural protected areas, forests and pollution. Another set of arguments was related to consumption problems. In this case, the consumers were thought of mainly outside their communities, and participants recognized it as a global problem. Finally, indirect effects like higher risk of legal crop damage due to aerial spraying were also mentioned. 
Table 3.1: Arguments used to explain why coca is bad for the community

\begin{tabular}{|c|c|c|}
\hline Argument & With coca... & Total \\
\hline \multirow{5}{*}{ Violence } & Social leaders who disagreed were killed & \multirow{5}{*}{16} \\
\hline & Armed groups support coca cultivation & \\
\hline & Violence, displacement and extortion increased & \\
\hline & Life without coca is safer, more time with the family & \\
\hline & Those who did not cultivate did not want problems & \\
\hline \multirow{4}{*}{ Values } & Good traditions were lost & \multirow{4}{*}{9} \\
\hline & Coca brings more bars and prostitution & \\
\hline & The children dropped out of school & \\
\hline & (No coca in order to be) a good example for the youth & \\
\hline \multirow{2}{*}{ Environment } & Natural parks are invaded with coca & \multirow{2}{*}{5} \\
\hline & Eradication has negative effects on the environment & \\
\hline \multirow{2}{*}{ Consumption } & Drug consumption among adolescents is higher & \multirow{2}{*}{6} \\
\hline & People do not understand consequences on consumption & \\
\hline
\end{tabular}

Note: The arguments are taken from discussions with people living in coca growing areas who are beneficiaries of an alternative development program. We classify the arguments based on the statements used. We select only a few examples based on the statements used. Total refers to the simple count of the number of times that arguments were used. We cannot measure the intensity of emotions that the arguments evoke.

The experiment was conducted with farmers living in the region of Putumayo, Colombia, between March and May 2012. Putumayo is one of the regions in Colombia with longest tradition in the cultivation of coca, where it started to be cultivated as early as the 1980's. By 2000 it was estimated that 66 thousand hectares were cultivated with coca only in this region, representing forty percent of all area with coca in the country. As a consequence, Putumayo has been targeted by different anti-drug programs such as aerial spraying, forced manual eradication and alternative development.

\section{Experimental design}

Our experimental design builds on Ibanez and Martinsson (2013). Participants were randomly and anonymously matched in groups of five. Each participant received ten experimental units $(E=10)$ that represent the amount of land, labor and capital available to them for investments in agricultural activities. Their task was to decide how to distribute the endowment between investments in coca and cattle farming. They could invest any amount, but investments had to be done in whole units $(0,1,2$, etc.).

The experiment mimics the three main features of coca cultivation. First, coca is more profitable than cattle. Hence, each unit allocated to coca receives one point in return, whereas each unit allocated to cattle receives $a<1$. Second, coca cultivation is illegal and with probability $p$, authorities will inspect investments. If coca investments are positive, participants are fined $f=1.2$ units. Otherwise, no fine applies. The fine punishes only those who invested part of 
the endowment in coca. Third, coca production generates negative externalities. For each unit invested in coca in the group, all participants in that group lose $b=0.17$ units, independently on whether they individually invested in coca or not.

The pay-off for subject $i$ when he is not discovered, which happens with probability $(1-p)$, can be expressed as

$$
\pi_{i}=c_{i}+a \times\left(10-c_{i}\right)-b \sum c_{i}
$$

where $c_{i}$ is the amount invested in coca and $a$ is the relative profit between coca and cattle. On the other hand, the expected pay-off for subject $i$ when they are discovered, which happens with probability $p$, can then be expressed as

$$
\pi_{i}=c_{i}+a \times\left(10-c_{i}\right)-b \sum c_{i}-f \times c_{i}
$$

The experimental design uses a between-within subject design that combines i) five different frames to persuade producers and ii) nine different marginal incentives to cultivate coca (three different levels of $a$ and $p$ ). We randomized the persuasion treatments over sessions so each participant was exposed to only one persuasive message. Yet, we allow participants to make decisions under nine scenarios that vary the relative return to the legal activity, $a$, and the probability of inspection, $p$, so we can compare how each participant behaves under different scenarios of risk and relative profitability between a legal activity and illegal coca.

\section{Between subject design}

Persuasion messages are introduced in a subtle way when we explain the experiment and payoffs to the participants. To illustrate the negative consequences associated with coca cultivation we used different frames that emphasized different potential consequences of coca cultivation. The frames serve only as cues and are not consequential for the payments in the experiment. In other words, the size of the negative effect of coca investments is kept constant $(b=0.17)$ over treatments. These messages are not deceptive as they are based on actual facts collected from secondary sources and coca growers' opinions. ${ }^{7}$ In the Control treatment we explained:

"Coca cultivation generates negative effects in the community. Hence, for each point invested in coca every participant in the group will lose $b$ points."

The persuasion messages were selected according to information that we collected in the two above-mentioned focus groups in November, 2011. We use three sets of persuasive messages that vary i) the degree of new information conveyed and ii) the salience of the information. The degree of informativeness is assessed according to how often people use the arguments as

\footnotetext{
${ }^{7}$ The participants in our experiment are not the same as those in the focus groups.
} 
a justification for not cultivating coca. ${ }^{8}$ We use four different frames to illustrate the negative consequences that coca has on the community. The first frame considers the effects of coca on violence. Based on our focus groups we found violence to be the most commonly cited reason for arguing against coca cultivation. Since association between coca and violence was clear to most participants, the Violence treatment can be considered to carry a low informative value. Participants in this treatment were told:

"Coca cultivation generates negative effects on the community as it increases violence. In coca growing areas people buy weapons and often get killed in quarrels. Criminals arrive and illegal armed groups fight to gain control of the territory. Hence, for each point invested in coca every participant in the group will lose $b$ points."

The second frame used to persuade producers was related with the change in values due to coca cultivation. In coca growing areas school attendance is lower than in non-coca growing areas (Angrist and Kugler, 2008). Children abandon school to work in coca fields. The proceeds of coca are not invested in better living conditions but instead are used to buy sex, alcohol and status goods. Some farmers told us that during the coca boom people stopped consuming rum and beer (the common drinks) and turned to whiskey (which is typically not even found in Colombian rural areas and is consumed by the wealthy), and that the best girls from a famous region came and were available. The women mentioned that the men were barely home, because of the presence of new bars and prostitution. Even though some participants mentioned the above reasons, they were not the most commonly mentioned to justify why coca is bad. Therefore we consider that this treatment has a middle informative value. Participants in the Value treatment were told:

"Coca cultivation generates a change in values. The money from coca is carelessly spent and people do not save. The young get used to earning money easily and do not study. They become lazy and get into bad habits. The proceeds from coca are spent in partying, alcohol, drugs and sex. Hence, for each point invested in coca every participant in the group will lose $b$ points."

The third frame illustrated the negative environmental impacts of coca cultivation. It is estimated that since 2001 at least 275,588 hectares of forest have been lost to coca (UNODC, 2014). This does not take into account the loss before 2001, which is hard to estimate without the satellite pictures available since 2001, and also does not include the hectares eradicated in order for coca farmers to establish survival crops around the coca crops. ${ }^{9}$ In addition, the production and processing of coca is intense in the use of chemicals that are freely disposed into the environment, polluting the soil and water sources (Bernal, 2006). As people do not associate

\footnotetext{
${ }^{8}$ This measure could also reflect the importance that this criteria has for the people.

${ }^{9}$ An additional very serious issue is that this deforestation does not follow deforestation by urban expansion, but happens in places that environmentally strategic, as in the deep forest. Additionally, farmers use a slashand-burn technique that depletes the land of its soils, making it much harder for it to recover (UNODC, 2006).
} 
coca with environmental problems we consider that this treatment carries a high informative value. Participants in the Environment treatment were told:

"Coca cultivation generates negative effects on the environment. Planting coca fields generates deforestation. The chemicals used to process coca pollute the soil and the water and affect human health. Hence, for each point invested in coca every participant in the group will lose $b$ points."

The last frame used is similar to the violence frame, except that it makes the relation between coca and violence more salient. When illustrating the negative effects of coca, we provide actual figures on violence in coca-growing areas versus non-coca-growing areas. This information is made salient by showing the order of magnitudes compared with other regions. For example, experiencing twice the number of violent deaths, being three times more likely to have illegal armed groups, etc. We consider that this frame has a low informative value as violence is commonly associated with coca. However, compared to the violence treatment, this treatment has a high level of salience. Participants in the treatment Violence Data were told:

"Coca cultivation generates negative effects in the community, as it increases violence. In coca growing areas, homicide rates are twice as high as those in noncoca areas. While in non-coca growing regions 33.35 out of a thousand people are killed, in coca growing areas this rate is 63.13. Coca growing areas are three times more likely to have a massacre. In coca growing areas there are over five combats per year, vis-a-vis less than one in non-coca areas. In coca growing areas there are over five land mine accidents per year, while in non-coca areas the average is less than one. Hence, for each point invested in coca every participant in the group will lose $b$ points."

Table 3.2 presents the summary of the persuasion treatments used. We compare the effect of frames with different informative values (low, middle and high information value) and with different degrees of salience (no salience or salience) with the control treatment.

Table 3.2: Between subject design: Persuasion treatments

\begin{tabular}{|c|c|c|c|}
\hline & & \multicolumn{2}{|c|}{ Salience } \\
\hline & & No & Yes \\
\hline \multirow[t]{2}{*}{ No Information } & & Control & - \\
\hline & Low & Violence & Violence Data \\
\hline \multirow[t]{2}{*}{ Information Value } & Middle & Values & - \\
\hline & High & Environment & - \\
\hline
\end{tabular}

Note: The frames are randomly allocated across sessions. Each participant is exposed to only one frame. 
The messages used emphasize a particular consequence of coca cultivation on the community. In our design we preferred to focus on the effects on the community only, as we considered that social distance is an important element in rationalizing coca investments. As discussed earlier, people in coca growing areas seem to have the perception that the problem of coca is for the consumer countries and not so much for the producer countries. We are aware that the information that we give farmers on the negative consequences of coca is not completely new to them. For this reason we try different levels of informativeness and salience. In fact, people may think that coca has negative effects, but the direct link between coca and its specific effects, such as extreme violence, environmental damage and value deterioration is not recognized to the same degree. One example from the field that this might be the case comes from a conversation we once had with a farmer, during which we asked him if he had experienced any type of violence during the coca boom in the region and he answered, "no, not really." And then he added: "Well, one of my sons was killed, but that was because a paramilitary wanted his girl." (Putumayo, Colombia. December, 2011).

The main hypothesis that we test in our experiment is that persuasion treatments can decrease coca investments compared to the control group that receives no messages.

\section{Hypothesis 1.}

Coca investments will be lower in treatments that emphasize a particular consequence of coca cultivation on the community compared to the control treatment.

Second, we expect that the effectiveness of the messages on decreasing coca investments, depends on the informative value and salience of the message. However, the direction of the effect would depend on the channel at play. If persuasion messages affect beliefs, then messages that have more information value would result in a larger decrease of coca investments compared to messages with low informative value. Moreover, in this case, changes in beliefs would be reflected on changes in the expected coca investments of other group members. We expect that messages that are more informative result in a larger change in the beliefs regarding how much money would be invested in coca by other group members. However, if persuasion messages operate via changes in attitudes, we expect that the behavioral change would not necessarily be correlated with the value of the information. Messages with low information value might result in a high change in coca investments as they could lead to less favorable attitudes towards coca. We test this hypothesis by comparing responses to a post-experimental survey on attitudes towards coca. Moreover, if persuasion operates via changes in attitudes, we would expect to find a change in behavior, even though beliefs about the expected investment of others has not changed. This leads us to the next hypotheses:

\section{Hypothesis 2.}

Changes in behavior will depend on the information value of the message. More informative messages will result in a larger behavioral response if the mechanism 
at play is belief formation. Persuasion treatments with a higher informative value would also result in larger changes in beliefs regarding what others will invest in coca.

The alternative hypothesis is:

\section{Hypothesis 2a}

Changes in behavior will depend on the informative value of the message. Less informative messages will result in a larger behavioral response if the mechanism at play is attitudinal change. Persuasion treatments with a lower informative value would result in larger changes in attitudes towards coca cultivation.

\section{Within subject design}

The second feature of the experimental design is that each participant is exposed to nine different scenarios that combine three relative profits of the alternative activity (cattle farming) and three levels of risk. Based on observations from real-life and likely future levels, we included the following three levels of relative profits between cattle farming and coca growing: $a=[0.2 ; 0.44 ; 0.68]$ and three levels of plausible successful eradication $p=[0 ; 0.1 ; 0.3]$. The parameters included in the experiment reflect historical values. For example, Ibanez (2007) estimates that in 2007 the relative mean return of the second best alternative to coca was about 0.28 while the risk of eradication was about 0.1 . The selected parameters ensure a social dilemma situation as the social cost related to the negative externalities $(0.17 * 5=0.85)$ is larger than the private benefit from investing in coca $(1-a)$ in all nine scenarios. It is expected that a risk-neutral, self-interested utility maximizer would make a non-zero investment in coca if $1-a-b-1.2 p>0$. Table 3.3 presents the marginal incentive to cultivate coca in each of the nine scenarios presented to participants, which are denoted by letters according to the order in which the decisions were presented in the experiment. All but one of the scenarios imply a positive marginal incentive to cultivate in coca and imply that risk-neutral participants should invest all their endowment in coca. In the ninth scenario the optimal response would be to not invest in coca.

Table 3.3: Within subject design: Marginal incentive to cultivate coca

\begin{tabular}{cccc} 
a & \multicolumn{3}{c}{$\mathrm{p}$} \\
\cline { 2 - 4 } & 0 & 0.1 & 0.3 \\
\hline 0.2 & $\mathrm{~A}=0.63$ & $\mathrm{D}=0.51$ & $\mathrm{G}=0.27$ \\
0.44 & $\mathrm{~B}=0.39$ & $\mathrm{E}=0.27$ & $\mathrm{H}=0.03$ \\
0.68 & $\mathrm{C}=0.15$ & $\mathrm{~F}=0.03$ & $\mathrm{I}=-0.21$ \\
\hline
\end{tabular}

Note: Estimated as $\pi^{\prime}=1-a-b-p f$. Each participant was exposed to all nine scenarios. 
We expect that participants would respond to economic incentives by reducing coca investments as the marginal return of the alternative, $a$, and the probability, $p$, increase. Yet, the empirical question that we want to test is the magnitude of the elasticity of investments to these two policies. Another hypothesis that we want to explore is whether the effectiveness of the persuasion messages increases as the marginal net return of the alternative activity is larger and as the risk of eradication is higher.

\section{Hypothesis 4.}

The effectiveness of persuasion treatments increases as the marginal incentives to cultivate coca are lower.

\section{Experimental procedures}

Four municipalities situated in Putumayo were included in the study: Puerto Asis, Valle del Guamuez, San Miguel and Puerto Leguizamo. UNODC (2012) estimated that about six thousand hectares were cultivated in coca in these four municipalities in 2011. This represents almost ten percent of the total area cultivated with coca in the country.

Participants in the experiment were recruited using a two step procedure. In the first step, within each municipality we selected communities (veredas) that had a medium or high density of coca crops and that were safe enough to visit. Local contacts who knew the areas helped us with this selection. In the second step, community leaders (veredal presidents) helped us with recruiting the participants. In order to avoid self-selection, they were instructed to use a random selection mechanism. After writing a numbered list of all head of households living in the neighborhood, the leader was asked to draw 30 to 40 numbers. ${ }^{10}$ The households identified with those numbers were invited to a one-day workshop with university researchers. No further information was given on the purpose of the workshop, and no more than one person per household was invited to participate. Community leaders controlled that only the randomly selected participants came to the activity.

In the morning session we conducted the experiment and after a lunch break participants were interviewed individually. We conducted 21 sessions with a total of 652 participants. The experimental sessions consisted of four stages. First, the experiment instructions were read out loud to the subjects. This was followed by several examples and individual exercises. To check for subjects' understanding of the experiment we used control questions that were checked by an enumerator before continuing the activity.

In the second stage participants simultaneously decided how much they wanted to invest in coca in each of the nine scenarios. The scenarios were presented in the same order to all

\footnotetext{
${ }^{10} \mathrm{We}$ had to use this procedure as there is no central registration of the population. The experimenter team verified that the selection process was conducted as instructed but did not have access to the list of inhabitants. This procedure was used to maintain anonymity of the participants, as explained below.
} 
participants and involved increasing relative returns of the alternative activity (cattle) and of risk of inspection. We also asked participants to note their expectations on how much would other group members invest in coca in each of the scenarios.

In the third stage, a lottery randomly selected one of the nine scenarios for payment. If the selected scenario involved a positive probability of inspection, then a second lottery determined whether they were caught or not. ${ }^{11}$ The selected scenarios and outcome of the lottery applied to all participants in the session. The outcomes from these two lotteries are common to everyone. This mimics real life since both relative profits and successful eradication are normally the same for people living close to each other.

Finally, in the last stage, all subjects were paid privately in cash. Earnings amounted to 9 USD on average, a little more than a full working day's wage. While the payouts were calculated, we had a group discussion and heard comments from the participants.

In order to encourage honest answers we did not ask names, addresses or any other information that would have allowed us to identify the participants. To match survey and experimental information we used participation numbers that were given to participants upon their arrival to the workshop. The participation number was composed of the date when the experimental session was conducted, followed by consecutive numbers to identify each participant. We instructed participants that payments would be done according to that identification number so they had to keep it with them. The survey consisted of 14 sections that asked rather standard questions on socioeconomic characteristics, land use, attitudes towards the state, experience cultivating coca, attitudes towards coca, and intentions to cultivate coca in the future.

\section{Results}

\section{Descriptive statistics and randomization checks}

Our group of enumerators collected secondary information on each one of the neighborhoods (veredas) where the experiment was conducted. This information was collected in local administrative offices or by interviews to local experts using a standardized format. ${ }^{12}$ To test whether the randomization process worked and whether characteristics of the neighborhoods assigned to each treatment are comparable, we ran the following regression model:

$$
Y_{i k}=\beta_{0}+\beta_{1} \text { Violence }_{i}+\beta_{2} \text { Values }_{i}+\beta_{3} \text { Environment }_{i}+\beta_{4} \text { QuantifiedViolence }_{i}+e_{i}
$$

where $Y_{i k}$ refers to a certain characteristic $k$ of individual $i$, and Violence, Values, Environment and QuantifiedViolence are dummy variables that take the value equal to one for participants

\footnotetext{
${ }^{11}$ We represented probabilities using colored balls. We filled a non-transparent bag with nine or seven green balls, and one or three red balls depending on the scenario. If a red ball was selected, participants with positive investments in coca were fined. Otherwise they escaped without being discovered and no fine applied.

${ }^{12}$ The smallest administrative unit for which there is official and consolidated information available is the municipality.
} 
assigned to the corresponding persuasion treatment, $T$. $\beta_{0}$ indicates the average value of characteristic $k$ for the control treatment, whereas $\beta_{1}$ to $\beta_{4}$ indicate the difference in each characteristic of persuasion treatment $j$ compared with the control. Table 3.4 presents the estimated coefficients.

The selected neighborhoods in the control treatment are relatively small with about 500 inhabitants. These communities are relatively poor and about one fourth of the population is beneficiary of the state subsidy for health services, as established by the system that targets public subsidy beneficiaries, Sisben. For every hundred inhabitants (including adults) there are on average two school teachers. About 75 percent of the schools have computers, yet the ratio of computers per inhabitant is relatively low, with only one computer for every hundred people. The control neighborhoods are not very remote and the closest urban center is $20 \mathrm{~km}$ away, a distance covered in 34 minutes. Sixty percent of the neighborhoods in the control treatment have electricity. Only 34 percent of the neighborhoods have public light. We asked local leaders to rate in a zero to five scale the density of coca in the neighborhood where zero indicates no coca and five indicates high density. In the control treatment, the average rating was three, indicating a medium density of coca. Finally, we asked local leaders whether the community was beneficiary of alternative development projects. Forty percent of the communities in the control treatment were beneficiary of alternative development projects and have not abandoned the alternative crop.

Compared with neighborhoods in the control treatment, communities where persuasion messages were sent differ in few variables. Communities in the Environment treatment are significantly poorer (more people have are eligible to public poverty related services as established by Sisben scores), have less computers in their schools per capita and have less neighborhoods with electricity. The communities under the QuantifiedViolence treatment have less teachers and computers per capita and are farther away than the control communities. These differences in the socioeconomic characteristics of the communities suggest that in the analysis we need to account for those variables. However, key variables where all communities are balanced are coca density and being beneficiaries of alternative development programs (and not having abandoned the alternative crop). Definitions of the variables can be found in Table A3.1 in the Appendix.

In the post-experimental survey we included a series of questions on the socioeconomic characteristics of the participants. We compare the socioeconomic characteristics of the participants in the different treatments using a randomization test as described in Equation 8. Table 3.5 presents the estimated results. In the control treatment participants were on average 43 years old, one tenth were women and have a low education achievements with only 1.4 years of education attained on average. About one half of the population was classified as poor using the standard of living index. While most of the population is catholic, one third of the respondents report being evangelic. About half of the participants have a land title and owned on average 14 hectares of land. One fourth of the respondents self-reported having cultivated coca the year before the survey was administered. 


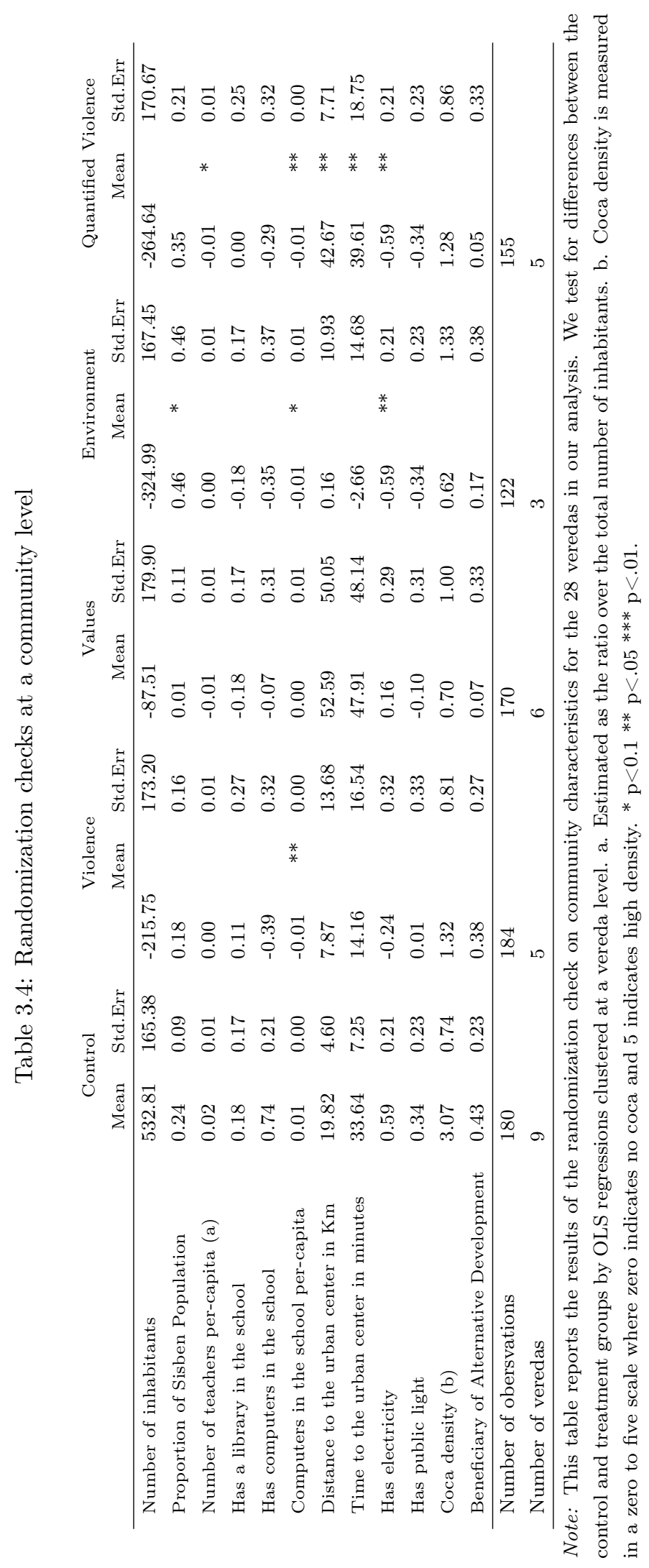


Table 3.5: Coca investments by treatment

\begin{tabular}{|c|c|c|c|c|c|}
\hline Panel A: Socioeconomic Characteristics & $\begin{array}{l}\text { Age HH } \\
\text { head }\end{array}$ & $\begin{array}{r}\text { Female } \\
\text { head HH }\end{array}$ & Education & Evangelical & Poverty \\
\hline Violence & $\begin{array}{r}1.628 \\
(2.100)\end{array}$ & $\begin{array}{r}-0.030 \\
(0.042)\end{array}$ & $\begin{array}{r}0.119 \\
(0.144)\end{array}$ & $\begin{array}{r}0.112 \\
(0.210)\end{array}$ & $\begin{array}{r}1.830 \\
(2.417)\end{array}$ \\
\hline Environment & $\begin{array}{r}-1.632 \\
(1.545)\end{array}$ & $\begin{array}{r}0.037 \\
(0.038)\end{array}$ & $\begin{array}{c}0.311^{* *} \\
(0.138)\end{array}$ & $\begin{array}{r}-0.117 \\
(0.089)\end{array}$ & $\begin{array}{r}1.862 \\
(2.530)\end{array}$ \\
\hline \multirow[t]{2}{*}{ Values } & 0.361 & $0.134^{*}$ & 0.249 & 0.073 & $6.266^{* *}$ \\
\hline & $(2.624)$ & $(0.076)$ & $(0.267)$ & $(0.147)$ & $(2.471)$ \\
\hline Quantified Violence & $\begin{array}{r}1.347 \\
(2.304)\end{array}$ & $\begin{array}{l}-0.021 \\
(0.030)\end{array}$ & $\begin{array}{r}0.062 \\
(0.179)\end{array}$ & $\begin{array}{r}-0.109 \\
(0.133)\end{array}$ & $\begin{array}{r}0.167 \\
(2.848)\end{array}$ \\
\hline Control & $\begin{array}{r}43.959^{* * *} \\
(1.442)\end{array}$ & $\begin{array}{r}0.123^{* * *} \\
(0.026)\end{array}$ & $\begin{array}{r}1.428^{* * *} \\
(0.126)\end{array}$ & $\begin{array}{r}0.329^{* * *} \\
(0.078)\end{array}$ & $\begin{array}{r}52.064^{* * *} \\
(1.923)\end{array}$ \\
\hline$N$ & 652 & 652 & 649 & 655 & 623 \\
\hline \multicolumn{6}{|l|}{ Panel B: Land Use } \\
\hline & $\begin{array}{r}\text { Land } \\
\text { Title } 1991\end{array}$ & $\begin{array}{r}\text { Land } \\
\text { Title } 2011\end{array}$ & $\begin{array}{r}\text { Land Size } \\
1991 \text { (HA) }\end{array}$ & $\begin{array}{l}\text { Land Size } \\
2011 \text { (HA) }\end{array}$ & Coca 2011 \\
\hline Violence & $\begin{array}{r}-0.114^{* *} \\
(0.041)\end{array}$ & $\begin{array}{r}-0.122 \\
(0.085)\end{array}$ & $\begin{array}{r}3.397 \\
(4.885)\end{array}$ & $\begin{array}{r}0.316 \\
(4.050)\end{array}$ & $\begin{array}{r}0.008 \\
(0.108)\end{array}$ \\
\hline \multirow[t]{2}{*}{ Environment } & -0.061 & $-0.122^{* *}$ & 5.133 & -3.101 & 0.076 \\
\hline & $(0.043)$ & $(0.051)$ & $(9.057)$ & $(2.566)$ & $(0.130)$ \\
\hline Values & $\begin{array}{r}0.066 \\
(0.080)\end{array}$ & $\begin{array}{r}0.054 \\
(0.075)\end{array}$ & $\begin{array}{c}-5.928^{*} \\
(2.868)\end{array}$ & $\begin{array}{r}-5.548^{* * *} \\
(1.650)\end{array}$ & $\begin{array}{l}-0.163^{*} \\
(0.084)\end{array}$ \\
\hline \multirow[t]{2}{*}{ Quantified Violence } & $-0.130^{* *}$ & $-0.253^{* * *}$ & 4.824 & -1.762 & 0.146 \\
\hline & $\begin{array}{r}(0.059) \\
0.364 * * *\end{array}$ & $\begin{array}{r}(0.045) \\
0.493^{* * *}\end{array}$ & $\begin{array}{r}(9.419) \\
14.509^{* * *}\end{array}$ & $\begin{array}{r}(4.454) \\
13.553^{* * *}\end{array}$ & $\begin{array}{r}(0.153) \\
0.248^{* * *}\end{array}$ \\
\hline Control & $\begin{array}{r}0.364 \\
(0.034)\end{array}$ & $\begin{array}{r}0.493 \\
(0.042)\end{array}$ & $\begin{array}{r}14.009 \\
(2.248)\end{array}$ & $\begin{array}{r}13.050 \\
(1.341)\end{array}$ & $(0.067)$ \\
\hline$N$ & 624 & 651 & 653 & 635 & 646 \\
\hline \multirow[t]{2}{*}{ Panel C: Social Capital } & & & & & \\
\hline & Participation & $\begin{array}{l}\text { Trust in } \\
\text { the State }\end{array}$ & $\begin{array}{r}\text { Trust } \\
\text { Neighbors }\end{array}$ & $\begin{array}{r}\text { Risk } \\
\text { Eradica- } \\
\text { tion }\end{array}$ & FGB \\
\hline Violence & $\begin{array}{l}-0.021 \\
(0.063)\end{array}$ & $\begin{array}{r}0.079 \\
(0.185)\end{array}$ & $\begin{array}{r}0.277 \\
(0.201)\end{array}$ & $\begin{array}{r}-1.218 \\
(0.710)\end{array}$ & $\begin{array}{r}-0.105 \\
(0.087)\end{array}$ \\
\hline Environment & $\begin{array}{r}0.031 \\
(0.059)\end{array}$ & $\begin{array}{r}0.216 \\
(0.170)\end{array}$ & $\begin{array}{r}0.192 \\
(0.194)\end{array}$ & $\begin{array}{r}-0.429 \\
(0.649)\end{array}$ & $\begin{array}{r}-0.044 \\
(0.106)\end{array}$ \\
\hline \multirow[t]{2}{*}{ Values } & -0.024 & 0.301 & $0.351^{*}$ & 0.527 & 0.110 \\
\hline & $(0.065)$ & $(0.197)$ & $(0.171)$ & $(0.672)$ & $(0.180)$ \\
\hline \multirow[t]{2}{*}{ Quantified Violence } & -0.010 & 0.124 & 0.246 & -0.302 & -0.111 \\
\hline & $(0.075)$ & $(0.232)$ & $(0.268)$ & $(0.361)$ & $(0.087)$ \\
\hline Control & $0.869^{* * *}$ & $2.616^{* * * *}$ & $2.834^{* * *}$ & $6.535^{* * *}$ & 0.111 \\
\hline$N$ & 649 & $\frac{6.147}{653}$ & 653 & $\frac{6.200)}{652}$ & $\frac{6}{645}$ \\
\hline \multirow[t]{2}{*}{ Panel D: Exposure to Violence } & & & & & \\
\hline & Displacement & Homicides & Landmines & Extorsion & $\begin{array}{r}\text { Accidents } \\
\text { with } \\
\text { Weapons }\end{array}$ \\
\hline \multirow[t]{2}{*}{ Violence } & 0.075 & 0.065 & 0.010 & 0.023 & 0.022 \\
\hline & $(0.068)$ & $(0.043)$ & $(0.014)$ & $(0.016)$ & $(0.026)$ \\
\hline \multirow[t]{2}{*}{ Environment } & 0.059 & 0.076 & $-0.021^{* *}$ & 0.012 & 0.012 \\
\hline & $(0.134)$ & $(0.048)$ & $(0.007)$ & $(0.029)$ & $(0.019)$ \\
\hline \multirow[t]{2}{*}{ Values } & 0.073 & 0.028 & -0.007 & 0.024 & 0.007 \\
\hline & $(0.100)$ & $(0.048)$ & $(0.008)$ & $(0.031)$ & $(0.024)$ \\
\hline \multirow[t]{2}{*}{ Quantified Violence } & 0.052 & 0.044 & -0.007 & -0.007 & -0.024 \\
\hline & $(0.070)$ & $(0.049)$ & $(0.015)$ & $(0.016)$ & $(0.018)$ \\
\hline \multirow[t]{2}{*}{ Control } & $0.288^{* * *}$ & $0.116^{* * *}$ & $0.027^{* * *}$ & $0.027^{* * *}$ & $0.034^{* *}$ \\
\hline & $(0.059)$ & $(0.034)$ & $(0.005)$ & $(0.009)$ & $(0.015)$ \\
\hline$N$ & 653 & 654 & 653 & 653 & 653 \\
\hline
\end{tabular}

Note: This table reports the results of the post-experimental survey. We test for differences estimating an independent regressions for each variable. Standard Errors are presented in parentheses and are clustered at the neighborhood level. ${ }^{*} \mathrm{p}<0.1 * * \mathrm{p}<.05 * * * \mathrm{p}<.01$ indicate significant differences with respect to the control treatment. Variable definitions can be found in Table A3.1 in the Appendix.

Participants in the survey have also been severely affected by violence and a significant frac- 
tion has had family members displaced by violence (29\%), murdered (12\%), killed in massacres $(7 \%)$, had accidents with land mines (3\%) and had accidents with fire arms (3\%). Participation in community activities was relatively high (90\% reported participating in a community organization). Trust in institutions was relatively low with an average of 2.6 in a one to five scale. The perceived risk of eradication, measured in a one to ten scale was 6.5. About one tenth of the participants were beneficiaries of the Forest Warden Families alternative development program. ${ }^{13}$ We find that there are significant differences between participants in the control treatment and participant in the persuasion treatments. In the treatment Values a larger proportion of the respondents is female, classified as poor, has higher levels of trust, less land and is less likely to cultivate coca than in the Control treatment. Similarly, in the treatment Environment, participants are more educated, less likely to have land titles and less likely to be affected by land mines than those in the control treatment. We control for these variables in the analysis.

To test for potential channels affecting changes in behavior, in the post experimental survey we asked participants to rate in a 1 to 5 scale the degree of acceptance to a series of statement regarding coca cultivation. Table 3.6 below presents the descriptive statistics of the answer to these questions. We find that participants have a quite negative attitude towards coca: 95 percent of the respondents consider that cultivating coca is not correct, 69 percent consider that it is never justifiable to cultivate coca and 65 percent disagree that coca cultivation should be legal. Participants recognize the problems associated with coca cultivation. 63 percent disagree with the statement that coca brings progress to the region, 86 percent consider that coca generates violence within the families and a similar fraction considers that it generates violence in the community. Besides, more than 90 percent of the participants recognize that coca promotes disrespect to the law and drug consumption habits. Hence, the majority of participants consider that coca should not be cultivated (76 percent).

\section{Impact of persuasion messages on investments}

Participants in the experiment made decisions under nine different scenarios. To account for possible correlation of the decisions over the different scenarios we estimate a panel random effects model. Due to the random assignment of the participants into treatment and control groups, the identification of the causal effect of the persuasion treatment on investment in coca is straightforward. The impact of the persuasion treatments on coca investments is estimated using the following model with clustered standard errors at the community level:

$Y_{i t}=\alpha+\beta_{1}$ Violence $_{i}+\beta_{2}$ Values $_{i}+\beta_{3}$ Environment $_{i}+\beta_{4}$ QuantifiedViolence $_{i}+\beta_{5} X_{i t}+\beta_{6} Z_{i}+u_{i}+\epsilon_{i t}$,

\footnotetext{
${ }^{13}$ This program gives a monetary subsidy to communities who accept to keep their land free of coca and received workshops on social capital, culture of legality and technical issues. The agreement is verified by UNODC and in case of default all farmers lose the subsidy.
} 


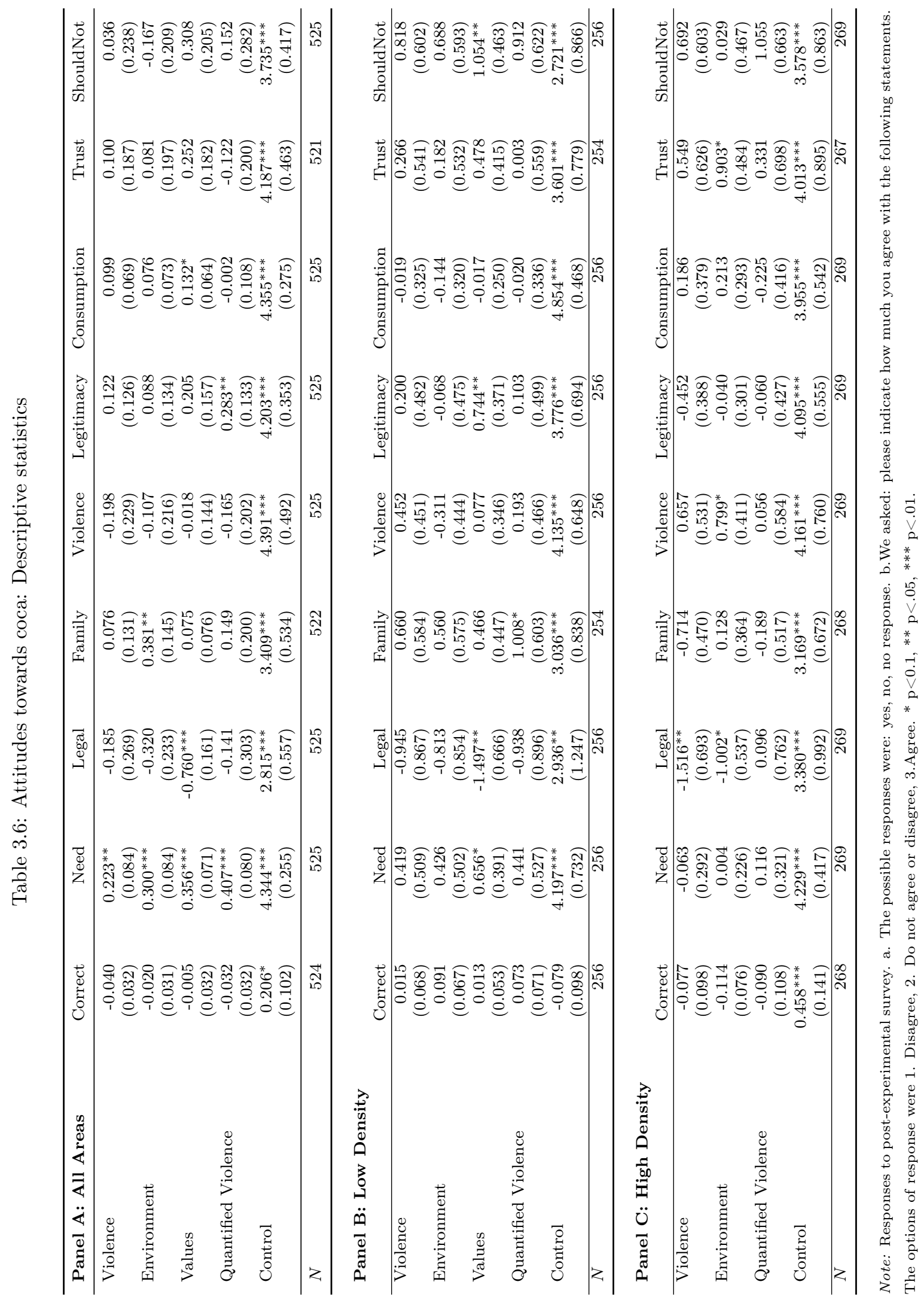


where $Y$ refers the following outcome variables for person $i$ in scenario $t$ : the likelihood of investing in coca, the amount invested in coca conditional on a non-zero investment, or the unconditional amount invested in coca. Violence, Values, Environment and QuantifiedViolence are defined as dummy variables equal to one for participants allocated to each of the different persuasion treatments, which are fixed throughout all scenarios. $X$ is a vector of incentives to invest in coca in the experiment that varies over the nice scenarios, while $Z$ is a vector of controls that include individual socioeconomic characteristics and municipality and veredal fixed effects. The parameter $u_{i}$ is an individual time invariant unobserved effect that is assumed to be uncorrelated with other variables, while $e_{i t}$ is the error term.

We estimate a random effects probit model for the likelihood of investing in coca and report the estimated marginal effects at the means of the independent variables. The conditional and unconditional investments in coca are estimated using a random effects linear model. In all models, standard errors are clustered at the vereda level to account for correlation between decisions within sessions.

Table 3.7 presents the results of the estimated models using three different specifications. The first specification controls only for persuasion treatments and municipality fixed effects. The second specification is similar to the first specification but also controls for the marginal incentives to invest in coca in the experiment (vector $X$ ). The last specification includes a vector of controls $Z$. We present the results for our three outcome variables: the likelihood to invest in coca, the conditional investment in coca and the unconditional amount invested in three separate columns for each specification.

The estimated models suggest that compared to the Control treatment, persuasion messages that emphasize the relation of coca with violence and that make this relationship salient by providing data on violence result in a lower likelihood to invest in coca in the experiment. Exposure to these messages reduce the likelihood of investing in coca by about 20 percent. Messages that emphasize the effect of coca on the environment or in changes in values have no significant effect on the likelihood to invest in coca.

Contrary to what we expected, we find that persuasion messages could result in higher coca investments. Treatments that relate coca with violence and with changes in values result in higher conditional investments by about 0.3 to 0.7 points. None of the persuasion messages have a significant effect on unconditional coca investments. Thus, while persuasion messages seem to deter farmers from investing in coca, they have no effect on the total amount invested. 
Table 3.7: Treatment effects on coca investments

\begin{tabular}{|c|c|c|c|c|c|c|c|c|c|}
\hline & \multicolumn{3}{|c|}{ No Controls } & \multicolumn{3}{|c|}{ Experimental Controls } & \multicolumn{3}{|c|}{ Socioeconomic Controls } \\
\hline & $\begin{array}{c}(1) \\
\text { dcoca }\end{array}$ & $\begin{array}{c}(2) \\
\text { coca } \mid \text { dcoca }=1\end{array}$ & $\begin{array}{l}(3) \\
\text { coca }\end{array}$ & $\begin{array}{c}(4) \\
\text { dcoca }\end{array}$ & $\begin{array}{c}(5) \\
\text { coca } \mid \text { dcoca }=1\end{array}$ & $\begin{array}{l}(6) \\
\text { coca }\end{array}$ & $\begin{array}{c}(7) \\
\text { dcoca }\end{array}$ & $\begin{array}{c}(8) \\
\text { coca } \mid \text { dcoca }=1\end{array}$ & $\begin{array}{l}(9) \\
\text { coca }\end{array}$ \\
\hline Violence & $\begin{array}{l}-0.204^{*} \\
(0.113)\end{array}$ & $\begin{array}{l}0.343^{*} \\
(0.193)\end{array}$ & $\begin{array}{l}-0.242 \\
(0.404)\end{array}$ & $\begin{array}{l}-0.156 \\
(0.106)\end{array}$ & $\begin{array}{l}0.388^{*} \\
(0.198)\end{array}$ & $\begin{array}{l}-0.244 \\
(0.403)\end{array}$ & $\begin{array}{l}-0.135 \\
(0.100)\end{array}$ & $\begin{array}{l}0.462^{* *} \\
(0.206)\end{array}$ & $\begin{array}{l}-0.040 \\
(0.307)\end{array}$ \\
\hline Environment & $\begin{array}{l}-0.086 \\
(0.132)\end{array}$ & $\begin{array}{c}0.089 \\
(0.214)\end{array}$ & $\begin{array}{c}0.064 \\
(0.333)\end{array}$ & $\begin{array}{l}-0.080 \\
(0.125)\end{array}$ & $\begin{array}{c}0.142 \\
(0.214)\end{array}$ & $\begin{array}{c}0.061 \\
(0.333)\end{array}$ & $\begin{array}{l}-0.087 \\
(0.086)\end{array}$ & $\begin{array}{c}0.276 \\
(0.245)\end{array}$ & $\begin{array}{c}0.056 \\
(0.310)\end{array}$ \\
\hline Values & $\begin{array}{l}-0.152 \\
(0.129)\end{array}$ & $\begin{array}{l}0.572^{* *} \\
(0.238)\end{array}$ & $\begin{array}{l}-0.079 \\
(0.333)\end{array}$ & $\begin{array}{l}-0.116 \\
(0.119)\end{array}$ & $\begin{array}{c}0.611^{* * *} \\
(0.228)\end{array}$ & $\begin{array}{l}-0.080 \\
(0.333)\end{array}$ & $\begin{array}{l}-0.117 \\
(0.128)\end{array}$ & $\begin{array}{c}0.704^{* *} \\
(0.277)\end{array}$ & $\begin{array}{l}-0.060 \\
(0.302)\end{array}$ \\
\hline Quantified Violence & $\begin{array}{c}-0.229^{* *} \\
(0.110)\end{array}$ & $\begin{array}{l}-0.088 \\
(0.303)\end{array}$ & $\begin{array}{l}-0.417 \\
(0.457)\end{array}$ & $\begin{array}{c}-0.173^{*} \\
(0.104)\end{array}$ & $\begin{array}{l}-0.057 \\
(0.294)\end{array}$ & $\begin{array}{l}-0.418 \\
(0.457)\end{array}$ & $\begin{array}{c}-0.252^{* *} \\
(0.099)\end{array}$ & $\begin{array}{c}0.009 \\
(0.394)\end{array}$ & $\begin{array}{l}-0.513 \\
(0.428)\end{array}$ \\
\hline Risk Sanction & & & & $\begin{array}{c}-0.533^{* * *} \\
(0.096)\end{array}$ & $\begin{array}{c}-2.219^{* * *} \\
(0.583)\end{array}$ & $\begin{array}{c}-2.554^{* * *} \\
(0.452)\end{array}$ & $\begin{array}{c}-0.565^{* * *} \\
(0.054)\end{array}$ & $\begin{array}{c}-2.116^{* * *} \\
(0.620)\end{array}$ & $\begin{array}{c}-2.362^{* * *} \\
(0.497)\end{array}$ \\
\hline Profit Alternative & & & & $\begin{array}{c}-0.090^{* * *} \\
(0.016)\end{array}$ & $\begin{array}{c}-0.717^{* * *} \\
(0.178)\end{array}$ & $\begin{array}{c}-0.546^{* * *} \\
(0.084)\end{array}$ & $\begin{array}{c}-0.095^{* * *} \\
(0.011)\end{array}$ & $\begin{array}{c}-0.678^{* * *} \\
(0.178)\end{array}$ & $\begin{array}{c}-0.481^{* * *} \\
(0.108)\end{array}$ \\
\hline Coca Farmer & & & & & & & $\begin{array}{c}0.221^{* * *} \\
(0.039)\end{array}$ & $\begin{array}{l}0.353^{*} \\
(0.191)\end{array}$ & $\begin{array}{c}0.691^{* * *} \\
(0.126)\end{array}$ \\
\hline Poverty Index & & & & & & & $\begin{array}{c}0.000 \\
(0.001)\end{array}$ & $\begin{array}{l}0.019^{*} \\
(0.011)\end{array}$ & $\begin{array}{c}0.009 \\
(0.007)\end{array}$ \\
\hline Female $\mathrm{HH}$ & & & & & & & $\begin{array}{l}0.041^{*} \\
(0.024)\end{array}$ & $\begin{array}{c}0.248 \\
(0.326)\end{array}$ & $\begin{array}{l}0.286 \\
(0.193)\end{array}$ \\
\hline Catholic & & & & & & & $\begin{array}{c}0.021 \\
(0.080)\end{array}$ & $\begin{array}{c}-0.835^{*} \\
(0.466)\end{array}$ & $\begin{array}{l}-0.309 \\
(0.462)\end{array}$ \\
\hline Evangelic & & & & & & & $\begin{array}{c}-0.177^{* *} \\
(0.074)\end{array}$ & $\begin{array}{l}-0.800 \\
(0.559)\end{array}$ & $\begin{array}{l}-0.672 \\
(0.468)\end{array}$ \\
\hline Age $\mathrm{HH}$ & & & & & & & $\begin{array}{c}-0.003^{* * *} \\
(0.001)\end{array}$ & $\begin{array}{l}-0.004 \\
(0.009)\end{array}$ & $\begin{array}{c}-0.010^{*} \\
(0.005)\end{array}$ \\
\hline Trust Institutions & & & & & & & $\begin{array}{l}-0.014 \\
(0.009)\end{array}$ & $\begin{array}{c}0.081 \\
(0.092)\end{array}$ & $\begin{array}{c}0.028 \\
(0.061)\end{array}$ \\
\hline Title 1991 & & & & & & & $\begin{array}{c}-0.005^{* * *} \\
(0.002)\end{array}$ & $\begin{array}{c}0.007 \\
(0.014)\end{array}$ & $\begin{array}{r}-0.007^{*} \\
(0.004)\end{array}$ \\
\hline Experience Coca & & & & & & & $\begin{array}{l}-0.000 \\
(0.002)\end{array}$ & $\begin{array}{l}-0.026 \\
(0.016)\end{array}$ & $\begin{array}{l}-0.011 \\
(0.013)\end{array}$ \\
\hline Control & & $\begin{array}{c}3.211^{* * *} \\
(0.245)\end{array}$ & $\begin{array}{c}1.405^{* * *} \\
(0.314)\end{array}$ & & $\begin{array}{c}3.788^{* * *} \\
(0.276)\end{array}$ & $\begin{array}{c}2.070^{* * *} \\
(0.318)\end{array}$ & & $\begin{array}{c}3.414^{* * *} \\
(0.911)\end{array}$ & $\begin{array}{c}2.149^{* * *} \\
(0.655)\end{array}$ \\
\hline Municipal effects & Yes & Yes & Yes & Yes & Yes & Yes & Yes & Yes & Yes \\
\hline Observations & 6241 & 2568 & 6241 & 6241 & 2568 & 6241 & 4691 & 1943 & 4691 \\
\hline People & 699 & 405 & 699 & 699 & 405 & 699 & 525 & 302 & 525 \\
\hline Clusters & 21 & 21 & 21 & 21 & 21 & 21 & 21 & 21 & 21 \\
\hline
\end{tabular}

Note: Standard errors presented in parenthesis are clustered at the vereda level. For models on dcoca: Likelihood to invest in coca, the marginal effects at the means of a Random Effects Probit Model are reported in the Table. For unconditional (coca|dcoca==1) and conditional investment in coca coca (coca) we estimate Random Effects Generalized Least Squares. c. Probability of being sanctioned in the experiment. d. Marginal return of the alternative product in the experiment. e. Self-Reported measure of having cultivated coca in 2011. Results of t-test indicated at following significance levels ${ }^{*} \mathrm{p}<0.1,{ }^{* *} \mathrm{p}<0.05,{ }^{* * *} \mathrm{p}<0.01$.

This effect is partly explained by the perverse effect that certain persuasion messages have on the conditional amount invested.

These results are robust for all three estimated models once we include additional controls and corroborate Hypothesis 1. 


\section{Result 1}

Persuasion treatments that emphasize the negative relation between coca cultivation and violence deter farmers from cultivating coca. Yet these treatments can also increase the conditional amount of coca cultivated.

Surprisingly, we find that participants react more to treatments that have low information value (treatments that make salient the relation between coca and violence). As previously discussed, this information is not new for participants. They often discuss the consequences that coca has on violence and are aware of this relationship. Hence, this finding suggests that persuasion messages operate not via changes in beliefs but via changes in attitudes. We further explore this potential mechanism below.

Regarding other control variables we find that participants do react to economic incentives as expected, by decreasing the likelihood to invest in coca and the conditional and unconditional amounts invested, when the risk of being sanctioned if discovered cultivating, $p$, and the marginal return of the alternative, $a$, increase. Consistent with results from Ibanez and Martinsson (2013), the elasticity of coca investments is higher to sticks (changes in the risk of sanction) than to carrots (changes in the marginal return of the alternative).

The regression results of the specification that includes controls on socioeconomic characteristics uncover other interesting relations. Participants who self-reported having cultivated coca one year prior to the experiment are also more likely to invest in coca in the experiment. This seems to suggest that participants bring to the game their past real life experiences with coca. Interestingly, we find that those who belong to an Evangelic church, who are older or who had a title over their land in 1991 are less likely to invest in coca in the experiment and also invest less. This result suggests that investments in coca are partly driven by norms of what is correct and by poverty. Similar results are obtained by Ibanez (2010) who finds a negative correlation between the likelihood of cultivating coca and belonging to a Evangelic church.

\section{Heterogeneous effects}

From a policy perspective it is important to understand if the effect of the persuasion messages is reaching those who are intended to be affected by a policy. In other words, we are interested in testing whether the message affects those who live in communities with high density of coca to a higher degree than those in low density communities. To explore this relation, we classified veredas as low or high density according to the fraction of participants who self-reported having cultivated coca the year before the survey. This measure is positively correlated with secondary information on coca density (Spearman Correlation Coefficient $=0.25$, p-value $<0.001$ ). Neighborhoods with a density score above the median level of density (more than 19 percent of the respondents reported having cultivated coca) are classified as high-density while those with lower scores are classified as low-density. ${ }^{14}$

\footnotetext{
${ }^{14}$ Due to confidentiality agreements with respondents in the survey, we do not report this information.
} 
Table 3.8 presents the results of the estimation of Equation 8. Models one to three refer to neighborhoods with low coca density, while models four to six present the results for neighborhoods with high coca density. We find that in areas with low density the only persuasion treatment that significantly decreases the likelihood to invest in coca is the QuantifiedViolence treatment. However, this treatment and the treatment Values result in larger conditional coca investments and an insignificant effect on unconditional investments. Surprisingly, the treatment Violence results in significantly larger unconditional investments in coca.

In areas with high coca density, all persuasion treatments used decrease the likelihood of investing in coca significantly. Participants who hear a persuasive message are between 40 to 60 percent less likely to invest in coca than the control group. Yet, conditional on investing, participants invest about five points more in coca than the controls. The net effect of the persuasion treatments is negative and significant in all treatments with an average reduction in investments of about 0.8 points.

\section{Result 2}

Our results suggest that the effectiveness of persuasion treatments is higher in areas with high density of coca than in areas with low density. In areas with high density, persuasion messages have a larger deterring effect and significantly decrease unconditional coca investments. The treatments Violence and QuantifiedViolence are the most effective in deterring coca investments.

Regarding the response to economic incentives, we find that in areas with high coca density the elasticity of coca investment to the risk of eradication is lower than in regions with low coca density. Yet, this difference is not significant (ttest, pvalue $>0.1$ ). There are also no significant differences in the elasticity of the investments to the return of the alternative product, a (ttest, pvalue $>0.1)$. 
Table 3.8: Heterogeneous treatment effects by density of coca in the neighborhood.

\begin{tabular}{|c|c|c|c|c|c|c|}
\hline & \multicolumn{3}{|c|}{ Low Density } & \multicolumn{3}{|c|}{ High Density } \\
\hline & $\begin{array}{c}(1) \\
\text { dcoca }\end{array}$ & $\begin{array}{c}(2) \\
\operatorname{coca} \mid \text { dcoca }=1\end{array}$ & $\begin{array}{c}(3) \\
\text { coca }\end{array}$ & $\begin{array}{c}(4) \\
\text { dcoca }\end{array}$ & $\begin{array}{c}(5) \\
\text { coca } \mid \mathrm{d} \operatorname{coc} \mathrm{a}=1\end{array}$ & $\begin{array}{c}(6) \\
\text { coca }\end{array}$ \\
\hline Violence & $\begin{array}{c}-0.224 \\
(0.190)\end{array}$ & $\begin{array}{c}0.728 \\
(0.676)\end{array}$ & $\begin{array}{c}0.764^{* * *} \\
(0.247)\end{array}$ & $\begin{array}{c}-0.421^{* * *} \\
(0.107)\end{array}$ & $\begin{array}{c}5.311^{* * *} \\
(1.229)\end{array}$ & $\begin{array}{c}-0.878^{* * *} \\
(0.066)\end{array}$ \\
\hline Environment & $\begin{array}{l}-0.097 \\
(0.221)\end{array}$ & $\begin{array}{c}0.378 \\
(0.683)\end{array}$ & $\begin{array}{c}0.000 \\
(.)\end{array}$ & $\begin{array}{c}-0.458^{* * *} \\
(0.080)\end{array}$ & $\begin{array}{c}5.213^{* * *} \\
(1.159)\end{array}$ & $\begin{array}{c}-0.691^{* * *} \\
(0.093)\end{array}$ \\
\hline Values & $\begin{array}{l}-0.028 \\
(0.202)\end{array}$ & $\begin{array}{l}0.404^{*} \\
(0.229)\end{array}$ & $\begin{array}{l}-0.046 \\
(0.113)\end{array}$ & & $\begin{array}{c}0.000 \\
(.)\end{array}$ & $\begin{array}{l}0.000 \\
(.)\end{array}$ \\
\hline Quantified Violence & $\begin{array}{c}-0.275^{*} \\
(0.162)\end{array}$ & $\begin{array}{c}2.681^{* * *} \\
(0.750)\end{array}$ & $\begin{array}{l}-0.373 \\
(0.266)\end{array}$ & $\begin{array}{c}-0.622^{* * *} \\
(0.140)\end{array}$ & $\begin{array}{c}4.734^{* * *} \\
(1.228)\end{array}$ & $\begin{array}{c}-0.709^{* * *} \\
(0.090)\end{array}$ \\
\hline Risk & $\begin{array}{c}-0.631^{* * *} \\
(0.107)\end{array}$ & $\begin{array}{c}-3.560^{* * *} \\
(0.978)\end{array}$ & $\begin{array}{c}-2.918^{* * *} \\
(0.878)\end{array}$ & $\begin{array}{c}-0.571^{* * *} \\
(0.081)\end{array}$ & $\begin{array}{c}-1.315^{*} \\
(0.681)\end{array}$ & $\begin{array}{c}-1.833^{* * *} \\
(0.517)\end{array}$ \\
\hline Alternative Profit & $\begin{array}{c}-0.103^{* * *} \\
(0.018)\end{array}$ & $\begin{array}{c}-0.904^{* * *} \\
(0.145)\end{array}$ & $\begin{array}{c}-0.484^{* * *} \\
(0.122)\end{array}$ & $\begin{array}{c}-0.101^{* * *} \\
(0.022)\end{array}$ & $\begin{array}{c}-0.553^{* *} \\
(0.276)\end{array}$ & $\begin{array}{c}-0.480^{* * *} \\
(0.183)\end{array}$ \\
\hline Municipal effects & Yes & Yes & Yes & Yes & Yes & Yes \\
\hline Socioeconomic Controls & Yes & Yes & Yes & Yes & Yes & Yes \\
\hline Observations & 2287 & 688 & 2287 & 2404 & 1255 & 2404 \\
\hline People & 256 & 118 & 256 & 269 & 184 & 269 \\
\hline Clusters & 10 & 10 & 10 & 11 & 11 & 11 \\
\hline
\end{tabular}

Note: Standard errors presented in parentheses are clustered at the neighborhood level. For models on likelihood to invest in coca (dcoca), marginal effects at the means of a Random Effects Probit Model are reported in the Table. For conditional (coca $\mid$ dcoca $==1$ ) and unconditional investments in coca (coca), we estimate Random Effects Generalized Least Squares. c. Probability of being sanctioned in the experiment. d. Marginal return of the alternative product in the experiment. e. Not enough observations in the Values treatment in order to estimate high density coefficients. f. We include the following controls: dummy on having cultivated coca one year before the experiment, dummy for female respondents, age, religion, indicator of poverty according to living conditions, trust in local institutions, number of years cultivating coca, title over the land in 1991, session fixed effects. Results of t-test indicated at following significance levels $* \mathrm{p}<0.1, * * \mathrm{p}<0.05, * * * \mathrm{p}<0.01$.

\section{Mechanisms}

If persuasion treatments are effective at decreasing investment decisions and affect those who live in areas with higher density of coca more, which are the channels that lead to the behavioral change? Our hypothesis is that the informative value of the message would determine the channel at play. One potential mechanism is that persuasion messages affect beliefs and change the expectations on how much others invest. To assess the importance of persuasion messages at affecting expectations on the behavior of others, we estimate Equation 8 with expected behavior of others as the dependent variable and with session fixed effects. Table 3.9 presents the results. We present the results for three different samples. The first column presents the results for all participants while the second and third columns present the results for participants living in low and high density coca areas respectively. We find that the persuasion treatments have no significant negative effects on beliefs on others' coca investments in any of the three samples considered. Yet, the treatment Environment actually increases the expected coca investments by others, indicating that the channel goes in the opposite direction than intended. It could be that people do not see the environment as a problem that affects them directly and may think that once others hear this argument, they may be less likely to reduce their coca investments. This result suggests that the mechanism associated with behavioral change is not related with 
beliefs. This result is also consistent with the finding that messages with a higher informative value do not result in a larger change in coca investments. We reject Hypothesis 2, and conclude:

\section{Result 3}

Persuasion treatments do not affect the beliefs on coca investments by others in the group.

Table 3.9: Treatment effects on beliefs of what others invest in coca

\begin{tabular}{lccc}
\hline & \multicolumn{3}{c}{ Beliefs Others' Investments } \\
\cline { 2 - 4 } & $(1)$ & $(2)$ & $(3)$ \\
& All & Low Density & High Density \\
\hline Treatments & & & \\
Violence & -0.269 & -0.001 & 1.913 \\
& $(1.729)$ & $(1.292)$ & $(1.643)$ \\
Environment & 0.100 & 0.130 & $2.133^{*}$ \\
& $(1.942)$ & $(1.273)$ & $(1.273)$ \\
Values & 0.117 & 0.286 & 0.000 \\
& $(1.348)$ & $(0.992)$ & $()$. \\
Quantified Violence & -0.256 & -0.656 & 1.809 \\
& $(2.070)$ & $(1.336)$ & $(1.809)$ \\
Economic Incentive & Yes & Yes & Yes \\
Municipal effects & Yes & Yes & Yes \\
Socioeconomic Controls & Yes & Yes & Yes \\
\hline Observations & 4710 & 2297 & 2413 \\
\hline
\end{tabular}

Note: Standard errors presented in parentheses. We estimate Ordinary Least Squares models. c. We include the following controls: dummy on having cultivated coca one year before the experiment, dummy for female respondents, age, religion, indicator of poverty according to living conditions, trust in local institutions, number of years cultivating coca, title over the land in 1991, economic incentives in the experiment, session fixed effects. d. Not enough observations in Values treatment in high-density areas to estimate the coefficient. Results of t-test indicated at following significance levels $* \mathrm{p}<0.1,{ }^{* *} \mathrm{p}<0.05,{ }^{* * *} \mathrm{p}<0.01$.

Another potential channel that could explain investment decisions is attitudinal change. Cues on the effects of coca on the community could have generated more negative attitudes towards coca. Hence, anti-coca attitudes should be higher in treatments where participants invest less than in the control treatment. To test this hypothesis, we regress the post experimental attitudinal questions on the same set of controls included in Equation 8 and include session fixed effects. Columns 4 to 6 in Table 3.9 present the results. Panel A presents the results for the complete sample whereas Panels $\mathrm{B}$ and $\mathrm{C}$ present the results by areas of low and high density respectively. We find that the persuasion treatments have ambiguous effects on attitudes towards coca compared with the control treatment. All treatments result in a larger fraction of respondents who agree with the statement that people cultivate coca due to need. Yet, depending on the message received, participants exhibit more negative attitudes towards coca in different questions. For instance, participants in the treatment Environment agree to a larger extent that coca brings problems to the family. Participants in the treatment 
Values disagree that coca should be legal and point at the problem of increased consumption. Participants in the treatment QuantifiedViolence agree to a larger extent that coca cultivation promotes disrespect for the law.

The results of the treatments by coca density in the region, as presented in Panels B and $\mathrm{C}$, confirm similar tendencies. Out of nine questions on attitudes towards coca, participants in persuasion treatments from low density areas expressed a more negative attitude in four questions and those in high density areas in three. Yet, for one question the attitudes towards coca were less negative. These findings lead us to believe that a change in attitudes is taking place.

\section{Result 4}

Persuasion treatments operate via changes in attitudes. Treatments that lead to lower coca investments are also associated with more negative attitudes towards coca.

\section{Impact of the message on intentions to cultivate coca in the future}

An interesting question is whether persuasion treatments have effects beyond the laboratory conditions. To asses this question, in the post experimental survey we asked: How likely is it that you will cultivate coca next year? Participants could answer in a one to five scale where one indicated not likely at all and five indicated very likely. Not surprisingly, we find that there is a significant and positive correlation between the intention to cultivate coca and the self-declared coca cultivation. The large majority of those cultivating coca declared that they would not cultivate coca next year (85 percent). Yet, only half of those who declared having cultivated in 2011, one year before the survey, declared that they would probably cultivate or be very likely to cultivate (49 percent) in the next year.

To establish the impact of the persuasion treatments on intentions to cultivate coca we run a model as expressed in Equation 8. Table 3.11 presents the results of this estimation for the whole sample and for areas with low and high density of coca. We find that the treatment ViolenceData significantly reduces the probability to cultivate coca for all areas. Yet in regions with low coca density, the probability to be willing to cultivate coca in the next year is significantly higher in the Value treatment. For areas with high coca density, two of the treatments increased the declared likelihood to cultivate coca in the future (Violence and Enviornment), while the treatment QuantifiedViolence had a negative effect. This result confirms the previous observation that in areas with high density of coca, participants react more to low information and to more salient information that in areas with low coca density. 


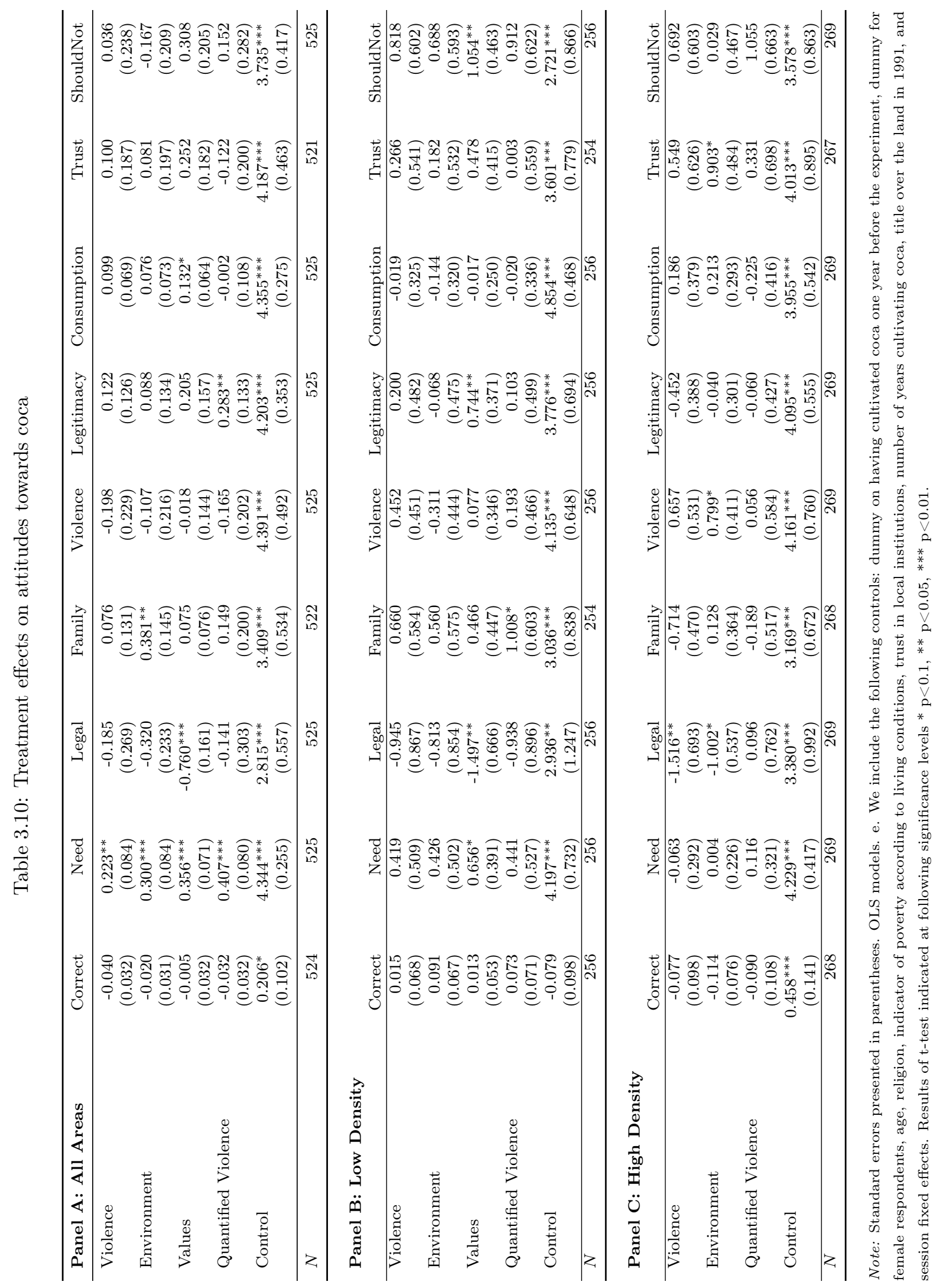


Table 3.11: Treatment effects on probability to cultivate next year

\begin{tabular}{lccc}
\hline & $(1)$ & $(2)$ & $(3)$ \\
Intention to Cultivate & All & Low Dens & High Dens \\
\hline Violence & -0.039 & -0.072 & $0.242^{* *}$ \\
& $(0.105)$ & $(0.062)$ & $(0.087)$ \\
Environment & -0.172 & -0.015 & $0.116^{* *}$ \\
& $(0.146)$ & $(0.065)$ & $(0.050)$ \\
Values & -0.025 & $-0.147^{* * *}$ & \\
& $(0.043)$ & $(0.039)$ & \\
Quant.Violence & $-0.505^{* * *}$ & -0.034 & $-0.295^{* * *}$ \\
& $(0.137)$ & $(0.094)$ & $(0.048)$ \\
Constant & $1.926^{* * *}$ & $1.819^{* *}$ & $2.388^{* * *}$ \\
& $(0.382)$ & $(0.592)$ & $(0.371)$ \\
\hline Observations & 522 & 254 & 268 \\
Num.Clusters & 21 & 10 & 11 \\
\hline
\end{tabular}

Note: Standard errors presented in parenthesis and clustered at the neighborhood level. If 19 percent or less of the population declared to be cultivating coca, the area was classified as low density. Otherwise it was classified as high density. We include the following socio-economic controls: dummy on having cultivated coca one year before the experiment, dummy for female respondents, age, religion, indicator of poverty according to living conditions, trust in local institutions, number of years cultivating coca, title over the land in 1991. Not enough observations in the Values treatment in High Density areas to estimate the coefficient. We also control for session fixed effects. Results of t-test indicated at following significance levels $* \mathrm{p}<0.1, * * \mathrm{p}<.05, * * * \mathrm{p}<.01$.

\section{External validity}

One potential concern with the experimental results is that they might have low external validity. We think that this is not the case.

First, our framed field experiment increases the external validity of the results by i) conducting the experiment with participants (coca farmers) who face similar decisions in their daily life; ii) using a frame that represents the decision context. Decisions were framed as investments in coca production or cattle farming. This feature of the experiment allows us to make salient both monetary and non-monetary dimensions affecting investment decisions in the game; iii) simulating the decision context by using parameters that capture real life values. Some evidence that supports our claim of achieving external validity is reflected by the the positive correlation between decisions in the experiment and in real life. About 90 percent of those who invested any positive amounts of coca during the experiment reported having grown coca at some point in their lives in the survey, and the longer the person had been growing coca, the more likely he/she was to invest in coca in the experiment. This shows that participants brought their own experiences to the game and is further strengthened by qualitative work with participant farmers which indicates that people considered that the game captured pretty well their decision to cultivate coca or not. When speaking about the experiment, people instantly equated their decisions in the experiment to their decisions in their daily life. Statements such as "I did not invest in coca (in the game) because I realized how bad it is for our family and we stopped growing coca last year" or "it's impossible not to invest in coca because how else can I send my children to school or feed them?" say a lot about the close link that people saw between their experimental decisions and their real life actions. 
Second, one could think that the investment decision in the persuasion treatments change not because people have internalized the message, but because they want to please the experimenter with their answers. In other words, the results of the experiment could be subject to experimenter demand effects. Yet, if participants wanted to please the experimenter, we would have seen a decrease in coca investments across all treatments compared to the control group. However, the results show that the likelihood to invest in coca varies according to the treatment (and region). Moreover, we also find significant treatment effects on responses to the likelihood of investing in the future. If people wanted to please the experimenter, reductions would not have been differential across treatments (or regions) compared to the control.

Moreover, if participants had been seeking to please the experimenter, they would have expressed more anti-coca attitudes that go in the same direction as the intervention. Hence treatments that give an example on the negative effects of coca on violence, would have also lead to higher acceptance of statements that coca is associated with increased violence in the family or increased violence in the community compared to the control group. Statistical analysis shows that this is not the case. As discussed previously, responses to the attitudinal question are influenced by each treatment in different directions. Participants change attitudes towards questions that are not directly related with the argument used or that go in an opposite direction (pro-coca attitudes).

\section{Discussion and conclusions}

Our work shows that persuasion messages that make salient the adverse consequences of coca on violence are the most effective in preventing people from investing in coca in the experiment. The results indicate that this type of intervention is more effective in areas where illegality is higher. The main mechanism behind behavioral change seems to be changes in attitudes rather than changes in beliefs.

One limitation of this study is that we are only able to capture short term effects of the type of persuasive communications used. In the future, it would be interesting to test the effectiveness of alternative interventions. For instance, it would be interesting to test the effect of interventions that highlight the positive effects of working in legality and that give hope by making the achievements of those that have switched to legality more salient. Also, since our intervention was introduced in a subtle way, it would be interesting to see what would happen if the persuasive messages were sent in a much powerful way (in songs, billboards, radio spots, for example). Similarly, it would be interesting to see how people react to the experience of others similar to them.

Another question that we cannot address in our analysis is whether short term interventions, like the ones tested in this paper, have longer term effects in coca investments. Is it enough to tell people once about the consequences of their behavior, or is it necessary to continuously bring up the same message? Could there be depreciation effects of these interventions, so that the effectiveness of using the same type of message falls over time? 
The result of our lab in the field experiment cannot predict how persuasion messages will affect coca growing decisions outside the experiment. Yet, the results of this paper are encouraging, since they confirm that persuasion messages are in fact capable of affecting behavior at least in a controlled environment. This finding suggests that alternative policies, different from carrots and sticks that are solely based on monetary incentives, can be used in the fight against drugs. Future research should focus on evaluating the effect of large-scale persuasive communications in the field. 


\section{Appendix}

\section{A1. Instructions}

The following instructions were read out loud to all participants. These are the instructions for the control group; those for the other groups are exactly the same, except that when group externalities of coca growing are explained, each treatment message is mentioned. The following instructions were translated by the authors. The original spanish instructions can be found in the online version of this document.

\section{Start}

Good morning, welcome to this workshop.

Before we begin we want to thank you for your participation. This workshop has been financed by a group of University Professors, and everything we do is an academic matter. Throughout the exercise we will not ask your name, where you live nor any other question that allows us to identify you or your family. We will carry out this workshop in different communities. For the exercise to be comparable between communities we have prepared the instructions that we will now read.

You will receive 15.000 pesos (8 USD). There are two conditions for you to receive this money. The first one is that you participate in this workshop. The second is that you complete the survey that we will have in the afternoon. Although participating in both activities entitles you to these 15.000 pesos, you can end up with more or less than this amount depending on the decisions that you make during the workshop, as well as on the decision on other participants from your group.

We will start by randomly forming groups of 5 . The groups will remain the same during the workshop. You will not know during or after the workshop who was part of your group.

How long is the workshop?

This workshop will last approximately 2 hours. You will have to make 9 different decisions. The decisions seem very similar at first, but they are different. This is why it is important that you carefully think about each one of them and consider what you would do if in reality you had to make these decisions.

Which type of decisions will you have to make?

In each decision you have 1 million pesos (526 USD approx.) to invest in coca or cattle. For each 100.000 pesos that you invest in coca you obtain 1.250 .000 pesos. For each 100.000 pesos that you invest in cattle raising you will get $250.000,550.000$ or 850.000 pesos depending of which of the 9 decisions is taking place. You have to decide how much you want to invest in coca and how much you want to invest in cattle. You can invest any amount between 0 and 1 million pesos. You are free to decide how you want to invest, but at the end the whole million has to be invested. Your investment has to happen in units of 100.000. For example, you can invest $0,100.000,200.000,300.000$ pesos, etc., but you can’t invest 10.000, 50.000, etc. 
[THIS IS WHERE THE TREATMENT MESSAGES ARE MENTIONED DEPENDING ON THE TREATMENT FOR EACH SESSION]. Coca generates negative effects on society. To represent the damage that coca generates on the community, we will discount 212.5 pesos for every 100.000 pesos invested in coca in the group. This discount applies to all the persons in the group, regardless of whether each grew coca or not.

Since coca is illegal, there is a risk that authorities find out that you are growing coca. If your investment is discovered, for each 100.000 that you invest in coca you will have to pay a fine of 1.500.000 pesos. However, like in real life, authorities not always discover you. To determine whether you are discovered or not, we will take a ball from a bag. If the ball is green you are not discovered. If the ball is red you are discovered and fined. In some decisions all balls will be green, so there will be no risk of being caught. In other decisions there will be two red balls and 8 green balls, meaning that the risk of being caught is $20 \%$. In other decisions there will be three red balls and 7 green balls, so that the risk is $30 \%$.

Correct guess

Your second assignment is to guess how much others from your group are investing in coca. You can increase your income by guessing correctly how much the others invested in coca. The closer your guess is to what others did, the higher your payment. If you guess the exact value that others are investing, you get 1000 pesos more. If your guess is more or less 100.000 pesos difference, you receive 500 pesos and if your guess is between 100.000-200.000 pesos different than the real value you get 200 pesos. If you are off by more than 200.000 pesos you don't receive anything. Do you believe others will do the same as you? Do you think they invest more than you in coca? Do you think they invest less than you in coca?

Procedure

You will receive 9 decision sheets like the one on the board.

\section{DECISION A}

You have 1.000.000 pesos that you can invest in coca or in cattle.

For every 100.000 pesos invested in coca you get 1.250 .000 pesos.

For every 100.000 pesos invested in cattle you get 250.000 pesos.

The impact that coca generated is so that for every 100 thousand pesos invested in coca each person in the group loses 212.500 pesos.

Coca is illegal. If you are discovered investing in coca you will have to pay a fine of 1.5000 .000 pesos for each 100.000 pesos invested in coca.

In this decision there is no risk of being discovered.

1. How much do you want to invest in coca?

2. How much do you want to invest in cattle?

3. How much do you think others will invest in coca? 
The heading of the decision sheet explains the payment conditions for each activity. [In our example, read the first three lines.] Then the sheet explains the negative effects that coca has and the cost that this entails [read treatment] The next line explains how risky it is to grow coca. [Read line on coca is illegal] Next you see the questions that you need to answer. The first is how much you want to invest in coca. Let's say that I invest 700.000 in coca. Write 700.000 in the box. The second question is how much you want to invest in cattle. If I invested 700.000 in coca, how much do I have left for cattle? 300.000 pesos. Write 300.000 in the box. The total sum of your investment in coca and cattle should be 1.000 .000 pesos. It's not necessary that you write down the sum, but you need to do it in your head. The last line asks how much you think others will invest in coca on average. This is the value that you have to guess! For instance, I think others will invest the same as me, then I write 700.000, or more, or less. In other words, I think on average they will invest 700.000 .

How are your payments calculated?

In our example I invested 700 thousand in coca, and 300 thousand in cattle. How do we calculate the return of our investment in coca? How many times is 100 in 700 ? 7 times, so that income for coca investment is 7 times 1.250.000, which is: 7 times 0 ? - 0,7 times five?- 35 [write down and calculate together on the board and say each step out loud] 5 and 3 remain. 7 times 2? 14, and 3 ? 17 , seven and we keep 1. 7 times 1 , seven, plus 1,8 . This means that for every 700.000 pesos invested in coca you receive $\$ 8.550 .000$ pesos. What is my income for my investment in cattle? How many times is 100 in 300 ? 3. Then, my income would be 3 times 250.000 pesos. How much is this? 750.000 pesos. The total amount of my investment is 9.500 .000 pesos. Let's suppose others invest in average 700.000, like I thought. Given the negative effects of coca, there is a reduction for all group members. In our example, I invested 700.000 pesos in coca and the others on average 700.000.How much was invested in total in the group? 5 people in the group times 700 thousand is 3.500 .000 . For each thousand pesos invested in coca there is a discount of 212.5 thousand. How many times is 100 thousand in 3.500.000? 35 times. So the reduction for investing in coca for each group member is 35 times 212.500 . This amounts to $\$ 7.437 .500$ pesos [Taking off 3 zeros], or approximately 7.438. My total income is thus 9500 (9.500.000 pesos) minus $7.438(7.438 .000$ pesos $)$, for a total of $2.062(2.062 .000)$ pesos. Since we come from a university, in the workshop we will not pay you 2 million. Instead, we will pay you the 1 per thousand of what you got for your investments. This means that in this example we would pay you 2.062 pesos. With an approximation, you would receive 2.100 pesos. In this example I guessed the exact value of what others invested, so as a prize I receive 1000 more. Additionally, I had received 15.000 for taking part in the workshop, so in total I receive 18.100 pesos (9.8 USD). Coca 100 thousand pesos give 1.250 (one million two hundred fifty thousand pesos). Invest $700700 / 100=7$ Receive: $7 x 1.250=8.750$ Cattle 100 thousand pesos give 250 thousand pesos. Invest $300300 / 100=3$ Receive $3 \times 250=750$ Income for Investments 9.500 Reduction for coca 100 thousand pesos in coca reduce income in 212.5700 in coca on average $700 * 5=3535 * 212.5=-7.438$ Net investment $2.062^{\sim} 2.100$ Correct guess 1.000 Payment for participation 15.000 Total payoff 18.100 
Let's now suppose that we are dealing with a decision where we can get caught by the authorities. Let's suppose I did the same investment as before, this is, that I invested 700 thousand in coca and 300 thousand in cattle. What happens if I get a green ball?- I get the same income that we calculated. What happens if I get a red ball? For each 1 thousand invested in coca, the authorities fine me with 1.500 pesos. This means that if I am caught I need to pay a fine of $1500 \times 7=10.500$. My payoff when I was not caught was 18.100 . If I take out what I had to pay as a fine, I am left with 7.600 pesos. Total payoff if not caught 18.100 Coca fine 100 thousand pesos in coca give a fine of 1.500 (one million five hundred) if caught 700 thousand in coca $700 / 100=77^{*} 1.500=-10.500$ Total payoff if caught 7.600

Let's see another example. Let's suppose that you invest 400 thousand pesos in coca. How much is left for investing in cattle? 600 thousand pesos. How much do you receive for your coca investment? How many times is 100 in 400 ? 4. Your income is then 4 times $1250=5000$ ( 5 million). How much do you get for cattle? 100 is 6 times in 600 , so 6 times $250=1.500(1.500 .000$ pesos). In total you receive 6.500 (six million 500 thousand pesos) for your investments. If others invest on average 700 thousand in coca, total investment in coca is $700 \times 4+400=3200$. (3 million 200 thousand pesos). The reduction for investing in coca is 32 (100 is 32 times in 3200 ) times $212,5=6.800$ (six million 800 thousand pesos). Your income is 6.500 (six million 500 thousand pesos), minus 6.800 (six million 800 thousand pesos), for a negative balance of 300 (300 thousand pesos). But don't worry, you don't have to pay from your pocket. As we had already explained we will only pay the one in one thousand so you will lose 300 pesos. These 300 pesos we will take from the 15.000 that we gave you for participating in the workshop and survey. So, in the end you will receive 14.700 pesos. This is if you are not caught by the authorities. Coca 100 thousand pesos give 1.250 (one million two hundred fifty thousand pesos). Invest $400400 / 100=4$ Receive: $4 x 1.250=5000$. Cattle 100 thousand pesos give 250 thousand pesos. Invest $600600 / 100=6$ Receive 6 x $250=1500$. Income for Investments 6.500 . Reduction for coca 100 thousand pesos in coca reduce income in 212.5700 in coca on average $700 * 4=28$ $28+4=3232^{*} 212.5=-6.800$ Net investment -300 . Correct guess 0. Payment for participation 15.000. Total payoff 14.700

What if authorities discover you-a red ball appears? You are fined. And what is the amount of the fine? 4 times $1.500=6.000$ (six million pesos). From this amount you only need to pay the 1 per thousand, which is 6.000 pesos. If you are discovered you will receive 8.700. If your guess is incorrect you don't receive any payment. Total payoff if not caught 14.700 . Coca fine 100 thousand pesos in coca give a fine of 1.500 (one million five hundred). If caught 400 thousand in coca $400 / 100=44^{*} 1.500=-6.000$. Total payoff if caught 8.700 .

Implementation

During the workshop you will have to make 9 decisions, but only one will be paid at the end. To determine which decision will be paid we will select one of the 9 cards marked with letters A through I. The letter that is randomly selected will determine which decision to pay. The decision will be the same for all participants. So that we keep everything confidential, you will receive your payment in an envelope marked with your participant number. 
Procedure

We will begin by assigning seats to everyone in the room. Once you all have a seat we will pass around an id number. This is the number we will use in the survey. If for any reason you lose it, we won't be able to pay you. Do you have any questions until now? Once we start you can't talk to anyone in the room. If someone starts talking he/she won't be able to participate in the workshop or in the payments anymore. If you have a question please raise your hand and one of us will go to your seat an assist you. If you want to change any of your decisions, please cross out with a line what you want to change and give your new answer next to it. Once you complete all your decisions we will pick up your sheets and we will proceed to determine which decision will be paid by taking out a card at random. This decision holds the same for everyone in the group. If necessary, we will decide whether you get caught or not by taking a ball out of the bag. Whether or not there is control applies to everyone in the group.

Workshop starts

Now we are going to begin the workshop. We are you to please come to the front so we can assign the seats. \{Assign seats and hand out practice round\} Practice Round Before we start with the investment decisions, we want to do a practice round. The idea is to be sure that we have explained to you clearly what you have to do. These decisions will not affect your payment.

\section{A2. Variable definitions}




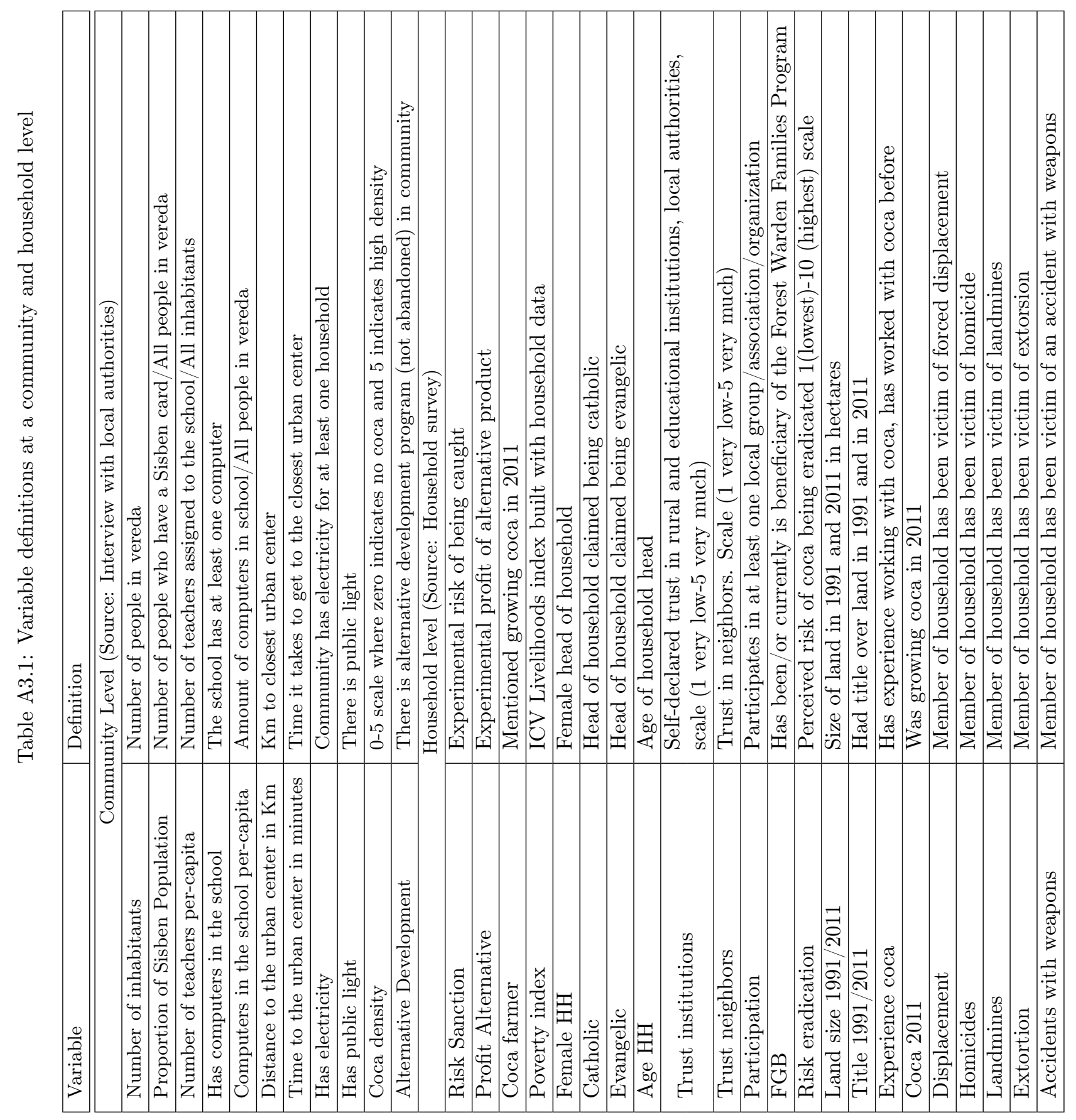




\title{
5. Changing minds and winning hearts: A natural experi- ment in Colombia ${ }^{\dagger}$
}

\begin{abstract}
Policy makers face a big challenge when designing policies whose effects depend on their interaction with other governmental actions. With a framed field experiment we study the effectiveness of two types of public policies in achieving legality and also look at their combined effect when interacted. We focus on policies that activate social norms within communities and on those that use standard deterrence mechanisms. Our experiment takes place in a coca growing area in Colombia, where we can study the impact of an alternative development program on the farmers' willingness to invest in coca and to establish mechanisms of social control. We find that the program enhances coca reduction and increases internal social control. In turn, internal control mechanisms decrease coca investments among program beneficiaries and social control is triggered when people observe other group members deviate from legality. By having exogenous punishment interact with internal compliance mechanisms, we find that external punishments that make whole groups liable crowd-out internal control mechanisms; whereas those that make individuals liable for their actions enhance internal social control. We conclude that by giving farmers incentives to act legally, there are positive effects that lead to enhancing compliance and reducing the need to rely explicitly on costly external punishment.
\end{abstract}

Keywords: Public policy, social norms, alternative development, compliance, framed field experiment, Colombia

JEL codes: K42, D74, D04

\footnotetext{
$\dagger$ Joint work with Marcela Ibanez. We would like to thank Axel Dreher, Michael Grimm, Gerhard Riener for valuable comments and suggestions. Special thanks to Econometria Consultores, Redes Ltda and Jacob Murillo for their outstanding support in carrying out the field work and the experimental sessions.
} 


\section{Introduction}

Extensive theoretical and empirical evidence supports the effectiveness of monetary incentives to align individual and social interests. However, the use of such incentives poses the question of whether these policies are sustainable and of how long can the government afford to pay people to do what they should be doing in the first place. One view is that a public policy can be used as an instrument to educate citizens by expressing social values towards what is right or wrong (Cooter, 1998; Cooter and Bohnet, 2003; McAdams, 2000). This would generate feedback effects, understood as the spillovers between policies, ${ }^{1}$ that translate into higher levels of sustainability of law compliance after monetary incentives are gone in the future. In this paper, we investigate this hypothesis and consider the feedback effects of monetary incentives on attitudes towards illegality, captured as the willingness to invest in illegal crops.

The context of our analysis is the fight against drugs in Colombia, one of the main producers of coca in the world. We focus on the Forest Warden Families Program (henceforth FGB), the country's flagship alternative development program, and the main "social" strategy in the fight against drug production. This program seeks to reduce coca cultivation by implementing voluntary agreements with the community, by which beneficiaries receive bimonthly payments conditional on keeping their territories free of coca. Compliance with the agreements is verified using satellite information and field inspections. If coca is detected, all members of the community lose the bimonthly remuneration. This program seeks to achieve a sustainable transformation towards the legal economy through three mechanisms: First, the monetary subsidy will allow coca farmers to switch to legal activities and learn the advantages of legality. Second, educational workshops aim at changing the attitudes towards illegality that will "eradicate coca from people's mind and heart." Third, by making farmers jointly liable in case of the re-appearance of coca in their community, the program aims at generating a social norm by establishing social control mechanisms. We ask: Does FGB achieve a permanent change in norms promoting a culture of lawfulness? Does it reduce farmers' willingness to invest in coca? Does it foster mechanisms of social control?

Monetary incentive-based policies, as the one implemented in FGB program, could generate positive feedback effects or externalities that translate into more pro-social behavior, assuring the sustainability of the legal activities in the future, once the economic incentives are gone. Yet, monetary incentives like this could also signal that anti-social behavior is expected and induce more anti-social behavior. Which of these two effects dominate is an empirical question.

We investigate the effect of the FGB program on the culture of lawfulness using a modified version of Ibanez and Martinsson's (2013) framed field experiment. Participants are randomly matched in groups and receive an endowment that they distribute between a secure but low return legal crop (cocoa) and the more profitable but illegal coca crop, that is also associated

\footnotetext{
${ }^{1}$ Mejia and Restrepo (2013) specifically use feedback effects as spillovers between policies in the drug market, by which they explicitly model the feedback effect between different anti-drug policies such as eradication and interdiction. Other studies in the drug literature that incorporate spillover effects in illegal markets are Becker et al. (2006), Naranjo (2004) and Chumacero (2008).
} 
with negative externalities to the community. To investigate the effectiveness of supply control policies, we implement external sanctions in some treatments, where with probability $p$ investments in coca are monitored and costly sanctions are imposed when coca is detected. We use two alternative sanction systems. The first system mimics the sanctioning in the aerial spraying program by making the whole group liable. The second sanctioning system makes individuals liable for their actions imposing individual sanctions, as it would be the case with manual eradication, incarceration or land expropriation. To simulate the effect of social control, in some treatments participants can use costly sanctions to signal disapproval over the investment decisions of others. We test the effects of program participation on: investments in coca, willingness to impose costly sanctions and response to sanctions.

To identify the impacts of the program on the culture of lawfulness, we explore the progressive time expansion of the program and compare beneficiaries, with those who although willing to participate in the program were not selected due to budget restrictions. First, we show that beneficiary and not beneficiary veredas ${ }^{2}$ were similar before the program was implemented in most observable characteristics such as having coca crops, distances to the local markets and institutional presence, among others. Second, we show that beneficiaries and non-beneficiaries who participated in our study were very similar before the program started. These two findings support our identification strategy.

We find evidence that participation in the program allows to "change minds and win hearts": Beneficiaries of the program invest less in coca and are more likely to establish mechanisms of social control than the control group of participants. We detect crowding in and out effects of external social control on social sanctioning. Yet, the direction of the effect depends on the type of external punishment used. When the whole group is made liable in case of detection, external control crowds-out social sanctions, whereas in the case of individual liability it crowds them in.

This paper contributes to different areas of research. Legal scholars and political scientists propose that policies express social values on what is right or wrong and help to coordinate the behavior by altering beliefs of what others will do (Cooter, 1988; Feldman, 2011 and McAdams, 2000 ) or by generating an educational or feedback effect that translates into behavioral changes (Mettler and Soss, 2004; Soss and Schram, 2007 and Svallfors, 2010). Recent, empirical studies from the economics field has provided evidence supporting that institutions can shape social preferences. For instance it has been shown that there are significant and persistent differences between East and West Germans in various individual and social preferences (Ockenfels and Weimann, 1999; Alesina and Fuchs-Schündeln, 2007; Svallfors, 2010; Brosig-Koch et al., 2011). Similarly, Kotsadam and Jakobsson (2011) find that implementation of anti-prostitution rules in Norway changed attitudes towards this activity. We present the first paper, to the best of our knowledge, that investigates the feedback effects of policies that pay people to comply with the law.

\footnotetext{
${ }^{2} \mathrm{~A}$ vereda is the smallest geographical division in Colombia. In this paper we speak about communities and veredas interchangeably, since those living in a vereda are usually thought as communities themselves.
} 
The second contribution of this paper is on the research on procedural justice. Tyler (1990) proposes that the procedures used in the implementation of the law can affect the perceived legitimacy of the institutions affecting law compliance. In this paper, we consider whether the fairness of the policies affect norms of compliance. In particular, we compare the effectiveness of mechanisms of external control based on joint liability with those based on individual liability. We expect that mechanisms of external control based on joint liability can be regarded as unfair, as the innocent are also punished, crowding-out compliance.

Third, we contribute to the evaluation of the effectiveness of anti-drug efforts in Colombia. While most of the studies focus on the effectiveness of eradication policies (Mejia and Restrepo, 2008; Ibanez and Carlsson, 2010; Ibanez and Martinsson, 2013; Ibanez, 2013; Mejía et al. 2013; Rozo, 2014; Reyes, 2011), we focus on the impact of alternative development, a topic that has received relatively less attention in the academic literature ${ }^{3}$ (an exception is Martinez, 2008). The focus of our research is however very different. Instead of focusing on the effectiveness of the program, measured as the decrease in areas cultivated with coca, we consider the effects of the policies on attitudes towards coca as captured by experimental measures, and on on how alternative development can be interacted with other anti-drug policies. This research is complementary to our work on the effects of participation in the FGB Program on honesty (Chapter 3).

Fourth, we contribute to the literature on punishment and social sanctions. Ample experimental and non-experimental evidence has shown that individuals are willing to incur in costly actions to sanction anti-social behavior (Ostrom, 2000; Carpenter and Matthews, 2004; Carpenter, 2007; Fehr and Gächter, 2000). The mere fact of receiving negative feedback from other members of society has been shown to alter people's behavior even when there are no monetary costs attached on the sanction (Bohnet and Frey, 1999; Ostrom and Walker, 1997; Ostrom, 2000; Gächter and Fehr, 1999; Rege and Telle, 2004; Fehr and Falk, 2002; Masclet et al., 2003; Sutter et al., 2007). Moreover, it has been shown that external punishment has a deterrent effect on anti-social behavior (Cameron, 1988; Andreoni et al., 1998). Yet, the interaction of external and social sanctions has not been investigated. This paper fills that gap in the literature and explores how social control interacts with different ways of applying external sanctions. Our second contribution to this area is that we investigate the dynamics of social norms of sanctioning. Yet, unlike existing papers that consider the dynamics of social sanctions within repeated games, we consider how exogenous variation in exposure to legality affects the willingness to use social sanctions. Hence our research has a similar flavor as Banerjee et al. $(2013)^{4}$ and Asiedu and Ibanez (2013).

The rest of the paper is organized as follows. Section 2 gives some background information on the FGB program. Section 3 discusses the identification strategy used. Section 4 presents the

\footnotetext{
${ }^{3}$ Outside of academia, the UNODC carried out monitoring of the Program's result in all of its waves and studied its changes over time. These studies can be found here: http://www.unodc.org/colombia/en/da2013/publicaciones.html. Moreover, the Colombian National Planning Department (DNP), together with the Program Against Illegal Crops (PCI) and the FGB Program itself commissioned a results and impact evaluation of the Program carried out in 2011-2012 by Econometria Consultores. However, this evaluation was carried out internally and as of now has not been made public.

${ }^{4}$ Work in progress, not out as working paper.
} 
experimental design while section 5 discusses the main hypothesis of the study. The experimental procedures are presented in section 6 . Section 7 presents the results regarding investments in coca and use of mechanisms of social control and the last section closes with some final remarks and conclusions.

\section{Local background}

\section{The war on drugs}

In 1971 US President Nixon declared drug abuse as a major public enemy and in response launched the war on drugs. Billions of dollars are being spent each year mainly in supplyreduction strategies. Colombia, one of the major producers of cocaine in the world, spent annually between 2000 and 2008 about 1.1 billion dollars only in the military component of the fight against drugs, costing the country almost as much as the annual public investment in higher education (Mejia et al. 2013). ${ }^{5}$ Given the high economic costs of this policy, and the evidence that raises serious questions on its lack of effectiveness (Mejia et al., 2013; Ibanez, 2013; Rozo, 2013; Reyes, 2011; Moreno-Sánchez et al., 2003), new alternative policies and strategies need to be evaluated.

\section{Forest Warding Families Program - FGB}

The emphasis of our study is on Colombia's flagship Alternative Development (AD) program: "Familias Guardabosques" - FGB (Forest Warden Families). FGB targets areas with high environmental value that already have or are very likely to grow coca and that show other geographic or socioeconomic vulnerabilities. Beneficiaries of the FGB program receive a monetary subsidy payable for a fixed number of years without the option of reentering the program. ${ }^{6}$ In exchange, communities promise to manually eradicate all their coca crops before the Program officially starts, and ensure that the community remains a coca free territory during the intervention. The United Nations Office on Drug and Crime (UNODC) verifies that the community starts and remains coca free using satellite information to identify areas where coca is being cultivated, and also carries out field inspections. If coca reappears, the Program ends and all the households from the community lose their benefits independently on whether they kept their land free of coca or not.

The program seeks to achieve a sustainable transformation towards the legal economy by three main built-in hypotheses. First, that to abandon coca, families need to learn to live in the legal economy. Hence, families are offered an economic incentive that enables them to start a

\footnotetext{
${ }^{5}$ Colombia's policy on the war on drugs is based on a two-sided strategy that combines stick-type and carrottype policies. On one hand, eradication (stick policy) focuses on the destruction of illicit drug plantations by aerial spraying of herbicides or by manually pulling out the crops. On the other hand, alternative development (carrot policy) aims at increasing the opportunity cost of cultivating coca by providing legal alternatives to coca.

${ }^{6}$ This program has been implemented in seven different phases. Depending on the implementation phase the cash amounts paid, the number of years they can benefit and compulsory saving rules have changed.
} 
food security project, while building a seed capital to start a legal productive project. Second, that coca must be eradicated not only from people's fields, but also from their minds and especially from their hearts. In consequence, a common denominator in the FGB has been the promotion of culture of lawfulness through workshops. Third, that coca eradication is sustainable if communities develop mechanisms that prevent other community members from growing it. In fact, a prerequisite of the program is that communities create a "verification committee" that ensures that their vereda is coca free and works together with UNODC during the annual inspection. This study aims at investigating the success of the program in changing attitudes toward coca.

\section{Identification strategy}

To evaluate the impact of the FGB Program on the attitudes towards coca (as captured in the willingness of people to invest in it), we benefit from the progressive expansion of the program in the region. We compare communities that benefit from the program with those that although willing to start the program have been allocated to start in a later stage. In the following paragraphs we explain the criteria used to select beneficiaries and present evidence that supports the progressive implementation of the program in otherwise similar communities.

Eligibility to the FGB program is defined in a step-wise procedure. First, the central government prioritizes municipalities using a targeting index that is based on the region's illegal crop affectation, its ecological value, the potential effect over the population, and the complementarity with other investment programs. ${ }^{7}$ Based on these criteria, municipalities are classified in a scale that goes from one to four, where one represents highest priority level of being selected. Table 4.1 shows how the program has been rolled out. It is important to note that since the Program began in 2003, every two years at most a new wave was starting. The largest influx of beneficiaries came in wave IV (the payment and duration were reduced and thus more people were treated), but overall, the priority level of the incoming municipalities has been very similar. Only the sixth phase that was aimed at preventing coca to enter regions that had been hardly hit by heavy rains is not comparable. The differences between the phases were mainly the duration and amount of the conditional payments and the way the savings component ${ }^{8}$ was designed.

\footnotetext{
${ }^{7}$ The components used to build the index are: number of hectares affected with illicit crops, whether the municipality belongs to a strategic eco-region, whether the region is an important trafficking region, the population affected and the impacts over ecosystems.

${ }^{8}$ The FGB Program wants its beneficiaries to save and has established different mechanisms to do so. First it was voluntary, then every beneficiary had to save in a group-account and in the last version the Program keeps part of their payments and gives it back when they agree on the productive investments that they want to make.
} 
Table 4.1: Phase-in of the Program in its initial seven waves

\begin{tabular}{llllllll}
\hline $\begin{array}{l}\text { Program } \\
\text { Wave }\end{array}$ & $\begin{array}{l}\text { Starting } \\
\text { year }\end{array}$ & Departments & Municipalities & Veredas & $\begin{array}{l}\text { New } \\
\text { municip }\end{array}$ & Families & $\begin{array}{l}\text { Mean } \\
\text { target index }\end{array}$ \\
\hline I & $2003-2004$ & 7 & 13 & 352 & 13 & 18,392 & 18.0 \\
II & $2005-2006$ & 13 & 34 & 709 & 26 & 17,832 & 20.0 \\
III & $2006-2007$ & 11 & 24 & 434 & 21 & 17,406 & 24.0 \\
IV & $2007-2008$ & 15 & 44 & 828 & 42 & 33,546 & 23.6 \\
V & 2008 & 10 & 25 & 763 & 19 & 19,743 & 24.6 \\
VI* & 2009 & 3 & 7 & 136 & 7 & 7,408 & 16 \\
VII & 2010 & 10 & 25 & 344 & 11 & 8,664 & 23.9 \\
\hline
\end{tabular}

Source: Forest Warden Families Program

*The VIth phase was intended at those municipalities that had suffered greatly from heavy rains, and it operated in a different fashion. It intended to prevent the introduction of illegal crops when people were economically vulnerable.

In a second step, local representatives of the alternative development Program prioritize the eligible veredas. First, they consider whether the veredas comply with legal requirements for participation. In particular, that they are are not located inside national parks or areas of conservation (as defined by the municipality). Second, local officials asses the ecological value of the vereda by considering the presence and state of ecological systems, the supply of environmental services and the existence of forests. The third criteria used considers the socioeconomic conditions like the willingness of the community to participate in the Program, the potential number of beneficiaries and the organizational capacity of the community. Another criteria considered is the economic sustainability of the Program. Hence, local representatives consider the ability of the community to establish food security projects and evaluate the experience of beneficiaries with strategic crops promoted by the Program. Finally, to guaranty the successful implementation of the intervention, local officials evaluate the security conditions to work in the area.

Table 4.2 presents the tabulation of municipalities according to the priority level assigned and whether they are selected or not to benefit from FGB. We see that out of 1120 municipalities in the country, 130 are classified as very high priority while 281 are classified as high priority. We also see that of those municipalities assigned to these categories, only a fraction are selected as beneficiaries of the FGB program. Not surprisingly, we observe that the proportion of municipalities selected to participate decreases as the degree of priority falls. Yet, we see that a significant fraction of municipalities classified in the highest level of priority do not benefit from the program. Hence, in the analysis, we use this overlap to identify the impact of the program on farmers' attitudes towards coca. 
Table 4.2: Priority to participate in the Program

\begin{tabular}{lccc}
\multirow{2}{*}{ Priority } & \multicolumn{2}{c}{ FGB Beneficiary } & Total \\
\cline { 2 - 4 } & 0 & 1 & \\
\hline Very High & 67 & 63 & 130 \\
High & 222 & 59 & 281 \\
Medium & 331 & 3 & 334 \\
Low & 366 & 9 & 375 \\
\hline Total & 986 & 134 & 1,120 \\
\hline \multicolumn{4}{l}{ Source: SIG, UNODC. }
\end{tabular}

To identify the impact of FGB we compare farmers who live in communities that were actually selected to benefit from the program, with the norms of compliance of farmers who despite being willing to participate in the program were not selected. Both types of communities are located within the same municipalities and, according to program officials, are willing to take the program. This means we have an intention to treat set up, where we are not directly evaluating the impact of FGB on its direct beneficiaries, but on households that live in a vereda that had beneficiaries, ${ }^{9}$ even if some or even most of the participants were FGB beneficiaries themselves.

A critical assumption in our identification strategy is that selection to participate in the program was as if random. While this hypothesis is not directly testable in our data, we compare the socioeconomic characteristics of beneficiaries and eligible beneficiaries and test for differences in the distribution of observables (See Section on Results).

\section{Experimental design}

Our experimental design is based on Ibanez and Martinsson's (2013) coca investment game. Participants are randomly and anonymously placed in groups of three, which remain constant through the entire session. Each participant receives an endowment of COP $\$ 100,000$ (USD 50) and has to to decide how to invest it in two alternative crops: coca or cocoa. The endowment is given to them in ten bills of $\$ 10,000$ that cannot be broken down into lower amounts. Simulating real conditions we allow coca to be more profitable than cocoa. Hence, for each bill invested in coca participants receive $\$ 160,000$ pesos (80 USD) in return, while each bill invested in cocoa gives $\$ 70,000$ pesos (35 USD). So the marginal return from investments in the alternative are almost half the return from coca.

The second feature replicated in the experiment is that investments in coca are associated with negative externalities. In coca growing areas, illicit armed groups dispute the control of the territory, which results in increased violence (Diaz and Sanchez, 2005). ${ }^{10}$ To capture this

\footnotetext{
${ }^{9}$ There is evidence of large spill-over effects from beneficiary households to non-beneficiary households within the same vereda. One reason is that although these non-beneficiaries did not receive payments, they were invited and welcomed to all of the workshops and FGB activities.

${ }^{10}$ In this setting we leave negative externalities as a general comment. However, Chapter 3 explores what happens when these externalities are made salient.
} 
feature, in the experiment we reduce the participants' payoff by $\$ 35,000$ pesos (17 USD) per bill of coca invested in the group. All participants in the group are affected by the negative externalities of coca, even when they are not investing.

After making investment decisions, participants receive feedback on their own payments and on the coca investment decisions of the other two group members. This decision problem is repeated five periods. Yet, to avoid ending-point effects participants do not know for how many periods the game will last. ${ }^{11}$

The pay-off for subject $i$ when can then be expressed as:

$$
\Pi_{i}=c_{i}+a\left(10-c_{i}\right)-b \sum_{i=1}^{3} c_{i}
$$

where $c_{i}$ is the amount invested in coca cultivation and $a$ is the relative profit.

In this situation, the marginal incentive to cultivate coca is larger than the marginal incentive of the alternative, net the cost of the externality $(c-a-b>0)$. Hence, the optimal individual decision is to invest all the endowment in coca. Yet, as the social cost of investing in coca $(3 *$ $35.000=105.000)$ is larger than the marginal incentive to cultivate in coca $(160.000-70.000=$ $90.000)$, socially it is better that nothing is invested in coca. The social dilemma created in the framed field experiment recreates behaviors that are close to real life, as mentioned by Lusk et al. (2006).

We frame our coca investment game as we consider that framing the investment problem between illegal coca and legal cocoa would make the decision more context-relevant and help participants understand their decision problem, making it as similar as possible to their real-life investment decisions.

\section{Experimental treatments}

Our experiment uses a between subject design with six different treatments. In the control treatment (T0) we allow participants to make investment decisions in the absence of control and sanctioning mechanisms. Hence this treatment captures how norms of compliance or noncompliance develop in the absence of drug-reducing interventions.

To test the effectiveness of different mechanisms on reducing illegal crop cultivation, we use five treatments that allow external control, social sanctions or both to be available. Besides, to test how the perceived fairness of the punishment mechanism affects compliance, we allow external control treatments to use either individual or group liability. Table 4.3 summarizes the treatments used in the experiment.

\footnotetext{
${ }^{11}$ At the beginning of the game we give them answer sheets for every round. We give them more answer sheets that rounds played.
} 
Table 4.3: Experimental treatments

\begin{tabular}{llll} 
& & \multicolumn{2}{c}{ Social Control } \\
\hline \multirow{3}{*}{ External Control } & No & Yes \\
\hline & Joint Liability & T0 & T2 \\
& Individual Liability & T3 & T4 \\
& T5 \\
\hline
\end{tabular}

In the treatment that exercises external control with joint liability (T1) participants get to know that there is a chance, $p$, that authorities discover the coca crops and destroy them. The probability of being discovered is set at $30 \% .{ }^{12}$ If the group is caught, all group members get their income reduced independently of whether they were cultivating coca or not, hence the joint liability. For each bill invested in coca in the group, the income is reduced by $\$ 90000$ (45 USD) for each person in the group independently on whether they were individually investing in coca.

The expected pay-off for subject $i$ when they are not discovered, which happens with probability $(1-p)$ is expressed in Equation 9, while the expected pay-off in case of being discover is equal to:

$$
\Pi_{i}=c_{i}+a\left(10-c_{i}\right)-b \sum_{i=1}^{3} c_{i}-f \sum_{i=1}^{3} c_{i},
$$

where $f$, is the cost of the sanction. Compared with the control treatment, the marginal incentive to invest in coca is lower in this treatment. Yet, as the marginal incentive to cultivate coca is still positive $(c-a-b-p f>0)$, risk neutral individuals would not be deterred by external sanctions. Hence, it is expected that a risk neutral individual would invest all the endowment in coca.

Treatment 2 (T2) introduces endogenous internal control and no external control. Participants have the chance to implement a mechanism of social control that operates in every round, and there is no probability of being caught, as there is no external punishment. Yet, they have to decide whether they want to incur in costly punishment in order to control coca investments of other group members; at a very low cost of $\$ 50$ pesos (3 US cents) they can send sad faces to reduce the other's income in $\$ 100$ (5 US cents) for each face received. As before, the expected pay-off for subject $i$ when they are not sanctioned is expressed in Equation 9, while the payoff in case of sanction is:

$$
\Pi_{i}=c_{i}+a\left(10-c_{i}\right)-b \sum_{i=1}^{3} c_{i}-r F s_{i}-s F r_{i},
$$

where $r$ and $s$ are the number of sanction points received and sent, respectively and $F_{r}$ and $F_{s}$ are the cost of receiving sanctions and sending sanctions. Sending sanctions is costly, so

\footnotetext{
${ }^{12}$ This experiment leaves the probability of being caught constant at $30 \%$. In other experiments (Chapter 4) $\mathrm{p}$ is allowed to vary between $10 \%$ and $30 \%$ and we find that people do in fact respond negatively to increases in $\mathrm{p}$, by decreases their coca investments.
} 
the optimal decision for participants is not to sanction anti-social behavior. Therefore, social sanctions are not deterrent (decision is simplified to Equation 9) and individuals should invest all their endowment in coca.

The institution with external control and individual liability (T3) is identical to T1 except that if coca is discovered only the person responsible is held liable. For each bill invested in coca the guilty participant's income diminishes by $\$ 90000$. In this case the pay-off in case of being discovered, which happens with probability $(p)$ is:

$$
\Pi_{i}=c_{i}+a\left(10-c_{i}\right)-b \sum_{i=1}^{3} c_{i}-f c_{i} .
$$

The marginal incentive to invest in coca in this treatment is equal to that in (T1), so the optimal decision is to invest all the endowment in coca.

The last two treatments ( $\mathrm{T} 4$ and $\mathrm{T} 5$ ) combine exogenous control with individual or joint liability (T1 and T3) with endogenous internal control (T2). These two treatments also imply that the optimal decision is to invest all the endowment in coca.

All parameters used in the experiment reflect real life in terms of risk of being caught and relative profit to alternative products. The following calculations show what is behind the experiment's parameters: the pay-off function is standardized so that coca pays 1 (i.e., all values are divided by 160000 ); $a$ is set to $0.44 .{ }^{13}$ The value of the negative externality, $b$, is set to 0.22 . While there are no estimations on the exact social cost of coca, negative externalities are present in these regions (increased violence and environmental damage, health problems, to name a few). The external punishment for being caught $f$ is set to 0.56 . The costs of receiving $(r)$ a sad face $(F r)$ and sending $(s)$ a sad face $(F s)$ reduce the payoff function after the investment decisions have been made, as they are a reaction to what people see in the feedback form. Thus, for whatever payment they received in a given round, $\$ 50$ pesos times the number of faces sent (Fs), and $\$ 100$ pesos times the number of faces received (Fr) are deducted from the payment.

\section{Hypothesis and predictions}

Two empirical irregularities in public good games (and public bad games, as the one used in our experiment) are that people are more pro-social than the model would imply, and that people are willing to sacrifice payments in order to sanction others. To account for these irregularities, behavioral models have considered that an individual's behavior is not only driven by economic incentives but that it also depends on norms and on the behavior of others. For instance, Ibanez and Martinsson (2013) consider that individuals take into account the negative externalities generated in the decision and consider social norms regarding coca cultivation. In this case Equation 9 can be reformulated as:

\footnotetext{
${ }^{13}$ Ibanez (2010) estimated that the relative profit of the best alternative to coca was 0.5 in 2006.
} 


$$
\Pi_{i}=c_{i}+a\left(10-c_{i}\right)-b \sum_{i=1}^{3} c_{i}-M\left(b, c_{i}, m\right)
$$

where $M$ is a function that captures the moral cost of harming others by investing in coca. According to Ibanez and Martinsson (2013), this function depends on the size of the damage generated or the value of the externality, $b$, the amount of coca cultivated, $c_{i}$, and an individual parameter, $m$, that captures how "moral" a person is. A completely moral person will feel very guilty by behaving against her moral values and would suffer a large moral cost. One implication of this extension is that the marginal incentive to cultivate coca will be lower. If the marginal moral cost of cultivating coca is high enough, participants will not invest in coca even if the economic incentive to do so is positive. This model helps to conceptualize zero coca investments in the game.

This formulation can be further extended. One extension is to consider that the degree of morality, $m$, or the extent to which the person is affected by going against his moral principles is not fixed, but can be shaped by environmental factors. The hypothesis that we are interested in testing in this paper is that the individual moral cost of investing in coca is shaped by the FGB program. Following Cooter (1988) we consider that participation in FGB generates a feedback effect that translates into a change in preferences towards coca or a change in parameter $m$. As discussed previously, there are many channels by which the FGB program can affect $m$. We can not isolate the effect of each of them as they occurred simultaneously so we test for their joint effect. Our first hypothesis is:

\section{Hypothesis 1}

Participants living in communities that benefit from FGB are less prone to invest in coca and when they do, they invest smaller amounts than those that come from non-FGB veredas.

Another potential extension to the conceptual framework is to consider that individuals care about social norms. This extension can be incorporated by reformulating Equation 13 as:

$$
\Pi_{i}=c_{i}+a\left(10-c_{i}\right)-b \sum_{i=1}^{3} c_{i}-M\left(b, c_{i}, m\right)-S\left(\left(c_{i}-\bar{c}\right)^{2}, s\right),
$$

where $S$ is a function that captures the cost of deviating from the social norm that is assumed to depend on the difference between own behavior and average behavior of others, $c_{i}-\bar{c}$, and a parameter $s$, that captures the weight that the society gives to deviations from the social norm. We assume that there is a social preference for conformity so the larger the difference between a person's decisions and the decisions of others is, $\bar{c}$, the larger is the cost of deviating from the social norm. The parameter $s$ captures the importance that the social norms have; for unimportant norms, $s=0$, reflecting no social cost of deviating. Increases in $s$ would reflect more importance of the social norm and a higher cost of deviating. We assume that the 
parameter $s$ is not fixed over time but can be shaped by cohesion within a social group. The higher the sense of identification with the group, the more importance given to conformity.

One implication of this extension is that participants' investments would depend on the expected investment of others. In a repeated game, participants will converge towards the accepted social norm. If FGB beneficiaries invest less than those who are not beneficiaries, it is expected that groups formed by only FGB beneficiaries will invest less in coca over time than groups of only non-beneficiaries. Another channel that can affect behavior is that participation in FGB increases the sense of cohesion, making the norm of conformity more important.

\section{Hypothesis 2}

Only-FGB groups create norms of low investments in coca and show lower levels of coca investment over time than mixed groups and all non-FGB groups. Presence of FGB in mixed groups will spill over positively to non-FGB group members resulting in intermediate levels of coca investments.

In the case of positive moral and social costs of investing in coca, the marginal incentive to cultivate coca would be lower, so given the incentives in the game, for sufficiently moral and social concerned participants the effect of the introduction of external sanctions would be to deter coca investments, as long as the expected marginal incentive is negative $\left(1-a-b-M^{\prime}-\right.$ $\left.S^{\prime}-p f<0\right)$.

\section{Hypothesis 3}

External control disciplines participants and leads to less coca investments with respect to the control treatment.

So far we have assumed that the cost of sanctioning peers is positive. If individuals care about relative investments in coca, they could derive a positive utility from using sanctions. Assume that the net cost of imposing a sanction is given by $r F s R(c i-c j, r)$, where, $R$ is a function that captures the sense of civic responsibility and depends on the relative investment of participant $i$ in comparison with participant $j$, and $r$ is a parameter that indicates how important this relation is. In this case, if the individual invests more than the other participants, $R$ is positive so individually it would be optimal not to impose sanctions on others. However if $c j$ is higher than $c i, R$ is negative, indicating that the participant derives positive utility of sanctioning the other, so in this situation social sanctions would be observed. We assume that $r$ is not fixed and can be changed with participation in the FGB Program. We expect that the Program will increase $r$, making it more costly for subjects not to sanction anti-social behavior.

\section{Hypothesis 4}


When internal social control is available, participants from FGB veredas are more likely to use it compared to non-beneficiaries.

The use of social sanctions increases the marginal incentive of cultivating coca, so it is expected that when external and social sanctions are present, these mechanisms will reinforce each other.

\section{Hypothesis 5}

Coca investments are lowest in treatments in which both external and endogenous internal control are implemented.

Participants have procedural justice preferences and consider the fairness of the procedures used. Participants who have not cultivated coca would perceive it as unfair to be sanctioned, as would be the case when there is joint liability. This can lead to a crowding-out effect on the motivation to comply with the law and result in relatively larger coca investments, compared with treatments that impose individual liability.

\section{Experimental procedures}

The department of Cordoba was considered a suitable place to carry out the study as this is a coca producing nucleus, concentrating about 40 percent of the areas with coca in the country in 2011. The main coca producing municipalities in the department are Tierralta, Puerto Libertador and Montelibano. Human occupation of this municipalities started in the late 1940's by landless farmers and intensified in the 1970's, when colonizers from the neighboring department, Antioquia, started illegal logging on national lands. The poverty and marginalization of this region favored the emergence of illicit crops in the late 1990's. By 2005 more than three thousand hectares were cultivated with coca in the department. This triggered an aggressive spraying campaign over the following years. For each hectare cultivated, 3.3 to 4.6 hectares were sprayed. The FGB program was implemented in the region in 2005 covering two thousand families. Since then, the program has expanded and in total about 5000 families have benefited.

We selected Tierralta and Puerto Libertador as our areas of study. Table 4.4 presents the descriptives of these two municipalities when the targeting index was created in 2003, and compares them with the national average for other municipalities where coca is cultivated. We see that Puerto Libertador and Tierralta have a high density of forest compared with the national average in municipalities with coca. For every hectare of land in the municipality 0.8 and 0.7 hectares are covered by forest, compared to 0.56 in the rest of the country. This could be due to the presence of a Natural Park in the area, which also prevents many communities that live within park boundaries to enter the Program. ${ }^{14}$ These two municipalities have been affected by illicit crops with 408 and 847 hectares cultivated with coca on average, since satellite pictures

\footnotetext{
${ }^{14}$ The Paramillo Natural Park covers 460.000 hectares and was established in 1977 when towns and human settlements were already there.
} 
became available in 2001. Compared with other municipalities that grow coca in the country, the density of coca is relatively high in Puerto Libertador, while Tierralta is similar to the average coca-growing municipality. The population density is comparable to other municipalities with coca with about 1.6 inhabitants in 10 hectares of land (the national average is 1.4). Both municipalities are classified as having a high priority to enter the FGB program with a score of 29 points in a 1 to 44 scale. These two municipalities have benefited from two and three waves of the FGB program respectively. In 2012, at the moment of the study, 91 families were beneficiaries in Puerto Libertador and 206 in Tierralta.

Table 4.4: Descriptive characteristics of study municipalities and other coca-growing areas

$\begin{array}{llll} & \text { Puerto Libertador } & \text { Tierralta } & \text { Coca Municipalities } \\ \text { Municipality Area (Ha) } & 138745.7 & 506536.4 & 340308.3 \\ \text { Coca (Ha) } & 408.9 & 847.14 & 382.1463 \\ \text { Coca Density } & 0.0029471 & 0.0016724 & 0.0016331 \\ \text { Forest Density } & 0.7976673 & 0.68481 & 0.5772568 \\ \text { Population } & 22601 & 45888 & 11023.73 \\ \text { Population Density } & 0.16 & 0.09 & 0.14095 \\ \text { Total Points } & 29 & 29 & 27.09 \\ \text { Priority } & 1 & 1 & 1.45 \\ \text { Waves } & \text { II,III,VII } & \text { V, VII } & \cdot \\ & \text { Source: SIG, UNODC. } & \end{array}$

The next step was to select veredas suitable for our study. We used secondary and primary information obtained directly from program officials and community leaders to select the relevant veredas. We obtained information on FGB status of each vereda within the two municipalities of our study. For those that had not received the program, we also dwelled into the reasons for its absence to make sure that the control group was in fact comparable and had not selected itself out of the program. Although we already know that the municipalities where both types of communities live have been targeted by the Program, we made sure that those veredas that were invited to our experiment were similar to each other on basic characteristics, and ensured that the control veredas had expressed their will to be part of the Program when it was offered to the region.

According to Program officials, there are several reasons why some veredas within targeted municipalities have not received the Program so far. The main reason is that the Program has been rolled-out progressively in time, as there are more eligible communities than resources. Since resources were not enough, program officials prioritize eligible veredas according to the exogenous criteria previously discussed. So municipalities that are more dispersed, or that have areas inside national parks are not included in a process that is as if random.

In our analysis, we made an effort to select veredas that are similar in observable characteristics. In cooperation with local Program officials, we identified specific characteristics that our control communities needed to have, namely, having expressed a will of participating in the Program, having similar socioeconomic and productive characteristics, and being close to the treatment villages so that our activity could be held with members of treatment and control communities 
at the same time. Most importantly, since our local contact was the person assigned by the Program to coordinate the selection process for the next years, we could ask him to match the treated communities with those that he thought would most likely join the Program in its next wave or version of the Program (now called post-eradication).

Once the local experts found the best possible control communities, we matched each treated vereda with its best possible match and then randomized the experimental treatments among them. We did this process independently for Tierralta and Puerto Libertador. When a vereda was chosen, the vereda's president ${ }^{15}$ was contacted and was asked to give us a list with the number of households and names of all of the vereda's residents. From this list we randomly invited 36. As other people from the community knew about the process, together with the president they ensured that only those invited participated.

The experiment was presented as a "workshop" for a university research project regarding the needs and behaviors of people in coca growing areas, and the FGB program was never mentioned. Since we are not evaluating the Program, and our workshop has no relationship to FGB itself or to how it will develop in the future, mentioning the Program to participants was not necessary. This prevented FGB beneficiaries to act according to what they think Program officials expect, which would bias the analysis. Moreover, the fact that half of the participants had benefited from the Program and the other half had not and were put together in the same room, made it clear that we were not carrying out a Program-related activity that would affect their probability of receiving its benefits in the future.

The experiment had four stages. First, people were seated and given a number that identified them for the whole session and which ensured anonymity of the answers at all times and allowed to merge the experimental choices with the post-experimental survey. Treatments were randomized over sessions. Second, instructions were read out loud and a trial round was played, after which the experiment took place. Each person was given a sheet for every round with 10 $\$ 10,000$ COP bills that they could invest in either coca or cocoa. After crossing out how much they wanted to invest in cocoa (whatever was left blank was invested in coca) their responses were recorded in a computer, and feedback sheets were returned to them, where they knew how much coca other group members had invested in. Depending on the treatment, they were told whether they had been punished and the amount of sad faces that they had received from other group members. Participants were paid over decisions in all rounds, but we explained to them at the beginning that we could not pay them the full amount of what they received, but that we would pay $0.1 \%$ of what they had obtained (See Instructions in the Appendix). The average payment for the game was around $\$ 6.6$ USD $(\$ 13,200 \mathrm{COP})$, which at the time was more than a half-day's wage. They received additionally 3 USD in order to cover transportation costs. Third, people answered an exit survey so that they could receive the money earned in the game. We closed the experiment with a final discussion.

\footnotetext{
${ }^{15}$ Communities elect their leaders and they represent them in both formal and informal situations. Presidents have legitimacy within communities and important decisions are never made without their approval.
} 


\section{Results}

Descriptive statistics

In December 2012 we conducted 28 experimental sessions with 867 participants in two municipalities in Cordoba: Tierralta and Puerto Libertador. Almost half of the participants (401 participants or $47 \%$ ) live in veredas where the Program had operated or currently operates, and 461 (53\%) live in veredas without Program intervention, due to the exogenous reasons mentioned above.

Table 4.5 presents descriptive statistics for both FGB and non-FGB and also for each experimental treatment employed, regarding the questions collected in the exit survey. As most of them were not altered by the Program or happened before it, they serve as a balance test between treatments. We find that the randomization worked well, as groups are very similar in their secondary characteristics. There are a few variables where the randomization did not work as expected: cost to the closest urban center (directly related with the time it takes to get there, so these two variables are a reflection of each other), years of household in the "vereda" and belonging to a non-catholic church. For this reason we will control for these variables in the regressions to come.

Even though there are some differences between $\mathrm{T} 4$ and $\mathrm{T} 6$ with respect to the control treatment in the amount of years people have grown coca, these differences disappear when we look at whether people have grown coca at all, probably a more important variable, since what we need is that people have had exposure to coca growing at all. 
Table 4.5: Descriptive statistics for beneficiary and control groups and experimental treatments

\begin{tabular}{|c|c|c|c|c|c|c|c|c|}
\hline \multirow{2}{*}{ Variable } & \multirow{2}{*}{\multicolumn{2}{|c|}{$\begin{array}{l}\text { Treatment vs. Control } \\
\text { Non-FGB FGB }\end{array}$}} & \multicolumn{6}{|c|}{ Experimental Treatments } \\
\hline & & & T0 & $\mathrm{T} 1$ & $\mathrm{~T} 2$ & $\mathrm{~T} 3$ & $\mathrm{~T} 4$ & T5 \\
\hline \multirow[t]{2}{*}{ Prop. Male } & 0.56 & 0.52 & 0.52 & 0.59 & 0.47 & 0.48 & $0.63^{*}$ & 0.57 \\
\hline & $(0.02)$ & $(0.02)$ & $(0.04)$ & $(0.04)$ & $(0.04)$ & $(0.04)$ & $(0.04)$ & $(0.05)$ \\
\hline \multirow[t]{2}{*}{ Age } & 39.44 & 38.71 & 38.35 & 40.08 & 37.75 & 39.98 & 38.98 & 39.25 \\
\hline & $(0.72)$ & $(0.72)$ & $(1.28)$ & $(1.30)$ & $(1.16)$ & $(1.22)$ & $(1.12)$ & $(1.32)$ \\
\hline \multirow[t]{2}{*}{ Over primary } & 0.35 & 0.36 & 0.37 & 0.31 & 0.40 & 0.35 & 0.35 & 0.36 \\
\hline & $(0.02)$ & $(0.02)$ & $(0.04)$ & $(0.04)$ & $(0.04)$ & $(0.04)$ & $(0.04)$ & $(0.04)$ \\
\hline \multirow[t]{2}{*}{ Cost to center } & 8,463 & 8,869 & 7,650 & $9,498 * * *$ & $10,220^{* * *}$ & 7,671 & $8,653^{*}$ & 8,101 \\
\hline & $(261.35)$ & $(235.94)$ & $(445.95)$ & $(383.19)$ & $(374.13)$ & $(467.53)$ & $(399.09)$ & $(474.36)$ \\
\hline \multirow[t]{2}{*}{ Hours to center } & 1.08 & 1.06 & 0.91 & 1.04 & $1.47^{* * *}$ & $0.79^{* *}$ & $1.27^{* * *}$ & 0.98 \\
\hline & $(0.04)$ & $(0.04)$ & $(0.05)$ & $(0.06)$ & $(0.07)$ & $(0.04)$ & $(0.10)$ & $(0.07)$ \\
\hline \multirow[t]{2}{*}{ HH Size } & 5.34 & 5.18 & 5.20 & 5.06 & 5.21 & 5.55 & 5.30 & 5.24 \\
\hline & $(0.10)$ & $(0.12)$ & $(0.16)$ & $(0.18)$ & $(0.19)$ & $(0.18)$ & $(0.20)$ & $(0.22)$ \\
\hline \multirow[t]{2}{*}{ Prop. Minors } & 0.45 & 0.42 & 0.43 & 0.48 & 0.44 & 0.43 & 0.42 & 0.41 \\
\hline & $(0.01)$ & $(0.01)$ & $(0.02)$ & $(0.02)$ & $(0.02)$ & $(0.02)$ & $(0.02)$ & $(0.02)$ \\
\hline \multirow[t]{2}{*}{ Years in $\mathrm{HH}$} & 10.02 & $11.54^{* *}$ & 12.51 & $9.35^{* *}$ & $9.79^{*}$ & $9.91^{*}$ & $9.19^{* *}$ & 14.38 \\
\hline & $(0.47)$ & $(0.58)$ & $(1.15)$ & $(0.70)$ & $(0.83)$ & $(0.68)$ & $(0.86)$ & $(1.19)$ \\
\hline \multirow[t]{2}{*}{ Years coca } & 2.01 & 2.50 & 3.07 & 3.18 & 1.91 & $1.54^{* *}$ & 2.46 & $1.18^{* * *}$ \\
\hline & $(0.25)$ & $(0.30)$ & $(0.55)$ & $(0.58)$ & $(0.46)$ & $(0.33)$ & $(0.53)$ & $(0.29)$ \\
\hline \multirow[t]{2}{*}{ Any coca } & 0.32 & 0.34 & 0.35 & 0.38 & 0.30 & 0.27 & 0.36 & 0.32 \\
\hline & $(0.02)$ & $(0.02)$ & $(0.04)$ & $(0.04)$ & $(0.04)$ & $(0.03)$ & $(0.04)$ & $(0.04)$ \\
\hline \multirow[t]{2}{*}{ Non-catholic ${ }^{(a)}$} & 0.46 & $0.42^{* * *}$ & 0.38 & $0.44^{* *}$ & $0.44^{* *}$ & $0.56^{* * *}$ & $0.48^{* * *}$ & $0.32^{* *}$ \\
\hline & $(0.01)$ & $(0.01)$ & $(0.02)$ & $(0.02)$ & $(0.02)$ & $(0.02)$ & $(0.02)$ & $(0.02)$ \\
\hline Observations & 461 & 406 & 143 & 160 & 150 & 168 & 126 & 120 \\
\hline
\end{tabular}

Notes: Differences are drawn between groups with respect to the base level: non-beneficiaries in the treatmentvs-control, and with respect to T0 in experimental treatment columns. (a) People that report following a religion different than catholicism (mostly new christian, protestant and evangelical churches).

\section{Descriptive results}

A first look at the coca investment behavior of people from FGB veredas and non-FGB veredas shows that both groups are different in their levels of investment, even though they follow similar patterns. Non-FGB participants tend to opt into coca more than their FGB counterparts and also to choose higher amounts, as can be seen in Figure 4.1. 
Figure 4.1: Coca investment by participant type
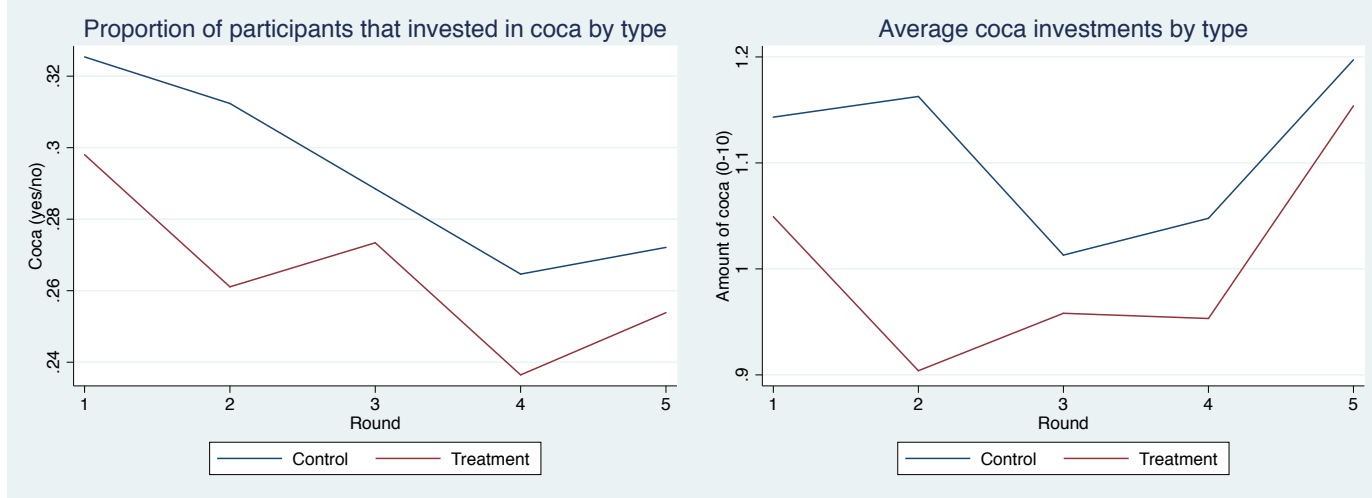

As described above, participants were anonymously placed in groups of three. The first group type only had participants that came from FGB veredas; the second group type had participants that lived in communities with no FGB beneficiaries and the third group type mixed people from FGB veredas and non-FGB veredas. We can see in Figure 4.2 that all-FGB groups opt less into coca and invest less in it than the other groups. It is interesting to see that mixed groups behave more similar to non-FGB groups than to FGB groups, and even end up with higher coca levels than the rest. This could point to emerging norms of social control only when everyone has been part of a Program that fosters these types of behaviors, but, once people are taken out of this framework and mixed with others who do not follow the same pattern, negative externalities from non-FGB to FGB participants emerge. This speaks against our hypothesis that FGB presence in a group would have positive externalities on other group members.

Figure 4.2: Coca investments by group type
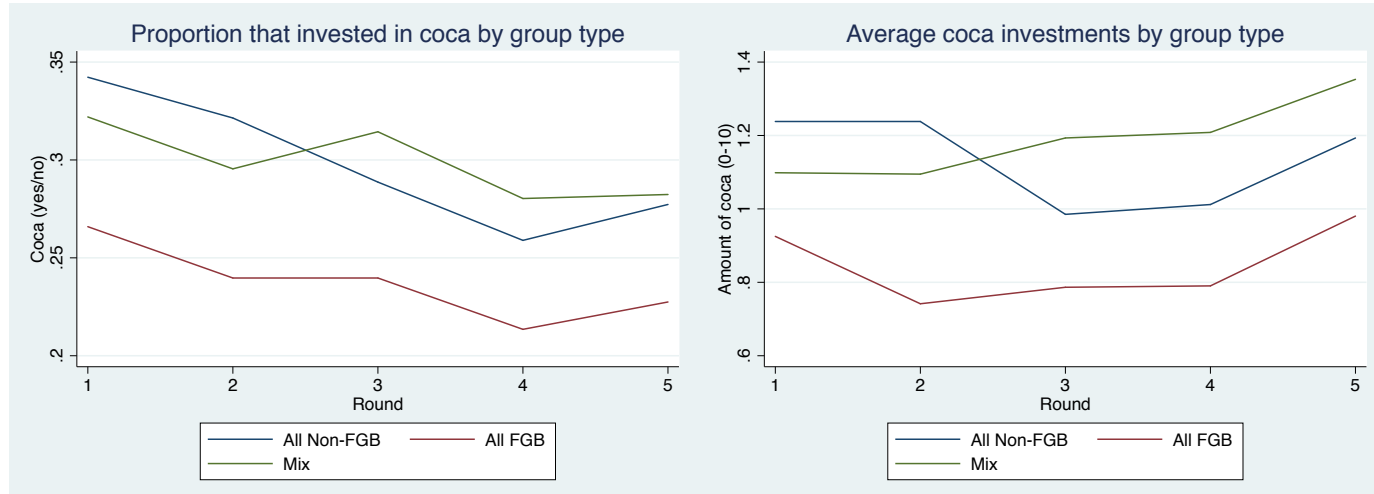

Effect of different coca reducing policies and their interactions

To investigate the impact of FGB on culture of lawfulness we estimate two separate models. The first one looks at the willingness to invest in coca and on the amount of coca invested. The second model captures the decision to use internal social control mechanisms in order to reduce coca among other community members. 
We model the willingness to invest in coca with a linear probability random effects panel model, where investing any positive amount of money in coca indicates willingness to invest, and model the amount of coca invested with a linear random effects panel regression. ${ }^{16}$ Since both veredas and participants are randomly selected and assigned into our experimental treatments, we can be sure that we do not have self-selection into the experiment, which means that our regressors should not be correlated with the individual effects, and therefore can use a random effects model. The random effects model is particularly useful when some people play the same strategy in every round, which would be considered "constant" in a fixed-effects model and dropped from the analysis. Additionally, the variables that interest us the most, namely being part of the FGB Program and the experimental treatment that people received do not change throughout the experiment, and thus would be lost in the fixed effects model. Each round is one time period, so we take into account correlations within individuals over time. We also cluster the standard errors at the vereda level, to account for correlations between members of the same community. ${ }^{17}$ We also control for the individual level variables that despite the randomization were by chance not balanced between treatments. We add session fixed effects to account for possible factors that might have altered the way people played the game that we could not control or observe. For instance, we were aware that members of illegal armed groups were present in some of the sessions, but we could not recognize their presence. We take this into account by adding session fixed effects. We run all regressions with the same observations (we make sure include observations that have all the control variables complete even in the specifications that do not include these variables).

The first two columns in Table 4.6 present the estimated coefficients for the willingness to invest and the amount of coca invested exclusively in terms of the experimental treatments. The third and fourth columns include interactions between the treatments and being part of the FGB program, as well as the type of group they were randomly assigned to during the experiment. The last two columns include control variables.

When only the experimental treatments are taken into account (Columns 1 and 2), willingness to engage in coca investments is reduced when farmers are exposed to individual punishment (at the 1\% significance level) or a combination of external punishment with internal community control (at the 5\% significance level when external punishment is aimed at the whole group and at the $10 \%$ significance level when it is aimed only at guilty individuals). In the absence of external punishment, internal control could increase people's engagement with coca crops. The amount of coca investments decreases when people are exposed to group punishment (at the $1 \%$ significance level), individual punishment (at the $1 \%$ significance level) or a combination of individual and community control (at the $5 \%$ significance level). In terms of the size of coca investments, internal control has a significant and decreasing effect.

\footnotetext{
${ }^{16}$ As robustness check we run a negative binomial panel model to account for the count nature of the dependent variable that goes from 0 to 10 and the results hold. We opt for a linear panel specification because interpretation of the results is more straightforward.

${ }^{17}$ The treatments were randomized at a session level. However, correlation among participants is likely to arise within a vereda and not within a session. In order to capture factors that might have risen at a session level we include session dummies.
} 
Once the experimental treatments are interacted with living in a FGB alternative development vereda, a very interesting story emerges. Those who have not taken part in the Program react to both individual and group external punishment strategies, but do not react to a policy where internal control is introduced. In fact, non-beneficiaries engage in larger amounts of coca investments when only internal control is introduced, and this is significant (at the $5 \%$ significance level). For their part, FGB beneficiaries react to policies where community control is introduced and interacted with group and internal punishment, by reducing their coca investments, at the $1 \%$ and $5 \%$ significance levels respectively. Furthermore, internal control by itself also reduces coca investments at the $10 \%$ significance level. This result makes sense since FGB beneficiaries have had to create their own internal community control groups in order to keep their whole vereda free of coca to prevent being dropped from the Program. Once community control is a reality for them, it becomes an efficient instrument to reducing engagement in coca and overall coca investments, especially when combined with external punishment policies.

After introducing the variables that were not balanced among the treatments in the randomization checks, such as the transportation cost to the closest urban center, being part of a non-Catholic church, the amount of years growing coca and the years in the vereda, most effects on beneficiaries and non-beneficiaries remain: beneficiaries reduce their engagement with coca when internal control is combined with external individual punishment and reduce the amount of coca grown when internal control is present, and when it is interacted with any type of external control. It is interesting to note that being part of a non-Catholic church also reduces engagement with coca, influencing the decision of whether to opt-in at all into investing in something illegal. The influence of these new churches in the decision to cultivate coca or not was first evidenced by Ibanez and Carlsson (2010) and Ibanez (2010) and received further support by testimonies from the field, whereby communities that accept the presence of these churches reduce their involvement with illegal crops greatly. We have first-hand evidence from conversations with members of christian churches and christian leaders that preaching against coca crops is common. It is interesting to note that these churches have a very strong community control element in themselves, as they preach that people should be examples of "righteousness" for others, and indirectly impose large non-economic sanctions, such as shame or guilt, on those that deviate from what is being preached.

A variable that is not included in the table due to great loss of observations is the lagged amount of coca that others invest in. Including this variable is equivalent to dropping all the observations from the first round where this variable is not observed, but the results can be seen in Table A4.1 in the Annex. People get feedback on what others are doing on every round, and thus can take this into account when deciding how much coca to grow in the next round. What is interesting to note is that people do react to what others are investing and follow their example: When other group members invested in coca, people were more willing to invest positive and larger amounts in the subsequent round. 
Table 4.6: Experimental coca investments by treatment and program type

\begin{tabular}{|c|c|c|c|c|c|c|}
\hline & $\begin{array}{c}(1) \\
\text { dcoca }\end{array}$ & $\begin{array}{c}(2) \\
\text { Coca }\end{array}$ & $\begin{array}{c}(3) \\
\text { dcoca }\end{array}$ & $\begin{array}{c}(4) \\
\text { Coca }\end{array}$ & $\begin{array}{c}(5) \\
\text { dcoca }\end{array}$ & $\begin{array}{c}(6) \\
\text { Coca }\end{array}$ \\
\hline \multicolumn{7}{|l|}{ Experimental Treatments } \\
\hline T1 Group Punish & $\begin{array}{l}-0.045 \\
(0.059)\end{array}$ & $\begin{array}{c}-0.698^{* * *} \\
(0.234)\end{array}$ & $\begin{array}{l}-0.040 \\
(0.081)\end{array}$ & $\begin{array}{c}-0.649^{* *} \\
(0.315)\end{array}$ & $\begin{array}{l}-0.085 \\
(0.083)\end{array}$ & $\begin{array}{c}-0.798^{* *} \\
(0.349)\end{array}$ \\
\hline T2 Int. Control & $\begin{array}{l}0.046^{* *} \\
(0.019)\end{array}$ & $\begin{array}{c}-0.301^{* *} \\
(0.129)\end{array}$ & $\begin{array}{l}0.071^{* *} \\
(0.031)\end{array}$ & $\begin{array}{l}-0.044 \\
(0.125)\end{array}$ & $\begin{array}{c}0.065 \\
(0.040)\end{array}$ & $\begin{array}{l}-0.062 \\
(0.173)\end{array}$ \\
\hline T3 Individual Punish & $\begin{array}{c}-0.186^{* * *} \\
(0.032)\end{array}$ & $\begin{array}{c}-0.974^{* * *} \\
(0.172)\end{array}$ & $\begin{array}{c}-0.160^{* * *} \\
(0.046)\end{array}$ & $\begin{array}{c}-0.857^{* * *} \\
(0.184)\end{array}$ & $\begin{array}{c}-0.134^{* * *} \\
(0.051)\end{array}$ & $\begin{array}{c}-0.767^{* * *} \\
(0.209)\end{array}$ \\
\hline T4 IntCont + GroupPunish & $\begin{array}{c}-0.086^{* *} \\
(0.041)\end{array}$ & $\begin{array}{l}-0.362 \\
(0.288)\end{array}$ & $\begin{array}{l}-0.064 \\
(0.050)\end{array}$ & $\begin{array}{l}-0.151 \\
(0.232)\end{array}$ & $\begin{array}{l}-0.066 \\
(0.056)\end{array}$ & $\begin{array}{l}-0.144 \\
(0.262)\end{array}$ \\
\hline T5 IntCont + IndPunish & $\begin{array}{c}-0.134^{*} \\
(0.075)\end{array}$ & $\begin{array}{c}-0.896^{* *} \\
(0.376)\end{array}$ & $\begin{array}{c}-0.032 \\
(0.060)\end{array}$ & $\begin{array}{c}-0.464 \\
(0.314)\end{array}$ & $\begin{array}{c}-0.076 \\
(0.082)\end{array}$ & $\begin{array}{c}-0.614^{*} \\
(0.364)\end{array}$ \\
\hline \multicolumn{7}{|c|}{ Program Treatment and Interactions } \\
\hline FGB & & & $\begin{array}{c}0.083 \\
(0.066)\end{array}$ & $\begin{array}{c}0.502^{*} \\
(0.279)\end{array}$ & $\begin{array}{c}0.077 \\
(0.063)\end{array}$ & $\begin{array}{c}0.478^{*} \\
(0.268)\end{array}$ \\
\hline T1 GP X FGB & & & $\begin{array}{c}0.003 \\
(0.081)\end{array}$ & $\begin{array}{l}-0.034 \\
(0.292)\end{array}$ & $\begin{array}{c}0.006 \\
(0.081)\end{array}$ & $\begin{array}{l}-0.009 \\
(0.285)\end{array}$ \\
\hline T2 IC X FGB & & & $\begin{array}{l}-0.035 \\
(0.057)\end{array}$ & $\begin{array}{l}-0.438^{*} \\
(0.223)\end{array}$ & $\begin{array}{l}-0.035 \\
(0.055)\end{array}$ & $\begin{array}{l}-0.428^{*} \\
(0.219)\end{array}$ \\
\hline T3 IP X FGB & & & $\begin{array}{l}-0.040 \\
(0.066)\end{array}$ & $\begin{array}{l}-0.163 \\
(0.294)\end{array}$ & $\begin{array}{l}-0.055 \\
(0.067)\end{array}$ & $\begin{array}{l}-0.203 \\
(0.296)\end{array}$ \\
\hline T4 ICGP X FGB & & & $\begin{array}{l}-0.028 \\
(0.042)\end{array}$ & $\begin{array}{c}-0.496^{* * *} \\
(0.157)\end{array}$ & $\begin{array}{l}-0.013 \\
(0.036)\end{array}$ & $\begin{array}{c}-0.449^{* * *} \\
(0.152)\end{array}$ \\
\hline T5 ICIP X FGB & & & $\begin{array}{c}-0.140^{* *} \\
(0.067)\end{array}$ & $\begin{array}{c}-0.600^{* *} \\
(0.271)\end{array}$ & $\begin{array}{c}-0.142^{* *} \\
(0.067)\end{array}$ & $\begin{array}{c}-0.616^{* *} \\
(0.275)\end{array}$ \\
\hline Group Types & & & & & & \\
\hline All FGB & & & $\begin{array}{l}-0.075 \\
(0.059)\end{array}$ & $\begin{array}{l}-0.408 \\
(0.286)\end{array}$ & $\begin{array}{l}-0.075 \\
(0.058)\end{array}$ & $\begin{array}{l}-0.414 \\
(0.280)\end{array}$ \\
\hline Mixed & & & $\begin{array}{l}-0.003 \\
(0.036)\end{array}$ & $\begin{array}{l}-0.003 \\
(0.191)\end{array}$ & $\begin{array}{l}-0.001 \\
(0.038)\end{array}$ & $\begin{array}{c}0.007 \\
(0.192)\end{array}$ \\
\hline Controls & & & & & & \\
\hline Cost to urban center & & & & & $\begin{array}{c}0.000^{*} \\
(0.000)\end{array}$ & $\begin{array}{c}0.000 \\
(0.000)\end{array}$ \\
\hline Other non-Catholic religion & & & & & $\begin{array}{c}-0.051^{* *} \\
(0.025)\end{array}$ & $\begin{array}{l}-0.151 \\
(0.128)\end{array}$ \\
\hline Years growing coca & & & & & $\begin{array}{c}0.003 \\
(0.002)\end{array}$ & $\begin{array}{c}0.013 \\
(0.013)\end{array}$ \\
\hline Years in vereda & & & & & $\begin{array}{c}-0.000 \\
(0.001)\end{array}$ & $\begin{array}{c}0.002 \\
(0.005)\end{array}$ \\
\hline Experimental Round & & & & & $\begin{array}{c}-0.016^{* * *} \\
(0.005)\end{array}$ & $\begin{array}{c}0.004 \\
(0.023)\end{array}$ \\
\hline Constant & $\begin{array}{c}0.437^{* * *} \\
(0.016)\end{array}$ & $\begin{array}{c}1.962^{* * *} \\
(0.119)\end{array}$ & $\begin{array}{c}0.416^{* * *} \\
(0.032)\end{array}$ & $\begin{array}{c}1.812^{* * *} \\
(0.129)\end{array}$ & $\begin{array}{c}0.435^{* * *} \\
(0.040)\end{array}$ & $\begin{array}{c}1.662^{* * *} \\
(0.201)\end{array}$ \\
\hline Observations & 4174 & 4174 & 4174 & 4174 & 4174 & 4174 \\
\hline Veredas & 30 & 30 & 30 & 30 & 30 & 30 \\
\hline R2 Overall & 0.11 & 0.07 & 0.11 & 0.08 & 0.12 & 0.09 \\
\hline R2 Within & 0.00 & 0.00 & 0.00 & 0.00 & 0.01 & 0.00 \\
\hline R2 Between & 0.17 & 0.11 & 0.17 & 0.12 & 0.19 & 0.13 \\
\hline
\end{tabular}

Vereda level clustered standard errors in parentheses. Session fixed effects included.

Significance levels ${ }^{*} \mathrm{p}<0.10,{ }^{* *} \mathrm{p}<0.05,{ }^{* * *} \mathrm{p}<0.01$ 
The self-reported number of years growing coca increased the willingness of a person to invest in coca, but did not raise the invested amount significantly. This was expected, as the experiment reflects real life situations and we expect people to bring their own background and experiences to the game.

We did not find significant effects of being placed in an all-FGB group or a mixed group versus non-FGB groups, although the signs went in the right directions of reducing coca in the former and increasing it in the latter (as can be seen in the descriptive graphs at the beginning). However, including FGB status in the regression already accounts for these differences, and we do not want to highlight an insignificant pattern.

As explained in the experimental set-up, there was a $30 \%$ chance of having coca investments caught in every round. A natural question is whether being caught in one round reduces coca investments in the next round. As expected, $28.3 \%$ of the rounds in the treatments that included external punishment were punished. However, this did not lead to a reduction in coca investments (see Table A4.2 in the Annex). We also tested whether cumulative punishment (i.e., the sum of times punishment had been in place) played a role in discouraging coca investments, and this also does not seem to be the case. One possible explanation is that people had already internalized the punishment even before it happened; people decided on less coca because of the possibility of punishments, but did not change their strategy once it materialized because they had already taken it into account.

\section{Use of social control mechanisms}

Table 4.7 explores the drivers of the use of internal control mechanisms (sad faces) and the intensity of their use (amount of sad faces sent to others).

This table tests our hypotheses on the efficiency of interactions of external punishment strategies with internal control vis-a-vis internal control alone, and on a more intensive use by FGB beneficiaries versus non-beneficiaries. Only the experimental treatments that include internal control come into play, making the base category the internal control treatment without any interactions with external punishment.

Moreover, since we are interested in what triggers the use of costly internal control mechanisms and on how group norms of control evolve, we interact the amount of coca that other people are investing with the type of group they are in. We square the coca investments made by others to capture non-linearities or inflection points. We also include a variable that compares people with the rest of the group they are in to see what happens when people are below or above their peers in terms of coca investments, which would capture conformity with a social norm. The last two columns include the control variables that were also included in the coca investment regression.

We find a crowding-out and a crowding-in effect of internal control mechanisms depending on the type of external punishment used. When external punishment makes the whole group liable for the actions of any of its members, crowding out occurs and people are around $10 \%$ less likely to punish their group members with sad faces. On the other hand, when individual liability 
external punishment is used, internal control is further enhanced, and people are between $20 \%$ and $23 \%$ more likely to send faces, and send one more face compared to those that only have the internal control treatment. It is important to note that this variable has the largest effect of all included variables on the use of sad faces and on the amount of faces used. This result could be linked to the legitimacy of the external control mechanism itself. Most people know that growing coca is illegal and would concede that it can bring negative effects to the community. Thus, an external punishment that makes individuals liable for their actions could be seen as legitimate, whereas external punishment that extends the consequences to the whole community might seem unjust. Although the crowding-in effect of individual punishment is larger than the crowding-out effect of group punishment in the probability of using social control and also in the amount of control employed, crowding-out is also significant and is a negative side-effect that external punishment may have.

Groups that only have FGB members start using sad faces when others are behaving badly, captured by the square of how much coca others in the group are growing. This effect is easier to see in Figure 4.3, where the marginal effects are presented for all-FGB groups and mixed groups, compared to the base group-type that does not have any FGB participants. Small levels of coca do not affect the use of internal control mechanisms, but when others start growing large amounts, social control is triggered. Being part of the alternative development Program makes people more willing to use internal control mechanisms, but only when the situation requires it. This is why members of groups that were composed by only FGB started using internal punishment mechanisms once others in their group deviated from legality to a large extent. The maximum amount of coca investments made by other group members is 20 (each person a maximum of 10, and a group has 3 people). Up to a total of 6 units being invested in coca by other members, the use of punishing faces is numerically very similar for all group types. From a total of 7 onwards, the use of sad faces starts to increase in groups with all-FGB participants; when the total reaches 11 units invested in coca by other group members, all-FGB groups send a statistically significant higher amount of faces than groups that have no FGB beneficiaries, and if the total reaches 17 or more units invested in coca the use of sad faces is statistically higher in all-FGB groups than in mixed groups. 
Table 4.7: Use of social control mechanisms (sad faces)

\begin{tabular}{|c|c|c|c|c|}
\hline & $\begin{array}{c}(1) \\
\text { UsedFaces }\end{array}$ & $\begin{array}{c}(2) \\
\text { Num.Faces }\end{array}$ & $\begin{array}{c}(3) \\
\text { UsedFaces }\end{array}$ & $\begin{array}{c}(4) \\
\text { Num.Faces }\end{array}$ \\
\hline \multicolumn{5}{|l|}{ Experimental/Program Treatments } \\
\hline T4 IntCont+GroupPunish & $\begin{array}{c}-0.108^{* * *} \\
(0.035)\end{array}$ & $\begin{array}{c}-0.164^{* * *} \\
(0.062)\end{array}$ & $\begin{array}{c}-0.081^{* *} \\
(0.040)\end{array}$ & $\begin{array}{l}-0.052 \\
(0.082)\end{array}$ \\
\hline T5 IntCont+IndPunish & $\begin{array}{c}0.201^{* * *} \\
(0.042)\end{array}$ & $\begin{array}{c}0.914^{* * *} \\
(0.033)\end{array}$ & $\begin{array}{c}0.228^{* * *} \\
(0.043)\end{array}$ & $\begin{array}{c}0.998^{* * *} \\
(0.078)\end{array}$ \\
\hline FGB & $\begin{array}{c}-0.094^{*} \\
(0.052)\end{array}$ & $\begin{array}{c}-0.340^{*} \\
(0.179)\end{array}$ & $\begin{array}{c}-0.097^{*} \\
(0.055)\end{array}$ & $\begin{array}{c}-0.364^{*} \\
(0.190)\end{array}$ \\
\hline \multicolumn{5}{|l|}{ Group Types and Interactions } \\
\hline Group: All FGB & $\begin{array}{c}0.071 \\
(0.067)\end{array}$ & $\begin{array}{c}0.187 \\
(0.185)\end{array}$ & $\begin{array}{c}0.074 \\
(0.070)\end{array}$ & $\begin{array}{c}0.178 \\
(0.202)\end{array}$ \\
\hline Group: Mixed & $\begin{array}{c}0.001 \\
(0.033)\end{array}$ & $\begin{array}{c}0.045 \\
(0.121)\end{array}$ & $\begin{array}{c}0.008 \\
(0.036)\end{array}$ & $\begin{array}{c}0.063 \\
(0.119)\end{array}$ \\
\hline Coca by others & $\begin{array}{c}0.017 \\
(0.012)\end{array}$ & $\begin{array}{l}-0.046 \\
(0.036)\end{array}$ & $\begin{array}{c}0.019 \\
(0.013)\end{array}$ & $\begin{array}{l}-0.044 \\
(0.036)\end{array}$ \\
\hline Coca by others (2) & $\begin{array}{c}-0.001 \\
(0.001)\end{array}$ & $\begin{array}{c}0.005 \\
(0.004)\end{array}$ & $\begin{array}{c}-0.001 \\
(0.001)\end{array}$ & $\begin{array}{l}0.005 \\
(0.004)\end{array}$ \\
\hline AllFGB X coca others & $\begin{array}{c}-0.047^{* * *} \\
(0.017)\end{array}$ & $\begin{array}{l}-0.118^{*} \\
(0.062)\end{array}$ & $\begin{array}{c}-0.051^{* * *} \\
(0.019)\end{array}$ & $\begin{array}{c}-0.123^{* *} \\
(0.056)\end{array}$ \\
\hline Mixed X coca others & $\begin{array}{l}-0.010 \\
(0.017)\end{array}$ & $\begin{array}{c}0.033 \\
(0.078)\end{array}$ & $\begin{array}{c}-0.014 \\
(0.018)\end{array}$ & $\begin{array}{c}0.028 \\
(0.079)\end{array}$ \\
\hline AllFGB X coca others (2) & $\begin{array}{c}0.007^{* * *} \\
(0.002)\end{array}$ & $\begin{array}{c}0.022^{* * *} \\
(0.008)\end{array}$ & $\begin{array}{c}0.007^{* * *} \\
(0.002)\end{array}$ & $\begin{array}{c}0.024^{* * *} \\
(0.007)\end{array}$ \\
\hline Mixed X coca others (2) & $\begin{array}{c}-0.000 \\
(0.001)\end{array}$ & $\begin{array}{c}-0.004 \\
(0.007)\end{array}$ & $\begin{array}{c}0.000 \\
(0.001)\end{array}$ & $\begin{array}{l}-0.004 \\
(0.007)\end{array}$ \\
\hline Controls & & & & \\
\hline Less coca than rest & $\begin{array}{l}0.096^{* *} \\
(0.041)\end{array}$ & $\begin{array}{c}0.361^{* * *} \\
(0.130)\end{array}$ & $\begin{array}{c}0.097^{* *} \\
(0.042)\end{array}$ & $\begin{array}{c}0.358^{* * *} \\
(0.132)\end{array}$ \\
\hline More coca than rest & $\begin{array}{l}0.062^{*} \\
(0.033)\end{array}$ & $\begin{array}{c}0.128 \\
(0.111)\end{array}$ & $\begin{array}{l}0.062^{*} \\
(0.033)\end{array}$ & $\begin{array}{c}0.126 \\
(0.113)\end{array}$ \\
\hline Cost to urban center & & & $\begin{array}{c}0.000 \\
(0.000)\end{array}$ & $\begin{array}{l}0.000 \\
(0.000)\end{array}$ \\
\hline Other non-Catholic religion & & & $\begin{array}{c}0.003 \\
(0.029)\end{array}$ & $\begin{array}{c}0.031 \\
(0.118)\end{array}$ \\
\hline Years growing coca & & & $\begin{array}{c}0.002 \\
(0.003)\end{array}$ & $\begin{array}{l}-0.003 \\
(0.008)\end{array}$ \\
\hline Years in vereda & & & $\begin{array}{c}-0.000 \\
(0.001)\end{array}$ & $\begin{array}{c}0.004 \\
(0.004)\end{array}$ \\
\hline Constant & $\begin{array}{c}0.267^{* * *} \\
(0.039)\end{array}$ & $\begin{array}{c}0.554^{* * *} \\
(0.075)\end{array}$ & $\begin{array}{c}0.230^{* * *} \\
(0.047)\end{array}$ & $\begin{array}{c}0.340^{* * *} \\
(0.127)\end{array}$ \\
\hline Observations & 1944 & 1944 & 1874 & 1874 \\
\hline Veredas & 24 & 24 & 24 & 24 \\
\hline R2 Overall & 0.18 & 0.14 & 0.17 & 0.14 \\
\hline R2 Within & 0.02 & 0.02 & 0.02 & 0.02 \\
\hline R2 Between & 0.31 & 0.23 & 0.30 & 0.23 \\
\hline
\end{tabular}

Vereda level clustered standard errors in parentheses. Session fixed effects included.

Significance levels ${ }^{*} \mathrm{p}<0.10,{ }^{* *} \mathrm{p}<0.05,{ }^{* * *} \mathrm{p}<0.01$. Treatment base level: T2 Internal Control. 
Interestingly, people punish those who act differently, more so when others invest more in coca, but also when they invest less. People want others to behave similarly and are willing to punish deviations from what they expect, even if it is costly for the individual and for the whole community. Although this has little economic sense, real life situations show that people are able to justify their own illegal actions if everyone around them is doing the same. When individuals find themselves investing less in coca than their peers, they use mechanisms of internal control and employ them more intensively, whereas when they find themselves above the mean they use sad faces, although they do not send a statistically significant higher amount. Lastly, none of the control variables explain the use of internal control mechanisms.

Figure 4.3: Use of sad faces by group type

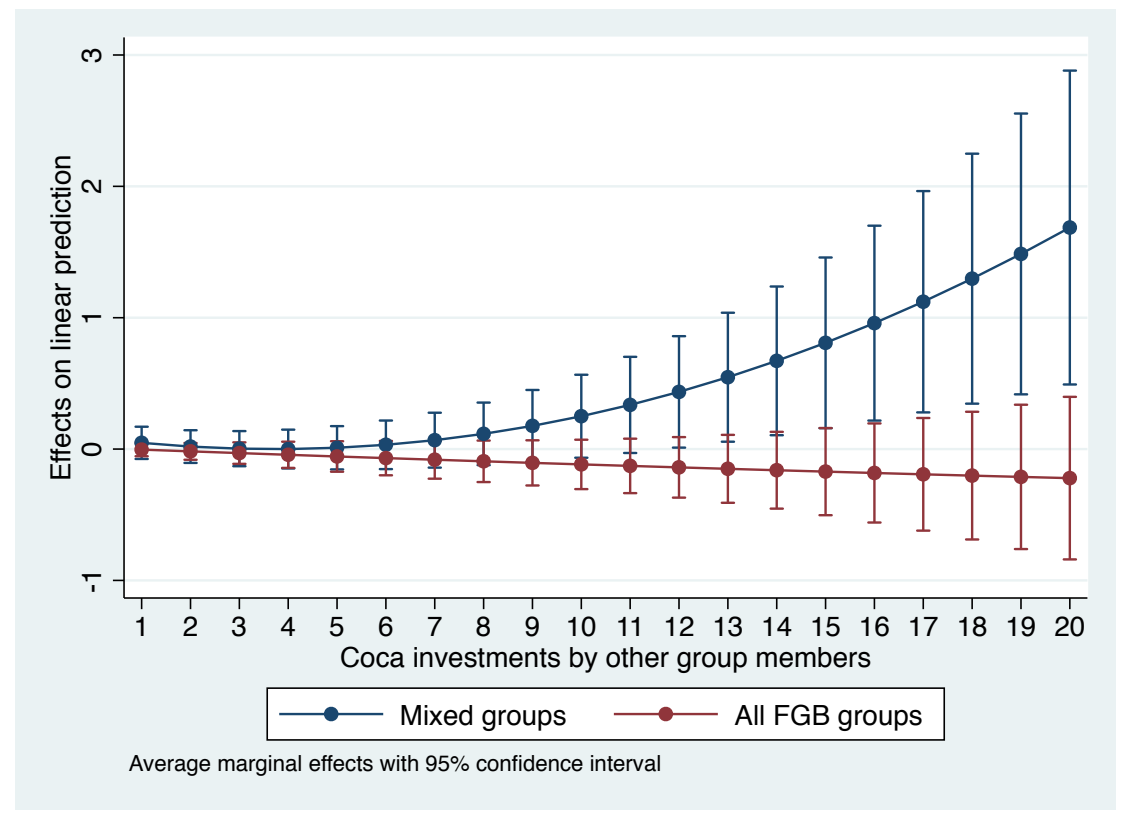

Finally, we checked if having received sad faces led to reductions in coca investments, and find that this was not the case. Similar to the punishment analysis, it seems that people internalize the existence of internal control before investing in coca, which is especially true for FGB beneficiaries that do invest less when this policy is in place. People have beliefs on how far they can go before they get punished and act accordingly from the beginning.

\section{Final discussion and concluding remarks}

This study provides evidence on the feedback effect of policies that provide incentives to comply with the law. Using the context of the war on drugs, we find that beneficiaries of the Forest Warden Families Program (FGB), the biggest illegal crop substitution program in Colombia are significantly less likely to invest in coca than non-beneficiaries, especially when mechanisms of community control are available. We find that programs that emphasize culture of legality, state legitimacy and social capital -as FGB does- seem to be an efficient way to enhance 
coca-reducing efforts, especially because they enhance the development of social control mechanisms within communities. The mere existence of such mechanisms was enough to bring coca investments down for people who had been exposed to the program. These mechanisms can be potentially combined with external governmental control mechanisms that target only those individuals that break the law and grow coca, instead of the whole communities in order to become even more efficient.

These internal mechanisms complement governmental efforts that punish those individuals that deviate from the norm. This complementarity arises when, for instance, the majority of a community makes up their mind to voluntarily eradicate coca, but lacks the capacity to ensure that every single community member complies. In this case, they even thank the existence of individual external control, which avoids internal conflict between community members. However, when the whole community is punished for the actions of possibly only a few (as is the case of aerial spraying, which negatively affects cash crops and legal investments in alternative crops), state legitimacy is decreased. This result is in line with Feldab-Brown's (2006) arguments related to "winning the hearts and minds" of farmers, where the author shows with qualitative-case study evidence that where aerial spraying is undertaken, the legitimacy of the state decreases and the local population ceases to cooperate with the authorities. For these reasons, special attention has to be paid to not crowding out mechanisms of internal control with external punishments that affect whole groups. They might seem too harsh or unjust to the people who might then decide to not even coordinate among themselves.

In terms of externalities, the program's effects do not seem to extend outside community boundaries, as seen with the mixed group results that did not show any signs of adjusting to lower levels of coca investments because of FGB presence in the group. Thus, special care of reaching an entire region might generate stronger internal community controls and might reduce the need for external control mechanisms. Any policy that aims at reducing coca needs to target entire communities, since people' decisions regarding coca cultivation are greatly affected by what they see others do.

One question that arises with the use of framed field experiments is how well they actually reflect what happens in real life and how valid the results are outside a lab setting. Although we can not quantitatively assure that what we observe in the lab is what would happen in the field, we have qualitative knowledge that leads us to believe that our results would hold outside the frame of the experiment. After every experiment we held a discussion with the participants about the experiment and asked them how well they thought the experiment captured real life and how they thought their experimental behavior reflected their day-to-day decisions. In short, as the discussion progressed, it was clear that their arguments for investing or not investing in coca in the experiment are the same ones they use for working or not working with coca in their life: the violence and fear that it brought and the high risks of being caught. When they mentioned aerial spraying the first question we asked was what they thought would happen as soon as the airplanes disappeared. Not surprisingly the answer was that they, or a majority of people would go back to coca, as it was still more profitable than everything else. Only 
those from the program communities showed more apprehension with going back to coca and mentioned their will to give alternative legal products a chance and were hopeful for better times with legal crops. However, the fear of the sustainability of legal crops is still worrisome for all participants and posits a threat to sustainable coca reductions.

Although the region where we conducted the study was not randomly selected it seems to be representative of other municipalities with coca in the country. As we conduct the study in only one region, our conclusions are not valid for all the country, but only for these municipalities. Yet, our findings are indicative of what could happen in other areas that have similar characteristics.

These discussions showed three things that are important for validating our experimental results: 1) People understood the game and translated it to their own dilemma between coca and a legal alternative; 2) the treatment group did show more engagement with legal alternatives and with staying away from illegality when the program ended and also in the face of a present lower risk of being caught and 3) the sustainability of coca reducing efforts depends not only on risk or punishment, but also on the provision of legal livelihoods and the strengthening of social norms within the community that align community members around a goal of being successful outside illegality.

Despite the fact that the usual limitations of framed field experiments of having high internal validity but low external validity apply to our study, we are confident that the experiment mimics reality and brings experimental responses closer to real life behaviors. In particular, participants are all farmers in coca growing areas that face the decision of growing coca or cacao (or other legal product) every harvest; and they all face both external deterrence (either through areal spraying, manual eradication or both) and alternative development options. The treatment group has also been exposed to internal mechanisms of social control through the verification committee that they created for the Program. Nonetheless, once field experiment hypotheses are confirmed, efforts should be undertaken in further research to test these hypotheses outside the "lab." 


\section{Appendix}

Table A4.1: Coca investments with coca invested by others in group

\begin{tabular}{|c|c|c|c|c|}
\hline & $\begin{array}{c}(1) \\
\text { dcoca }\end{array}$ & $\begin{array}{c}(2) \\
\text { Coca }\end{array}$ & $\begin{array}{c}(3) \\
\text { dcoca }\end{array}$ & $\begin{array}{c}(4) \\
\text { Coca }\end{array}$ \\
\hline \multicolumn{5}{|l|}{ Experimental Treatments } \\
\hline T1 Group Punish & $\begin{array}{c}-0.116 \\
(0.096)\end{array}$ & $\begin{array}{c}-0.728^{*} \\
(0.382)\end{array}$ & $\begin{array}{l}-0.097 \\
(0.096)\end{array}$ & $\begin{array}{c}-0.636^{*} \\
(0.366)\end{array}$ \\
\hline T2 Int. Control & $\begin{array}{c}0.032 \\
(0.044)\end{array}$ & $\begin{array}{c}-0.036 \\
(0.189)\end{array}$ & $\begin{array}{c}0.040 \\
(0.043)\end{array}$ & $\begin{array}{c}0.001 \\
(0.182)\end{array}$ \\
\hline T3 Individual Punish & $\begin{array}{c}-0.151^{* * *} \\
(0.050)\end{array}$ & $\begin{array}{c}-0.683^{* * *} \\
(0.217)\end{array}$ & $\begin{array}{c}-0.132^{* *} \\
(0.052)\end{array}$ & $\begin{array}{c}-0.587^{* * *} \\
(0.213)\end{array}$ \\
\hline T4 IntCont + GroupPunish & $\begin{array}{l}-0.082 \\
(0.067)\end{array}$ & $\begin{array}{l}-0.125 \\
(0.308)\end{array}$ & $\begin{array}{c}-0.077 \\
(0.063)\end{array}$ & $\begin{array}{c}-0.104 \\
(0.287)\end{array}$ \\
\hline T5 IntCont + IndPunish & $\begin{array}{l}-0.109 \\
(0.086)\end{array}$ & $\begin{array}{c}-0.681^{*} \\
(0.378)\end{array}$ & $\begin{array}{c}-0.101 \\
(0.083)\end{array}$ & $\begin{array}{c}-0.638^{*} \\
(0.364)\end{array}$ \\
\hline \multicolumn{5}{|c|}{ Program Treatment and Interactions } \\
\hline FGB & $\begin{array}{c}0.059 \\
(0.067)\end{array}$ & $\begin{array}{c}0.421 \\
(0.291)\end{array}$ & $\begin{array}{c}0.055 \\
(0.065)\end{array}$ & $\begin{array}{c}0.400 \\
(0.279)\end{array}$ \\
\hline T1 GP X FGB & $\begin{array}{c}0.012 \\
(0.085)\end{array}$ & $\begin{array}{c}-0.064 \\
(0.298)\end{array}$ & $\begin{array}{c}0.012 \\
(0.084)\end{array}$ & $\begin{array}{l}-0.061 \\
(0.288)\end{array}$ \\
\hline T2 IC X FGB & $\begin{array}{l}-0.017 \\
(0.058)\end{array}$ & $\begin{array}{l}-0.354 \\
(0.228)\end{array}$ & $\begin{array}{l}-0.010 \\
(0.057)\end{array}$ & $\begin{array}{l}-0.317 \\
(0.223)\end{array}$ \\
\hline T3 IP X FGB & $\begin{array}{l}-0.039 \\
(0.075)\end{array}$ & $\begin{array}{l}-0.121 \\
(0.340)\end{array}$ & $\begin{array}{l}-0.031 \\
(0.073)\end{array}$ & $\begin{array}{l}-0.083 \\
(0.332)\end{array}$ \\
\hline T4 ICGP X FGB & $\begin{array}{l}-0.026 \\
(0.037)\end{array}$ & $\begin{array}{c}-0.565^{* * *} \\
(0.168)\end{array}$ & $\begin{array}{l}-0.013 \\
(0.036)\end{array}$ & $\begin{array}{c}-0.499^{* * *} \\
(0.153)\end{array}$ \\
\hline T5 ICIP X FGB & $\begin{array}{l}-0.128^{*} \\
(0.072)\end{array}$ & $\begin{array}{c}-0.554^{*} \\
(0.297)\end{array}$ & $\begin{array}{l}-0.112 \\
(0.069)\end{array}$ & $\begin{array}{c}-0.477 \\
(0.292)\end{array}$ \\
\hline \multicolumn{5}{|l|}{ Group Types } \\
\hline All FGB & $\begin{array}{c}-0.058 \\
(0.060)\end{array}$ & $\begin{array}{l}-0.358 \\
(0.301)\end{array}$ & $\begin{array}{l}-0.057 \\
(0.057)\end{array}$ & $\begin{array}{c}-0.353 \\
(0.281)\end{array}$ \\
\hline Mixed & $\begin{array}{c}0.010 \\
(0.039)\end{array}$ & $\begin{array}{c}0.081 \\
(0.212)\end{array}$ & $\begin{array}{c}0.007 \\
(0.037)\end{array}$ & $\begin{array}{c}0.069 \\
(0.198)\end{array}$ \\
\hline \multicolumn{5}{|l|}{ Controls } \\
\hline Cost to urban center & $\begin{array}{c}0.000 \\
(0.000)\end{array}$ & $\begin{array}{c}0.000 \\
(0.000)\end{array}$ & $\begin{array}{c}0.000 \\
(0.000)\end{array}$ & $\begin{array}{c}0.000 \\
(0.000)\end{array}$ \\
\hline Other non-Catholic religion & $\begin{array}{c}-0.042 \\
(0.026)\end{array}$ & $\begin{array}{c}-0.125 \\
(0.132)\end{array}$ & $\begin{array}{l}-0.041 \\
(0.027)\end{array}$ & $\begin{array}{c}-0.119 \\
(0.133)\end{array}$ \\
\hline Years growing coca & $\begin{array}{l}0.004^{*} \\
(0.002)\end{array}$ & $\begin{array}{c}0.017 \\
(0.015)\end{array}$ & $\begin{array}{l}0.004^{*} \\
(0.002)\end{array}$ & $\begin{array}{c}0.016 \\
(0.014)\end{array}$ \\
\hline Years in vereda & $\begin{array}{c}-0.000 \\
(0.001)\end{array}$ & $\begin{array}{c}0.000 \\
(0.005)\end{array}$ & $\begin{array}{l}-0.000 \\
(0.001)\end{array}$ & $\begin{array}{l}-0.000 \\
(0.005)\end{array}$ \\
\hline Experimental Round & $\begin{array}{c}-0.013^{* *} \\
(0.006)\end{array}$ & $\begin{array}{c}0.032 \\
(0.024)\end{array}$ & $\begin{array}{c}-0.012^{* *} \\
(0.005)\end{array}$ & $\begin{array}{c}0.035 \\
(0.022)\end{array}$ \\
\hline Coca by others (t-1) & & & $\begin{array}{c}0.010^{* * *} \\
(0.003)\end{array}$ & $\begin{array}{c}0.050^{* * *} \\
(0.015)\end{array}$ \\
\hline Constant & $\begin{array}{c}0.454^{* * *} \\
(0.044)\end{array}$ & $\begin{array}{c}1.539^{* * *} \\
(0.208)\end{array}$ & $\begin{array}{c}0.416^{* * *} \\
(0.042)\end{array}$ & $\begin{array}{c}1.353^{* * *} \\
(0.200)\end{array}$ \\
\hline Observations & 3332 & 3332 & 3332 & 3332 \\
\hline Veredas & 30 & 30 & 30 & 30 \\
\hline R2 Overall & 0.12 & 0.08 & 0.13 & 0.10 \\
\hline R2 Within & 0.00 & 0.00 & 0.00 & 0.00 \\
\hline R2 Between & 0.17 & 0.12 & 0.19 & 0.14 \\
\hline
\end{tabular}

Vereda level clustered standard errors in parentheses. Session fixed effects included.

Significance levels ${ }^{*} \mathrm{p}<0.10,{ }^{* *} \mathrm{p}<0.05,{ }^{* * *} \mathrm{p}<0.01153$ 
Table A4.2: Coca investments after being punished

\begin{tabular}{|c|c|c|c|c|c|c|c|c|}
\hline & $\begin{array}{c}(1) \\
\mathrm{dCoca}\end{array}$ & $\begin{array}{c}(2) \\
\text { Coca }\end{array}$ & $\begin{array}{c}(3) \\
\mathrm{dCoca}\end{array}$ & $\begin{array}{c}(4) \\
\text { Coca }\end{array}$ & $\begin{array}{c}(5) \\
\mathrm{dCoca}\end{array}$ & $\begin{array}{c}(6) \\
\text { Coca }\end{array}$ & $\begin{array}{c}(7) \\
\mathrm{dCoca}\end{array}$ & $\begin{array}{c}(8) \\
\text { Coca }\end{array}$ \\
\hline \multicolumn{9}{|l|}{ Punishment } \\
\hline Punishment (t-1) & $\begin{array}{c}0.011 \\
(0.016)\end{array}$ & $\begin{array}{c}0.080 \\
(0.091)\end{array}$ & & & $\begin{array}{c}0.019 \\
(0.013)\end{array}$ & $\begin{array}{c}0.087 \\
(0.094)\end{array}$ & & \\
\hline Cumm. punishment (t-1) & & & $\begin{array}{c}-0.039^{* * *} \\
(0.015)\end{array}$ & $\begin{array}{c}-0.022 \\
(0.055)\end{array}$ & & & $\begin{array}{l}-0.018 \\
(0.018)\end{array}$ & $\begin{array}{l}-0.062 \\
(0.089)\end{array}$ \\
\hline \multicolumn{9}{|l|}{ Experimental Treatments } \\
\hline T3 Individual Punish & $\begin{array}{l}-0.107 \\
(0.090)\end{array}$ & $\begin{array}{l}-0.229 \\
(0.336)\end{array}$ & $\begin{array}{l}-0.107 \\
(0.090)\end{array}$ & $\begin{array}{l}-0.229 \\
(0.336)\end{array}$ & $\begin{array}{l}-0.009 \\
(0.088)\end{array}$ & $\begin{array}{c}0.131 \\
(0.362)\end{array}$ & $\begin{array}{l}-0.009 \\
(0.088)\end{array}$ & $\begin{array}{c}0.131 \\
(0.363)\end{array}$ \\
\hline T4 IntCont + GroupPunish & $\begin{array}{l}-0.035 \\
(0.099)\end{array}$ & $\begin{array}{c}0.301 \\
(0.396)\end{array}$ & $\begin{array}{c}0.007 \\
(0.101)\end{array}$ & $\begin{array}{c}0.343 \\
(0.402)\end{array}$ & $\begin{array}{c}0.068 \\
(0.101)\end{array}$ & $\begin{array}{c}0.714 \\
(0.444)\end{array}$ & $\begin{array}{c}0.091 \\
(0.101)\end{array}$ & $\begin{array}{l}0.800^{*} \\
(0.459)\end{array}$ \\
\hline T5 IntCont + IndPunish & $\begin{array}{c}0.049 \\
(0.090)\end{array}$ & $\begin{array}{c}0.145 \\
(0.324)\end{array}$ & $\begin{array}{c}0.084 \\
(0.090)\end{array}$ & $\begin{array}{c}0.201 \\
(0.326)\end{array}$ & $\begin{array}{c}0.172 \\
(0.107)\end{array}$ & $\begin{array}{c}0.625 \\
(0.470)\end{array}$ & $\begin{array}{l}0.195^{*} \\
(0.106)\end{array}$ & $\begin{array}{c}0.716 \\
(0.477)\end{array}$ \\
\hline \multicolumn{9}{|l|}{ Interactions } \\
\hline FGB & $\begin{array}{c}0.100 \\
(0.067)\end{array}$ & $\begin{array}{c}0.468^{* *} \\
(0.229)\end{array}$ & $\begin{array}{c}0.100 \\
(0.067)\end{array}$ & $\begin{array}{c}0.468^{* *} \\
(0.229)\end{array}$ & $\begin{array}{c}0.110^{*} \\
(0.064)\end{array}$ & $\begin{array}{c}0.504^{* *} \\
(0.214)\end{array}$ & $\begin{array}{l}0.110^{*} \\
(0.064)\end{array}$ & $\begin{array}{c}0.505^{* *} \\
(0.214)\end{array}$ \\
\hline T3 IP X FGB & $\begin{array}{l}-0.023 \\
(0.070)\end{array}$ & $\begin{array}{c}0.038 \\
(0.320)\end{array}$ & $\begin{array}{l}-0.023 \\
(0.070)\end{array}$ & $\begin{array}{c}0.038 \\
(0.320)\end{array}$ & $\begin{array}{c}-0.044 \\
(0.062)\end{array}$ & $\begin{array}{c}0.003 \\
(0.302)\end{array}$ & $\begin{array}{l}-0.045 \\
(0.062)\end{array}$ & $\begin{array}{c}0.003 \\
(0.301)\end{array}$ \\
\hline T4 ICGP X FGB & $\begin{array}{l}-0.065 \\
(0.078)\end{array}$ & $\begin{array}{c}-0.568^{*} \\
(0.319)\end{array}$ & $\begin{array}{l}-0.065 \\
(0.078)\end{array}$ & $\begin{array}{c}-0.568^{*} \\
(0.319)\end{array}$ & $\begin{array}{l}-0.045 \\
(0.072)\end{array}$ & $\begin{array}{c}-0.510^{*} \\
(0.286)\end{array}$ & $\begin{array}{l}-0.045 \\
(0.072)\end{array}$ & $\begin{array}{l}-0.511^{*} \\
(0.286)\end{array}$ \\
\hline T5 ICIP X FGB & $\begin{array}{c}-0.134^{* *} \\
(0.059)\end{array}$ & $\begin{array}{c}-0.451 \\
(0.288)\end{array}$ & $\begin{array}{c}-0.134^{* *} \\
(0.059)\end{array}$ & $\begin{array}{l}-0.451 \\
(0.288)\end{array}$ & $\begin{array}{c}-0.148^{* *} \\
(0.065)\end{array}$ & $\begin{array}{l}-0.480 \\
(0.318)\end{array}$ & $\begin{array}{c}-0.148^{* *} \\
(0.065)\end{array}$ & $\begin{array}{l}-0.481 \\
(0.317)\end{array}$ \\
\hline \multicolumn{9}{|l|}{ Group Types } \\
\hline All FGB & $\begin{array}{c}-0.115^{* *} \\
(0.059)\end{array}$ & $\begin{array}{c}-0.584^{*} \\
(0.331)\end{array}$ & $\begin{array}{c}-0.115^{* *} \\
(0.059)\end{array}$ & $\begin{array}{c}-0.584^{*} \\
(0.331)\end{array}$ & $\begin{array}{c}-0.112^{*} \\
(0.059)\end{array}$ & $\begin{array}{c}-0.572^{*} \\
(0.313)\end{array}$ & $\begin{array}{c}-0.112^{*} \\
(0.060)\end{array}$ & $\begin{array}{c}-0.572^{*} \\
(0.313)\end{array}$ \\
\hline Mixed & $\begin{array}{c}0.010 \\
(0.038)\end{array}$ & $\begin{array}{c}0.091 \\
(0.243)\end{array}$ & $\begin{array}{c}0.010 \\
(0.038)\end{array}$ & $\begin{array}{c}0.091 \\
(0.243)\end{array}$ & $\begin{array}{c}0.017 \\
(0.038)\end{array}$ & $\begin{array}{c}0.110 \\
(0.230)\end{array}$ & $\begin{array}{c}0.017 \\
(0.038)\end{array}$ & $\begin{array}{c}0.111 \\
(0.230)\end{array}$ \\
\hline \multicolumn{9}{|l|}{ Controls } \\
\hline Coca by others (t-1) & & & & & $\begin{array}{c}0.005 \\
(0.003)\end{array}$ & $\begin{array}{c}0.043^{* * *} \\
(0.014)\end{array}$ & $\begin{array}{c}0.005 \\
(0.003)\end{array}$ & $\begin{array}{c}0.042^{* * *} \\
(0.015)\end{array}$ \\
\hline Constant & $\begin{array}{c}0.368^{* * *} \\
(0.086)\end{array}$ & $\begin{array}{c}1.251^{* * *} \\
(0.323)\end{array}$ & $\begin{array}{c}0.368^{* * *} \\
(0.086)\end{array}$ & $\begin{array}{c}1.251^{* * *} \\
(0.323)\end{array}$ & $\begin{array}{c}0.269^{* *} \\
(0.132)\end{array}$ & $\begin{array}{c}0.455 \\
(0.616)\end{array}$ & $\begin{array}{l}0.246^{*} \\
(0.132)\end{array}$ & $\begin{array}{c}0.373 \\
(0.636)\end{array}$ \\
\hline Observations & 2260 & 2260 & 2260 & 2260 & 2196 & 2196 & 2196 & 2196 \\
\hline Veredas & 24 & 24 & 24 & 24 & 24 & 24 & 24 & 24 \\
\hline R2 Overall & 0.09 & 0.07 & 0.10 & 0.07 & 0.11 & 0.09 & 0.11 & 0.09 \\
\hline R2 Within & 0.00 & 0.00 & 0.01 & 0.00 & 0.01 & 0.00 & 0.01 & 0.00 \\
\hline R2 Between & 0.14 & 0.10 & 0.14 & 0.10 & 0.16 & 0.12 & 0.16 & 0.12 \\
\hline
\end{tabular}

Clustered standard errors in parentheses. Significance levels ${ }^{*} \mathrm{p}<0.10,{ }^{* *} \mathrm{p}<0.05,{ }^{* * *} \mathrm{p}<0.01$

Treatment base level: T1 Group punishment. Session fixed effects and controls in last 4 columns included.

\section{Translated english instructions}

We translated the instructions from Spanish and present them below. During the experiment each treatment had an independent instruction manuscript. Because of space considerations the following instructions will highlight where each treatment entered and what varied depending on the treatment. You can access the original spanish instructions in the online version of the 
document.

Begin

Good morning/good afternoon. My name is welcome to this workshop. Before starting, we want to thank you for your participation. This workshop was prepared by a group of university professors for a study about living conditions in areas that have had coca crops or still have coca crops in Colombia. Throughout the exercise we will not ask your name or any other question that identifies you or your family. All the information will be analyzed as a group and we will not look into individual responses.

We will carry out this same exercise in different communities. In order to make it comparable, we have prepared the instructions that we will read to you now.

For participating in the workshop and answering a final survey you will receive $\$ 10.000$ pesos (approx. 5 USD). However, throughout the exercise you can win or lose money, so you can end up with more than $\$ 10.000$, less than $\$ 10.000$ or even lose the $\$ 10.000$. The amount of money that you get will depend on the decisions that you make during the workshop, as well as on the decisions made by other participants in your group.

We start the activity by randomly forming groups of 3 people. The groups will remain the same during the whole workshop, and you will never know who was in your group.

How long is the workshop?

This activity will last approximately three hours. You will have to make a series of decisions. It is important that you carefully think about the decisions that you make, as if you were in the situations that we will present.

What type of decisions will you have to make?

You will decide whether you invest in coca or in cacao, and you have $\$ 100.000$ pesos to invest in these products. For every $\$ 10.000$ pesos that you invest in coca, you will get $\$ 160.000$. For each thousand pesos that you invest in cacao you will get $\$ 70.000$ pesos. You can invest any amount you want between 0 and $\$ 100.000$. You are free to choose how much you invest in each activity, but you will always have to invest the whole $\$ 100.000$ pesos.

However, coca cultivation generates various negative effects on society. To represent the harm that it causes to communities, we will deduct $\$ 35.000$ pesos for each $\$ 10.000$ pesos invested in coca by each group member. This discount applies to all the people in the group, independently of if they invest in coca or not, or of how much they invested. [The next sentence in cursive appears only for the control group T0] Initially there is no risk of being caught cultivating coca; this means that there is no eradication, no spraying and not control of the authorities over coca investments.

In order to facilitate the way in which you invest, each one will receive a sheet of paper with ten bills of $\$ 10.000$ that in total sum up to $\$ 100.000$. You can cross out the amount of bills that you want to invest in cacao, and everything else will be invested in coca. For example, 
if you want to invest $\$ 70.000$ in cacao, cross out 7 bills from the sheet, and the $\$ 30.000$ that are left will be invested in coca. If you want to invest $\$ 20.000$ in cacao, cross out two bills in the sheet that says cacao, and the $\$ 80.000$ left ( 8 bills) will be invested in coca. If you want to invest all the $\$ 100.000$ in coca, you should not cross any bill.

When you are done, fold your paper in half so that no one sees your decision, raise your hand and an assistant will go to your seat and take your sheet. Please do not stand up. Wait patiently and we will get your paper. After every round you will be able to know how much you got in coca, how much for cacao, how much the other group members invested in coca and how much of your profits were discounted for coca investments in your group. [The treatments that include external punishment, T1, T3, T4 and T5, include the following statement in cursive] We will also inform you on whether a green or red ball was drawn, and how much was the value of the fine.

You will receive a paper like this for each round that we play. You will receive all the pages at the beginning. However, you should only mark the sheet that corresponds to the round that we are playing. Please, do not mark all the sheets at the same time! We will let you know when you can answer the next round. In each sheet the participant number that we gave you at the beginning of the game should be visible. Please verify that all your sheets have your participating number.

[The treatments that include external group liability punishment, T1, T3, T4 and T5, include the following statement in cursive depending on whether they have group or individual liability] [Group liability $\mathrm{T} 1$, :] There exists a risk that authorities do an inspection and find the coca crops. If the authorities find that any person of the group has coca, every person from the group has to pay $\$ 90.000$ pesos for every $\$ 10.000$ pesos invested in coca by the group. The punishment applies to all group members independently of if they grew coca or not. [Individual liability:] There exists a risk that authorities do an inspection and find the coca crops. If the authorities find that you have coca, you will have to pay $\$ 90.000$ as punishment for each $\$ 10.000$ invested in coca. The punishment applies for those that invested in coca. [All external punishment treatments:] In order to determine if there is an inspection or not, the workshop assistants will have a bag with 10 balls (show the balls and the empty bag). Seven will be green and three will be red. In each round they will take out a ball. If the ball is green, the group will be not be monitored. If the ball is red, the group will be monitored, and if any of its members invested in coca in that round. [Group liability external punishment] each person will be discounted $\$ 90.000$ pesos for every $\$ 10.000$ (one bill) invested in coca by the group. [Individual liability:] the persons who invested in coca will have a punishment of $\$ 90.000$ for every $\$ 10.000$ (one bill) invested in coca by yourself.

This procedure will repeat itself for many rounds. However, the amount of rounds that we will play is a surprise. When we are done we will calculate the total sum of your payments from all the rounds. Since we come from the university, we are not able to pay you all the money that you would make with coca or with cacao, so we will pay a fraction of what you make (we will take 3 zeroes out), and we will add the $\$ 10.000$ that you initially had from participating in 
the activity. For example, if after all the rounds you gained $\$ 3.000 .000$ (approx.. 1500 USD) for your decisions, you will receive $\$ 13.000$, which is equal to 3.000 .000 with three zeroes less: $3.000+10.000$. If after all the rounds you lost $\$ 2.000 .000$, and $\$ 2.000 .000$ without three zeroes is 2.000 , then you will receive $10.000-2000=\$ 8.000$ in total. [All numerical explanations are being written down in the board].

[For the treatments with internal control, T2, T4 and T5, the following statement was included] As we told you, when each round ends you will know how other people from your group invested. If you disagree with their investments you can show your dissatisfaction by sending a "sad face." Each "sad face" has a cost of $\$ 50$ pesos for the person that buys it, which represents the costs of having to tell another person that you don't agree with what they do, like for example generating problems in a friendship, start a disagreement with a community member, etc. Each sad face that you send reduces the income of the person that receives it in $\$ 100$ pesos. You can buy the faces with the income that you received from coca and cacao in the round that you are playing. You can send as many sad faces as you want as long as you don't exceed the amount that you have in your budget. The profit from each round will be given in its true form, which means without the three zeroes, and from this real profit you can decide how many sad faces you can send. You will see the sad faces that were sent to you by other group members in the next round. This means that in the information that we give you in the second round, the faces that were sent to you in round 1 will appear. However, the amount of sad faces that you send and that you receive affect the payments only in the round in which they were sent. This means, the faces sent and received in round 1 only affect the payments in round 1.

How do you calculate your payments? Let's do an example

Initially you have $\$ 100.000$ pesos to invest, and you can invest them in coca or in cacao. Let's say that I decide to invest $\$ 70.000$ (7 bills) in coca and $\$ 30.000$ (3 bills) in cacao. So in the decision sheet I cross out 3 bills for cacao (show). How do we calculate the profits made from coca? If I invested 3 bills in cacao I have 7 left for coca and $7^{*} 160.000=1.120 .000$. What is my income for investing in cacao? Since I crossed out 3 bills for caca and each bill gives me $\$ 70.000$, 3 bills give me $3 * 70.000=210.000$. The total income for my investments is the sum of what I receive from coca, which is 1.120 .000 pesos, plus what I receive from cacao, 210.000 pesos, in total, 1.330.000.

Given the negative effects of coca, here is a reduction in the payoffs for all group members. Let's suppose that one person from the group invests in coca and the other one doesn't. In our example I invested 7 bills and the others invested one bill in total. Each bill invested in coca generates a discount of 35.000 pesos. Thus, the reduction for investing in coca for each group member from this group is $8 * 35.000$. This gives $\$ 280.000$ pesos. My total income in pesos is then $1.120 .000+210.00-280.000=1^{\prime} 050.000$ for this round.

[The treatments that include external punishment, T1, T3, T4 and T5, include the following statement in cursive] However, you will not always get the green ball. Since three of the10 balls in the bag are red, and I could get one of them, what would be my payment in this case? 
[The treatments with group liability external punishment have the following statement] In the case of monitoring, since group members invested in coca they need to pay a fine. How much would the fine be for everyone? In total there are 8 bills invested in coca in my group. For each bill there is a fine of $\$ 90.000$, which means that the fine for the group is $90.000 * 8=\$ 720.000$. My final payment would be 1.050.000-720.000=330.000.

[The treatments with individual liability external punishment have the following statement] In the case of monitoring, since group members invested in coca they need to pay a fine. How much would the fine be for everyone? In total I invested 7 bills in coca. For each bill there is a fine of $\$ 90.000$, which means that the fine for me is $90.000^{*} y=\$ 630.000$. My final payment would be 1.050.000-630.000=420.000.

[The treatments with internal control heard this statement:] After your first investment you will know what happened in the round, how much you got from coca, form cacao and how much was taken because of coca's social costs. From the payment that you obtained you can buy sad faces to send other group members. In order to buy the sad faces we will give you a sheet with sad faces. In the upper part of this sheet, you will cross the amount of sad faces that you want to send participant A from your group, and in the lower part the amount you want to send to the second participant. You will fold the sheet and we will collect it. In the information we give you in the next round you will know how many faces were sent to you by other group members. The acquisition of sad faces comes out of your "real" profit and not from the initial \$100.000!

Let's say that you want to tell other group members that you don't agree with the investments that they did, and you decide to send them sad faces. In total, you buy 1 sad face. Because each sad face costs $\$ 50$, you send $1 * 50=\$ 50$ in sad faces. Let's say that the other people in the group were also not happy with how you made your decisions, and each sends you one sad face; in total you received two sad faces. Since each sad face generates a punishment of \$100, your income is reduced by $2^{*} 100=\$ 200$ pesos. In order to know what your payment is after the sad faces, we will need to take out the 3 zeroes that we spoke about out of your income form cacao and coca. In the example we will understand it better. The payment that you receive without the three zeroes is $\$ 1.050$. You buy 1 sad face at 50 pesos, $1^{*} 50$, and since it's a loss it is -50 . You receive two faces, each punishes 100, ${ }^{*} 100=200$, since it's a loss, -200. Your net income you be: $1.050-50-200=800$

[The treatments with internal control and external group punishment heard this statement:] My final payment would be 330-250=80.

[The treatments with internal control and individual external punishment heard this statement:] My final payment would be 420-250=170

Now let's look at another example. This time, I decide to invest 3 bills $(\$ 30.000)$ in coca and 7 bills (\$70.000) in cacao. If in my group one person invested one bill in coca and the other invested two bills, in this case how would my payments look like?

1 bill in coca gives $\$ 160.000$ and I invest 3 I get $160.000 * 3=\$ 480.000$

1 bill in cacao gives $\$ 70.000$ and I invest 7 , I get $\$ 70.000 * 7=490.000$ 
My total income from my investments would then be $480.000+490.000=970.000$

Due to negative effects of coca I get a reduction of 35.000 pesos per bill: $3+2+1=6$, so $6^{*} 35.000=210.000$ pesos in reduction.

My net profit is then $970.000-210.000=760.000$

[The treatments with group liability external punishment have the following statement] And in case of getting the red ball, what would be my payments? 1 bill in coca reduces income in $\$ 90.000$, so $3+2+1=6$ bills, $6^{*} 90.000=-540.000$. So total income would be: $760.000-540.000=220.000$.

[The treatments with individual liability external punishment have the following statement] And in case of getting the red ball, what would be my payments? 1 bill in coca reduces income in $\$ 90.000$, so $3^{*} 90.000=-270.000$. So total income would be: $760.000-270.000=490.000$.

[The treatments with internal control mechanisms hear:] Let's say that again you are not happy with what other did, and you sent one sad face to one of them. In this case you also only received one sad faces. What would your payments be like now? You buy one sad face, $1{ }^{*} 50$, since it's a loss -50 , and send a face, $1{ }^{*} 100$, since it's a loss -100 . Your net income would be 760-150=\$610. [The treatments with external group punishment hear] Your net income would be 220-150=\$70. [The treatments with external individual punishment hear] Your net income would be 490-150=\$340.

Do you have any questions until now?

Once we start you cannot talk to anyone in the room. If anyone talks he/she will be excluded from the workshop and from the payments. If you have any questions please raise your hand and one of us will come and answer. When you are already sitting, the pages with the $\$ 100.000$ in bills of $\$ 10.000$ will be given to you to so you can invest.

Before we start with the investment decisions, we want to do one practice round. The idea is to be sure that we have been able to explain to you clearly what we are going to do. These decisions will not affect your pay.

(After finishing crossing out) Now we will pick up your marked sheets. The next thing we will do is to enter them in the computer to see how you did in this round. When we are done we will give you a little sheet that has the following information information (show sheet and explain) : what you got from coca, what you got from cacao, the cost of the group's coca investments, what each person invested in coca, [for treatments with external punishment] if there was or not a fine, the size of the fine [again for all] and the final round payment. The payment is already reduced in the 3 zeroes as we had talked about. 


\section{Bibliography}

\section{References}

Abadie, Alberto and Guido Imbens, "Matching on the Estimated Propensity Score," 2012.

_ and Guido W Imbens, "Large Sample Properties of Matching Estimators for Average Treatment Effects," Econometrica, January 2006, 74 (1), 235-267.

_ and _, "Bias-Corrected Matching Estimators for Average Treatment Effects," Journal of Business $\&$ Economic Statistics, January 2011, 29 (1), 1-11.

Akerlof, George A and Janet L Yellen, "Rational models of irrational behavior," The American Economic Review, 1987, pp. 137-142.

Andreoni, James, Brian Erard, and Jonathan Feinstein, "Tax compliance," Journal of Economic Literature, 1998, pp. 818-860.

Angrist, Joshua D and Adriana D Kugler, "Rural windfall or a new resource curse? Coca, income, and civil conflict in Colombia," The Review of Economics and Statistics, 2008, 90 (2), 191-215.

Apesteguia, Jose, Patricia Funk, and Nagore Iriberri, "Promoting rule compliance in daily-life: Evidence from a randomized field experiment in the public libraries of Barcelona," European Economic Review, November 2013, 64, 266-284.

Aquino, Karl and Americus II Reed, "The self-importance of moral identity.," Journal of Personality and Social Psychology, 2002, 83 (6), 1423-1440.

Arias, María Alejandra, Ana María Ibáñez, and Andrés Zambrano, “Agricultural Production amidst Conflict: The Effects of Shocks, Uncertainty and Governance of Non-State Armed Actors," Documento CEDE, February 2014.

Ariely, Dan, The Honest Truth About Dishonesty How We Lie to Everyone-Especially Ourselves, HarperCollins, June 2013.

Axelrod, Robert, "An Evolutionary Approach to Norms," American Political Science Review, December 2006, 80 (04), 1095-1111.

Azar, Ofer H, Shira Yosef, and Michael Bar-Eli, "Do customers return excessive change in a restaurant?: A field experiment on dishonesty," Journal of Economic Behavior and Organization, September 2013, 93, 219-226.

Balmer, Thomas A, "Some Thoughts on Proportionality," Oregon Law Review, 2008, 87, 783.

Bazerman, Max $\mathbf{H}$ and Mahzarin R Banaji, "The social psychology of ordinary ethical failures," Social Justice Research, 2004, 17 (2), 111-115.

Becker, Gary S, "Crime and punishment: An economic approach," Journal of Political Economy, 1968, pp. 169-217. 
_ , Kevin M Murphy, and Michael Grossman, "The Market for Illegal Goods: The Case of Drugs," Journal of Political Economy, 2006, 114 (1), 38-60.

Bernal, H, "Generadores de impacto ambiental de los cultivos ilícitos y de la extracción y refinamiento de alcaloides," January 2007.

Bertrand, Marianne, Dean Karlan, Sendhil Mullainathan, Eldar Shafir, and Jonathan Zinman, "What's advertising content worth? Evidence from a consumer credit marketing field experiment," March 2009.

Bjerk, David, "Measuring the relationship between youth criminal participation and household economic resources," Journal of Quantitative Criminology, 2007, 23 (1), 23-39.

Blumenthal, Marsha, Charles Christian, and Joel Slemrod, "Do Normative Appeals Affect Tax Compliance? Evidence from a Controlled Experiment in Minnesota," National Tax Journal, May 2005, LIV, 1-15.

Bó, Ernesto Dal and Pedro Dal Bó, “"Do the Right Thing:” The Effects of Moral Suasion on Cooperation," Journal of Public Economics, 2014.

Bogliacino, Francesco and Alberto J Naranjo, "Coca Leaves Production and Eradication: A General Equilibrium Analysis," Economics Bulletin, 2012, 32 (1), 382-397.

Bohnet, Iris and Bruno S Frey, "The sound of silence in prisoner's dilemma and dictator games," Journal of Economic Behavior and Organization, 1999.

Brosig-Koch, Jeannette, Christoph Helbach, Axel Ockenfels, and Joachim Weimann, "Still different after all these years: Solidarity behavior in East and West Germany," January 2011.

Bucciol, Alessandro, Fabio Landini, and Marco Piovesan, "Unethical behavior in the field: Demographic characteristics and beliefs of the cheater," Journal of Economic Behavior and Organization, September 2013, 93, 248-257.

Burn, Shawn M and Stuart Oskamp, "Increasing community recycling with persuasive communication and public commitment," Journal of Applied Social Psychology, 1986, 16 (1), 29-41.

Busse, Matt D, Alice W Ratcliff, Carol J Shestak, and Robert F Powers, "Glyphosate toxicity and the effects of long-term vegetation control on soil microbial communities," Soil Biology and Biochemistry, 2001, 33 (12), 1777-1789.

Butler, D, "Journals step up plagiarism policing," Nature, 2010.

Camacho, Adriana and Daniel Mejía, "Consecuencias de la aspersión aérea en la salud: Evidencia desde el caso colombiano," Presented at the ISSDP Conference 2013, May 2013, pp. 1-21.

Cameron, Samuel, "The economics of crime deterrence: a survey of theory and evidence," Kyklos, 1988, 41 (2), 301-323.

Campbell, Ernest Q, "The internalization of moral norms," Sociometry, 1964, pp. 391-412. 
Carlson, Ann E, "Recycling norms," California Law Review, 2001, pp. 1231-1300.

Carpenter, Jeffrey P, "Punishing free-riders: How group size affects mutual monitoring and the provision of public goods," Games and Economic Behavior, 2007.

_ and Peter Hans Matthews, "Why punish? Social reciprocity and the enforcement of prosocial norms," Journal of Evolutionary Economics, 2004, 14 (4), 407-429.

Childs, Jason, "Gender differences in lying," Economics Letters, February 2012, 114 (2), $147-149$.

Choi, James J, Emily Haisley, Jennifer Kurkoski, and Cade Massey, "Small cues change savings choices," 2012.

Chong, Alberto, Dean S Karlan, Jeremy Shapiro, and Jonathan Zinman, "(Ineffective) Messages to Encourage Recycling," May 2013.

Chumacero, Romulo, Evo, Pablo, Tony, Diego and Sonny: General Equilibrium Analysis of the Market for Illegal Drugs, World Bank Policy Research Working Papers, March 2008.

CICR, "Situación Humanitaria Informe de Actividades Colombia 2011," December 2011, pp. 1-11.

Clemens, Jeffrey, "Opium in Afghanistan: Prospects for the success of source country drug control policies," Journal of Law and Economics, 2008, 51 (3), 407-432.

Cooter, Robert D, "Expressive law and economics," The University of Chicago Press, 1988.

_ and Iris Bohnet, "Expressive Law," John F. Kennedy School of Government Harvard University Faculty Research Working Papers RWP03-046 2003.

Dahrendorf, Ralf, "Effectiveness and Legitimacy: On the "Governability" of Democracies," The Political Quarterly, 1980, 51 (4), 393-409.

Dávalos, Liliana M, Adriana C Bejarano, Mark A Hall, H Leonardo Correa, Angelique Corthals, and Oscar J Espejo, "Forests and Drugs: Coca-Driven Deforestation in Tropical Biodiversity Hotspots," Environmental Science $\&$ Technology, February 2011, 45 (4), 1219-1227.

Degiovanni, Hernan Botero, "The Effects of Drug Enforcement on Violence in Colombia 1999-2010: A Spatial Econometric Approach," $M P R A$, September 2013.

DellaVigna, Stefano and Ethan Kaplan, "The Fox News effect: Media bias and voting," The Quarterly Journal of Economics, August 2007.

_ and Matthew Gentzkow, "Persuasion: empirical evidence," 2009.

_, Ruben Enikolopov, Vera Mironova, Maria Petrova, and Ekaterina Zhuravskaya, "Cross-border effects of foreign media: Serbian radio and nationalism in Croatia," American Economic Journal: Applied Economics, 2012. 
Derzon, James $\mathbf{H}$ and Mark W Lipsey, "A meta-analysis of the effectiveness of mass communication for changing substance use knowledge, attitudes and behavior.," in "Mass media and drug prevention: Classic and contemporary theories and research" January 2002, pp. 231-258.

Díaz, Ana María and Fabio Sánchez, "A Geography of Illicit Crops (coca Leaf) and Armed Conflict in Colombia," 2004.

Dion, Michelle L and Catherine Russler, "Eradication efforts, the state, displacement and poverty: explaining coca cultivation in Colombia during Plan Colombia," Journal of Latin American Studies, 2008, 40 (03), 399-421.

Dube, Oeindrila and Juan F Vargas, "Commodity price shocks and civil conflict: Evidence from Colombia," The Review of Economic Studies, 2013, 80 (4), 1384-1421.

Econometria, "Evaluación del Programa Familias Guardabosques y Grupo Móvil de Erradicación," April 2013, pp. 1-74.

Elster, Jon, "Social norms and economic theory," The Journal of Economic Perspectives, 1989, $3(4), 99-117$.

Etzioni, Amitai, The Moral Dimension: Toward a New Economics, Free Press, June 1990.

Eyster, Erik and Matthew Rabin, "Rational and Naive Herding," C.E.P.R. Discussion Papers, 2009, p. 50.

Fehr, Ernst and Armin Falk, "Psychological foundations of incentives," European Economic Review, March 2002, pp. 687-724.

_ and Simon Gächter, "Cooperation and punishment in public goods experiments," The American Economic Review, 2000, pp. 980-994.

Felbab-Brown, Vanda, Shooting Up Counterinsurgency and the War on Drugs, Brookings Institution Press, 2009.

Feldab-Brown, Vanda, "The Coca Connection: Conflict and Drugs in Colombia and Peru," May 2006, pp. 1-25.

Feldman, Yuval, "Complexity of Disentangling Intrinsic and Extrinsic Compliance Motivations: Theoretical and Empirical Insights from the Behavioral Analysis of Law, The," Wash. UJL \& Pol'y, 2011, 35, 11.

Fellner, Gerlinde, Rupert Sausgruber, and Christian Traxler, "Testing Enforcement Strategies in the Field: Legal Threat, Moral Appeal and Social Information," Journal of the European Economic Association 2013.

Fischbacher, Urs and Franziska Heusi, "Lies in disguise: An experimental study on cheating," 2008.

Fosgaard, Toke Reinholt, "Asymmetric default biasin dishonesty - how defaults work but only when in one's favor," IFRO Working Paper, April 2013, pp. 1-10. 
Franz, J E, M K Mao, and J A Sikorski, "Glyphosate: a unique global herbicide.," American Chemical Society, 1997.

Freeman, Richard B, "The economics of crime," Handbook of Labor Economics, 1999, 3, 35293571.

Frey, Bruno S and Reto Jegen, "Motivation crowding theory," Journal of Economic Surveys, 2001, 15 (5), 589-611.

Fuchs-Schundeln, Nicola and Alberto Alesina, "Good-Bye Lenin (Or Not?): The Effect of Communism on People's Preferences," The American Economic Review, September 2007, 97 (4), 1507-1528.

Gamson, William A, Talking Politics, Cambridge University Press, August 1992.

García, Miguel, "Cultivos ilícitos, participación política y confianza institucional," Unpublished manuscript, June 2011, pp. 1-26.

GCDP, "War On Drugs. Report of the Global Commission on Drug Policy," Technical Report 2011.

Gentzkow, Matthew and Jesse Shapiro, "What Drives Media Slant? Evidence from U.S. Daily Newspapers," NBER working paper, 2006, p. 66.

Gerber, Alan, Dean S Karlan, and Daniel Bergan, "Does the media matter? A field experiment measuring the effect of newspapers on voting behavior and political opinions," A Field Experiment Measuring the Effect of Newspapers on Voting Behavior and Political Opinions (February 15, 2006). Yale Economic Applications and Policy Discussion Paper, 2006, (12).

Gerber, Alan S, Donald P Green, and Christopher W Larimer, "Social pressure and vote turnout: Evidence from a large-scale field experiment," American Political Science Review, 2008, $102(1), 33$.

Gino, F, M I Norton, and D Ariely, "The Counterfeit Self The Deceptive Costs of Faking It," Psychological Science, 2010.

Gino, Francesca, Shahar Ayal, and Dan Ariely, "Contagion and differentiation in unethical behavior the effect of one bad apple on the barrel," Psychological Science, 2009, 20 (3), 393-398.

_, , and _, "Self-serving altruism? The lure of unethical actions that benefit others," Journal of Economic Behavior and Organization, September 2013, 93, 285-292.

Gneezy, Uri, "Deception: The role of consequences," The American Economic Review, 2005, 95 (1), 384-394.

_ , Bettina Rockenbach, and Marta Serra-Garcia, "Measuring lying aversion," Journal of Economic Behavior and Organization, September 2013, 93, 293-300.

Gravert, Christina, "How luck and performance affect stealing," Journal of Economic Behavior and Organization, September 2013, 93, 301-304. 
Grossman, Herschel I and Daniel Mejía, "The war against drug producers," Economics of Governance, 2008, 9 (1), 5-23.

Gutierrez, C Martinez, "How does Programa Familias Guardabosques Affect Criminality?," January 2008.

Hasseldine, John, Peggy Hite, Simon James, and Marika Toumi, "Persuasive Communications: Tax Compliance Enforcement Strategies for Sole Proprietors*," Contemporary Accounting Research, 2007, 24 (1), 171-194.

Hipp, John R and Daniel K Yates, "Ghettos, thresholds and, and crime: does concentrated poverty really have an accelerating increasing effect on crime?," Criminology, 2011, 49 (4), 955-990.

Ibáñez, A M, J C Muñoz-Mora, and P Verwimp, "Abandoning Coffee Under the Threat of Violence and the Presence of Illicit Crops: Evidence from Colombia," Documento CEDE, 2013.

Ibáñez, Marcela, "Who crops coca and why? The case of Colombian farmers," Courant Research Centre Discussion Papers, 2010.

_, "Is the war on drugs working? Examining the Colombian case using micro data," Courant Research Centre: Poverty, Equity and Growth - Discussion Papers, 2013.

- and Fredrik Carlsson, "Journal of Development Economics," Journal of Development Economics, November 2010, 93 (2), 249-263.

_ and Juanita Vasquez, "Can we fight illegal drugs with communication campaigns? An experimental approach," Unpublished manuscript, January 2015, pp. 1-43.

- and Peter Martinsson, "Journal of Public Economics," Journal of Public Economics, September 2013, 105 (C), 1-10.

Idrobo, Nicolás, Daniel Mejía, and Ana María Tribin, "Illegal Gold Mining and Violence in Colombia," Peace Economics, Peace Science and Public Policy, January 2014, 20 (1).

Jackson, Jonathan, Ben Bradford, Mike Hough, Andy Myhill, Paul Quinton, and Tom Tyler, "Why do people comply with the Law? Legitimacy and the Influence of Legal Institutions," Legitimacy and the Influence of Legal Institutions (January 28, 2012), 2012.

Kahan, Dan M, "Social influence, social meaning, and deterrence," Virginia Law Review, 1997, pp. 349-395.

Kahneman, Daniel and Amos Tversky, "Prospect Theory: An Analysis of Decision under Risk," January 1979.

Kallgren, C A, R R Reno, and R B Cialdini, "A Focus Theory of Normative Conduct: When Norms Do and Do not Affect Behavior," Personality and Social Psychology Bulletin, October 2000, 26 (8), 1002-1012.

Kamenica, Emir and Matthew Gentzkow, "Bayesian persuasion," American Economic Review, October 2011. 
Karlan, Dean, Margaret McConnell, Sendhil Mullainathan, and Jonathan Zinman, "Getting to the top of mind: How reminders increase saving," 2010.

Kellstedt, Paul M, "Media framing and the dynamics of racial policy preferences," American Journal of Political Science, 2000, pp. 245-260.

Kluegel, James R and David S Mason, "Fairness matters: social justice and political legitimacy in postcommunist Europe," Europe-Asia Studies, 2004, 56 (6), 813-834.

Knack, Stephen and Philip Keefer, "Does Social Capital Have an Economic Payoff? A Cross-country Investigation," The Quarterly Journal of Economics, 1997, 4, 1251-1288.

Kotsadam, Andreas and Niklas Jakobsson, "Do laws affect attitudes? An assessment of the Norwegian prostitution law using longitudinal data," International Review of Law and Economics, June 2011, 31 (2), 103-115.

Kuperan, K and Jon G Sutinen, "Blue water crime: deterrence, legitimacy, and compliance in fisheries," Law and Society Review, 1998, pp. 309-338.

Levitt, Steven D, "Understanding Why Crime Fell in the 1990s: Four Factors that Explain the Decline and Six that Do Not," December 2004.

Loewen, Peter J, Christopher T Dawes, Nina Mazar, Magnus Johannesson, Philipp Koellinger, and Patrik K E Magnusson, "The heritability of moral standards for everyday dishonesty," Journal of Economic Behavior and Organization, September 2013, 93, 363-366.

Masclet, D, C Noussair, S Tucker, and M C Villeval, "Monetary and nonmonetary punishment in the voluntary contributions mechanism," American Economic Review, 2003.

Mazar, Nina and Dan Ariely, "Dishonesty in Everyday Life and Its Policy Implications," American Marketing Association, 2006, 25 (1).

_, On Amir, and Dan Ariely, "The dishonesty of honest people: A theory of self-concept maintenance," Journal of Marketing Research, 2008, 45 (6), 633-644.

McAdams, Richard, "An attitudinal theory of expressive law," Oregon Law Review, 2000, 79, 339-390.

McGraw, Kathleen M, "Appeals to Civic Virtue versus Attention to Self-Interest: Effects on Tax Compliance," January 1991.

Mejía, Daniel and Carlos Esteban Posada, "Cocaine Production and Trafficking:," Policy Research Working Paper, May 2008, pp. 1-62.

- and Pascual Restrepo, "The War on Illegal Drug Production and Trafficking: An Economic Evaluation of Plan Colombia," Documentos CEDE October 2008.

_ and _, "Bushes and Bullets. Illegal Cocaine Markets and Violence in Colombia.," Documentos CEDE, November 2013.

_ and _, "The Economics of the War on Illegal Drug Production and Trafficking," Documento CEDE, 2013, (2013-54). 
_ , Sandra Rozo, and Pascual Restrepo, "On the Effectiveness of Supply Reduction Efforts in Drug Producing Countries: Evidence from Colombia," October 2013, pp. 1-35.

Mesina, Edith V, "Mass Media Exposure on Family Planning," Master of Arts Thesis, Mahidol University 2005.

Milgrom, $\mathbf{P}$ and $\mathbf{J}$ Roberts, "Price and advertising signals of product quality," The Journal of Political Economy, 1986, 94 (4), 796-821.

Monsanto, "Response to "The impact of insecticides and herbicides on the biodiversity and productivity of aquatic communities"," April 2005, pp. 1-4.

Moreno-Sanchez, Rocio, David S Kraybill, and Stanley R Thompson, "An econometric analysis of coca eradication policy in Colombia," World Development, 2003, 31 (2), 375383.

Mullainathan, Sendhil, Joshua Schwartzstein, and Andrei Shleifer, "Coarse Thinking and Persuasion," The Quarterly Journal of Economics, May 2008, 123 (2), 577-619.

Muroi, Chihiro and Robert Baumann, "The non-linear effect of wealth on crime," College of the Holy Cross, Department of Economics Faculty Research Series, 2009.

Naranjo, Alberto J, "Illicit drugs, rebel movements and anti-drug policies," May 2004, pp. 1-21.

Navarrete-Frías, Carolina and Francisco E Thoumi, "Illegal Drugs and HumanRights of Peasants and Indigenous Communities: The case of Peru," UNESCO, August 2005, pp. 1-40.

Nelson, P, "Information and consumer behavior," The Journal of Political Economy, 1970, pp. 311-329.

Nelson, Thomas E, Rosalee A Clawson, and Zoe M Oxley, "Media framing of a civil liberties conflict and its effect on tolerance," American Political Science Review, 1997, pp. 567583.

Oberholzer-Gee, Felix and Joel Waldfogel, "Media Markets and Localism," 2006.

Ockenfels, Axel and Joachim Weimann, "Types and patterns: an experimental East-WestGerman comparison of cooperation and solidarity," January 1999.

Ostrom, Elinor, "Collective action and the evolution of social norms," The Journal of Economic Perspectives, 2000, pp. 137-158.

- and James Walker, "Neither markets nor states: linking transformation processes in collective-action arenas," in "Perspectives on Public Choice," Cambridge University Press, 1997.

Palacios, Paola, "Forced displacement: legal versus illegal crops," July 2010.

Palmgreen, P, S M Noar, and R S Zimmerman, "Mass media campaigns as a tool for HIV prevention," Perspectives on HIV, 2008. 
Paluck, Elizabeth Levy, "Reducing intergroup prejudice and conflict using the media: a field experiment in Rwanda.," Journal of Personality and Social Psychology, 2009, 96 (3), 574.

_ and Donald P Green, "Deference, dissent, and dispute resolution: An experimental intervention using mass media to change norms and behavior in Rwanda," American Political Science Review, 2009, 103 (4), 622.

Pascual-Ezama, David, Drazen Prelec, and Derek Dunfield, "Motivation, money, prestige and cheats," Journal of Economic Behavior and Organization, September 2013, 93, 367-373.

Ploner, Matteo and Tobias Regner, "Self-image and moral balancing: An experimental analysis," Journal of Economic Behavior and Organization, September 2013, 93, 374-383.

Pruckner, Gerald J and Rupert Sausgruber, "Honesty on the streets: A field study on newspaper purchasing," Journal of the European Economic Association, June 2013, 11 (3), 661-679.

Rege, $\mathrm{M}$ and $\mathrm{K}$ Telle, "The impact of social approval and framing on cooperation in public good situations," Journal of Public Economics, 2004.

Relyea, Rick A, "The impact of insecticides and herbicides on the biodiversity and productivity of aquatic communities," Ecological Applications, August 2005, (2), 618-627.

Reyes, Luis Carlos, "Estimating the causal effect of forced eradication on coca cultivation in Colombian municipalities," 2011.

Rincón-Ruiz, Alexander and Giorgos Kallis, "Caught in the middle, Colombia's war on drugs and its effects on forest and people," Geoforum, 2013, 46, 60-78.

Rozo, Sandra, "On the Effectiveness and Welfare Consequences of Anti-drug Eradication Programs," Presented at the ISSDP Conference 2013, March 2013, pp. 1-39.

Rydell, C Peter, Jonathan P Caulkins, and Susan S Everingham, "Enforcement or Treatment? Modeling the Relative Efficacy of Alternatives for Controlling Cocaine," Operations Research, October 1996, 44 (5), 687-695.

Sariaslan, Amir, Niklas Långström, Brian D’Onofrio, Johan Hallqvist, Francis Teal, and Paul Lichtenstein, "The impact of neighbourhood deprivation on adolescent violent criminality and substance misuse: A longitudinal, quasi-experimental study of the total Swedish population," International Journal of Epidemiology, October 2013, pp. 1057-1066.

Schonlau, Matthias, "Boosted regression (boosting): An introductory tutorial and a Stata plugin," Stata Journal, December 2007, 5 (3), 1-25.

Schwartz, Richard D and Sonya Orleans, "On Legal Sanctions," January 1967.

Schweitzer, Maurice E and Christopher K Hsee, "Stretching the truth: Elastic justification and motivated communication of uncertain information," Journal of Risk and Uncertainty, 2002, 25 (2), 185-201. 
Sen, Amartya K, "Rational Fools: A Critique of the Behavioral Foundations of Economic Theory," January 1977.

Shalvi, Shaul and David Leiser, "Moral firmness," Journal of Economic Behavior and Organization, September 2013, 93, 400-407.

Sheffrin, Steven M and Robert K Triest, "Can Brute Deterrence Backfire?," 1991.

Shu, Lisa L, Francesca Gino, and Max H Bazerman, "Dishonest Deed, Clear Conscience: When Cheating Leads to Moral Disengagement and Motivated Forgetting," Personality and Social Psychology Bulletin, February 2011, 37 (3), 330-349.

_, Nina Mazar, Francesca Gino, Dan Ariely, and Max H Bazerman, "Signing at the beginning makes ethics salient and decreases dishonest self-reports in comparison to signing at the end," Proceedings of the National Academy of Sciences, 2012, 109 (38), 1519715200.

_ , _ , , , , , and Harvard Business School, "When to Sign on the Dotted Line?," 2011.

Stigler, George J, "The Economics of Information," The Journal of Political Economy, 1961, 69 (3), 213-225.

Sutter, Matthias, Stefan Haigner, and Martin Georg Kocher, "Choosing the carrot or the stick? Endogenous institutional choice in social dilemma situations," The Review of Economic Studies, 2010, 77 (4), 1540-1566.

Svallfors, Stefan, "Policy feedback, generational replacement, and attitudes to state intervention: Eastern and Western Germany, 1990-2006," European Political Science Review, February 2010, 2 (01), 119.

Telser, L G, "Advertising and competition," The Journal of Political Economy, 1964.

Thoumi, Francisco E, "Políticas antidrogas y la necesidad de enfrentar las vulnerabilidades de Colombia," Análisis Político, November 2009, (septiemre-diciembre), 60-82.

Tyler, Tom and Jeffrey Fagan, "Legitimacy and cooperation: why do people help the police fight crime in their communities?," Ohio State Journal of Criminal Law, 2008, pp. 231275 .

Tyler, Tom R, Why People Obey the Law, Yale University Press, 1990.

_ , "Public mistrust of the law: A political perspective," U. Cin. L. Rev., 1997, 66, 847.

_ , "Psychological Perspectives on Legitimacy and Legitimation," Annual Review of Psychology, January 2006, 57 (1), 375-400.

_, Jonathan D Casper, and Bonnie Fisher, "Maintaining allegiance toward political authorities: The role of prior attitudes and the use of fair procedures," American Journal of Political Science, 1989, pp. 629-652.

UNODC, "Environmental effects of illicit drug cultivation and processing," June 2006, pp. 1-30. 
_ , "Censo Cultivos Coca 2011," July 2012, pp. 1-112.

_ , "Monitoreo de Cultivos de Coca 2013," June 2014.

Vanberg, Viktor, Morality and Economics De Moribus Est Disputandum, RSM Press, 1988.

Vasquez, Juanita, "Estimación del impacto del conflicto armado sobre la producción agrícola en Colombia," Unpublished manuscript, April 2010, pp. 1-40.

_ , "When too much punishment decreases legality. The case of coca reducing policies in Colombia," Unpublished manuscript, January 2015, pp. 1-45.

_ and Marcela Ibáñez, "How alternative development spills over into more honest communities: An experimental approach in Colombia," Unpublished manuscript, November 2014, pp. 1-26.

Vetter, Stefan, Daniel Houser, and Joachim Winter, "Fairness and Cheating," GESY Discussion Paper, 2010, pp. 1-30.

von Hirsch, Andrew, "Proportionality in the Philosophy of Punishment," Crime Es Just., $\mathbf{1 9 9 2 ,} 16, \mathbf{5 5}$.

Wilson, J Q and G L Kelling, "Broken windows," Atlantic Monthly, 1982.

Wislar, J S, A Flanagin, P B Fontanarosa, and C D DeAngelis, "Honorary and ghost authorship in high impact biomedical journals: a cross sectional survey," $B M J$, October 2011, 343 (oct25 1), 6128-6128.

Witte, Ann Dryden and Robert Witt, "Crime causation: economic theories," Preprint, 2000, pp. 07-19.

Wood, Wendy, "Attitude change: Persuasion and social influence," Annual Review of Psychology, 2000, 51 (1), 539-570. 


\section{Thesis Committee}

$\begin{array}{ll}\text { First academic advisor: } & \text { Prof. Marcela Ibanez } \\ \text { Other academic advisors: } & \text { Prof. Axel Dreher } \\ & \text { Prof. Stephan Klasen }\end{array}$

Date of the oral examination: February 27th, 2015 